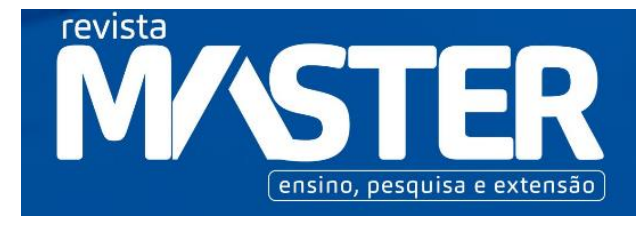

REVISTA MASTER - ENSINO, PESQUISA E EXTENSÃO

ISSN: 2447-8539

VOLUME 4, NÚMERO 7, SUPLEMENTO 1, 2019

\title{
ANAIS \\ V CONGRESSO CIENTÍFICO \\ IMEPAC
}

ARAGUARI | MG | 21 A 23 DE MAIO DE 2019

DOI: $10.5935 / 2447-8539.20190011$

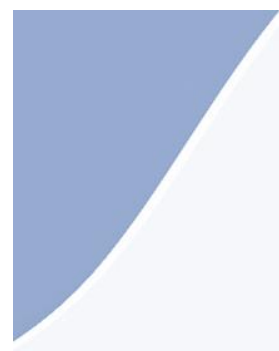

V CONGRESSO

CIENTÍIFICO

IMEPAC

RESPONSABILIDADE SOCIOAMBIENTAL 
INSTITUTO MASTER DE ENSINO PRESIDENTE ANTÔNIO CARLOS - IMEPAC

Av. Minas Gerais, 1889 - Bairro Centro

Araguari - Minas Gerais

CEP. 38440-042

Tel.: (34) 3249-3900

\section{ESTRUTURA ORGANIZACIONAL}

Direção Executiva

José Júlio Lafayette Rodrigues Pereira

Direção Geral

Divânia Araújo Freitas

Direção de Graduação e Pós-graduação

Roberto Félix Iasbik

\section{Direção de Graduação e Pós-graduação de Medicina \\ Marcelo Cardoso Assis}

\section{Comissão Organizadora}

Roberto Félix Iasbik

Lucille Garcia Gomes

Herbert Cristian de Souza

\section{Comissão Científica}

Presidente:

Herbert Cristian de Souza

Membros:

Cristiane Divina Lemes Hamawaki

Danielle Vitorino Moraes

Iara Guimarães Rodrigues

Jaqueline Pontes Batista

Lucivânia Marques Pacheco

Rita Alessandra Cardoso

Rosana de Cássia Oliveira

\section{Comissão de Programação Geral}

Presidente

Roberto Félix lasbik

Membros

Lucille Garcia Gomes

Mirna Gertrudes Ribeiro Oliveira

\section{Comissão de Recepção e Monitoria \\ Presidente \\ Karla Cristina Walter}

Membros

Fabiana Pires Teobaldo

Danielle Fernandes Alves
Raphael Fonseca Dias

Hugo Ribeiro Zanetti

\author{
Comissão de Logística e Infraestrutura \\ Presidente \\ Emanuel Soares Ponciano \\ Membros \\ César Antônio de Oliveira \\ Danilo Faria de Moura \\ Gleice Mara da Silva
}

Comissão de Inscrições, Certificados e Avaliação do Congresso

Presidente

Raphael Rodrigues Pereira

Membros

Lucille Garcia Gomes

Walter Rodrigues de Andrade

Comissão de Patrocínio

Iolanda Zacharias França

Comissão de Publicidade e

Propaganda

Alfa Propaganda

\section{Revisão e Análise Gramatical}

Lucivânia Marques Pacheco

Rosana de Cássia Oliveira 


\section{Congresso Científico IMEPAC: a serviço da responsabilidade socioambiental}

Paulo Roberto Oliveira Santos

Professor Adjunto. Instituto Master de Ensino Presidente Antônio Carlos - IMEPAC Araguari.

O conhecimento científico é um bem valioso nas sociedades humanas com pretensão de serem consideradas desenvolvidas. Não por outro motivo, a disseminação desse saber é algo importante no processo de emancipação da humanidade. Afinal, ele é o elemento capaz de franquear reais possibilidades de escolhas livres e conscientes tão desejadas pelo ser humano. Foi pensando nisso que o IMEPAC escolheu a temática geral do seu V Congresso Científico realizado nesse ano de 2019: a responsabildiade socioambiental.

Uma instituição de ensino nos tempos hodiernos não pode deixar de levar em consideração esse importante aspecto da realidade, pois seu sentido de existir está profundamente inserido num cenário de efetivo compromisso com a realidade na qual está inserida, seja a nível local, regional, nacional ou mesmo global. Dito de outra forma, uma comunidade acadêmica deve estar sempre atenta aos desafios socioambientais do seu tempo e do seu "locus".

Assim sendo, o IMEPAC reconhece que os desafios socioambientais devem ser enfrentados, para além das legítimas boas intenções de diversos atores sociais no campo do senso comum, com rigor científico, porquanto uma das suas marcas é a complexidade. Tal caracterísitica, mais do que um problema a ser encarado, constitui-se numa enorme riqueza, posto que é capaz de abrir um vasto campo de possibilidades para a ação humana livre e consciente. A isso chama-se responsabilidade. Nessa perspectiva, a comunidade acadêmica envolvida nesse $\mathrm{V}$ Congresso Científico IMEPAC, pretende prestar um triplo serviço; por um lado, reconhece e valoriza as experiências desafiadoras da sociedade com a qual deseja colaborar; por outro, lança as luzes da razão acerca desses problemas e, por fim, colabora com a capacitação de alunos e professores de diversas áreas, agregando valor de primeira grandeza ao trabalho desses últimos.

Nestes termos, o V Congresso Científico IMEPAC, ao tratar da temática da Responsabilidade Socioambiental, abre um espaço de produção de conhecimento científico acerca da necessidade de uma tomada de consciência em torno do necessário equilíbrio social e do meio ambiente. Chamar a atenção para esses aspectos da vida humana é, sobretudo, alertar para a urgência de se abandonar, de vez, posturas pessoais, profissionais e sociais marcadas pela falta de sensibilidade com o meio circundante. De há muito já se sabe: o futuro da humanidade depende da busca responsável por uma existência sustentável, dentre tantos aspectos, destaca-se os de natureza social e ambiental.

Todos esses pontos até o momento indicados constituem-se como justiificativa de uma mobilização de imenso contingente de produtores de conhecimento científico. Todos esses agentes (professores, alunos, pessoal técnico de apoio, etc.) vislumbraram na importância desse assunto um estímula a mais para o envolvimento nesse desafio de produzir o maior e mais produtivo congresso científico no âmbito do IMEPAC. 
0 resultado não poderia ser outro, qual seja, um sucesso quanto à participação e ao envolvimento da comudanidade acadêmica, não só do próprio IMEPAC, mas também de outras instituições de ensi no da região do entorno de Araguari e até do Estado do Paraná. Junto ao IMEPAC, outras cinco se fizeram representar; fato esse capaz de indicar a grandeza e importância do Congresso.

Na mesma senda dos outros quatro congressos realizados em anos anteriores, esse V Congresso, em torno da temática geral da Responsabilidade Socioambiental, buscou dar vez e voz aos discentes e docentes de variados cursos nas mais diversas áreas do conhecimento científico. Orientados por profesosres com formação extremamente diversificadas, foram duzentos e quarenta e nove trabalhos apresentados e discutidos nas modalidades de Comunicação Oral (quarenta e nove) e Apresentação em Poster (duzentas). Como forma de organizar os trabalhos, foi realizada uma organização por temas de estudo. 0 gráfico seguinte demonstra tal organização:

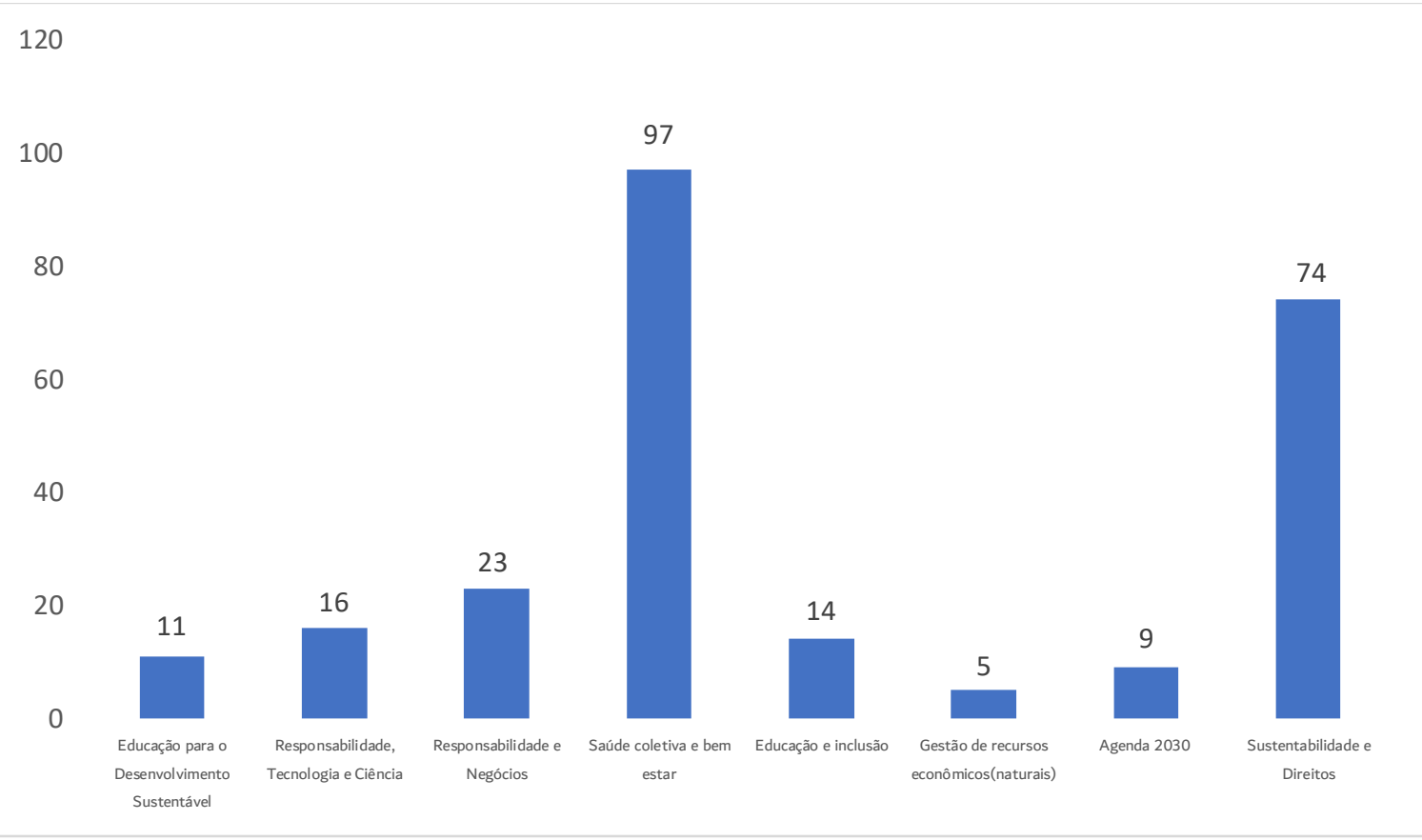

Dessa forma, tudo quanto aqui já demonstrado dá conta do enorme esforço representado pela realização do V Congresso Científico IMEPAC. Contudo, se esses números já chamam a atenção para a grandeza do evento, é sempre importante salientar o aspecto do ganho de qualidade no tratamento do problema da busca da sustentabilidade socioambiental. Muito além de palavras de ordem, por vezes destuídas de sentido e, via de conquência, de responsabildiade, a discussão, o debate saudável de ideias e, sobretudo, a produção de denso conhecimento científico, conseguiram reforçar a ideia de que as comunidades acadêmicas só têm sentido de existir na medida em que se envolvem, de forma ativa, na busca de soluções para os graves problemas a assolar a sociedade nos termos hodiernos.

A ideia lançada há quase uma década com o I Congresso germinou e está dando frutos saudáveis e evidentes. Em que pese a complexidade dos problemas a serem enfrentados, essa comunidade acadêmica está demonstrando ser capaz de superar-se a cada dia, em busca da excelência tão desejada! Parabéns a todos os envolvidos na organização e na realização desse V Congresso Científico do IMEPAC! 


\section{SUMÁRIO}

(IN)CONTROLE DA CONSTITUCIONALIDADE NO IMPÉRIO

A APLICAÇÃO DO PRINCÍPIO DA DIGNIDADE DA PESSOA HUMANA AOS INIMPUTÁVEIS........11

A DIFICULDADE NA ADAPTAÇÃO

PEDAGÓGICAPARA OS DEFICIENTES

INTELECTUAIS NAS ESCOLAS REGULARES E

SUAS CONSEQUÊNCIAS PARA OS DIREITOS

FUNDAMENTAIS DE ACESSIBILIDADE.

A DIFUSÃO DA AUTO-HEMOTERAPIA EM OPOSIÇÃO AO SEU CARÁTER PROIBITIVO BRASILEIRO

A EFETIVIDADE NA APLICAÇÃO DO PRINCÍPIO DA PROTEÇÃO INTEGRAL ÀS CRIANÇAS E ADOLESCENTES NO BRASIL

A EVOLUÇÃO TECNOLÓGICA E SUA INFLUÊNCIA NO DIREITO SOCIAL . .15

A GESTÃO ECONÔMICA DOS MEDICAMENTOS VIA ORAL UTILIZADOS PARA TRATAMENTO DE DIABETES MELLITUS EM ARAGUARI - MG ......... 16

A IMPORTÂNCIA DA REGULAMENTAÇÃO DA AUDIÊNCIA DE CUSTÓDIA NO PROCESSO PENAL BRASILEIRO

A INFLUÊNCIA DA MÍDIA NAS DECISÕES DO TRIBUNAL DO JÚRI.

A INSERÇÃO ERRÔNEA DE DADOS FISCAIS NO PLANEJAMENTO TRIBUTÁRIO

A JUSTIÇA GRATUITA: INSTRUMENTO DE ACESSO À JUSTIÇA E A SUA APLICABILIDADE..20

A MEDIAÇÃO ENQUANTO DESENVOLVIMENTO SUSTENTÁVEL E PACIFICAÇÃO SOCIAL À LUZ DA AGENDA 2030.

A RESCISÃO POR MÚTUO ACORDO COMO FORMA DE EXTINÇÃO DO CONTRATO DO TRABALHO. .22

A RESPONSABILIZAÇÃO DO PAGAMENTO DAS VERBAS TRABALHISTAS INADIMPLIDAS NA TERCEIRIZAÇÃO
A SATISFAÇÃO DOS MÉDICOS QUE ATENDEM EM ARAGUARI - MG QUANTO AOS PLANOS DE SAÚDE 24

A SOCIEDADE DE RISCO COMO CONSEQUÊNCIA DA INEFICIÊNCIA DO ESTADO

A TRAJETÓRIA DE INCLUSÃO DE ALUNOS SURDOS: A IMPORTÂNCIA DA FAMÍLIA NA COMUNICAÇÃO POR MEIO DA LÍNGUA DE SINAIS.

A TRANSMISSIBILIDADE DA PROPRIEDADE VIRTUAL X A TUTELA PÓSTUMA DOS DIREITOS DA PERSONALIDADE.

A TUTELA PROVISÓRIA DE URGÊNCIA COMO EFETIVIDADE DO SISTEMA PROCESSUAL............28

A VALORAÇÃO PROBATÓRIA DO DEPOIMENTO DA TESTEMUNHA DO "OUVI DIZER" (HEARSAY TESTIMONY) NO ÂMBITO DO PROCESSO PENAL BRASILEIRO

A VIOLÊNCIA OBSTÉTRICA NO BRASIL SOB PERSPECTIVA JURISPRUDENCIAL. 30

ABRINDO O CAMINHO PARA A INCLUSÃO: MUDANDO O OLHAR SOBRE ACESSIBILIDADE NA REALIDADE DOS JOVENS..

AÇÃO DE SAÚDE NA UNIDADE DE SAÚDE DA FAMÍLIA GUTIERREZ: AVALIAÇÃO NUTRICIONAL E DEGUSTAÇÃO DE SUCO.

ACESSO À JUSTIÇA OU DEMOCRATIZAÇÃO DA JUSTIÇA?

AGRAVAMENTO DOS DESASTRES AMBIENTAIS E SUAS EVENTUAIS RESPONSABILIDADES..........34 ÁGUA VIRTUAL E SUA IMPORTANCÂNCIA PARA A SOCIEDADE.

ALIENAÇÃO PARENTAL 36

ANÁLISE CINESIOLÓGICA DO ARREMESSO COM APOIO DO BASQUETE. 37

ANÁLISE CINESIOLÓGICA DO PASSE DE GANCHO NO BASQUETE.. 38 
ANÁLISE CINESIOLOGICA DO PASSE QUICADO

(PICADO).

ANÁLISE CORRELATIVA ENTRE O PERFIL ANTROPOMÉTRICO E CARDIOVASCULAR DE IDOSOS PRATICANTES DE ATIVIDADE FÍSICA ..40

ANÁLISE CRÍTICA DE CONFORMIDADE DA ROTULAGEM NUTRICIONAL DE SUCOS E NÉCTARES COMERCIALIZADOS NO SETOR VAREJISTA DE UBERLÂNDIA, MINAS GERAIS....41

ANÁLISE DA DEMANDA DE MEDICAMENTOS ANTIRRETROVIRAIS NO MUNICÍPIO DE ARAGUARI-MG

ANÁLISE DA FLEXIBILIDADE EM JOGADORES DAS CATEGORIAS DE BASE DO MANCHA ESPORTE CLUBE DE ARAGUARI/MG EM PERIODO DE PRÉ-TEMPORADA.

ANÁLISE DA GESTÃO ADMINISTRATIVA EM UMA INSTITUIÇÃO FILANTRÓPICA NA CIDADE DE ARAGUARI-MG .44

ANÁLISE DA INTENSIDADE DE SINTOMAS DE DEPRESSÃO E ANSIEDADE DE ESTUDANTES DO CURSO DE GRADUAÇÃO EM FARMÁCIA E ENFERMAGEM DE UMA INTITUIÇÃO DE ENSINO SUPERIOS DE ARAGUARI -MG .45

ANÁLISE DA NR 06 (EQUIPAMENTOS DE PROTEÇÃO INDIVIDUAL) APLICADA EM UMA EMPRESA PROCESSADORA DE BEBIDAS NÃO ALCOÓLICAS

ANÁLISE DO CUSTO-EFETIVIDADE DE MEDICAMENTOS ANTIDEPRESSIVOS FORNECIDOS PELA FARMÁCIA MUNICIPAL DE ARAGUARI-MG

ANÁLISE DO PERFIL ANTROPOMÉTRICO E DA PRESSÃO ARTERIAL DE REPOUSO EM ATLETAS DE ESCOLINHA DE FUTSAL INFANTO-JUVENIL48 ANÁLISE DO PROGRAMA SAÚDE NA ESCOLA EM ARAGUARI-MG 49

ANÁLISE EPIDEMIOLÓGICA DA INCIDÊNCIA DE DENGUE NO MUNICÍPIO DE ARAGUARI-MG ...50

ANÁLISE MICROBIOLÓGICA DOS CELULARES DE ACADÊMICOS DO CURSO DE MEDICINA EM UMA INSTITUIÇÃO DE ENSINO PRIVADA ...........51

ANTIMICROBIANOS MAIS DISPENSADOS EM ESTABELECIMENTOS DE SAÚDE NO MUNICÍPIO DE ESTRELA DO SUL-MG. .52
AS DIFICULDADES ENVOLVIDAS NO PROCESSO DE APRENDIZAGEM DA EQUIPE DE ENFERMAGEM EM UM HOSPITAL DO TRIÂNGULO MINEIRO .53

AS IMPLICAÇÕES DO NÚCLEO FAMILIAR NO DIREITO DE FAMÍLIA .54

ASSÉDIO SEXUAL E MORAL CONTRA A MULHER NO AMBIENTE DO TRABALHO. .55

ATENDIMENTO, UMA CULTURA DE JUSTIÇA PARA QUEM BUSCA PELAS FORMAS CONSENSUAIS DE SOLUÇÕES DE CONFLITOS.56

ATIVIDADES INSALUBRES QUE AFETAM A POPULAÇÃO. 57

ATIVISMO JUDICIAL E DEMOCRACIA. .58

ATOS DE VIOLÊNCIA: ALUNOS CONTRA PROFESSORES NAS ESCOLAS MUNICIPAIS ARAGUARINAS .59

ATUAÇÃO DO ADVOGADO NO INQUÉRITO POLICIAL EM FACE DA LEI 13.245/2016 60

AVALIAÇÃO DA DEMANDA CLÍNICA SEGUNDO O PROTOCOLO MANCHESTER DA UNIDADE DE PRONTO ATENDIMENTO EM ARAGUARI - MG61

AVALIAÇÃO DA EFICÁCIA DO OUTUBRO ROSA EM UMA UNIDADE BÁSICA DE SAÚDE DA FAMÍLIA DE ARAGUARI-MG 62

AVALIAÇÃO DA POTÊNCIA DE MEMBROS SUPERIORES EM ATLETAS DE CATEGORIAS DE BASES DO MANCHA ESPORTE CLUBE NO PERÍODO DE PRÉ-TEMPORADA.

AVALIAÇÃO DA RESISTÊNCIA ABDOMINAL EM ATLETAS DE FUTEBOL DAS CATEGORIAS DE BASE DO MANCHA ESPORTE CLUBEDE ARAGUARI/MG NO PERÍODO DE PRÉTEMPORADA

AVALIAÇÃO DE AGILIDADE DOS ATLETAS DA CATEGORIAS DE BASES DO MANCHA ESPORTE CLUBE NO PERÍODO DE PRÉ-TEMPORADA.......65

AVALIAÇÃO DE POTÊNCIA DE MEMBROS INFERIORES EM ATLETAS DE CATEGORIAS DE BASES DO MANCHA ESPORTE CLUBE NO PERÍODO DE PRÉ.

AVALIAÇÃO DO CONSUMO MÁXIMO DE OXIGÊNIO EM ATLETAS DE CATEGORIAS DE BASES DO MANCHA ESPORTE CLUBE NO PERÍODO DE PRÉ-TEMPORADA. 
AVALIAÇÃO DO PERFIL ANTIMICROBIANO UTILIZADO EM HOSPITAIS E DROGARIAS............68 AVALIAÇÃO DO USO DE FIBRAS PARA REFORÇO DE CONCRETOS 69

AVALIAÇÃO TÉCNICA DA FABRICAÇÃO DE BLOCOS DE SOLO-CIMENTO NA ONG AÇÃO MORADIA - UBERLÂNDIA -MG 70

BEM-ESTAR ANIMAL: UM CONCEITO CONHECIDO E APLICADO OU AINDA MERAMENTE SUPERFICIAL?

CASOS BRUMADINHO E MARIANA: PERSPECTIVA LEGALISTA AO BEM JURÍDICO AMBIENTAL PENALMENTE TUTELADO. . .72

CLASSIFICAÇÃO DE CUSTOS QUANTO À VARIEDADE (FIXOS E VARIÁVEIS). 73

COLORINDO A APRENDIZAGEM NOS DIVERSOS ESPAÇOS DA EDUCAÇÃO ESCOLAR: RE-

SIGNIFICANDO A SALA DE AULA. 74

COMO DESENVOLVER A PERSONALIDADE HUMANA DE CRIANÇAS INSERIDAS EM MEIO AMBIENTE INSALUBRE 75

COMO OS COMPULSORES PODEM AUXILIAR NA APRENDIZAGEM POR MEIO DOS TREINAMENTOS ORGANIZACIONAIS . .76

COMPARAÇÃO DAS CAPACIDADES FÍSICAS ENTRE ATLETAS DE DIFERENTES CATEGORIAS DO MANCHA ESPORTE CLUBE NO PERÍODO DE PRÉ-TEMPORADA . .77

CONCILIAÇÃO E MEDIAÇÃO NO NOVO CÓDIGO DE PROCESSO CIVIL. . .78

CONHECIMENTO DO HIPERTENSO SOBRE A DOENÇA:ADESÃO AO TRATAMENTO E IMPACTOS .79

CONSCIENTIZAÇÃO SOBRE A IMPORTÂNCIA DA RECICLAGEM EM UMA POPULAÇÃO CARENTE DE ARAGUARI- MG. . .80

CONSEQUÊNCIAS DO EXCESSO NA JORNADA DE TRABALHO 81

CONSOLIDAÇÃO E ACOLHIMENTO DO DIREITO INTERNACIONAL DOS DIREITOS HUMANOS ...82 CONSTRUÇÕES COM PAINÉIS MONOLÍTICOS DE EPS . .83

CONTABILIDADE AMBIENTAL: UM ESTUDO SOBRE AS NORMAS REGULAMENTADORAS ....84
CORRELAÇÃO DAS CAPACIDADES FÍSICAS DOS ATLETAS DA CATEGORIA DE BASE DO MANCHA ESPORTE CLUBE DA CIDADE DE ARAGUARI/MG. .85

CRIPTOCOCOSE CANINA: RELATO DE CASO ....86 CRITÉRIOS DE SUBSTITUIÇÃO DE DORMENTES DE MADEIRA

CUSTO MÉDIO DE UMA ANGIOPLASTIA PELO SISTEMA ÚNICO DE SAÚDE EM UM HOSPITAL DE UBERLÂNDIA-MG.

DESCARTE DE MEDICAMENTOS E SEU IMPACTO SOCIOAMBIENTAL NA CIDADE DE OUVIDOR$\mathrm{GO}$

DESCARTE DE MEDICAMENTOS: CONDUTA DE PACIENTES ATENDIDOS PELA FARMÁCIA MUNICIPAL DE ARAGUARI (MG) .90

DIAGNÓSTICO DO RACIOCÍNIO LÓGICO MATEMÁTICO ENTRE ALUNOS DO $1^{\circ}$ PERÍODO DO CURSO DE PEDAGOGIA NO ANO DE 201791

DIFERENÇA TRIBUTÁRIA NA COMPRA DE PRODUTOS FORA DO ESTADO DE PRODUÇÃO

DIREITO URBANISTICO E SUAS

CONSEQUENCIAS NOS CENTROS

POPULACIONAIS. .93

DIREITOS FUNDAMENTAIS NO ESTADO

DEMOCRÁTICO DE DIREITO E A REALIDADE DAS COTAS RACIAIS.

DISPENSAÇÃO DE ANTIMICROBIANOS EM DROGARIAS PRÓXIMAS A HOSPITAIS DE ARAGUARI

DISPENSAÇÃO DE ANTIMICROBIANOS PELOS FARMACÊUTICOS NAS DROGARIAS CENTRAIS DE ARAGUARI (MG) 96 DOCÊNCIA ORIENTADA: RESPONSABILIDADE SOCIAL E PRÁTICA PROFISSIONAL..........................97 DUPLA PATERNIDADE DO REGISTRO CIVIL.......98 ECOGEOMETRIA: MATEMÁTICA COM MATERIAIS RECICLADOS

EDUCAÇÃO AMBIENTAL DESENVOLVIDA PELO PROGRAMA GIRA SOL. 100

EDUCAÇÃO E SUSTENTABILIDADE NO CURSO DE PEDAGOGIA: DICAS PARA O USO CONSCIENTE DO ESPAÇO NOSSO DE CADA DIA 
EDUCAÇÃO EM SAÚDE NO PUERPÉRIO: O PAPEL DO ENFERMEIRO NA ATENÇÃO PRIMÁRIA

EFEITO DA CAPOTERAPIA SOBRE OS COMPONENTES DA CAPACIDADE FÍSICA DE IDOSAS NÃO INSTITUCIONALIZADAS 103

EFEITOS DA EMBRIAGUEZ NO TRABALHO E O RISCO DE RESCISÃO CONTRATUAL POR JUSTA CAUSA 104

EFEITOS DO BARBATIMÃO NA CICATRIZAÇÃO EM EQUINOS 105

EJA: O DESPERTAR DO ENCANTO PELA LEITURA 106

EQUIPAMENTO DE PROTEÇÃO INDIVIDUAL EPI NR6 107

ERROS NAS INSERÇÕES DE DADOS E O IMPACTO DO PLANEJAMENTO TRIBUTÁRIO. 108 ESCASSEZ DOS RECURSOS HÍDRICOS: A BUSCA PELA EDUCAÇÃO AMBIENTAL SUSTENTÁVEL109 ESTADO NUTRICIONAL, PERFIL BIOQUÍMICO E HÁBITOS ALIMENTARES DE MOTORISTAS DE ÔNIBUS NOTURNOS E DIURNOS 110

ESTÁGIO CURRICULAR SUPERVISIONADO NA ATENÇÃO PRIMÁRIA À SAÚDE: VISÃO DOS ACADÊMICOS DE FARMÁCIA

ESTRATÉGIAS PARA AUXILIAR O TRABALHO VOLUNTÁRIO DO GRUPO SEMENTE ESPERANÇA DE ASSISTÊNCIA À PACIENTES ONCOLÓGICOS

ESTUDO DA NR - 13: CALDEIRAS E VASOS DE PRESSÃO EM UMA EMPRESA DE ARAGUARI-MG

ESTUDO E CARACTERIZAÇÃO DA CADEIA DE SUPRIMENTOS DE ARROZ, FEIJÃO E CAFÉ UMA REVISÃO DE LITERATURA.

ESTUDO SOBRE O USO DE ANTIDEPRESSIVOS EM UMA FARMÁCIA PRIVADA DE DAVINÓPOLIS (GO) 115

EVOLUÇÃO DOS CASOS DE SÍFILIS GESTACIONAL NA ÚLTIMA DÉCADA EM ARAGUARI-MG

EVOLUÇÃO HISTÓRICA DA LEGISLAÇÃO BRASILEIRA SOBRE PROTEÇÃO AOS ANIMAIS
EXERCÍCIO AERÓBIO CONTÍNUO É MAIS EFICAZ PARA PROMOVER HIPOTENSÃO POS ESFORÇO QUE EXERCÍCIO AERÓBIO INTERVALADO.......118

FALHA NA INTEGRAÇÃO DO SISTEMA INTERNO E CONTROLE DOS RECEBÍVEIS DA EMPRESA CALÇADOS JR. 119

FATORES DE RISCO ASSOCIADOS À ÚLCERA POR PRESSÃO: DESAFIO NA SAÚDE PÚBLICA DO BRASIL

FATORES QUE INFLUENCIAM A TENACIDADE DO CONCRETO REFORÇADO COM FIBRAS (CRF)

FECHEM OS OLHOS, TAPEM OS OUVIDOS: O DIREITO DE EXERCER A CIDADANIA EM SUA PLENITUDE COM RESPONSABILIDADE E COMPROMISSO SOCIAL.

FORMAS CONSENSUAIS DE RESOLUÇÃO DE CONFLITOS

GERENCIAMENTO DE PEQUENOS PROJETOS A

PARTIR DO GUIA PMBOK ${ }^{\circledR}$ 124

GESTÃO DA CADEIA DE SUPRIMENTOS DOS EQUIPAMENTOS DE PROTEÇÃO INDIVIDUAL (EPIS) DA REDE PÚBLICA DE SAÚDE DO MUNICÍPIO DE ARAGUARI-MG 125

GRUPOS E ATIVIDADES COLETIVAS DE EDUCAÇÃO EM SAÚDE NA ATENÇÃO PRIMÁRIA À SAÚDE 126 HORTAS VERTICAIS URBANAS: UMA REALIDADE PARA TODAS AS FAMIILIAS EM QUAISQUER ESPAÇOS 127

HUMANIZAÇÃO E CUIDADO EM SAÚDE EM PACIENTES COM CÂNCER: UM ESTUDO DE CASO DE UMA ONG. 128

IMPACTO DO CONTROLE DE ESTOQUE NO PLANEJAMENTO TRIBUTÁRIO E FINANCEIRO129 IMPACTOS DA FISIOTERAPIA EM PACIENTE INSTITUCIONALIZADO COM DIAGNÓSTICO DE DEMÊNCIA E DEGENERAÇÃO CEREBELAR ALCÓOLICA: UM RELATO DE CASO....................130 IMPORTUNAÇÃO SEXUAL 131 INCESTO E SUAS IMPLICAÇÕES PENAIS ACERCA DA CRIMINALIZAÇÃO DA CONDUTA 132 INDENIZAÇÃO POR TEMPO ÚTIL PERDIDO DO CONSUMIDOR. 
INDICADORES HOSPITALARES DE GESTÃO:

LOGÍSTICA HOSPITALAR 134

INFLUÊNCIA DA DENSIDADE NO CONTROLE DE QUALIDADE DE ENCAPSULADOS 135

INTERCEPTAÇÃO TELEFÔNICA E

ADMISSIBILIDADE COMO MEIO DE PROVA... 136

INTERFACE ENSINO E EXTENSÃO NA ATENÇÃO

À SAÚDE DA MULHER: RELATO DE EXPERIÊNCIA

DO PROJETO OUTUBRO ROSA 137

JUSTIÇA RESTAURATIVA NO BRASIL 138

LEAN HEALTHCARE COMO ESTRATÉGIA DE MELHORIA NA PRESTAÇÃO DE SERVIÇOS NA ÁREA DE SAÚDE: UMA REVISÃO DA LITERATURA 139

LEI MARIA DA PENHA LEI N. ${ }^{\circ} 11.340$. 140

LEISHMANIOSE VISCERAL CANINA NO MUNICÍPIO DE UBERLÂNDIA-MG 141

LESÃO POR PRESSÃO: A IMPORTÂNCIA DO PROTOCOLO PARA MINIMIZAR DANOS

LEVANTAMENTO DE CISTICERCOSE BOVINA EM UM MATADOURO FRIGORIFICO NO MUNICÍPIO DE ARAGUARI-MG NO PERÍODO DE 01/01/2018 A 31/01/2018

LUDICICLAGEM: A REUTILIZAÇÃO DE MATERIAIS RECICLÁVEIS EM ESPAÇOS OCIOSOS DA EDUCAÇÃO INFANTIL. 144

MANUFATURA ADITIVA 145

MÃOS QUE FALAM: UM OLHAR AOS CONSUMIDORES DEFICIENTES AUDITIVOS ... 146

MATERIAIS NÃO ESTRUTURADOS NA APRENDIZAGEM INFANTIL.O BRINCAR NA CONSTRUÇÃO DO SUJEITO.

MATERIAIS NÃO ESTRUTURADOS: PRA QUE TE QUERO? 148

MÉDIA DA PRODUÇÃO LEITEIRA DA CIDADE DE ARAGUARI E REGIÃO, NO PERÍODO DE 01/01/2019 A 31/01/2019 149

MEDIDA DA AMPLITUDE ATIVA DE DORSIFLEXÃO DE TORNOZELO EM JOGADORES DE BASE DO MANCHA ESPORTE CLUBE NO PERÍODO PRÉ-TEMPORADA 150

MORINGA OLEÍFERA: POTENCIAL ANTIOXIDANTE DOS EXTRATOS DA PLANTA OBTIDOS A PARTIR AMOSTRAS COLHIDAS EM
ÁREA URBANA SOB CONSTANTE POLUIÇÃO, ESTRESSE HÍDRICO E DE NUTRIENTES 151

NR6 - EQUIPAMENTO DE PROTEÇÃO INDIVIDUAL 152

O ACESSO DA PESSOA PORTADORA DE DEFICIÊNCIA AUDITIVA À JUSTIÇA COMO PRECEITO DE DIGNIDADE DA PESSOA HUMANA 153

O ASSÉDIO SEXUAL NO CONTEXTO ACADÊMICO: UM DEBATE NECESSÁRIO. 154

O ATRASO DO FECHAMENTO CONTÁBIL DA EMPRESA MACEDO S/A PARA COM O ESCRITÓRIO DE CONTABILIDADE

O DESASTRE AMBIENTAL DE BRUMADINHO E SUAS CONSEQUÊNCIAS JURÍDICAS NO MEIO AMBIENTE LABORAL. 156

O INSTITUTO DA COLABORAÇÃO PREMIADA E SEU CARÁTER PROBATÓRIO 157

O INSTITUTO DO FEMINICÍDIO SOB A ÓTICA DOS TRANSEXUAIS 158

O PAPEL DO ESTÁGIO NA EDUCAÇÃO INFANTIL PARA A FORMAÇÃO DOCENTE: UMA EXPERIÊNCIA EM CURSO. 159

O PERFIL DO FARMACÊUTICO NA SAÚDE ESTÉTICA

O PERFIL DOS DEPENDENTES QUÍMICOS E A IMPORTÂNCIA DA IMPLEMENTAÇÃO DA ASSISTÊNCIA FARMACÊUTICA EM UMA CASA DE AUXÍLIO EM ARAGUARI- MG.

O PRINCÍPIO DO CONTRADITÓRIO E DA AMPLA DEFESA NO INQUÉRITO POLICIAL. 162

O SISTEMA PRISIONAL E A RESSOCIALIZAÇÃO DO PRESO

O TERMO DE AJUSTAMENTO DE CONDUTA COMO INSTRUMENTO DE GESTÃO E MANEJO ADEQUADO AO MEIO AMBIENTE EQUILIBRADO. 164

O TRABALHO DE GESTANTES E LACTANTES EM AMBIENTE INSALUBRE PELA ÓTICA CONSTITUCIONAL 165

O TRATAMENTO SUCESSÓRIO PARA O COMPANHEIRO(A) FRENTE A INCONSTITUCIONALIDADE DO ARTIGO 1790 DO CÓDIGO CIVIL 166 
O USO DA INTELIGÊNCIA EMOCIONAL ASSOCIADO DIRETAMENTE A LIDERANÇA NA GESTÃO DE PROJETOS 167

O USO DE "METODOLOGIAS ATIVAS DE APRENDIZAGEM BASEADA EM PROJETOS" NO COMPONENTE CURRICULAR: ENGENHARIA DE SOFTWARE 168

OCORRÊNCIA DE RAIVA EM HERBÍVOROS DO MUNICÍPIO DE ARAGUARI-MG, NOS PERÍODOS DE 2015 A 2019 169

OMISSÃO LEGISLATIVA PREVIDENCIÁRIA EM RELAÇÃO AOS TRANSEXUAIS E A QUEBRA DO PARADIGMA DA DIGNIDADE DA PESSOA HUMANA. 170

OS GÊNEROS MULTIMODAIS NO DESENVOLVIMENTO DOS ALUNOS NAS SÉRIES INICIAIS. 171

OS MEIOS ALTERNATIVOS DE RESOLUÇÃO DE CONFLITOS: A CHAVE PARA A ATUAL MOROSIDADE DO JUDICIÁRIO. 172

OUVIR, FALAR, LER E ESCREVER: O CAMINHO CERTO PARA A APRENDIZAGEM. 173

PEDAGOGITALIZANDO: APROXIMANDO O EDUCADOR DA GERAÇÃO DIGITAL E DO USO DE NOVAS TECNOLOGIAS 174

PERCEPÇÃO DOS ACADÊMICOS DA ÁREA DE SAÚDE SOBRE A ATUAÇÃO DO MÉDICO VETERINÁRIO NA SAÚDE PÚBLICA 175

PERCEPÇÃO DOS ACADÊMICOS DE MEDICINA A RESPEITO DOS MEDICAMENTOS GENÉRICOS 176

PERFIL ANTROPOMÉTRICO DE JOGADORES DE CATEGORIAS DE BASE DO MANCHA ESPORTE CLUBE NO PERÍODO PRÉ-TEMPORADA............ 177 PERFIL DE MULHERES COM PREDISPOSIÇÃO AO CÂNCER DE COLO DO ÚTERO E CÂNCER DE MAMA 178

PERFIL DE SAÚDE DO TRABALHADOR RURAL NO MUNICÍPIO DE ARAGUARI - MG:

ABORDAGEM PRELIMINAR. 179

PERFIL DEMOGRÁFICO E EPIDEMIOLÓGICO DE GESTANTES EM ATENDIMENTO PRÉ-NATAL EM UMA UNIDADE BÁSICA DE SAUUDE DA FAMÍLIA 180

PERFIL DOS FATORES CAUSAIS DE PARALISIA CEREBRAL EM PACIENTES DE INSTITUIÇÃO DE
APOIO ÀS PESSOAS COM DEFICIÊNCIA NO MUNICÍPIO DE ARAGUARI-MG 181

PERFIL DOS POTENCIAIS USUÁRIOS DE UM CONSULTÓRIO FARMACÊUTICO: ANÁLISE DA POPULAÇÃO NA CIDADE DE CATALÃO - GOIÁS

PLANEJAMENTO JURÍDICO E EMPRESARIAL.. 183

PLANEJAMENTO TRIBUTÁRIO E FINANCEIRO/ FALTA DE CONTROLE DE ENTRADAS E SAÍDAS FISCAIS / FINANCEIRAS E O SEU IMPACTO NO PLANEJAMENTO TRIBUTÁRIO. 184

PLATAFORMAS VIRTUAIS COMO MEIO DE PACIFICAÇÃO SOCIAL NO ÂMBITO PRÉPROCESSUAL NAS RELAÇÕES DE CONSUMO185 POLUIÇĀO ATMOSFÉRICA E DOENÇAS RESPIRATÓRIAS: UMA BREVE REVISĀO 186

PREVALÊNCIA DA AUTOMEDICAÇÃO E AUTOSSUPLEMENTAÇÃO DE ESTUDANTES DA ÁREA DA SAÚDE EM UM CENTRO UNIVERSITÁRIO EM ARAGUARI-MG. 187

PREVALÊNCIA DA SÍNDROME DE BURNOUT EM UMA UNIDADE BÁSICA DE SAÚDE DA FAMÍLIA NO MUNICÍPIO DE ARAGUARI - MG.. 188

PREVALÊNCIA DE ANSIEDADE DURANTE A RELIZAÇÃO DE AVALIAÇÕES ACADÊMICAS EM ESTUDANTES DO CURSO DE MEDICINA EM UM CENTRO UNIVERSITÁRIO DE ARAGUARI-MG 189 PREVALÊNCIA DE DIABETES EM IDOSOS RESIDENTES EM INSTITUIÇÕES DE LONGA PERMANÊNCIA LOCALIZADAS EM ARAGUARI$M G$. 190

PRISÃO EM SEGUNDA INSTÂNCIA EM OPOSIÇÃO À PRESUNÇÃO DE INOCÊNCIA .... 191 PROBLEMAS NAS DOCUMENTAÇÕES CONTÁBEIS. 192

PRODUÇÃO DE BIOGÁS A PARTIR DE BAGAÇO DE CANA-DE-AÇÚCAR APÓS PRÉ-TRATAMENTO COM ÁCIDO CÍTRICO DILUIDO. 193

PRODUÇÃO DE PISO DE CONCRETO COM ADIÇÃO DE BORRACHA 194

PROJETO INTEGRADOR: "ESPORTE E DEFICIÊNCIA INFANTO-JUVENIL: UMA ABORDAGEM INTERVENCIONAL DA DANÇA E LAZER". 195 
PROJETO VOLUNTARIO: EDUCAÇÃO, SAÚDE E

LAZER... 196

PROMOVENDO SAÚDE NA EDUCAÇÃO. 197

PROSTITUIÇÃO, DIGNIDADE DA PESSOA HUMANA E DIREITOS TRABALHISTAS 198

RASTREIO DE HIPERTENSOS EM CIDADE DO NORTE DE MINAS GERAIS: RESPONSABILIDADE SOCIAL DO ATENDIMENTO VOLUNTÁRIO..... 199 REFORMA DA PREVIDÊNCIA: UM DILEMA POLÍTICO, SOCIAL OU ECONÔMICO? 200

REGULAMENTAÇÃO DA PROSTITUIÇÃO: UMA QUESTÃO DE DIGNIDADE 201

RELATO DE CASO - BEM ESTAR E ESTRESSE NO MANEJO NA FAZENDA TRONCOS - GRUPIARA - MG. 202

RELATO DE CASO CLÍNICO: GIARDIA SPP. EM UM CANÍDEO DA RAÇA GOLDEN RETRIEVER NA REGIÃO DE CAMPINAS/SP. 203

RELATO DE CASO: TROMBOCITOPENIA CAUSADA POR ANCYLOSTOMA CANINUM EM CÃO SRD NA REGIÃO DE CAMPINAS-SP.......... 204

RELATO DE EXPERIÊNCIA SOBRE PROJETO VOLUNTÁRIO VOLTADO PARA ORIENTAÇÃO DE GESTANTES 205

RESPONSABILIDADE EMPRESARIAL E SOCIAL SOBRE A LEI DE COTAS PARA PESSOAS COM DEFICIÊNCIA NO MERCADO DE TRABALHO.. 206 RESPONSABILIDADE SOCIAL COM O ATENDIMENTO PEDIÁTRICO: CONHECIMENTO DE ACADÊMICOS DE MEDICINA SOBRE HUMANIZAÇÃO E COMUNICAÇÃO. 207

REUSO: VOCÊ DEFENDE ESSA IDEIA?. 208

SAÚDE DA MULHER: AVALIAÇÃO DO PERFIL DAS MULHERES QUE PARTICIPARAM DE UMA AÇÃO SOCIAL REALIZADA NO CONTEXTO DO OUTUBRO ROSA NA CIDADE DE ARAGUARI MG. 209

SAÚDE DO HOMEM: AVALIAÇÃO DO PERFIL DOS TRABALHADORES EM UMA EMPRESA NA CIDADE DE ARAGUARI - MG. 210

SEMELHANÇA ENTRE URSACOL E ÁCIDOS BILIARES DE AVES PARA POSSÍVEL TRATAMENTO DE ASCITE E COLESTASE EM CÃES.
SERVIÇO DE LIMPEZA URBANA, A SOCIEDADE, E UM AMBIENTE ECOLOGICAMENTE

EQUILIBRADO.

SÍNDROME DE CHURG-STRAUSS: UMA

SÍNDROME RARA DISFARÇADA DE DOENÇAS

COMUNS. 213

SÍNDROME DE FOURNIER: A IMPORTÂNCIA DA ATENÇÃO BÁSICA NOS CUIDADOS PÓS-

OPERATÓRIOS. 214

SISTEMA DE INTEGRAÇÃO LAVOURA PECUÁRIA NO AUMENTO DA PRODUÇÃO ANIMAL INTERLIGADO AO DESENVOLVIMENTO SOCIOAMBIENTAL 215

SISTEMA GERENCIAL E SEUS IMPACTOS NO PLANEJAMENTO TRIBUTÁRIO. 216

TECNIFICAÇÃO DA PROPRIEDADE, VISANDO A PRODUTIVIDADE LEITEIRA. 217

TERRORISMO E O DIREITO PENAL DO INIMIGOA ANÁLISE DA INFLUENCIA DO DIREITO PENAL DO INIMIGO SOBRE O TERRORISMO. 218

TESTE DE HIPÓTESE 219

TOJOTA: TORNEIO DE JOGOS DE TABULEIRO COMO ESTRATÉGIA DE APRENDIZAGEM........220 TRABALHO VOLUNTÁRIO: A VIVÊNCIA DE ACADÊMICOS DE MEDICINA EM VIAGEM MISSIONÁRIA AO CONTINENTE AFRICANO..221 TREINAMENTO E DESENVOLVIMENTO 222 UM ESTUDO DE CASO: GESTÃO HOSPITALAR EM UMA UNIDADE MISTA DE SAÚDE DE ARAGUARI - MG

UMA EXPERIÊNCIA DE APRENDIZAGEM COM CRIANÇAS INSTITUCIONALIZADAS: ATIVIDADE EDUCATIVA E DINÂMICA. 224

USO DA MEDITAÇÃO COMO FERRAMENTA AUXILIAR NO TRABALHO DE PSICÓLOGOS: UM ESTUDO TEÓRICO E REFLEXIVO SOBRE O TEMA 225

USO DO INFOGRÁFICO COMO INSTRUMENTO FORMATIVO DO PROFISSIONAL CRÍTICOREFLEXIVO NO CURSO DE MEDICINA ...............226 VALORAÇÃO DO DANO EXTRAPATRIMONIAL

VIOLAÇAO DOS DIREITOS FUNDAMENTAIS DOS ENCARREGADOS DA APLICAÇÃO DA LEI .........228 
VIVÊNCIA DE UMA CUIDADORA DE PACIENTE COM A DOENÇA DE ALZHEIMER: UM RELATO DE CASO 229

VIVÊNCIAS DOS ACADÊMICOS DE FARMÁCIA EM GRUPOS DO PROGRAMA HIPERDIA...........230 VOCÊ SOBREVIVERIA NO TITANIC? UM EXEMPLO DE REGRESSÃO LOGÍSTICA 231

VOLUNTÁRIOS: BUSCANDO AJUDAR O

PRÓXIMO DOANDO CUIDADO E CARINHO.. 232 


\title{
(IN)CONTROLE DA CONSTITUCIONALIDADE NO IMPÉRIO
}

\author{
GRAÇAS CATARINA LOMAZZI, GEILSON NUNES
}

INSTITUTO MASTER DE ENSINO PRESIDENTE ANTÔNIO CARLOS - IMEPAC

sacarag@gmail.com

Apresentação de Pôster

Resumo

Área do Conhecimento: Sustentabilidade e Direitos

INTRODUÇÃO: A corrente liberalista induzia as colônias americanas a liberdade das metrópoles, no Brasil a republica seria implantada e eliminaria o autoritarismo do imperador que observaria uma constituição liberalista. PROBLEMA DA PESQUISA. Dom Pedro I na expectativa de lograr as ideias iluministas oriundas da Europa constituiu uma Assembleia para a elaboração da Constituição do Império que atendesse seus interesses, permitindo o controle constitucional mesmo contra o poderio econômico dos latifundiários aos judiciário? OBJETIVO: analisar os elementos vigentes na Constituição de 1824 apontando no judiciário o controle de constitucionalidade. MÉTODO: buscou-se fontes em obras literárias de Direito e Historia, analisou, resumiu e comentou se pelo método dedutivo em busca da resposta da problemática apresentando a dedução da pesquisa. RESULTADOS ALCANÇADOS: Controle de constitucionalidade é a pratica institucional da defesa e vigilância da Constituição, através da ação do órgão judicial. Detectando a validade formal e material das leis e dos atos normativos em sua rica e complexa estrutura que desenvolveram-se na vigência da Constituição de 1824. Não foi introduzido em seu contexto as ações de controle constitucional. Os juízes mantiveram-se no principio da separação dos três poderes e atividade judicial que ao julgar se apoiavam em princípios nem sempre esclarecedores. Acatavam o anticolonialismo (recolonização), antiabsolutismo: limitação dos poderes imperiais valorização do Legislativo, Forças Armadas obedeceria ao Legislativo, e classismo: controle e reserva do poder pelos politico latifúndios. 0 que desagradou o Imperador que imediatamente dissolveu a Assembleia. Este frente a insatisfação dos latifúndios convocou nova comissão de dez membros ao final de 40 dias concluiu se o texto do anteprojeto constitucional. Com a aprovação das Câmaras Municipais outorgou a Constituição que estabelecia a organização do Estado em quatro poderes: Judiciário:( juízes e tribunais) órgão máximo Supremo Tribunal; os juízes eram nomeados pelo imperador; Legislativo: elaborar as leis do império, senador (vitalício) e deputados ( 3 anos) sua indicação ou eleição esta subordinada a condição financeira; Executivo: poder do imperador, através de seus ministros de Estado com função administrativa publica e zelar pelo cumprimento da lei; Moderador: poder absoluto podia nomear e demitir livremente os ministros de Estado, também nomear senadores, dissolver a Câmara, vetar atos do Poder Legislativo. Esta explicito a desconsideração sobre os direitos fundamentais ao determinar que o Estado sustentasse com luxo a família real. Absurdo ao determinar que a pessoa do imperador era inviolável e sagrada. É obvio a ausência de controle constitucionalidade

PALAVRAS-CHAVE: ABSOLUTISMO; CONTROLE DE CONSTITUCIONALIDADE; IMPÉRIO. 


\title{
A APLICAÇÃO DO PRINCÍPIO DA DIGNIDADE DA PESSOA HUMANA AOS INIMPUTÁVEIS
}

\author{
LUCY ANA ALVES DE SOUSA, FRANCELI BARBOSA BRITO, JOSÉLIA CONCEIÇÃO SOARES CARVALHO \\ SANTANA, FERNANDO DE ALMEIDA SANTOS, GEILSON NUNES
}

INSTITUTO MASTER DE ENSINO PRESIDENTE ANTÔNIO CARLOS - IMEPAC

lucyanaas@gmail.com

Apresentação de Pôster

Resumo

Área do Conhecimento: Sustentabilidade e Direitos

INTRODUÇÃO: 0 presente trabalho analisará a aplicação da medida de segurança sob a ótica da dignidade da pessoa humana, qual seja, o tratamento a que são submetidos os inimputáveis nos manicômios judiciais. OBJETIVO: 0 objetivo a ser alcançado refere-se em averiguar a eficácia dos direitos e garantias fundamentais na aplicação das medidas de segurança aos indivíduos que não operam com consciência e vontade ao praticar fato tipificado como crime, que, no caso em análise, são os inimputáveis. METODOLOGIA: Para alcançar o proposto na pesquisa, adotou-se o método dedutivo, a partir de argumentos gerais para particulares, utilizando-se da pesquisa teórica, por meio de doutrinas, legislação e demais documentos pertinentes ao tema. RESULTADOS ALCANÇADOS: A Constituição da República Federativa do Brasil de 1988 (CRFB/88), em seu art. 1ํ, inciso III, elegeu a dignidade da pessoa humana como um de seus fundamentos. Nesta esteira, Sarlet destaca a vedação da tortura e tratamento desumano, a proibição da redução do ser humano a objeto de ação estatal. Greco leciona que antes do século XVIII, a aplicação da pena era diretamente no corpo do condenado. Porém, no final desse século e início do século XIX, foi iniciada uma das maiores transformações no que diz respeito a qualidade das penas. Com base nessas premissas, faz-se necessário admitir que todos os princípios cabíveis as penas, devem do mesmo modo incidir sobre a medida de segurança. Para Masson medida de segurança é uma modalidade de sanção penal, com objetivo preventivo, caráter terapêutico que se destina a tratar inimputáveis e semi-imputáveis portadores de periculosidade, cuja finalidade seja evitar a prática de novos delitos. Podemos afirmar que sua aplicação tem o caráter indeterminado, pois, embora o Código Penal, no seu art. 97, §1ํ indique limite mínimo de 01 (um) a 03 (três) anos, sua duração fica vinculada ao laudo médico firmado por profissional capacitado que ateste o fim da periculosidade. Destarte, a fim de que seja dado o efetivo tratamento e avaliada a periculosidade do agente, faz-se necessário vagas suficientes e ambientes próprios para que as medidas de segurança atendam realmente o que se propõe. Nesse sentido, leciona Gonçalves que por falta de previsão na Constituição Federal, algumas garantias como progressão de regime, de cumprir sanção alternativa, prescrição da execução da pena, e outras formas de extinção da punibilidade, não seriam aplicáveis a medida de segurança. CONCLUSÃO: A aplicação da medida sem os meios adequados, necessários e proporcionais foge de sua finalidade, de modo que ao invés de tratar vai apenas punir, o que ocorrerá duplicadamente a esse inimputável estigmatizado como louco e criminoso. Assim, aquele que comete ilícito penal declaradamente inimputável não deve ser encarcerado sem que exista meios para aplicação de um tratamento eficaz que assegure seus direitos.

PALAVRAS-CHAVE: DIGNIDADE; INIMPUTÁVEIS; SANÇÃO. 


\title{
A DIFICULDADE NA ADAPTAÇÃO PEDAGÓGICAPARA OS DEFICIENTES INTELECTUAIS NAS ESCOLAS REGULARES E SUAS CONSEQUÊNCIAS PARA OS DIREITOS FUNDAMENTAIS DE ACESSIBILIDADE
}

\author{
LARA CRISTINA CLEMENTE, MAURíCIO RIBEIRO ALVES, RODRIGO GUILHERME TOMAZ, ANNYE \\ MARIE
}

INSTITUTO MASTER DE ENSINO PRESIDENTE ANTÔNIO CARLOS - IMEPAC

larinhaclemente@hotmail.com

Apresentação de Pôster

Resumo

Área do Conhecimento: Educação e Inclusão

Introdução: A ausência da efetividade dos direitos constitucionais que deve ser oferecida por meio da educação, tem sido evidenciada pela dificuldade na adaptação pedagógica para os deficientes intelectuais nas escolas regulares. Assim, impossibilitando os alunos especiais de alcançarem de modo real os privilégios educacionais já pertencentes a eles. Apesar de incontáveis avanços já alcançados em relação aos deficientes intelectuais, ainda há obstáculos a serem superados, tanto nas escolas, como nas famílias, e até mesmo, na sociedade, devendo desenvolver uma reflexão crítica sobre a formação dos professores em geral e as políticas de inclusão.

Objetivo: 0 presente trabalho tem por objetivo explanar a efetividade dos Direitos Fundamentais que os deficientes intelectuais possuem na adaptação pedagógica, frente às escolas regulares, demonstrando como a legislação auxilia no aperfeiçoamento das possibilidades de aprendizagem para inclusão dos referidos alunos. Elucidando, ainda, a importância da adaptação no aspecto educacional, dos profissionais do Atendimento Educacional Especializado, com o fim de garantir a acessibilidade aos especiais.

Metodologia: 0 método de abordagem a ser descrito será o dialético-jurídico, que abrange a teoria e fatos exemplificativos, simultaneamente, de forma a alcançar os resultados propostos.

Resultados: Observa-se a evidência da necessidade da prática inclusiva de alunos como modelo para que todas as escolas ofereçam de forma efetiva uma adaptação pedagógica qualificada e real aos deficientes intelectuais. A temática da inclusão dos deficientes intelectuais na rede regular, ainda traz inúmeras problemáticas, porém deve existir o trabalho dos professores habituais em parceria com os professores do atendimento educacional especializado, juntamente com a escola. Proporcionando um ambiente pedagógico estruturado para cada dificuldade apresentada e compreendendo que não há divisão entre os profissionais habituais e os especialistas, mas sim uma complementaridade.

Conclusão: 0 aluno com limitações intelectuais deve estar integrado em uma turma regular de ensino, participando das atividades, apropriando-se de valores e conhecimentos, extinguindo processos de segregação e implantando o AEE, que considere as singularidades de aprendizagem desses alunos. Assim, haverá uma efetividade de direitos na adaptação pedagógica para os deficientes intelectuais, com exigências da educação inclusiva e da educação regular, para ampliação concreta das oportunidades educacionais e dos direitos assegurados a todos aqueles que necessitam, ou não, do atendimento especializado.

PALAVRAS-CHAVE: DIREITOS FUNDAMENTAIS; EFETIVIDADE; INCLUSÃO. 


\title{
A DIFUSÃO DA AUTO-HEMOTERAPIA EM OPOSIÇÃO AO SEU CARÁTER PROIBITIVO BRASILEIRO
}

\author{
MARCELO CARVALHO, ALINE FERNANDES HIPÓLITO, CARINE FIRMINO CARVALHO ROEL, KARINE \\ ELEN FIGUEREDO RIBEIRO, MARIANA DE FÁTIMA LOPES RESENDE, NORMA CRISTINA DE SOUSA, \\ RITA ALESSANDRA CARDOSO
}

INSTITUTO MASTER DE ENSINO PRESIDENTE ANTÔNIO CARLOS - IMEPAC

marcellocarvalhopianist@hotmail.com

Apresentação de Pôster

Resumo

Área do Conhecimento: Saúde coletiva e bem-estar

Introdução: A auto-hemoterapia (AHT) é uma técnica antiga, considerada um procedimento relativamente simples e barato, que consiste na administração intramuscular de sangue autólogo, visando o tratamento de doenças infecciosas, alérgicas, autoimunes e vários outros problemas de saúde. Recentemente, desencadeou-se no Brasil uma atuação do Conselho Federal de Medicina e da Agência Nacional de Vigilância Sanitária, amparados pelo Ministério Público, no sentido de proibir a utilização dessa terapia. Há por isso, a necessidade de se realizar pesquisas para compreensão dos mecanismos, aplicação, efeitos, riscos, aspectos sociais e legais que permeiam a prática. A técnica só poderá ser utilizada baseada no rigor científico a partir da existência de estudos que avaliem sua eficácia e segurança, além de uma regulamentação legislativa.

Objetivo: Analisar a eficácia e o papel da auto-hemoterapia, bem como sua legitimidade no mundo, em oposição ao entendimento da antijuricidade desta prática no Brasil, sobrepondo uma reflexão abrangente sobre tema.

Metodologia: Configura-se como um estudo bibliográfico qualitativo em revisão narrativa da literatura, realizado por busca em bases de dados nacionais e internacionais, como Pubmed, SciELO e LILACS, incluindo filtros inerentes ao tema.

Resultados: Vários trabalhos realizados em todo mundo têm demonstrado a utilidade, eficácia e segurança da AHT no combate e na profilaxia de múltiplas doenças, explanando direta ou subjetivamente, sua validez, papel, influência nos fatores de saúde coletiva e bem-estar, defesa do direito (popular e comum, científico e profissional) por participação às medicinas alternativas nas estratégias de saúde consoantes com a legislação proposta pelo Sistema Único de Saúde e alinhadas aos princípios da Organização Mundial de Saúde.

Conclusão: Considera-se que a amplitude contextual da AHT estabelece evidentemente uma condição questionável em seu caráter proibitivo em território brasileiro, onde a legislação aplicada oportuniza privilégios de domínio de práticas e interesses mercantis, distanciando da serventia comum à sociedade e invertendo os valores à aplicação da saúde. Sugere-se uma reflexão autocrítica, firmada pelas pesquisas já sucedidas e seus elementos substanciais proporcionados, incluindo a interpretação de condições legais para prática da AHT fora do país, unidos por forças de integração entre comunidade, profissionais de saúde, corpo científico e representantes legislativos, no incentivo à realização de sua aplicabilidade nas práticas integrativas e complementares, sob estudos de hemovigilância na avaliação do seu uso em grupo populacional, para estabelecer finalmente o valor terapêutico da auto-hemoterapia como objeto estratégico em saúde.

PALAVRAS-CHAVE: SANGUE AUTÓLOGO; MEDICINA ALTERNATIVA; TERAPIAS COMPLEMENTARES. 


\title{
A EFETIVIDADE NA APLICAÇÃO DO PRINCÍPIO DA PROTEÇÃO INTEGRAL ÀS CRIANÇAS E ADOLESCENTES NO BRASIL
}

\author{
ALBERTO WYUKER PEDRO, FERNANDA CRISTINA DOS SANTOS, GEILSON NUNES
}

INSTITUTO MASTER DE ENSINO PRESIDENTE ANTÔNIO CARLOS - IMEPAC

beto_wyu@hotmail.com

Apresentação de Pôster

Resumo

Área do Conhecimento: Sustentabilidade e Direitos

Introdução: 0 princípio da proteção integral é imprescindível à manutenção e ampliação dos direitos das crianças e adolescentes no Brasil, que na condição de pessoas em fase de desenvolvimento carecem de cuidados que devem ser resguardados pela família, Estado e sociedade.

Objetivo: 0 objetivo que se pretende alcançar é apontar formas de promover a efetividade na aplicação do princípio da proteção integral às crianças e adolescentes no Brasil por meio dos sujeitos de obrigação.

Metodologia: Para a consecução dos objetivos propostos foi utilizado o método dedutivo, que parte de argumentos gerais para específicos, possibilitando a produção de conclusão que contemple sugestões viáveis e factíveis ao problema apresentado.

Resultados: A Constituição Federal Brasileira de 1988 prevê no caput do art. 227 que a família, a socied ade e o Estado devem assegurar à criança, ao adolescente e ao jovem, o direito à vida, à saúde, à alimentação, à educação, ao lazer, à profissionalização, à cultura, à dignidade, ao respeito, à liberdade e à convivência familiar e comunitária, asseverando que as crianças e os adolescentes devem ser resguardados de toda forma de negligência, discriminação, exploração, violência, crueldade e opressão. O Estatuto da Criança e do Adolescente (ECA) - Lei n.o 8.069/90 regulamenta a previsão constitucional supracitada e faz alusão ao princípio da proteção integral à criança e ao adolescente já no seu primeiro artigo. Além disso, o Estatuto estabelece a necessidade de considerar a condição peculiar da criança e do adolescente como pessoas em desenvolvimento, conceituando criança a pessoa com até doze anos de idade incompletos e adolescente aquela entre doze e dezoito anos de idade. Ademais, o Estatuto atua como um microssistema jurídico que visa proteger os direitos fundamentais de seus destinatários, assegurando-lhes, também, direitos próprios, por intermédio de instrumentos efetivos de defesa, no entanto, a efetividade jurídica e social de uma norma identifica-se pela capacidade desta em gerar efeitos, assim, mesmo que a Constituição Federal e o ECA estabeleçam a proteção integral, no contexto atual, não é possível afirmar que a família, a sociedade e o Estado estejam cumprindo integralmente com as suas obrigações.

Conclusão: Para o alcance da efetividade na aplicação do princípio da proteção integral às crianças e adolescentes no Brasil é preciso que a família, o Estado e a sociedade atuem com observância aos preceitos legais citados. Propõe-se a criação de espaços de convivência com foco no conhecimento e aperfeiçoamento da família e da sociedade, para que todos conheçam a relevância do seu papel na promoção e fiscalização de atividades relacionadas à proteção integral das crianças e adolescentes, denunciando possíveis práticas ilegais que prejudiquem a sua efetividade.

PALAVRAS-CHAVE: DIREITO; PRINCÍPIO DA PROTEÇÃO INTEGRAL; CRIANÇAS E ADOLESCENTES. 


\title{
A EVOLUÇÃO TECNOLÓGICA E SUA INFLUÊNCIA NO DIREITO SOCIAL
}

\author{
YASMIN CARDOSO FERNANDES, ERICK CARDOSO CLAUDOMIRO, DONNER RODRIGUES QUEIROZ
}

INSTITUTO MASTER DE ENSINO PRESIDENTE ANTÔNIO CARLOS - IMEPAC

yasmincbscj@icloud.com

Apresentação de Pôster

Resumo

Área do Conhecimento: Sustentabilidade e Direitos

Introdução: No presente estudo abordaremos a perspectiva da tecnologia e sua influência social, mais notadamente no que tange, ao direito digital, já tutelado pelo Estado.

Problemática de Pesquisa: Analisando o funcionamento dos mais variados tipos de redes sociais, percebemos que elas possuem um amplo conhecimento vital do cidadão que à ela se agrega, logo eis que surge a questão, estamos protegidos ao navegar na internet

Objetivo: 0 estudo tem a finalidade de apontar alguns caminhos que podem ser seguidos por nossos legisladores quanto a proteção da identidade virtual do cidadão, bem como apontar caminhos aos usuários para que usem de maneira mais segura, o livre mundo virtual.

Método: Foi realizada uma pesquisa usando o método dedutivo, partindo da premissa do geral para o particular.

Resultados: A internet surgiu de forma surpreendente, gerando uma explosão virtual em pouco mais de 20 anos, mudando a forma de nos comunicar e interagir, sendo que grande parte dessa interação acontece em um chamado "mundo virtual" ,com isso as relações sociais cotidianas sofreram grande alteração com o início das atividades virtuais no mundo. Observando a rentabilidade do mercado cada vez mais empresas ingressaram neste meio, criando todo tipo de atividade por lá, fazendo com que as pessoas de hoje usem a internet para a grande maioria das suas atividades, partindo de mandar um simples oi para um amigo até o ponto de realizar transações bancárias milionárias. Começou-se então a discutir bastante como deve-se tutelar normas para situações ocorridas no mundo virtual. A lei 12.965/14 foi criada para regulamentar o uso da internet, mas o que percebemos é que, apesar, do Estado ter começado a coibir mais as condutas geradas na internet, está longe de se ter realmente uma norma eficaz, pois a norma, possui erros técnicos. Um dos erros técnicos encotrados, pode ser observado em seu no art. 13 da lei 12.965/14. Neste artigo esta substanciado que os dados devem ser armazenados pelo servidor de determinada empresa virtual pelo prazo de 01 ano, nesta perspectiva ao analisar o artigo 109 do CP, vemos que o prazo mínimo de prescrição de um crime é de 03 anos, ou seja, se um usuário sofrer uma ameaça virtualmente, mesmo que exista um prazo prescricional de 03 anos no Código Penal, ele estará resguardado pelo servidor pelo prazo de apenas 01 ano.

Conclusão: Apesar da evolução que tivemos com a internet e a tutela jurisdicional, ainda nos encontramos vulneráveis aos possíveis danos do mundo virtual. Pois, embora a internet tenha surgido há meados de 20 anos, ainda é um campo que está em constante evolução, contudo o nosso ordenamento jurídico não tem conseguido acompanhar esse desenvolvimento tecnológico, neste sentido, 0 estado Brasileiro deve tutelar ainda mais sobre o assunto e dessa forma proteger de maneira plena a população.

PALAVRAS-CHAVE: DIREITO; VIRTUAL; ESTADO. 


\title{
A GESTÃO ECONÔMICA DOS MEDICAMENTOS VIA ORAL UTILIZADOS PARA TRATAMENTO DE DIABETES MELLITUS EM ARAGUARI - MG
}

\author{
CECÍLIA BARBOSA DE MORAIS, ADRIANA RODRIGUES PESSOA LONDE, CAMILA FLÁVIO DE LIMA, \\ LUDMYLA ISADORA SILVEIRA, RENNER PEREIRA DA SILVA MELO, CÉSAR ANTÔNIO DE OLIVEIRA
}

INSTITUTO MASTER DE ENSINO PRESIDENTE ANTÔNIO CARLOS - IMEPAC

cecibmorais@gmail.com

Comunicação Oral

Resumo

Área do Conhecimento: Gestão de recursos econômicos (naturais)

O diabetes mellitus é uma patologia de acometimento metabólico, relacionado a defeitos na secreção de insulina ou a resistência de sua ação nos tecidos. Essa condição crônica de saúde destaca-se pelo aumento de prevalência no cenário nacional e mundial, bem como pela alta taxa de morbimortalidade. Dessa forma, a patologia uma vez instalada requer educação contínua e cuidados clínicos, dentre esses estão as alterações referentes ao estilo de vida - prática de atividades físicas e reeducação alimentar - bem como, a introdução medicamentosa, prática indispensável na contribuição para a diminuição das complicações agudas e crônicas, além do aumento da qualidade de vida.

A introdução medicamentosa faz-se necessário na tentativa de controle glicêmico, visando uma melhora e estabilidade na qualidade de vida do paciente, com o objetivo de prevenir a piora da doença, e o acometimento dos mais diversos sistemas do organismo.

Assim, a garantia de acesso aos medicamentos de forma racional é um dos aspectos fundamentais na estratégia de atenção básica à saúde. Logo, faz-se necessário o abastecimento satisfatório de medicamentos previsto pela lei no 11.347 de 27 de setembro de 2006 e reforçada pela Portaria № 2.583, de 10 de outubro de 2017, que garante que os portadores de diabetes mellitus devem receber gratuitamente, do Sistema Único de Saúde - SUS , os medicamentos necessários para o tratamento de sua condição e os materiais necessários à sua aplicação e à monitoração da glicemia capilar. No entanto, para que as políticas descritas e firmadas sejam implantadas de maneira eficaz é necessário que haja uma correta e transparente distribuição de verba pública, além de assegurar os recursos fundamentais que tange a assistência farmacêutica.

Nesse sentido, este trabalho objetivou analisar a gestão de medicamentos via oral para Diabetes Mellitus em Araguari-MG através de uma análise descritiva, quantitativa e temporal, com dados secundários obtidos por meio de consulta a Farmácia Municipal de Araguari, vigentes entre o período de 2018 e 2019.

Os resultados encontrados indicam a disponibilização de três medicamentos via oral, sendo eles: glibenclamida, glicazida e metformina, com um custo de $\mathrm{R} \$ 12.952,00$ por período de remessa, sendo essa realizada a cada 60 dias e consumido pela cota reservada a Secretaria de Estado de Saúde na Ata de RP 199/2018 do Estado de Minas Gerais e reservado para utilização exclusiva do Município.Assim, ficou demonstrado que a gestão dos medicamentos hipoglicemiantes orais realizada na cidade de Araguari-MG funciona de maneira efetiva e dentro dos preceitos legais estabelecidos pela Política Nacional de Assistência Farmacêutica (PNAF), pois a seleção, programação,aquisição, armazenamento , distribuição, prescrição e dispensa de medicamentos de acordo com a demanda e a oferta , está sendo realizada de forma adequada na cidade.

PALAVRAS-CHAVE: GESTÃO ECONÔMICA; DIABETES MELLITUS; MEDICAMENTOS. 


\title{
A IMPORTÂNCIA DA REGULAMENTAÇÃO DA AUDIÊNCIA DE CUSTÓDIA NO PROCESSO PENAL BRASILEIRO
}

\author{
FABIANO MARQUES VIEIRA FILHO, YURI STOECKLI VIRGA DE ANDRADE,
}

INSTITUTO MASTER DE ENSINO PRESIDENTE ANTÔNIO CARLOS - IMEPAC

fabiano_filho_@hotmail.com

Apresentação de Pôster

Resumo

Área do Conhecimento: Sustentabilidade e Direitos

Introdução: 0 presente trabalho buscou tratar da questão da audiência de custódia dentro do processo penal brasileiro, enfatizando acerca de sua efetividade na persecução penal, bem como a sua realização, a fim de evitar que prisões injustas e falta de consideração sofrida pelos presos que não tem contato imediato com uma autoridade judiciária.

Objetivo: Frente ao exposto, o objetivo deste trabalho foi discorrer sobre a importância da realização das audiências de custódia, uma vez que as mesmas trazem maior eficácia, justiça e equidade ao processo penal. Metodologia: Para se alcançar o proposto na pesquisa, adotou-se o método dedutivo com a metodologia exploratória do conteúdo proposto através de revisão bibliográfica, doutrinas, legislação e demais documentos pertinentes ao tema.

Resultados: No ano de 1992, o Brasil ratificou o Pacto de San José da Costa Rica, no qual consta em seu art. 7ํㅡㄴ item 5, que, a pessoa detida deve ser conduzida sem demora à autoridade judiciária. Em 2011 houve uma alteração legislativa no Código de Processo Penal trazendo em seu art. 306, § 1ำ que o auto de prisão em flagrante deveria ser encaminhado em até 24 (vinte e quatro) horas após a realização da prisão. A Constituição Federal de 1988, por sua vez, garante vários direitos aos presos, os instituto da ampla defesa, contraditório e o princípio da dignidade da pessoa humana. Devido a superlotação dos presídios e bem como a alta taxa de prisão errônea, a audiência de custódia, pode ser considerada como a realização de uma audiência sem demora após a prisão em flagrante, permitindo o contato imediato do preso com o juiz, com um defensor público, dativo ou constituído e com o Ministério Público, tendo como principal objetivo de evitar que o preso seja ouvido pelo juiz somente muito tempo após a sua prisão, sendo que não é de difícil realização, visto que há sempre um magistrado plantonista para receber e analisar os flagrantes que lhe são competentes. Ademais, o primeiro e rápido contato com a autoridade judiciária, evita de modo considerável prisões irregulares materialmente ou formalmente, partindo por esta análise, há abusos que são cometidos pelos agentes de segurança no momento do flagrante, posto isto, deve ser observado e respeitado todo o ordenamento jurídico vigente e consequentemente, todas às garantias destinadas ao preso.

Conclusão: Com base nos resultados alcançados, concluímos que a audiência de custódia é muito importante para a evolução do direito penal, uma vez que a mesma pode ser observada como um meio de amenizar dificuldades que o sistema penal vem enfrentando atualmente, necessitando assim, de uma normatização uniforme em todo o ordenamento jurídico, assim, a regulamentação da audiência de custódia traz benefícios para o atual direito penal brasileiro.

PALAVRAS-CHAVE: AUDIÊNCIAS DE CUSTÓDIA; DIREITO PENAL; PRESO. 


\title{
A INFLUÊNCIA DA MÍDIA NAS DECISÕES DO TRIBUNAL DO JÚRI
}

\author{
LUANA MILLEYDE RESENDE SILVA, LUCAS VINÍCIUS DE SOUSA, GEILSON NUNES
}

INSTITUTO MASTER DE ENSINO PRESIDENTE ANTÔNIO CARLOS - IMEPAC

luanamilleyde.rs@hotmail.com

Apresentação de Pôster

Resumo

Área do Conhecimento: Sustentabilidade e Direitos

O presente trabalho se propõe a analisar o instituto do Tribunal do Júri, sob a ótica de que as decisões ali engendradas podem ser antidemocráticas ou antijurídicas, em virtude de influência por ações midiáticas. Outrossim, serão abordados princípios ínsitos ao Processo Penal, bem como questões referentes à liberdade de imprensa, e a colisão entre eles. Por que as decisões de processos submetidos ao rito do Júri podem sem parciais? 0 presente trabalho visa analisar a influência da mídia nas decisões proferidas em processo submetidos ao Tribunal do Júri, e detectar o seu real alcance, e se ele é suficientemente amplo a ponto de gerar prejuízos sociais.

Quanto ao método utilizado, optou-se pelo dedutivo, partindo de uma premissa geral para uma específica. Como metodologia optou-se pela pesquisa bibliográfica, embasada na Constituição Federal, na legislação pertinente, na jurisprudência e na doutrina.

Com base na imensa gama de recursos informacionais existentes atualmente, e o anseio de boa parcela da população por notícias, em especial aquelas que abordam crimes contra a vida, nota-se que os meios de comunicação de massa abraçaram a divulgação desses episódios, trazendo os desdobramentos fáticos e jurídicos, inclusive em programas de cunho sensacionalista, com o fito de criar comoção social, levando o conteúdo aos espectadores que não raro, tomam o que ali é apresentado como verdades absolutas.

Além da versão verídica dos fatos, a sua exposição e divulgação devem cercar-se de objetividade e serenidade para evitar que o público receptor da notícia formule juízos de valor decorrentes não das informações - verdadeiras ou falsas -, mas dos artifícios apresentados por aquele que narrou os acontecimentos de maneira ambígua, excessivamente carregadas de expressões inúteis e agressivas. (GREC0, 2002, p. 79).

A informação deve ser livre e sem censura prévia, uma vez que a Constituição assim o estabeleceu, posto que aos cidadãos é garantido o direito ao conhecimento dos atos que ocorrem em seu entorno, inclusive no que tange às esferas de poder, para que possam exercer o controle social, sendo is to manifesto corolário do Estado Democrático de Direito.

Com relação à realidade processual, tem-se que os atos processuais também se revestem de publicidade garantindo aos jurisdicionados e à sociedade como um todo acesso às informações concernentes às de cisões judiciais, porquanto a sentença não tem o mero condão de oferecer respostas apenas aos litigantes, mas a toda a sociedade. Ademais, o processo público é o que assegura o respeito dos procedimentos e as garantias fundamentais.

PALAVRAS-CHAVE: JÚRI POPULAR; MÍDIA; INFLUÊNCIA. 


\title{
A INSERÇÃO ERRÔNEA DE DADOS FISCAIS NO PLANEJAMENTO TRIBUTÁRIO
}

\author{
ELAINE GIANINI GODOY, ANA CAROLINA DA SILVA BORGES, FABIANA XAVIER DA SILVA, GABRIEL \\ ROCHA NASCIMENTO, GABRIELLA INÊS SILVA FARIA, ISABELA CRISTINA FERREIRA JORDÃO, \\ FABIANO JOSÉ LUCAS DOS SANTOS
}

INSTITUTO MASTER DE ENSINO PRESIDENTE ANTÔNIO CARLOS - IMEPAC

elainegianini@yahoo.com.br

Apresentação de Pôster

Resumo

Área do Conhecimento: Responsabilidade e Negócios

Este estudo tem como objetivo mostrar a importância do profissional contábil para o crescimento e a sustentabilidade dos negócios nas organizações. Realizamos um estudo na empresa FAGEI Alimentos LTDA, localizada em Araguari - MG e detectamos algumas deficiências de gestão, na qual dificultava o trabalho do contador e dos gestores da empresa. A conclusão deste estudo conduziu a constatação de solução dos principais problemas encontrados na empresa. Com as informações corretas o contador junto aos gestores planejará quais ações deverão ser tomadas e quais controles serão utilizados para a explicação e interpretação dos fenômenos patrimoniais além de manter a empresa cada vez mais competitiva, garantindo seu sucesso.

Tendo em vista o desenvolvimento de um trabalho de pesquisa utilizando a Metodologia da Problematização com o Arco de Maguerez, escolhemos como campo de observação da realidade a empresa FAGEI Alimentos Ltda. Tal escolha se deve pela facilidade de acesso nos documentos da empresa através de um dos integrantes do grupo.

No campo investigado, notamos que há funcionários sem registros, aproveitamento indevido de alíquota e recebimento de mercadoria sem nota fiscal. Além disso, não há um planejamento tributário que atenda às necessidades da empresa e a falta de funcionário capacitado para ocupar o cargo. A empresa não autorizou a divulgação de sua razão social, ela possui como atividade principal o comércio varejista e a análise é baseada no último ano.

Dessa forma, as observações feitas nos conduziram ao delineamento do seguinte problema de investigação, a inserção errônea de dados fiscais no impacto do planejamento tributário.

Compreendemos que estudar mais profundamente sobre este tema buscando possíveis soluções para esse problema, contribuirá para termos maior conhecimento na área fiscal, atuando especificamente com a gestão e o controle do recolhimento do tributo. Sob o ponto de vista dos colaboradores da FAGEI Alimentos LTDA a aplicação correta do planejamento tributário acarretará em benefícios para os funcionários, além de o governo receber de forma adequada os seus tributos e reverte - los para a sociedade. E, finalmente, para nossa formação acadêmica, com domínio em saber discernir o regime tributário adequado para cada empresa, gerar economia para a organização, elaborar um orçamento anual eficaz, aumentar a competitividade do negócio no mercado e o aproveito de possíveis incentivos fiscais.

0 projeto de aprendizagem é dinâmico, com uma pedagogia construtiva, visando aprendizagem profunda dos conhecimentos por meio da resolução de problemas, pesquisas, investigação. Dessa forma, precisamos ter conhecimento de todos os assuntos relacionados ao ponto chave determinado, a fim de, teorizar e solucionar.

PALAVRAS-CHAVE: PLANEJAMENTO TRIBUTÁRIO E FINANCEIRO. 


\title{
A JUSTIÇA GRATUITA: INSTRUMENTO DE ACESSO À JUSTIÇA E A SUA APLICABILIDADE
}

\author{
ANYELLE PERES MARTINS, NEYLMA DO NASCIMENTO, ADRIANA ALVES QUINTINO MENEZES
}

INSTITUTO MASTER DE ENSINO PRESIDENTE ANTÔNIO CARLOS - IMEPAC

anyelleperes@hotmail.com

Apresentação de Pôster

Resumo

Área do Conhecimento: Sustentabilidade e Direitos

Introdução: 0 presente trabalho buscou discorrer sobre o reconhecimento ao direito à gratuidade da justiça como forma de aplicação do princípio constitucional de acesso à justiça. Para isso, foi feita uma análise do acesso à justiça como um direito fundamental previsto na Constituição Federal de 1988, analisando a proporção da eficácia da justiça gratuita, a fim de conhecer a importância da assistência judiciária gratuita para a efetividade da tutela de direitos.

Objetivo: Frente ao exposto, o objetivo a ser tratado se referiu à intenção de demonstrar que o sistema deve ser igualmente acessível a todos e deve produzir resultados que sejam próprios, justos e uma garantia fundamental do indivíduo, podendo-se considerar como um dos direitos fundamentais mais básicos presentes em um sistema jurídico moderno e igualitário que visa garantir os direitos de todos e proporcionar aos mais desprovidos de recurso a paridade de armas em um duelo judicial.

Metodologia: Para a obtenção dos resultados almejados na presente pesquisa foi adotado o método dedutivo, a partir de argumentos gerais para argumentos particulares, de forma a alcançar os resultados propostos na problemática e, por conseguinte, uma conclusão do que se consignou na pesquisa.

Resultados: 0 princípio do acesso à justiça não se trata de nenhuma inovação legislativa, pois o referido princípio, após anos de aprimoramento hermenêutico, passou a ser considerado um dos pilares do sistema político-jurídico do país, na medida em que, deixou de se importar apenas com a simples possibilidade do cidadão poder, eventualmente, requer a tutela jurisdicional, para, enfim, preocupar-se, com a qualidade e a eficácia do provimento judicial prestado. Por sua vez, pode-se destacar que a efetividade trata-se de dar igualdade de armas às partes, pois as diferenças entre elas jamais serão aniquiladas e umas das barreiras a serem ultrapassadas para se alcançar essa tutela e viabilizar a ordem jurídica, é fortalecer as instituições que prestam tais serviços, dando a essas, tratamento condizente com suas atribuições constitucionais de função essencial à Justiça. Desta feita, é sabido que as barreiras ao acesso à justiça são mais frequentes nas pequenas causas e alcançam geralmente os mais desprovidos de recursos, razão pela qual se torna indispensável colocar os litigantes em mesmo nível de condições.

Conclusão: Diante do exposto, pôde-se concluir que o acesso à justiça é um direito fundamental intrínseco a toda pessoa, não podendo ser suprimido, razão pela qual, o Estado, por meio do Poder Público, deve buscar ter uma atuação bastante próxima da sociedade e assegurar assistência jurídica a todos, em especial aos mais necessitados, assegurando o livre exercício do acesso à justiça em seu real sentido.

PALAVRAS-CHAVE: ACESSO À JUSTIÇA; APLICABILIDADE; JUSTIÇA GRATUITA. 


\title{
A MEDIAÇÃO ENQUANTO DESENVOLVIMENTO SUSTENTÁVEL E PACIFICAÇÃO SOCIAL À LUZ DA AGENDA 2030
}

\author{
MARIANA PENA COSTA E COSTA, LUCIANA MENDONÇA FERNANDES, ADRIANA ALVES QUINTINO \\ MENEZES
}

INSTITUTO MASTER DE ENSINO PRESIDENTE ANTÔNIO CARLOS - IMEPAC

maripenac@hotmail.com

Apresentação de Pôster

Resumo

Área do Conhecimento: Sustentabilidade e Direitos

\begin{abstract}
Introdução: 0 desenvolvimento sustentável tem como um dos objetivos o atendimento das necessidades humanas e baseia-se em princípios sociais, ambientais e econômicos. A Agenda 2030 foi criada a partir da necessidade de ações que trabalhassem o desenvolvimento sustentável para erradicação da pobreza, proteção do planeta e para garantir que as pessoas alcancem a paz e a prosperidade. Dessa forma, a mediação vem ganhando destaque em debates nacionais e internacionais, pois tem como desafio a construção de uma cultura da paz e a solução pacífica dos conflitos.

Objetivo: 0 presente trabalho tem como objetivo trabalhar a mediação à luz do objetivo 16 da Agenda 2030 para a efetivação ao direito fundamental ao acesso à justiça e pacificação social a partir do diálogo.

Metodologia: Adotou-se o método dedutivo, a partir de argumentos gerais para particulares, utilizando-se da pesquisa teórica, por meio de doutrinas e demais documentos pertinentes ao tema.

Resultados: Com um conjunto de 17 objetivos e 169 metas que estimulam ações de incentivo e desenvolvimento da cultura da paz a serem alcançados até o ano de 2030 pelo Brasil e por outros países, a Agenda 2030 traz como um dos desafios, promover o diálogo a partir da mediação buscando a pacificação dos conflitos. Além disso, tem como Objetivo do Desenvolvimento Sustentável 16, proporcionar o acesso à ordem jurídica justa para todos como direito fundamental, a fim de promover sociedades pacíficas e inclusivas que possibilitam o desenvolvimento sustentável, pois entende-se que não há desenvolvimento sustentável sem paz. Assim sendo, a efetividade da prestação jurisdicional, junto aos princípios processuais e o acesso à justiça, não se resume em garantir a possibilidade das partes irem até os tribunais, mas sim, está ligado a capacidade de pacificar os conflitos. A mediação como solução de conflitos, portanto, dinamiza o acesso à justiça e reduz a judicializacão. Assim, a mediação deve ser tratada como uma porta para promover uma justiça sustentável, a democratização ao acesso à justiça, aos direitos e a solução pacifica dos conflitos a partir da capacidade de exercitar o diálogo. Nesse viés, a Agenda 2030 busca uma proteção mais efetiva dos direitos fundamentais em geral e especialmente o direito não só ao acess o à justiça, mas à ordem jurídica justa, com base em uma justiça eficaz, com o desenvolvimento de um sistema jurídico mais humano e igualitário, promovendo assim a paz social dos conflitos.

Conclusão: Assim conforme exposto, conclui-se que a promoção do diálogo e da cultura da paz, são fatores essenciais para que se possa efetivar o direito fundamental ao acesso à justiça e pacificação social a partir da chamada "Ação para mudar o mundo", a qual implementou a Agenda 2030 e seus Objetivos do Desenvolvimento Sustentável.
\end{abstract}

PALAVRAS-CHAVE: AGENDA 2030; DIREITO FUNDAMENTAL; MEDIAÇÃO; PACIFICAÇÃO SOCIAL. 


\section{A RESCISÃO POR MÚTUO ACORDO COMO FORMA DE EXTINÇÃO DO CONTRATO DO TRABALHO}

RENATA BARBOSA CARDOSO, LORRAYNE ANDRADE SILVA BELO, RODRIGO GUILHERME TOMAZ

INSTITUTO MASTER DE ENSINO PRESIDENTE ANTÔNIO CARLOS - IMEPAC

renata_contabeis@hotmail.com

Apresentação de Pôster

Resumo

Área do Conhecimento: Sustentabilidade e Direitos

O presente exame dedica-se a elucidar uma das mudanças trazidas pela reforma trabalhista de 2017. Apesar de modificar diversos dispositivos, o tema central do estudo realizado é a forma inovadora de extinção do contrato de trabalho dada pelo art. 484-A da CLT, esclarecendo do que se trata o dispositivo e apontando os benefícios trazidos pelo referido artigo.

PROBLEMA DA PESQUISA

: Qual o real impacto do surgimento do artigo 484-A na prática? Quais as mudanças trazidas pelo dispositivo e como era tratado o assunto antes da reforma trabalhista?

OBJETIVO

Comprovar que o dispositivo analisado foi introduzido para adaptar se a sociedade facilitando a solução de controvérsias e evitando atividades lesiva aos direitos dos empregados e empregadores, tudo isso aplicado à rescisão do contrato trabalhista por mútuo acordo.

MÉTODO

Será utilizado o método dedutivo de pesquisa, analisando variadas obras acerca do tema, de maneira a concluir o objetivo traçado, posteriormente explicando de forma clara e sucinta o teor do art. 484 -A, da CLT e findando a pesquisa numa conclusão expondo os resultados da pesquisa e o posicionamento das autoras frente ao tema.

RESULTADOS ALCANÇADOS

Entendemos ser merecedora de aplausos a inserção do artigo 484-A da CLT, que versa sobre a extinção do contrato de trabalho por acordo mútuo entre empregado e empregador.

Antes da "reforma trabalhista" o contrato de trabalho só seria ultimado em duas hipóteses que se diferenciam de forma extremamente avessas: Pelo pedido de demissão do trabalhador e demissão por parte do empregador,. A distância entre as duas modalidades refletia em uma relação empregatícia não-saudável, uma vez que o trabalhador, não satisfeito com o emprego continuava em um ambiente que não o agradava para não perder verbas rescisórias, bem assim o empregador mantinha em seu quadro de funcionários um colaborador que não satisfazia a pretensão da empresa para não desembolsar numerário para quitar as multas e demais verbas rescisórias.

Com o advento da Lei 13.467/17 e a inserção do dispositivo contido no art. 484-A, da CLT, um meio termo foi firmado. Desde a promulgação da referida Lei, empregado e empregador poderão rescindir o contrato de trabalho de comum acordo, onde cada um abrirá mão de alguns proventos relacionados à rescisão. Caso optarem pela nova forma de rescisão, a multa de $40 \%$ sobre o Fundo de Garantia do Tempo de Serviço e o aviso prévio serão pagos pela metade, já as demais verbas trabalhistas serão pagas integralmente. No que toca à possibilidade do saque do montante do FGTS, com a rescisão por acordo mútuo é permitido saque, limitado à quantia de $80 \%$ do valor depositado. A nova forma de extinção do contrato de trabalho soluciona alguns problemas, principalmente no que toca o excesso de ações de distrato ajuizadas na Justiça do Trabalho, que é uma ação de acordo entre as partes envolvidas.

PALAVRAS-CHAVE: EXTINÇÃO DO CONTRATO; RESCISÃO POR MÚTUO ACORDO. 


\title{
A RESPONSABILIZAÇÃO DO PAGAMENTO DAS VERBAS TRABALHISTAS INADIMPLIDAS NA TERCEIRIZAÇÃO
}

\author{
DANILO DOS SANTOS FERREIRA, RODRIGO GUILHERME TOMAZ
}

INSTITUTO MASTER DE ENSINO PRESIDENTE ANTÔNIO CARLOS - IMEPAC

danlim00@hotmail.com

Apresentação de Pôster

Resumo

Área do Conhecimento: Sustentabilidade e Direitos

INTRODUÇÃO: O presente estudo tratará da terceirização, levando em consideração sua tamanha importância para o desenvolvimento econômico, bem como seus impactos com as novas mudanças e entendimentos do STF, sobre quem recai a responsabilização em eventual inadimplência no pagamento de verbas trabalhistas.

OBJETIVO: Tem-se o intuito esclarecer as atuais mudanças das normas que regem a terceirização, sempre levando em consideração sua importância econômica, mas acima de tudo enfatizar a maior importância em proteger os direitos daqueles indivíduos que submete-se a esse regimento. MÉTODO: Para que sejam alcançados os resultados pretendidos será feito o uso do método dedutivo, fazendo aplicação de vários entendimentos e unificando-os em um só plano, expondo os objetivos propostos na problemática apresenta. RESULTADOS ALCANÇADOS: 0 trabalho é fundamental para o desenvolvimento da sociedade, de maneira a estar presente na vida de todos, independentemente da forma que é tratado por cada um. As diferentes modalidades que são introduzidas na sociedade, devem ser controladas de maneira que possa manter o desenvolvimento econômico, bem como resguardar a sociedade de eventuais abusos. A terceirização é de suma importância para o desenvolvimento econômico. De maneira singela, intende-se a terceirização como a prestação de serviços formada trilateralmente, diferente do modelo tradicional, bilateral. Incide na transferência da execução de determinada atividade, inclusive podendo ser atividade principal. Diante de tantas dúvidas, vale deixar claro que o empregado não está subordinado diretamente a empresa tomadora, no entanto isso não o exime de obedecer às regras da mesma quando submetido ao trabalho interno. É de responsabilidade da mesma manter a integridade, segurança e condições dignas de trabalho para o empregado. A terceirização tem seus pontos positivos e negativos a depender do caso concreto. No que concerne a responsabilização das verbas trabalhistas, entende-se que estas poderão incidir de maneira subsidiária, podendo recair em culpa in elegendo ou in vigilando, sendo que a primeira condiz na culpabilidade do indivíduo por contratar alguém incompetente ou irresponsável, já a segunda à falta de cautela do contratante ao contratar. Podemos de forma clara observar o disposto no inciso IV do enunciado 331 do TST.

CONCLUSÃO: Conclui-se que concernente à terceirização tem a tomadora responsabilidade subsidiário sobre as verbas trabalhistas de empresa a qual contratou para prestação de serviço, devendo se atentar a sua idoneidade e condições financeiras resguardando-se de eventuais danos. Nos casos os quais a administração pública for tomadora, deverá haver comprovação de culpa ou dolo. A terceirização tem crescido cada vez mais no Brasil, sendo fundamental para o desenvolvimento do país

PALAVRAS-CHAVE: INADIMPLEMENTO - RESPONSABILIDADE - TERCEIRIZAÇÃO. 


\title{
A SATISFAÇÃO DOS MÉDICOS QUE ATENDEM EM ARAGUARI - MG QUANTO AOS PLANOS DE SAÚDE
}

\author{
DAMILA BARBIERI PEZZINI, DANIEL DANTAS, EMANUEL LUCAS JOAQUINA COELHO DE CARVALHO, \\ GABRIELLE SANTIAGO SILVA, GUSTAVO MORAES, ROSÂNIA EMÍLIA RIBEIRO CUNHA
}

INSTITUTO MASTER DE ENSINO PRESIDENTE ANTÔNIO CARLOS - IMEPAC

barbieri.damila@gmail.com

Comunicação Oral

Resumo

Área do Conhecimento: Saúde coletiva e bem-estar

Introdução: A saúde suplementar consiste em todo atendimento privado de saúde. 0 sistema suplementar é formado mais especificamente pelas seguradoras especializadas em seguros-saúde, empresas de medicina de grupo, cooperativas, entidades filantrópicas, companhias de a utogestão e administradoras.

Objetivos:Frente ao exposto, os objetivos deste trabalho são: aprofundar a discussão a respeito da satisfação dos médicos em relação a serviços disponibilizados pelos planos de saúde e suas implicações gerenciais.

Metodologia: Trata-se de um estudo transversal, descritivo com abordagem quantitativa, baseados em dados coletados em campo através do questionário "Satisfação dos Médicos com os Planos de Saúde" elaborado pelos pesquisadores. Para a pesquisa, foram definidos critérios de inclusão e exclusão, nestes estão contidos: os médicos atenderem ou não na cidade de Araguari - MG; aceitar ou não participar da pesquisa; estar ou não associado a algum plano ou cooperativa de saúde. 0 questionário é acompanhado de um termo de consentimento livre e esclarecido (TCLE) e encontra-se em consonância com a Resolução CNS $n^{0} 510$, de 07 de abril de 2016, assim não será submetido ao Comitê de Ética.

Resultados: Foi possível observar que em relação ao tempo de prática clínica, obteve-se que 59\% dos participantes estão a mais de 10 anos em atuação, 30\% estão de 5 a 10 anos e 11\% estão a menos de 5 anos de atuação. Já em relação ao tempo de atendimento nos planos, têm-se que 40\% atendem entre 5 e 10 anos e $60 \%$ atendem entre 10 ou mais anos nos convênios de saúde.Em relação aos atendimentos médicos obteve-se que $27 \%$ dos médicos atendem unicamente no serviço privado, enquanto que $73 \%$ atendem no público/privado. Quando questionados em relação à satisfação com os planos de saúde, $60 \%$ declararam não estar satisfeitos e 40\% declararam satisfação regular com os serviços. Dentre os planos de saúde atendidos pelos participantes, 100\% atendem UNIMED, 80\% FUSEX, 40\% IPSEMG - BRADESCO - PMMG CEMIG SAÚDE E CASSI e 22\% SUL AMERICA e outros. Dentre estes, UNIMED e BRADESCO foram considerados os melhores planos por $40 \%$ dos médicos pesquisados, enquanto CEMIG e CAIXA representaram apenas $20 \%$ cada de satisfação. Quanto às reclamações feitas aos planos de saúde, obtevese que $63 \%$ dos servidores precisaram fazer reclamações, enquanto 37\% não precisaram. Destes, 66\% obtiveram sua obtiveram suas demandas resolvidas e 34\% não obtiveram sucesso nas suas solicitações.

Conclusão: Dessa forma e buscando otimizar os resultados, vê-se a necessidade de aprimorar a saúde suplementar, principalmente, a forma como os planos de saúde funcionam, tanto para os beneficiários, buscando uma maior adesão, quanto aos servidores desse plano, através de um compromisso mútuo, uma vez que o presente trabalho evidenciou que apesar da insatisfação dos médicos em relação aos planos, os mesmos recomendam a sua utilização.

PALAVRAS-CHAVE: SAÚDE SUPLEMENTAR; PLANOS DE PRÉ PAGAMENTO EM SAÚDE; INQUÉRITOS E QUESTIONÁRIOS. 


\title{
A SOCIEDADE DE RISCO COMO CONSEQUÊNCIA DA INEFICIÊNCIA DO ESTADO
}

\author{
LAURA ARAÚJO CLEMENTE, CINDY MORAIS E SOUSA, DONNER RODRIGUES QUEIROZ
}

INSTITUTO MASTER DE ENSINO PRESIDENTE ANTÔNIO CARLOS - IMEPAC

laurinh.2008@hotmail.com

Apresentação de Pôster

Resumo

Área do Conhecimento: Sustentabilidade e Direitos

Introdução: O presente estudo demonstrará a relação existente entre o medo sofrido pela população diante de uma sociedade de risco e de que maneira o Estado pode contribuir para minimizar ou agravar essa mal que assola toda uma coletividade

Objetivo: Busca-se mostrar que o Direito está em constante evolução para tentar acompanhar os anseios da sociedade que, por sua vez, busca por mais segurança. Além disso, se propõe a demonstrar que, para acompanhar estas alterações sociais, o Estado entra num patamar que fere princípios básicos para proteger bens jurídicos nem tão relevantes e que, ao final das contas, causa o mesmo temor na população que cobiça a proteção de seus interesses.

Metodologia: Será utilizado o método dedutivo que, a partir de argumentos gerais, afunila-se em argumentos particulares, buscando-se alcançar respostas para a problemática da presente pesquisa e uma conclusão sobre o tema.

Resultados alcançados: Com o advento da Revolução Industrial e da consequente Globalização, a distribuição de riquezas, novas tecnologias e ciências trouxeram, intrinsecamente, aos próprios anseios, riscos para a sociedade. 0 Estado, por conseguinte, desde então, preocupou-se em reerguer o país economicamente não se atendo, porém, às necessidades básicas das pessoas, ou seja, atrelou-se ao desenvolvimento econômico sem se voltar para políticas afetas à garantia de direitos. Diante da aludida realidade, o presente estudo tratará, em especial, dos riscos advindos de uma sociedade que vive sobre a sombra do medo incidente pela ausência de direitos fundamentais que, mesmo garantidos pela lei maior, no caso, a Constituição da República Federativa do Brasil, não são, efetivamente, consolidados. Diante da realidade de ineficiência do Estado, surge o Direito Penal como instrumento de viabilização da coexistência das liberdades individuais, o que, por si só, ou seja, dissociado das garantias mínimas de existência e dignidade do indivíduo, não remetem à segurança de paz social almejada pela coletividade. Referida insegurança social incrementa, ainda, a denominada sociedade de risco, na medida em que a ausência do Estado faz com que as pessoas busquem resolver eventuais conflitos pelas próprias razões, ou seja, pelo uso da força, o que, em regra, se admite na atualidade, apenas, em caráter de extrema exceção.

Conclusão: Diante do estudo apresentado, nota-se que o Estado precisa, em suma, debruçar-se sobre políticas públicas que, antes de combater a criminalidade em si, busquem garantir direitos, estendendo-se, ainda, às bases valorativas da sociedade com investimentos educacionais reais e de longo prazo, implementando, assim, políticas Estatais de Segurança Pública que passem, antes de qualquer coisa, pela garantia do mínimo existencial para, só após, debater questões afetas à incrementação dos crimes, pois, sem dúvidas, as mesmas se diluirão em um Estado, verdadeiramente, garantista.

PALAVRAS-CHAVE: DIREITO PENAL DO INIMIGO; MARGINALIDADE; RISCOS. 


\title{
A TRAJETÓRIA DE INCLUSÃO DE ALUNOS SURDOS: A IMPORTÂNCIA DA FAMÍLIA NA COMUNICAÇÃO POR MEIO DA LÍNGUA DE SINAIS
}

\author{
LAURICE MENDONÇA DA SILVEIRA, ANA LÚCIA COSTA E SILVA,
}

INSTITUTO MASTER DE ENSINO PRESIDENTE ANTÔNIO CARLOS - IMEPAC

laumesil@gmail.com

Comunicação Oral

Resumo

Área do Conhecimento: Educação e Inclusão

Introdução: À margem do processo escolar, por dificuldades muitas, inclusive aquelas de acesso à ação comunicativa, um novo horizonte vem se abrindo para aqueles que têm deficiências, especialmente, os auditivos, considerando a família como parte essencial para que este processo ocorra como facilitador da comunicação dos surdos com o mundo que o cerca. Deste modo, esse projeto de pesquisa documental, com foco na trajetória de inclusão de alunos com deficiência auditiva e o papel das famílias como articuladores da LIBRAS - língua brasileira de sinais, parte da análise de documentos que expressam as histórias de vida dessas famílias, sendo este um importante instrumento de busca de informações e conhecimentos sobre a trajetória de vida de pessoas impares na sociedade.

Objetivo: comprovar que o êxito escolar de alunos com deficiência auditiva está relacionado ao papel da família enquanto facilitadora da comunicação por meio da LIBRAS, que antecede ao processo escolar, partindo da análise de documentos da sociedade dos surdos de Araguari.

Metodologia: pesquisa utilizando análise documental contendo relatos de familiares de pessoas com deficiência auditiva e também desses que faltam o sentido da audição, bem como análise da vida cotidiana e escolar dessas pessoas com deficiência, podendo perceber se houve ou não dificuldades na convivência familiar ou se atrapalhou no rendimento escolar. Avaliar suas frustrações, sonhos e desejos com a pretensão de auxiliar no sentido de trabalhar os aspectos emocionais que interferem de modo a facilitar ou dificultar a adaptação e o sucesso e ou fracasso do deficiente auditivo, dentro do contexto escolar. Esta pesquisa documental, situada dentro da temática social, concentra-se na questão do significado e do sentido, subjacentes na ação comunicativa (HABERMAS,2012).

Resultados: Do deficiente auditivo cobram-se a leitura e a escrita, como se o português fosse sua língua materna. Essas experiências, se não forem verbalizadas e refletidas, não se tornam questões intersubjetivas que permitam a apropriação e a compreensão de outros. Habermas (2006), ao relatar sua experiência de dificuldades com a língua na forma oral, devido ao seu problema de lábio-leporinidade, mostra que fora da linguagem, o ser humano restringe suas possibilidades. Nesse sentido, essa pesquisa ainda não possui dados conclusivos, pois aguarda a liberação do comitê de ética e pesquisa, uma vez que além da leitura dos documentos, as autoras também farão entrevista com familiares. Portanto, os resultados que se tem, são apenas dos documentos analisados, que reportam e confirmam as dificuldades enfrentadas pelas famílias, e pelo próprio deficiente, em sua trajetória educacional.

PALAVRAS-CHAVE: LIBRAS, FAMÍLIA, DEFICIÊNCIA AUDITIVA. 


\title{
A TRANSMISSIBILIDADE DA PROPRIEDADE VIRTUAL X A TUTELA PÓSTUMA DOS DIREITOS DA PERSONALIDADE.
}

\author{
GIOVANA DE OLIVEIRA GOMES, LARISSA ATHENIEL MIRANDA, GEILSON NUNES
}

INSTITUTO MASTER DE ENSINO PRESIDENTE ANTÔNIO CARLOS - IMEPAC

giovanag443@gmail.com

Apresentação de Pôster

Resumo

Área do Conhecimento: Sustentabilidade e Direitos

INTRODUÇÃO: O presente estudo trata do Direito Digital, mais especificamente sobre a transmissibilidade do patrimônio pertencente ao ambiente virtual, o qual, em tese, deveria ser transmitido aos sucessores do usuário após seu falecimento. Assim, considerando o novo contexto introduzido pela revolução tecnológica, representado pela utilização da internet para armazenagem e aquisição de bens em meios virtuais, bem como para a manutenção de perfis em redes sociais para a obtenção de lucros, tem-se no ordenamento jurídico brasileiro uma tentativa de regulamentação da sucessão desses bens pertencentes ao meio digital através do Projeto de Lei no 4.099-A/2012, o qual, se aprovado, irá modificar o art. 1.788 do Código Civil, garantindo aos familiares total acesso ao patrimônio virtual do de cujus, o que dá ensejo à discussão sobre os efeitos dessa sucessão sobre a tutela póstuma dos direitos da personalidade.

OBJETIVO: Neste sentido, o objetivo deste trabalho foi demonstrar a necessidade de de se analisar os aspectos afetos à Sucessão Digital, levando-se em consideração a proteção da honra, imagem e privacidade do usuário falecido.

METODOLOGIA: Trata-se de uma pesquisa bibliográfica por meio da qual buscou-se verificar os principais pontos relativos à transmissibilidade do patrimônio digital, analisando, ainda, se essa sucessão afetaria a tutela "post mortem" dos direitos da personalidade do usuário que não gostaria de ter seu conteúdo virtual exposto após seu falecimento.

RESULTADOS: Foi possível perceber que com a evolução tecnológica, a morte passou a desencadear efeitos jurídicos não somente no mundo físico, mas também no meio virtual. Assim, apesar de ser inerente ao Direito acompanhar as constantes mudanças sociais e principalmente as oriundas da tecnologia, ainda que estas fujam da alçada de conhecimento técnico da área jurídica, como é o caso da regulamentação do patrimônio virtual dos usuários, não pode a codificação do referido tema ignorar o fato de que a sucessão de bens digitais deve ser discutida levando-se em consideração a tutela póstuma dos direitos da personalidade do usuário que, quando em vida, não forneceu os dados de acesso ao seu patrimônio virtual, para que o conteúdo de aplicativos de fotos ou de troca de mensagens administrados de forma privada não fosse exposto, mesmo após o seu falecimento.

CONCLUSÃO: O Projeto de Lei no 4.099-A/2012 gera efeitos negativos sobre a tutela póstuma dos direitos da personalidade do usuário, uma vez que irá expor o conteúdo administrado privativamente por ele durante a vida. Dessa forma, apesar de reconhecer a necessidade de regulamentação sobre a Sucessão Digital, deve esta ser editada buscando-se a preservação da honra, imagem e privacidade do de cujus.

PALAVRAS-CHAVE: DIREITOS DA PERSONALIDADE; HERANÇA DIGITAL; PROJETO DE LEI; DIREITOS DA PERSONALIDADE; TUTELA PÓSTUMA. 


\title{
A TUTELA PROVISÓRIA DE URGÊNCIA COMO EFETIVIDADE DO SISTEMA PROCESSUAL
}

\author{
BIANCA MACHADO DOS SANTOS, NATÁLIA XAVIER MARQUES, DONNER RODRIGUES QUEIROZ
}

INSTITUTO MASTER DE ENSINO PRESIDENTE ANTÔNIO CARLOS - IMEPAC

biancaamaachado@hotmail.com

Apresentação de Pôster

Resumo

Área do Conhecimento: Sustentabilidade e Direitos

INTRODUÇÃO: A presente pesquisa abordará a modificação existente no ordenamento jurídico processual civil brasileiro, em razão da constante mudança dos ideais jurisdicionados e da necessidade de normatizar e regular diversas situações, de forma analisar tal alteração no novo sistema brasileiro.

PROBLEMA DE PESQUISA: A Lei 13.105/15 que instituiu o Código de Processo Civil estabeleceu novos requisitos para a concessão da Tutela de Urgência, que não fazia parte da legislação anterior com o ânimo de regulamentar a necessidade jurisdicional. Desta forma há que se indagar, tal sistema ocasiona a maior eficácia do processo?

OBJETIVOS: Analisar a inovação instituída pelo Código de Processo Civil de 2015 nos métodos e instituto da Tutela de urgência. Pretende investigar a forma de aplicação prática desse instituto, seu conceito e a importância dele como facilitador do acesso à justiça e auxiliar na celeridade e na eficiência das tramitações judiciais.

MÉTODO: Quanto ao método utilizado optou-se pelo dedutivo, partindo de uma premissa geral para uma específica. Como metodologia adotou-se bibliografias embasadas no Código de Processo Civil, na jurisprudência e na doutrina.

RESULTADOS ALCANÇADOS: Veja-se, a tutela de urgência é forma de dar efetividade a garantia de um direito no decorrer processual. A tutela de urgência antecipada trata-se de um pedido sobre um direito que será analisado em cognição sumária, ou seja, se concedê-la o Juiz dará uma decisão interlocutória garantindo àquele direito com base em dois requisitos específicos. A tutela é simplesmente formada pelo requisito da fundada probabilidade do direito, ou seja, na aparência de que aquele direito tutelado realmente faz jus ao que lhe foi pedido, com base em prévias provas documentais. Então, o ônus do autor que propõe um pedido com tutela de urgência, é de provar que a partir daquilo que apresenta existe um direito tutelado. E também pelo perigo da demora, que se refere a delonga que um processo judicial tem. Considera-se que o intuito da tutela de urgência é dar celeridade ao processo desde seu início, é conceder a alguém certo direito que aparentemente parece ser certo, além disso para propor a tutela, se tem a necessidade de que a concessão seja rápida, podendo causar um dano irreversível pelo seu perigo de demora.

CONCLUSÃO: Por fim, entende-se que a instituição da tutela foi a forma que o legislador encontrou para tornar que a eficácia processual aconteça sem majorar os danos emocionais e patrimoniais que um processo judicial possa causar. Além disso tentou priorizar alguns dos princípios constitucionais para resolver e desafogar o judiciário de possíveis demandas que se resolveriam anos depois, causando prejuízo aos requerentes e as contas públicas.

PALAVRAS-CHAVE: EFICÁCIA DO PROCESSO; PROCESSO CIVIL; TUTELA DE URGÊNCIA. 


\title{
A VALORAÇÃO PROBATÓRIA DO DEPOIMENTO DA TESTEMUNHA DO “OUVI DIZER" (HEARSAY TESTIMONY) NO ÂMBITO DO PROCESSO PENAL BRASILEIRO
}

\author{
JÉSSICA THALITA DE SOUSA OLIVEIRA, MAYÃ FERREIRA STOPA, GEILSON NUNES
}

INSTITUTO MASTER DE ENSINO PRESIDENTE ANTÔNIO CARLOS - IMEPAC

jessica_jtso@hotmail.com

Apresentação de Pôster

Resumo

Área do Conhecimento: Sustentabilidade e Direitos

\begin{abstract}
Introdução: 0 presente estudo aborda acerca da hearsay testimony, ou seja, a testemunha do "ouvi dizer", bem como os requisitos para ser considerada uma testemunha. Suscita por fim, o valor probatório do depoimento de uma testemunha que apenas informe que ouviu dizer sobre o fato, perante o julgamento de um processo judicial penal.

Objetivo: Quanto ao objetivo a ser alcançado, tem-se como intuito esclarecer o valor probatório de uma testemunha que não presenciou o crime em questão e vai a juízo depor com base em notícias que ouviu dizer por terceiros, mas acima de tudo enfatizará, que é um meio admissível de prova no ordenamento jurídico brasileiro e pode ser valorado pelo Magistrado de acordo com o seu convencimento.

Metodologia: Para a obtenção dos resultados pretendidos será feito o uso do método dedutivo, fazendo aplicação através de pesquisa bibliográfica, dessa maneira expondo os objetivos propostos na problemática apresentada, e por fim, trazendo uma conclusão passível de compreensão geral.

Resultados: No que concerne ao tema do presente artigo podemos inferir que a hearsay testimony no processo penal é a testemunha que não presenciou o fato criminoso, sendo que, inclusive, ficou sabendo de informações através de terceiros que viram a determinada ação, conhecida também como testemunha do "ouvi dizer" ou testemunha indireta. Desta feita, é sabido que para se valorar uma prova o sistema adotado pelo ordenamento jurídico brasileiro é o do livre convencimento, ou seja, o juiz, com base estabelece o valor de cada prova com base em seu convencimento e devidamente fundamentado. Diante disso, pôde-se concluir que a testemunha do "ouvi dizer" não está excluída do sistema probatório brasileiro, sendo ouvida a critério do Juiz, sendo que, na opinião do autor, tais depoimentos devem ser valorados pelo juiz atendendo as restrições de sua cognição, pois não se trata de uma testemunha presencial, daí decorrendo um maior nível de desconhecimento do fato e, portanto, de contaminação.

Conclusão: Diante do que foi exposto, podemos concluir que a testemunha do "ouvi dizer" é aquela que não presenciou fato delituoso, mas recebeu informações de terceiros que estavam presentes. Verificamos ainda que apesar de ser considerada com um meio probatório frágil, a mesma é admissível dentro do ordenamento jurídico brasileiro, considerando que os fatos informados podem interessar o Magistrado no momento de sua decisão. Por fim, quanto ao seu valor probatório, verificamos que cabe ao juiz, no momento de sua análise processual e de acordo com seu convencimento, apreciar se os fatos apresentados pela testemunha do "ouvi dizer" são pertinentes e se estão em consonância com as demais provas colhidas nos autos.
\end{abstract}

PALAVRAS-CHAVE: PROVA; TESTEMUNHA INDIRETA; VALOR PROBATÓRIO. 


\title{
A VIOLÊNCIA OBSTÉTRICA NO BRASIL SOB PERSPECTIVA JURISPRUDENCIAL
}

\author{
AMANDA LEMOS RODRIGUES, BRUNA SANTOS LELES, GEILSON NUNES
}

INSTITUTO MASTER DE ENSINO PRESIDENTE ANTÔNIO CARLOS - IMEPAC

amanda_araguari@hotmail.com

Apresentação de Pôster

Resumo

Área do Conhecimento: Sustentabilidade e Direitos

Introdução: 0 presente trabalho estuda a jurisprudência pátria sobre o tema da violência obstétrica. Neste sentido, discorre-se sobre a parte conceitual referente ao tema, a proteção legal disponível para a mulher em face das garantias fundamentais e do acesso à justiça, os direitos feridos em decorrência da prática da violência obstétrica, bem como o descompasso entre o ordenamento jurídico e a realidade social no que diz respeito à vida, à saúde e a integridade física e mental da mulher no momento da maternidade.

Objetivo: Frente ao objetivo a ser alcançado, tem-se o intuito de esclarecer as características da denominada violência obstétrica, o modo como os casos são julgados nos tribunais brasileiros, mas acima de tudo enfatizar os recursos disponíveis paras as vítimas.

Metodologia: Trata-se de um método dedutivo, fazendo aplicação da pesquisa teórica, por meio de doutrinas, legislação e demais documentos pertinentes ao tema com o fim de sustentar a formulação proposta no trabalho.

Resultados:Foi possível observar que a violência obstétrica pode ser constatada de diversas formas no período pré-natal, parto e puerpério, desde a omissão de informação e solicitação de autorização para a realização de procedimentos, até a injúria verbal. As condutas com intuito de obter recursos financeiros de mulheres em processos reprodutivos, violando seus direitos, em benefício de pessoa física ou jurídica. Ações praticadas por profissionais da saúde através de meios de comunicação são consideradas caráter midiático, dirigidas a violar psicologicamente mulheres em processos reprodutivos, bem como denegrir seus direitos mediante mensagens, apologia à cirurgia cesariana por motivos vulgarizados e sem indicação científica, ridicularização do parto normal, incentivo ao desmame precoce. A maioria dos processos que chegam ao Judiciário não são classificados como violência obstétrica, uma vez que a tabela utilizada pelos tribunais na formação dos processos não possui essa classificação. Considerando a falta de tipificação específica no ordenamento jurídico brasileiro em relação à violência obstétrica, resta ser caracterizada a violação de princípios e direitos, podendo haver a aplicação da responsabilidade civil da equipe hospitalar e do Estado ou ainda aplicação da lei penal.

Conclusão: a inexistência de uma legislação específica não impede que os aplicadores do direito possam punir a prática de violência obstétrica. 0 Poder Público deve investir na divulgação do tema por meio de políticas públicas de prevenção, para que as parturientes possam reconhecer tal modalidade de violência e saber a quem recorrer quando seus direitos forem lesionados.

PALAVRAS-CHAVE: DIREITOS DA MULHER. RESPONSABILIDADE. VIOLÊNCIA OBSTÉTRICA. 


\title{
ABRINDO O CAMINHO PARA A INCLUSÃO: MUDANDO O OLHAR SOBRE ACESSIBILIDADE NA REALIDADE DOS JOVENS
}

\author{
JÉSSICA PINHEIRO DE SOUZA, MARIA EDUARDA SANTOS DA SILVA, MARIA HELENA BELO DE \\ ARAUJO, NATÁLIA MEDEIROS DE ALMEIDA, NATALIA SILVA, MARIA TERESA DE BEAUMONT
}

INSTITUTO MASTER DE ENSINO PRESIDENTE ANTÔNIO CARLOS - IMEPAC

jessicapinheiro763@gmail.com

Apresentação de Pôster

Resumo

Área do Conhecimento: Educação e Inclusão

\begin{abstract}
Introdução: A acessibilidade vai além de atender pessoas com deficiências (PCDs), pois diz respeito à melhoria da qualidade de vida. Deve estar presente em todos os espaços, como também nos recursos tecnológicos, pois ampliam habilidades de PCDs, mobilidade reduzida ou incapacidades, promovendo autonomia, inclusão e melhoria da qualidade de vida. A temática pertence à unidade Projeto Integrador III do curso de Pedagogia do IMEPAC. Além da acessibilidade arquitetônica, é preciso que o outro seja visto sem preconceitos, estereótipos e discriminações, com acessibilidade atitudinal, pois é a atitude que impulsiona a remoção de barreiras. Objetivos: colaborar para sanar a falta de informação sobre acessibilidade; conscientizar, sensibilizar e mobilizar sobre a realidade vivida pelas PCDs, apresentando o conceito de acessibilidade e a necessidade de se promover a inclusão em todos os contextos e aspectos. Metodologia: 0 projeto foi desenvolvido em uma turma de $3^{\circ}$ ano do Ensino Médio de uma escola estadual de Araguari (MG), e constou de uma oficina com conteúdo teórico, depoimentos de pessoas com deficiência, explicações sobre o tema e dinâmica. Através de uma plataforma digital (Padlet) os alunos adicionaram seus depoimentos sobre o tema. A dinâmica constou de um percurso com vários obstáculos, cada participante representava uma pessoa com deficiência (visual, física, auditiva) e para sua conclusão precisava da cooperação de outros, encontrando uma maneira de se entender.

Relato da experiência: A introdução da oficina conteve vídeos com exemplos de PCDs que superam as barreiras cotidianas, sobretudo na interação com pessoas que têm um olhar empático. Foram abordadas as deficiências auditiva, visual, física e alguns recursos que melhoram sua qualidade de vida, como campainha de luz (surdez), piso tátil (deficiência visual) e rampa de acesso (cadeirantes). A dinâmica exercitou e desenvolveu a empatia, pois os jovens precisavam da ajuda uns dos outros. Pôde-se notar a dificuldade em um primeiro momento, mas posteriormente compreenderam que precisavam da cooperação de todos para a conclusão da tarefa. Por último foi realizada uma roda de conversa sobre acessibilidade e sobre como eles compreendiam a questão. Observou-se como o olhar dos jovens foi ampliado e, em alguns casos, modificado de uma visão preconceituosa e estereotipada, para um olhar empático que entende a necessidade de contribuir com o outro, sendo essa pessoa deficiente ou não.

Considerações finais: 0 projeto foi valoroso para a formação acadêmica e pessoal dos pesquisadores, pois a troca de conhecimentos com os jovens proporcionou experiências favoráveis e evidenciou a necessidade de abordar esse tema nas escolas. A inclusão, empatia e acessibilidade atitudinal, nem sempre exercitada, devem estar interiorizadas. Também impactou a vida dos jovens e proporcionou experiências que os levarão a reflexões no decorrer de suas vidas.

PALAVRAS-CHAVE: ACESSIBILIDADE; INCLUSÃO; EMPATIA; DEFICIÊNCIAS.
\end{abstract}




\title{
AÇÃO DE SAÚDE NA UNIDADE DE SAÚDE DA FAMÍLIA GUTIERREZ: AVALIAÇÃO NUTRICIONAL E DEGUSTAÇÃO DE SUCO
}

\author{
KEILIANE WIKELY ALVES DA SILVA, ANDERSON JOSÉ ALVES COELHO, MARCELA HADASSA MELO \\ DE OLIVEIRA, RAYANE BEZERRA DA SILVA, SARAH EDUARDA LIRA MARQUES, LUANA \\ THOMAZETTO ROSSATO
}

INSTITUTO MASTER DE ENSINO PRESIDENTE ANTÔNIO CARLOS - IMEPAC

keilianywikelly@outlook.com

Apresentação de Pôster

Resumo

Área do Conhecimento: Saúde coletiva e bem-estar

Introdução: A obesidade é uma doença que vem aumentando em todo o mundo nos últimos anos, acometendo indivíduos de todos os ciclos da vida. Sabe-se que a principal causa da gênese dessa situação está relacionada ao estilo de vida, incluindo o sedentarismo e a hábitos alimentares inadequados. Assim, orientações nutricionais são necessárias para alertar a população acerca da importância da boa alimentação, principalmente no que se refere ao consumo de açúcar.

Objetivo: Realizar uma ação de educação em saúde, visando a conscientização da população em relação ao consumo excessivo de açúcar.

Metodologia: No âmbito da disciplina "Projeto Integrador 2: Redes de Atenção à Saúde" do curso de Farmácia e Enfermagem foram realizadas visitas domiciliares aos residentes do bairro Gutierrez. Durante as visitas foi aplicado um questionário para identificar o perfil dos moradores. Uma vez que os dados foram coletados, foi observada alta prevalência de obesos e diabéticos. Diante disso, foi planejada uma ação de educação em saúde sobre educação nutricional, para abordar sobre o uso do açúcar. Fizeram parte da ação os indivíduos adscritos na UBSF Gutierrez.

Relato de experiência: No dia da ação de educação em saúde foram realizadas diversas atividades com a população. De início foi realizada avaliação nutricional dos indivíduos, incluindo aferição de peso, estatura e cálculo do índice de massa corporal. Posteriormente, os participantes da ação degustaram um suco natural saudável sem açúcar (laranja e cenoura). Para finalizar, orientações sobre a quantidade de açúcar presente em sucos industrializados foi ofertada aos participantes, onde os mesmos puderam visualizar os teores de açúcares nestes alimentos por meio de apresentação em cartaz. A comunidade usuária da UBSF Gutierrez foi bastante receptiva comparecendo ao evento, maioria dos indivíduos era do sexo feminino, com idade superior a 30 anos e apresentava excesso de peso.

Considerações finais: A realização dessa ação de educação em saúde para a população adscrita à UBSF Gutierrez foi de grande importância, tanto para o aprendizado dos mesmos quanto a uma alimentação mais saudável quanto para a formação acadêmica e profissional dos alunos idealizadores da atividade, visto que proporcionou grandes experiências teórico-prático. Assim, esperamos que este trabalho possa fortalecer a importância da realização de ações envolvendo educação em saúde, buscando a promoção da saúde, a prevenção e as doenças.

PALAVRAS-CHAVE: EDUCAÇÃO EM SAÚDE, ATENÇÃO BÁSICA, OBESIDADE, DOENÇAS CRÔNICAS NÃO TRANSMISSÍVEIS. 


\title{
ACESSO À JUSTIÇA OU DEMOCRATIZAÇÃO DA JUSTIÇA?
}

\author{
WALTER JOSÉ PIRETTE PEIXOTO, CRISTIANO MOISES DA SILVA, DONNER RODRIGUES QUEIROZ
}

INSTITUTO MASTER DE ENSINO PRESIDENTE ANTÔNIO CARLOS - IMEPAC

pirette@ig.com.br

Apresentação de Pôster

Resumo

Área do Conhecimento: Sustentabilidade e Direitos

Introdução: Justiça é igualdade de oportunidade entre as pessoas. 0 acesso à justiça deve ser a efetiva igualdade de oportunidade a todos os cidadãos. A Constituição Federal enumera uma série de direitos sociais, inclusive o principio da inafastabilidade da jurisdição, como direito fundamental. A luz deste princípio, a doutrina considera o acesso à justiça como o ponto máximo da reivindicação dos direitos do cidadão, com resoluções dos conflitos, embasados no ordenamento jurídico e na justiça social. 0 Poder Judiciário é uma das formas de se ter acesso a esses direitos sociais. Para tanto, o ordenamento jurídico vem ao longo do tempo, instituindo mecanismos de solução para os conflitos, por intermédio do judiciário (processo judicial), porém, estes mecanismos, tem se mostrado serem ineficazes e ineficientes.

Objetivo: 0 objetivo deste resumo foi demonstrar que o acesso à justiça, atualmente se transveste de mera democratização da justiça.

Metodologia: Nesta pesquisa foi adotado o método dedutivo, partindo-se de argumentos gerais para argumentos particulares, através de leituras de obras literárias e trabalhos científicos publicados sobre o assunto, onde se obteve os resultados alcançados e, consequentemente, uma conclusão sobre o tema pesquisado.

Resultados: 0 acesso à justiça compreende o efetivo acesso aos direitos sociais garantidos pela Constituição Federal. Este acesso, por meio do Poder Judiciário, de acordo com a doutrina, passa pelas ondas de assistência judiciária em juízo e fora dele, nos interesses individuais, coletivos e difusos, com a necessidade de simplificação dos procedimentos, do direito processual e do direito material. Neste sentido, observou-se que ao longo do tempo, já houve grandes avanços em nosso ordenamento jurídico, com a implantação de órgãos públicos voltados à assistência judiciária gratuita às classes menos favorecidas, assim como, a criação de mecanismos que incentiva as conciliações, mediações e arbitragem. Objetivando uma prestação jurisdicional efetiva, o Poder Judiciário, constantemente, vem procurando implantar formas alternativas de resolução de conflitos. Para a prestação jurisdicional, o processo judicial, não pode ser um mero instrumento jurídico na solução do direito material, e sim o principal mecanismo desta atividade, resolvendo os conflitos entre as pessoas e entre elas e suas relações sociais, de forma a atingir a paz social, com desfechos satisfatórios.

Conclusão: Estes mecanismos, até então, criados pelo ordenamento jurídico e, implantados pelo Poder Judiciário, como formas alternativas de resolução de conflitos, são meios de democratização da justiça, pois, facilita ao cidadão, o acesso ao judiciário em busca de seus direitos e, amplia o número de jurisdicionados atendidos.

PALAVRAS-CHAVE: ACESSO À JUSTIÇA; DIREITOS SOCIAIS; PODER JUDICIÁRIO. 


\title{
AGRAVAMENTO DOS DESASTRES AMBIENTAIS E SUAS EVENTUAIS RESPONSABILIDADES
}

\author{
RÔMULO MANUEL AUGUSTO DE DEUS, WOILLE AGUIAR BARBOSA
}

INSTITUTO MASTER DE ENSINO PRESIDENTE ANTÔNIO CARLOS - IMEPAC

romulo_dedeus@hotmail.com

Apresentação de Pôster

Resumo

Área do Conhecimento: Sustentabilidade e Direitos

Introdução: Nos últimos anos, no Brasil, os desastres ambientais e a repercussão destes, tem ganhado destaque nas mídias devido a gravidade e ao número crescente. Nesse sentido torna-se fundamental entender os fatores relacionados a esse aumento, e os autores responsáveis por essa conjuntura atual, uma vez que é dever de todos, a preservação, manutenção e continuidade dos recursos ambientais, em observância ao conteúdo disposto no art.225 da Constituição Federal de 1988.

Objetivo: Entender de que maneira o aparato jurídico brasileiro se relaciona com o número crescente de desastres ambientais.

Metodologia: 0 método abordado para o desenvolvimento deste estudo foi a análise documental, conforme o artigo $2^{\circ}$ da Resolução Conama, que prevê a elaboração de estudo de impacto ambiental (EIA), em caráter restrito, e o respectivo relatório de impacto ambiental (RIMA), de caráter público, submetidos à aprovação do órgão estadual competente, e do IBAMA em caráter supletivo, realizados para o licenciamento de atividades modificadoras do meio ambiente. A pesquisa investigou os impactos causados por atividades como: mineração, agricultura, produção de energia, projetos urbanísticos, distritos industriais, zonas estritamente industriais e aterros sanitários.

Resultados: A Constituição Federal brasileira posicionou proteção ao bem jurídico ambiental, pondo-o a salvo tanto entre direitos e garantias fundamentais, bem como instrumento da ordem econômica, conforme art.225, impondo tanto ao poder público quanto à coletividade o dever de defendê-lo e preservá-lo para as presentes e futuras gerações. No entanto, observou-se que os estudos realizados para o licenciamento das atividades econômicas sobre o meio ambiente, são insuficientes quando comparado às conseqüências efetivas ao aumento dos desastres ambientais, ratificado com base em dados oficiais, e últimos acontecimentos, como por exemplo, o vazamento da barragem de celulose em Cataguases-MG em 2003, e o rompimento de barragens de mineração, como Miraí-MG em 2007, Mariana-MG em 2015, Brumadinho-MG e Machadinho D'Oeste-RO em 2019. Prova-se, portanto, a ineficiência do estado na fiscalização e controle, proteção da fauna e da flora, e atividades produtivas, que utilizam-se de técnicas, métodos ou substâncias que comportam risco para a vida, a qualidade de vida e o meio ambiente.

Conclusão: Resultante das atividades humanas, os impactos ambientais alteram as propriedades físicas, químicas e biológicas do meio ambiente, e afetam direta ou indiretamente a saúde, a segurança e o bemestar de toda a população. Danos irreparáveis são ocasionados. Por fim as instituições públicas e privadas devem ser responsabilizadas pela má gestão, fiscalização e proteção deste patrimônio imensurável.

PALAVRAS-CHAVE: MEIO AMBIENTE; DESATRES; RESPONSABILIDADE. 


\title{
ÁGUA VIRTUAL E SUA IMPORTANCÂNCIA PARA A SOCIEDADE
}

\author{
ROGÉRIO WILLIAN SANTANA GUEDES, WOILLE AGUIAR BARBOSA
}

INSTITUTO MASTER DE ENSINO PRESIDENTE ANTÔNIO CARLOS - IMEPAC

rogeriowilliansantana2016@gmail.com

Apresentação de Pôster

\section{Resumo}

Área do Conhecimento: Sustentabilidade e Direitos

Introdução: 0 presente trabalho tem por objetivo mostrar que a Água virtual é um conceito utilizado para fazer referência à quantidade de água utilizada, de forma direta ou indireta, na produção de algum bem ou serviço. É, na verdade, um indicador da água que será necessária no processo produtivo de qualquer produto. Evidencia-se ainda que o consumo inconsciente da água está causando uma crise hídrica no país, agravado ainda pelo mercado internacional de commodities. Assim, é utilizado quantidade considerável de água para a produção de produtos em todos os ramos da economia.

Objetivo: Conscientizar a população, no sentido de que a quantidade de água utilizada em determinados produtos é exorbitante. Além disso, por meio do presente estudo, visa-se explanar o impacto ambiental hídrico causado pela má utilização desse recurso imprescindível à vida na terra, bem como incentivar o consumo sustentável e consciente.

Metodologia: Analisar os estudos sobre o consumo e os impactos ambientais em nosso país, as suas tributações, análises dos impactos negativos destas atividades ao sistema ambiental, avaliação dos consumos da água virtual, bem como de que modo estes impactos interferem e afetam nos aspectos socioeconômicos e ambientais.

Resultados: A lei de recursos hídricos, (Lei n. 9.433/97), elencou aspectos fundamentais, e representa importante avanço em termos da gestão da água. Dentre estes aspectos estão a cobrança pelo uso de água bruta como instrumento de gestão. Vale ressaltar que o Estado do Ceará, por exemplo, possui a experiência mais antiga, sendo que recentemente, a partir de 2003, a cobrança foi implementada também na bacia do rio Paraíba do Sul, que abrange os estados de Minas Gerais, Rio de Janeiro e São Paulo, e é discutida por Pereira (2003). Conforme apontamos anteriormente, a agricultura é o setor que mais consome recursos hídricos. Entretanto, o setor agrícola é também o que mais resiste a se enquadrar na legislação da cobrança. Conclusão: Os cálculos e dados relacionados à água virtual são importantes, pois através deles é possível verificar o impacto ambiental em termos hídricos (pegada hídrica), custos de fabricação de bens e serviços e formas de reduzir o consumo de água nos processos produtivos. Neste último caso, é de grande importância no sentido de garantir o uso racional da água, possibilitando a redução do seu uso.

PALAVRAS-CHAVE: REFLEXÃO SOBRE ÁGUA VIRTUAL; PRODUÇÃO; BENS; SERVIÇOS. 


\section{ALIENAÇÃO PARENTAL}

\section{RICHARDISON RESENDE OLIVEIRA, LEONARDO SOARES MIGUEL,}

INSTITUTO MASTER DE ENSINO PRESIDENTE ANTÔNIO CARLOS - IMEPAC

richardisonresende@hotmail.com

Apresentação de Pôster

Resumo

Área do Conhecimento: Sustentabilidade e Direitos

O presente trabalho tratará da Alienação parental, também é chamada de Síndrome da Alienação Parental, cujo está cada vez mais comum nos dias de hoje, devido aos grandes números de divórcios nos últimos anos, onde tal alienação é de difícil identificação, acarretando mais prejuízos para o alienado, e após identificado, a morosidade processual acaba sendo um agravante da situação psicológica e emocional da criança podendo se tornar irreversível.

No entanto essa situação se advém de divórcios mal resolvidos, onde o direito da criança fica em segundo plano, prevalecendo o ego dos pais, onde o alienante usa da criança (o alienado) para causar prejuízo ao outro genitor, acabando que o maior prejudicado é a criança.

PROBLEMA DE PESQUISA

Considerando a Alienação Parental uma realidade da sociedade brasileira, o problema dessa pesquisa é perquiri: se o menor ou o incapaz, estão preparados para uma desconstrução familiar , como que eles agiriam devido a essa situação,e quais consequências seriam para eles?

OBJETIVO

Quanto ao objetivo principal a ser alcançado, refere-se à de conferir maiores poderes aos juízes, a fim de proteger os direitos individuais da criança e do adolescente, vítimas de abuso exercido pelos seus genitores. MÉTODO

Para a obtenção dos resultados almejados na presente pesquisa será adotado o método dedutivo, o qual, de acordo com Mezzaroba e Monteiro (2009), parte de fundamentação genérica para chegar à dedução particular, o que faz com que as conclusões do estudo específico geralmente valham para aquele caso em particular, sem generalizações de seus resultados. Desse modo será a partir de argumentos gerais para argumentos particulares, de forma a alcançar os resultados propostos na problemática em tela e, por conseguinte, uma conclusão do que se consignou na pesquisa.

CONSIDERAÇÕES FINAIS

O sofrimento do menor, por ter seus pais se divorciando ja é grande devido a desconstrução de sua família, ou seja, de sua base, fica importante resaltar devido a alienação que o menor pode se sentir culpado, fazendo que ele crie sentimentos negativos provenientes desta situação.

Havendo várias consequências para a criança, depressão, a falta de estabilidade emocional, repulsa de determinado gênero por falta de estimulo de convivência, são consequências que afetam o psicológico e a saúde moral da criança ou adolescente prejudicando seu desenvolvimento como um adulto e um ser humano pleno de exercer suas funções e direitos perante a sociedade.

A criança está em um processo de identificação, construindo sua própria identidade como pessoa, e tal identificação vem de ambas partes genitoras pai e mãe, que são figuras importantes para tal formação.

Preservando o Princípio do melhor interesse da criança, mesmo após a separação ou o divórcio é importante manter um ambiente semelhante àquela que a criança estava acostumada.

PALAVRAS-CHAVE: SÍNDROME DA ALIENAÇÃO PARENTAL; MEDIAÇÃO; NÚCLEO FAMILIAR. 


\title{
ANÁLISE CINESIOLÓGICA DO ARREMESSO COM APOIO DO BASQUETE
}

\begin{abstract}
NATÁLIA JANAÍNA DOS REIS DIAS, JÉSSICA EVANGELISTA DE ASSIS, JOÃO ALAN SILVA LOPE, JONAS EDUARDO SANTOS, THAIS DO VALE CABRAL ALMEIDA, WELLIGTON PRATEDO DA SILVA, LARA FERREIRA PARAISO
\end{abstract}

INSTITUTO MASTER DE ENSINO PRESIDENTE ANTÔNIO CARLOS - IMEPAC

nataliareisdias211@gmail.com

Apresentação de Pôster

Resumo

Área do Conhecimento: Saúde coletiva e bem-estar

Introdução: O basquetebol pode ser considerado um esporte complexo, por conta de uma grande variação de ações, ocorrendo de forma dinâmica e contínua. Para atingir um nível de execução considerado adequado, os atletas devem estar preparados fisicamente, tecnicamente e taticamente. Por esses e entre outros móvitos há a necessidade analisar a cinesiologia dos gestos executados no basquete. Através da análise cinesiológica é possível analisar o movimento, possibilitando o ensino correto do gesto esportivo e o aperfeiçoamento da técnica. Objetivo: Realizar a análise cinesiológica d o arremesso com apoio executado no basquete. Metodologia: 0 estudo foi realizado com um voluntário do sexo masculino. Para a análise do arremesso o movimento foi dividido em 04 fases: inicial, intermediária e de execução 01 execução 02. Todas as imagens foram capturadas com uma câmera profissional e as imagens foram analisadas cinesiologicamente. 0 estudo foi realizado no Instituto Master de Ensino Presidente Antônio Carlos, na cidade de Araguari-Minas Gerais. Resultados: Para iniciar a execução do arremesso, o voluntário mantêm os cotovelos flexionados com uma leve abdução de ombro. Os músculos envolvidos na flexão dos cotovelos são músculos bíceps braquial, braquial e braquiorradial. E para a abdução de ombro ocorre a solicitação dos músculos deltoide e supraespinhal. As pernas estão alternadas e os joelhos semi flexionados. Na continuidade da execução do arremesso o voluntário realiza uma flexão de ombros e elevação escapular para levantar a bola. Os músculos envolvidos na flexão do ombro são o peitoral maior na porção ânterosuperior do peitoral maior, e o deltoide na porção/feixe anterior do deltoide. A elevação escapular ocorre através do trapézio no feixe superior, levantador da escápula e rombóides. Os cotovelos continuam levemente flexionados e a articulação do punho é estendida para segurar melhor a bola. A extensão do punho é realizada através da ação dos músculos extensores radiais longo e curto do carpo e extensor ulnar do carpo. 0 joelho esquerdo permanece levemente flexionado, já o esquerdo está estendido. Na posição final do arremesso o voluntário faz o movimento no lado direito do corpo de flexão do ombro, elevação da escápula, extensão do cotovelo e flexão do punho. Do lado esquerdo ocorre flexão do ombro, elevação da escápula e flexão do cotovelo. Os músculos envolvidos são deltoide, peitoral maior, trapézio, levantador da escápula, romboides, tríceps braquial, flexor radial do carpo, flexor ulnar do carpo. Ambos joelhos estão estendidos e ocorre uma de flexão plantar, através da ação dos músculos gastrocnêmico e sóleo. Conclusão: Através da análise podemos concluir que o deltoide e peitoral maior são os músculos predominantes do arremesso. As articulações predominantes foram a do ombro, cotovelo e pulso.

PALAVRAS-CHAVE: BASQUETE, ARREMESSO COM APOIO, ANÁLISE CINESIOLÓGICA. 


\title{
ANÁLISE CINESIOLÓGICA DO PASSE DE GANCHO NO BASQUETE
}

\author{
TÚLIO SANTOS MOTA PEIXOTO, ALEXANDRE FERREIRA COSTA, AMANDA BATISTA PÉREZ, GABRIEL \\ GEBHARDT CHIOVATO, RÉGIS MATHEUS GONZAGA LEITE, THALIS ALVES RAMOS, LARA FERREIRA \\ PARAÍSO
}

INSTITUTO MASTER DE ENSINO PRESIDENTE ANTÔNIO CARLOS - IMEPAC

tulio.mota.p@gmail.com

Apresentação de Pôster

Resumo

Área do Conhecimento: Saúde coletiva e bem-estar

Introdução: 0 basquete é um esporte regido por sua beleza e ritmo. Atualmente, existem cerca de 300 milhões de praticantes no mundo. Possui como características principais esforços breves e intensos, realizados em diversos ritmos, um conjunto de saltos, corridas, movimentos coordenados ataque-defesa, passes, arremessos, assim sendo um esporte de grande movimentação e coordenação. A cinesiologia tem como enfoque a análise dos movimentos do corpo humano sob o ponto de vista físico. Seu estudo abrange uma análise do movimento tanto a estrutura esquelética quanto muscular. A análise do gesto motor é de fundamental importância para o conhecimento e o entendimento na execução ou aperfeiçoamento da técnica de diferentes gestos esportivos.

Objetivo: Realizar uma análise cinesiológica sobre cada etapa do passe de gancho.

Metodologia: Foi utilizado neste estudo 1 voluntário, com experiência em basquete 0 passe foi executado na lateral da quadra próximo ao garrafão de frente para a cesta. 0 voluntário participou de um breve aquecimento de 5 minutos dos quais ele mesmos conduziu. 0 passe foi dividido em 3 etapas para analise. Primeira fase: é o ato de segurar a bola com uma mão só; segunda fase: fazer a elevação do braço no qual segura a bola e terceira fase: flexão do cotovelo ao finalizar o movimento. Todas as etapas do estudo foram realizadas no Instituto Master de Ensino Presidente Antônio Carlos, na cidade de Araguari-Minas Gerais. Resultados: Na fase inicial do passe de gancho, ocorre uma flexão de cotovelo. Os músculos envolvidos neste movimento são o braquial, bíceps braquial e braquiorradial. No início da execução do passe ocorre uma abdução de ombro com extensão de cotovelo. Os músculos envolvidos nesta fase do movimento são: deltoide, supraespinhal e tríceps braquial. Já na fase final de execução, ocorre uma abdução de ombro, flexão de cotovelo, rotação da escápula e flexão da articulação do punho. Os músculos envolvidos nesta fase do movimento são: deltoide, supraespinhal, bíceps braquial, braquial, braquioradial, partes ascendentes e descendentes do trapézio, serrátil anterior, flexor radial do carpo e flexor ulnar do carpo.

Conclusão: Com o trabalho foi possível identificar os principais grupos msuculares que são exigidos durante a realização do passe de gancho, assim, se for executado de forma incorreta poderá dificultar e atrapalhar a desenvoltura do passe.

PALAVRAS-CHAVE: BASQUETE, PASSE DE GANCHO, ANÁLISE CINESIOLÓGICA. 


\title{
ANÁLISE CINESIOLOGICA DO PASSE QUICADO (PICADO)
}

\author{
DENER BELKLIN DA SILVA ALVES, GLAUCIA CRISTINA CARVALHO GOMES, VINICIUS DA SILVA \\ TRONCHA, LARA FERREIRA PARAISO
}

INSTITUTO MASTER DE ENSINO PRESIDENTE ANTÔNIO CARLOS - IMEPAC

alunoaluno06@gmail.com

Apresentação de Pôster

Resumo

Área do Conhecimento: Saúde coletiva e bem-estar

Introdução: A cinesiologia utiliza princípios da mecânica, da anatomia do aparelho locomotor e da fisiologia neuromuscular para compreender o movimento e as forças que agem sobre o corpo humano e aprender como a manipulação dessas forças previne a lesão, restaura a função e gera o desempenho humano ideal. A partir da análise qualitativa é possível identificar as etapas do movimento localizando os pontos a serem trabalhados para garantir, como por exemplo, a execução de um bom passe, promovendo noções de qua is músculos e articulações geram influência no movimento. Objetivo: Analisar o gesto motor do "passe quicado", realizado no basquetebol. Metodologia: Participaram do estudo 02 voluntários, um homem e uma mulher sendo estudantes do curso de educação física. Um voluntário possui experiência em basquete, já a outra participante nenhuma experiência. Após um aquecimento os voluntários executaram o passe quicado. Foi registrado através de fotos as fases de preparação e execução do movimento. Todas as etapas da pesquisa foram realizadas no Instituto Master de Ensino Presidente Antônio Carlos, da cidade de Araguari - Minas Gerais. Resultados: Na fase inicial ocorreu uma abdução horizontal de ombro e flexão dos cotovelos. Os músculos envolvidos foram o deltoide (parte espinhal), infra espinal, o redondo menor, o bíceps braquial e o braquiorradial. Na fase de execução ocorreu uma abdução horizontal do ombro com extensão dos cotovelos e uma leve flexão da articulação do punho. Os músculos atuantes nesta fase incluem o deltoide (parte espinhal), o infra espinal, redondo menor, tríceps braquial, flexor radial do carpo e flexor ulnar do carpo. Durante o final da execução do passe ocorreu flexão de ombro, extensão do cotovelo e punho. Os músculos envolvidos foram o deltoide, peitoral maior (parte clavicular), o tríceps braquial e extensores do carpo. A finalização o passe envolveu a extensão de ombros e cotovelos. Os músculos envolvidos foram deltoide (parte espinal), latíssimo do dorso, redondo maior, peitoral maior (parte externo costal) e tríceps braquial. Conclusão: Concluímos que os músculos mais solicitados no movimento são deltoide e flexores do punho. De maneira que, um maior fortalecimento destes músculos e a prática do dia adia, induz-se que favorecem o bom aperfeiçoamento da técnica deste passe.

PALAVRAS-CHAVE: BASQUETE, PASSE QUICADO, ANÁLISE CINESIOLÓGICA. 


\title{
ANÁLISE CORRELATIVA ENTRE O PERFIL ANTROPOMÉTRICO E CARDIOVASCULAR DE IDOSOS PRATICANTES DE ATIVIDADE FÍSICA
}

\author{
CHAYONARA KATIANA RIBEIRO ALVES, CAROLINA FONSECA VISO, EDUARDO TADEU DE PAULA, \\ JESSICA CRISTINA DOS SANTOS COSTA, WILLIAM PRADO NUNES, JAQUELINE PONTES BATISTA
}

INSTITUTO MASTER DE ENSINO PRESIDENTE ANTÔNIO CARLOS - IMEPAC

chayonararibeiro@bol.com.br

Comunicação Oral

Resumo

Área do Conhecimento: Saúde coletiva e bem-estar

Introdução: Avaliar os benefícios do exercício físico sobre intervenções é uma das formas mais eficientes para quantificar a melhoria da qualidade de vida, pois o exercício físico atua promovendo a independência e autonomia nas atividades do cotidiano.

Objetivo: Verificar a partir de dados coletados a correlação dos dados antropométricos com os dados cardiovasculares de um grupo de idosos ativos.

Materiais e métodos: Participaram do estudo 7 idosas (65 \pm 5 anos; 71,9 $\pm 12,1 \mathrm{Kg} ; 1,56 \pm 0,03 \mathrm{~m}$ ) praticantes de 3 sessões semanais de aulas de ginástica. Os exercícios realizados são na maioria multiarticulares aproximando dos movimentos das atividades do cotidiano. Foi efetuada coleta de Pressão Arterial (PA) de repouso com o aparelho esfigmomanometro P.A.MED devidamente calibrado, com os indivíduos na posição sentada, em um ambiente calmo e com 15 minutos de repouso para mensuração da pressão arterial sistólica (PAS) e pressão arterial diastólica (PAD). A frequência cardíaca foi mensurada através do frequencímetro oregon. A circunferência abdominal foi obtida entre as costelas e a crista com base na medida acima da cicatriz umbilical. A circunferência do quadril foi obtida ao redor da região do quadril na área de maior protuberância, sem comprimir a pele. A circunferência da cintura foi obtida na menor curvatura localizada no tronco, todas as circunferências foram obtidas por uma fita inelástica e flexível. 0 índice de massa corporal IMC é feito dividindo o peso (Kg) pela altura (m) ao quadrado. A relação cintura-quadril também foi calculada pelo valor da cintura dividido pelo valor do quadril. A correlação foi mensurada através da correlação de Pearson, considerando o valor de $p<0,05$, utilizando o software SPSS versão 21.0.

Resultados: A correlação de Pearson demonstrou uma correlação forte e positiva entre a circunferência da cintura e a abdominal ( $\mathrm{r}=0,778)$, quadril $(\mathrm{r}=0,761)$ e IMC ( $\mathrm{r}=829)$, assim como o IMC manteve a correlação em relação à circunferência do quadril $(r=0,956)$. A circunferência abdominal também correlacionou de forma positiva e forte com a circunferência do quadril $(r=0,756)$ e IMC $(r=0,796)$. Quando observados os dados hemodinâmicos, observou-se uma correlação entre a PAS e PAD ( $r=0,843$ ). Não foi verificada nenhuma correlação significativa nas demais variáveis. Vale ressaltar que os achados do estudo podem ter sido delimitados à quantidade de participantes. Para estudos prospectivos faz- se necessário uma amostra maior e com tempo de duração para analise mais consistentes

Conclusão: Não houve correlação entre as variáveis cardiovasculares e o perfil antropométrico. Porém, o estudo demonstrou uma positiva e forte correlação entre as circunferências mensuradas bem como entre os dados de pressão arterial.

PALAVRAS-CHAVE: ATIVIDADE FÍSICA, CORRELAÇÃO, ANTROPOMETRIA, PRESSÃO ARTERIAL. 


\title{
ANÁLISE CRÍTICA DE CONFORMIDADE DA ROTULAGEM NUTRICIONAL DE SUCOS E NÉCTARES COMERCIALIZADOS NO SETOR VAREJISTA DE UBERLÂNDIA, MINAS GERAIS
}

\author{
RAYANE BEZERRA DA SILVA, ALINE RODRIGUES GONÇALVES, BRIANY RODRIGUES SILVA, \\ NATHÁLIA DE FÁTIMA ARAÚJO FONSECA, PAULA ALVARES BORGES FERREIRA, LAURA CRISTINA \\ TIBILETTI BALIEIRO
}

INSTITUTO MASTER DE ENSINO PRESIDENTE ANTÔNIO CARLOS - IMEPAC

rayanesilvaa_@live.com

Apresentação de Pôster

Resumo

Área do Conhecimento: Saúde coletiva e bem-estar

\begin{abstract}
Introdução: Nas últimas décadas, o Brasil foi marcado por uma transição nutricional caracterizada pelo aumento no consumo de ultraprocessados associado com a alteração da distribuição de macronutrientes, como o aumento do consumo de açúcares e de gorduras. Nesse sentido, a rotulagem dos alimentos é essencial para que o consumidor faça escolhas alimentares saudáveis, pois é através das informações nutricionais da embalagem que ocorre a comunicação da indústria alimentícia com o cliente. Objetivo: Analisar a conformidade da rotulagem nutricional de sucos e néctares comercializados no setor varejista de Uberlândia. Metodologia: Trata-se de um estudo descritivo, foi realizado uma caracterização dos produtos em relação ao número de ingredientes e aditivos alimentares e a posição de açúcar. Para verificar a conformidade foram criados 3 check-lists elaborados a partir de normas estabelecidas pela legislação vigente: resolução da diretoria colegiada (RDC) n³60/03 referente à rotulagem nutricional obrigatória, que dispõe de 16 itens; instrução normativa $n$ ํ42/2013 que é constituída por 5 itens que descrevem as características dos produtos; e RDC nํ259/02 referente à prováveis induções de engano ao consumidor, apresentando 14 itens. Resultados: Foram analisados 109 produtos (56 néctares e 53 sucos), de diferentes marcas e sabores. Foi verificado que os néctares possuem em média 8,25 $\pm 1,97$ ingredientes, enquanto os sucos 2,9 $\pm 2,63$; em relação ao número de aditivos alimentares, os néctares apresentaram em média 4,7 \pm 2,01 , enquanto os sucos $1 \pm 1,30$; e a respeito da adição de açúcar, $94 \%$ dos sucos não possuem adição, à proporção que $89,5 \%$ dos néctares apresentam açúcar na segunda ou terceira posição dos ingredientes. Através do check-list da RDC n²59/02 encontramos que 50\% dos néctares e $17 \%$ dos sucos apresentaram não conformidade para os itens: não é permitido declarar propriedade nutricional própria a todo alimento de mesma natureza; e não é permitido declarar componente que seja adicionado como ingrediente em todo alimento com tecnologia de fabricação semelhante. No check-list da RDC $n^{\circ} 360 / 03$ apenas um item apresentou não conformidade para os sucos (4\%), esse item define que é obrigatório expressar a quantidade de qualquer nutriente que se faça declaração de propriedade nutricional. Em relação a Instrução Normativa n⿳0022/2013, de acordo com item referente à declaração obrigatória da quantidade de polpa de fruta no rótulo apenas os sucos apresentaram não conformidade $(n=23)$ e sobre a obrigatoriedade da declaração da quantidade de polpa estar no painel principal do rótulo e em destaque, 23 sucos e 8 néctares apresentaram não conformidade. Conclusão: Constatou-se que ainda existem muitas inadequações no cumprimento das legislações e isso pode trazer diversos prejuízos ao consumidor, induzindo a equívocos e levando a escolhas ruins sem que haja conhecimento do valor nutricional do produto.
\end{abstract}

PALAVRAS-CHAVE: SUCOS, ROTULAGEM DE ALIMENTOS, LEGISLAÇÃO SOBRE ALIMENTOS. 


\title{
ANÁLISE DA DEMANDA DE MEDICAMENTOS ANTIRRETROVIRAIS NO MUNICÍPIO DE ARAGUARI-MG
}

\author{
CLARA COUTO VINY RESENDE, ANA PAULA ROCHA VINHAL, BIANCA ROCHA SANTOS, BRUNA \\ LARISSE LOPES COUTO, GABRIELLA ALVES DE OLIVEIRA , LORENA FARIA BATISTA , MARIANA DOS \\ SANTOS MELO, HERBERT CRISTIAN DE SOUZA
}

INSTITUTO MASTER DE ENSINO PRESIDENTE ANTÔNIO CARLOS - IMEPAC

clarissima5@hotmail.com

Comunicação Oral

Resumo

Área do Conhecimento: Saúde coletiva e bem-estar

Análise da Demanda de Medicamentos Antirretrovirais no Município de Araguari-MG

Alunas: Ana Paula Rocha Vinhal, Bianca Rocha Santos, Bruna Larisse Lopes Couto, Clara Couto Viny Resende, Gabriella Alves de Oliveira, Lorena Faria Batista, Mariana dos Santos Melo

Introdução

A infecção pelo vírus da imunodeficiência humana (HIV) e a Síndrome da Imunodeficiência Adquirida (AIDS), ainda é uma doença sem cura e em expansão, principalmente em regiões economicamente menos desenvolvidas. A epidemia atinge especialmente a população jovem, com a maioria dos casos, concentrando-se na faixa etária entre 20 a 39 anos. Por outro lado, mesmo que o indivíduo seja portador do virus HIV, ele pode não ter desenvolvido a AIDS. A equipe de saúde do Centro de Apoio Especializado (CAE) de cada cidade tem o dever de incentivar o paciente a fim de que a adesão completa dele seja através da terapia contínua, além dos medicamentos. Para isto é necessário a aceitação do processo saúde-doença, primeiramente, pelo paciente, para que ele consiga e integrar na sua totalidade o esquema terapêutico com a equipe multidisplinar, para promover uma melhora na qualidade de vida dele enquanto HIV positivo.

Objetivo:

Analisar o fluxo de serviços e logística da disponibilização antirretrovirais, destinados ao tratamento de pacientes HIV+, na cidade de Araguari.

Metodologia:

Foi realizado um estudo transversal, com levantamento de dados quantitativos por meio de pesquisa documental, observação não participante e revisão bibliográfica. A pesquisa de campo (visita ao CAE) foi realizada nos meses de março e abril de 2019. Foram realizadas quatro visitas, nas quais foram levantados dados acerca dos medicamentos mais utilizados no tratamento de pacientes HIV+, a demanda e a logística de distribuição dos mesmos, assim como dados sociodemográficos, em um intervalo de seis meses.

Resultados

Os medicamentos mais utilizados no tratamento de pacientes HIV+ distribuídos pelo CAE de Araguari são: Tenofovir + Lamivudina; Dolutegravir; Tenofovir + Lamivudina + Efavirenz; Zidovudina + Lamivudina; Ritonavir; Atazanavir; Danuravir.

Conclusão:

O CAE é para a cidade de Araguari (MG) um substancial serviço público de saúde destinado, principalmente, ao reconhecimento e à notificação, em nível federal, de pessoas infectadas com o vírus HIV. A partir da oferta de verbas ao Estado e consequente disponibilização de medicamentos ao município, instaura-se um sistema integral de controle logístico no qual os fármacos antirretrovirais são repassados ao CAE, fechando um ciclo em que esse centro viabiliza os medicamentos aos pacientes HIV+. Diante disso, ressalta-se a relevância da função prestada pelo serviço de saúde especializado como uma rede de suporte aos indivíduos portadores do vírus, aspecto que potencializa a qualidade da terapêutica e o bem-estar desses pacientes.

PALAVRAS-CHAVE: ANTIRRETROVIRAIS, HIV, SÍNDROME DE IMUNODEFICIÊNCIA ADQUIRIDA. 


\title{
ANÁLISE DA FLEXIBILIDADE EM JOGADORES DAS CATEGORIAS DE BASE DO MANCHA ESPORTE CLUBE DE ARAGUARI/MG EM PERIODO DE PRÉ-TEMPORADA
}

\author{
BRUNA DE FÁtIMA PEREIRA COELHO, AMANDA NOGUEIRA DE OLIVEIRA, GEOVANA FERNANDES \\ PEREIRA, HUGO RIBEIRO ZANETTI, DANIELLE FERNANDES ALVES
}

INSTITUTO MASTER DE ENSINO PRESIDENTE ANTÔNIO CARLOS - IMEPAC

bruna_fatima_mendes@hotmail.com

Apresentação de Pôster

\section{Resumo}

Área do Conhecimento: Saúde coletiva e bem-estar

\begin{abstract}
Introdução: A flexibilidade é um importante coeficiente da aptidão física, tolerando a maior amplitude de movimento para execução de um gesto motor qualquer, o futebol sendo um esporte complexo e abrangente exige desenvolvimento dos jogadores, resultando boa movimentação, coordenação e potencial aeróbico, desta forma para melhores resultados foi realizado o teste de flexibilidade nos jogadores para descobrimento de seus déficits e a visualização de seus maiores desempenhos. Objetivo: Avaliar a flexibilidade dos jogadores das categorias de base do Mancha Esporte Clube da cidade de Araguari/MG no período de pré temporada. Metodologia: Trata-se de um estudo transversal descritivo executado com atletas das categorias pré-mirim (10 e 11 anos), mirim (12 e 13 anos), infantil (14 e 15 anos) e juvenil (16 e 17 anos) das categorias de base do Mancha Esporte Clube da cidade de Araguari/MG no período de prétemporada e afim de avaliar a flexibilidade foi utilizado o teste de sentar e alcançar com o auxílio do banco de Wells. 0 atleta foi orientado a realizar o teste sem calçado, alinhar os joelhos, deixando-os totalmente estendidos, com os calcanhares tocando o solo e a parte inferior dos pés em contato com o banco, sendo solicitado para o que individuo realizasse o movimento de flexão de toda coluna vertebral e do quadril, empurrando um anteparo que fica sobre o banco. No comando de "já" o sujeito realizava o teste de forma lenta até atingir sua capacidade máxima. Realizaram-se três tentativas, sendo considerado válido aquele que o atleta alcançou maior distância. Os dados estão expressos em média \pm desvio-padrão. Resultados: Foram avaliados 97 atletas sendo 17 atletas pré-mirim, 38 atletas mirim, 33 atletas infantil e 14 atletas juvenil. Observou-se que os atletas pré-mirim apresentaram flexibilidade de 28,1 $\pm 10,1 \mathrm{~cm}$; os atletas mirim tiveram flexibilidade de $24,6 \pm 6,3 \mathrm{c}$,; os atletas juvenil obtiveram flexibilidade de $27,5 \pm 6,6 \mathrm{~cm}$ e os atletas juvenil tiveram flexibilidade de $28,8 \pm 6,7 \mathrm{~cm}$. Conclusão: 0 teste de flexibilidade é um bom indicador para os atletas para a prática de futebol, pois seus resultados demonstram a importância para prescrição de exercícios onde ocorre o déficit de dificuldade, podendo ser trabalhado para obtenção de melhores corolários, conclui-se que o teste é confiável e autêntico para a prescrição de treinamentos e melhoramentos.
\end{abstract}

PALAVRAS-CHAVE: FLEXIBILIDADE, TESTE, ATLETAS. 


\title{
ANÁLISE DA GESTÃO ADMINISTRATIVA EM UMA INSTITUIÇÃO FILANTRÓPICA NA CIDADE DE ARAGUARI-MG
}

\author{
JULIANO CHAVES DE SOUSA, ISABEL CUNHA SANTOS, IZABELA SILVA REZENDE, RAFAELLA CUNHA \\ MENEZES, RICARDO FARIA ANDRADE FILHO, HERBERT CRISTIAN DE SOUZA
}

INSTITUTO MASTER DE ENSINO PRESIDENTE ANTÔNIO CARLOS - IMEPAC

jchsousa@bol.com.br

Apresentação de Pôster

Resumo

Área do Conhecimento: Saúde coletiva e bem-estar

Introdução: O fim da Segunda Guerra Mundial propiciou o desenvolvimento de problemas de ordem social e econômica, com mudanças no campo da comunicação, produção e urbanização. Esse fato contribuiu muito para a geração da pobreza, culminando no surgimento das primeiras instituições sem fins lucrativos e sem o apoio governamental, caracterizadas como Instituições Filantrópicas, voltadas a grupos populacionais específicos nos quais as ações governamentais eram ineficazes. É de fundamental importância, nessas instituições, a atuação dos Controles Internos, responsáveis pela administração, organização e tomada de decisões, possibilitando a devida aplicação dos recursos e evitando erros gerenciais quanto à sua destinação.

Objetivo: Analisar a gestão administrativa de uma entidade filantrópica da cidade de Araguari (MG). Metodologia: Trata-se de uma investigação transversal, descritiva e qualitativa, realizada em uma Instituição Filantrópica da cidade de Araguari (MG), no período de setembro a outubro de 2017. Foi utilizado um questionário não validado aplicado aos gestores da Entidade, que contou com informações relacionadas aos dados gerais, visão, valores, organização e financiamento. Além disso, o documento destinou espaço para análise, por parte dos gestores, sobre os pontos fortes e fracos da entidade. A pesquisa seguiu princípios éticos com o preenchimento do Termo de Consentimento Livre e Esclarecido (TCLE).

Resultados: Verificou-se na instituição um total de 11 funcionários, a maioria vinculado pelo regime celetista (91\%) e apenas 1 (9\%) enquadrado na categoria voluntário fixo. Desse total, a grande maioria (55\%) possuem o ensino fundamental incompleto e apenas $18 \%$ concluíram o ensino superior. No momento havia 30 institucionalizados, em que a maioria é do sexo feminino (80\%), com idade entre 19 e 25 anos (11\%). Com relação ao setor financeiro, a entidade é mantida com o recebimento do BPC dos residentes, recursos oriundos de TAC entre Município e Ministério Público, repasse Estadual e doações de terceiros. As gestoras consideram como ponto forte o fato de a instituição ser a única nesse ramo de serviço, enquanto o principal ponto fraco relatado foi a insuficiência de recursos financeiros. Nenhuma das entrevistadas foi capaz de descrever os valores da empresa, bem como de detectar alguma oportunidade de crescimento e possíveis ameaças. Não consta documento com organograma e fluxograma.

Conclusão: A baixa escolaridade dos funcionários da instituição, associada à ausência de organograma e fluxograma bem elaborados, é um obstáculo à formação de gerenciamento efetivo da entidade por parte dos Controles Internos. Por outro lado, a falta de recursos financeiros e a baixa adesão de voluntários dificulta a prestação de serviço centrada em um padrão de qualidade que promova uma visão positiva da sociedade e aumente a credibilidade da instituição

PALAVRAS-CHAVE: GESTÃO, ADMINISTRAÇÃO, FILANTROPIA. 


\title{
ANÁLISE DA INTENSIDADE DE SINTOMAS DE DEPRESSÃO E ANSIEDADE DE ESTUDANTES DO CURSO DE GRADUAÇÃO EM FARMÁCIA E ENFERMAGEM DE UMA INTITUIÇÃO DE ENSINO SUPERIOS DE ARAGUARI -MG .
}

\author{
ANTONIELE CAROLINE MARQUES VALADÃO, HERBERT CRISTIAN DE SOUZA， LUANA \\ THOMAZETTO ROSSATO, MARIA CLÁUDIA CÂNDIDA RODRIGUES
}

INSTITUTO MASTER DE ENSINO PRESIDENTE ANTÔNIO CARLOS - IMEPAC

antonielecaroline@outlook.com.br

Apresentação de Pôster

Resumo

Área do Conhecimento: Saúde coletiva e bem-estar

\begin{abstract}
Introdução: Estudantes da área da saúde, ao ingressar na faculdade acabam mudando, o seu estilo de vida, com perdas na sua vida pessoal, nas suas relações sociais e no seu lazer, com o intuito de adaptar-se ao novo contexto de ensino-aprendizagem da vida universitária. Essas mudanças podem levar ao desenvolvimento de episódios de depressão e ansiedade, o que pode provocar queda no rendimento nos estudos.Objetivos: Avaliar a intensidade de sintomas depressivos e estado de ansiedade em estudantes dos Cursos de Enfermagem e Farmácia do Instituto Master de Ensino Presidente Antonio Carlos de Araguari - MG. Metodologia: Trata-se de um estudo quantitativo, descritivo, de corte transversal realizado entre os meses de março a abril de 2019 em alunos dos cursos de Enfermagem e Farmácia do IMEPAC (IES) de Araguari MG. A amostra total constou de 193 participantes que se dispuseram a participar da investigação. Foram excluídos do estudo aqueles estudantes provenientes de transferência de outra IES, aqueles com outra graduação, e os que se recusaram a assinar o TCLE. Os instrumentos de coletas de dados foram as versões brasileiras do IDB e IDATE-E, além de um questionário sócio demográfico. A Análise dos dados foi feita pela estatística descritiva (mediana, percentis), após o teste de normalidade se Shapiro-Wilk indicar que os dados não apresentam distribuição normal para o IBD, IDATE-E e questionário sócio demográfico. 0 teste de Mann-Whitney foi utilizado para comparar os escores do IDB e IDATE-E entre os alunos dos cursos, com relação a depressão e ansiedade, respectivamente. Ademais, usou-se o teste de Kruskall-Wallis para comparar os escores do IDB e IDATE-E entre estado civil, custeio e mensalidade. A correlação de Spearman foi realizada para correlacionar os escores IDB e IDATE-E entre satisfação com o curso e período do curso. A confiabilidade da consistência interna do IBD e IDATE-E foi feita pelo alfa de Cronbach e o nível de significância foi de $\mathrm{P}<0,05$. Resultado: A amostra foi composta 193 sujeitos, sendo a maioria de estudantes de enfermagem $(67,9 \%)$. Com relação ao sexo e estado civil dos dois cursos avaliados, predominou o feminino $(80,8 \%)$ e solteiros $(72,5 \%)$. Mais de 57\% arcam com a mensalidade com recursos próprios, e para $73,1 \%$ dos participantes relataram não haver problemas psicológicos, e, para 96,9\% não existe envolvimentos com álcool e drogas ilícitas. 0 coeficiente de alfa de Cronbach foi $>0,86$ nas duas escalas. A mediana do IDB foi de 11,49 e do IDATE-E foi de 49,0. Não foram encontradas correlações entre as variáveis sociodemográficas, onde apenas foram encontradas diferenças significativas entre os sexos (IDB e IDATE > sexo feminino).Conclusão: Conclui-se que os instrumentos foram confiáveis e que os estudantes de enfermagem e farmácia tem uma baixa intensidade de sintomas depressivos e escores de ansiedade baixa para moderada, predominante no sexo feminino.

PALAVRAS-CHAVE: ANSIEDADE; DEPRESSÃO; ESTUDANTES.
\end{abstract}




\title{
ANÁLISE DA NR 06 (EQUIPAMENTOS DE PROTEÇÃO INDIVIDUAL) APLICADA EM UMA EMPRESA PROCESSADORA DE BEBIDAS NÃO ALCOÓLICAS
}

\author{
ALEXANDRE LUCAS DIAS COSTA, DANIELE CHAGAS BARBARESCO, ESTER CRISTINA DOS SANTOS, \\ JEFERSON FERNANDES RIBEIRO, LEONARDO MARTINS RIBEIRO, DANIELA ALMEIDA DANTAS
}

INSTITUTO MASTER DE ENSINO PRESIDENTE ANTÔNIO CARLOS - IMEPAC

alexandrelucasdiascosta@yahoo.com.br

Comunicação Oral

Resumo

Área do Conhecimento: Saúde coletiva e bem-estar

\begin{abstract}
Introdução (Contextualização): Para os fins de aplicação desta Norma Regulamentadora - NR, considera-se Equipamento de Proteção Individual - EPI, todo dispositivo ou produto, de fabricação nacional ou estrangeira, de uso individual utilizado pelo trabalhador, destinado à proteção de riscos suscetíveis de ameaçar a segurança e a saúde no trabalho e que possua o Certificado de Aprovação, fornecido pelo Ministério do trabalho e emprego. A empresa é obrigada a fornecer aos empregados, gratuitamente, EPI adequado ao risco, em perfeito estado de conservação e funcionamento. A análise de tipos de ambientes de trabalho teve como objetivo demonstrar a necessidade de utilização de EPI's.

Metodologia: Para o referido estudo, elegeu-se uma empresa processadora de bebidas não alcoólicas de Araguari - MG para a análise da aplicação da NR 06, por se tratar de uma empresa industrial que processa polpa de frutas na fabricação de sucos naturais. O tipo de trabalho operacional e de manutenção desenvolvido na mesma exige a utilização de EPI's, visando à segurança e o bem-estar dos colaboradores, em virtude dos riscos inerentes às atividades ocupadas por esses profissionais. Foi feita uma coleta informal de dados no dia 11/03/2019 na empresa, e em 2 horas de observação, foram anotados os EPI's que os colaboradores estavam utilizando no ambiente fabril.

Relato da experiência: Em verificação in-loco no factory floor "chão de fábrica", na companhia do gestor local da saúde e segurança do trabalho, percebeu-se a necessidade dos seguintes EPI's para atividades operacionais de "chão de fábrica", de um modo geral: Protetor Auricular, devido ao alto ruído em que os colaboradores são expostos, podendo acarretar em perda gradativa da audição; Capacete, devido ao risco de queda de objetos sobre as cabeças dos colaboradores; Bota com bico de aço, devido ao risco de queda de objetos sobre os pés dos colaboradores; Luvas, devido ao risco de lesões por parte de objetos cortantes, agentes queimadores, entre outros; Óculos de proteção, devido à existência de agentes que possam colidir com os olhos dos colaboradores; Máscara, devido à existência de pó e/ou outros agentes que possam introduzir nos pulmões dos colaboradores.

Considerações finais: Por ser uma norma, cabe ao empregado utilizar os equipamentos de proteção individual estabelecidos tecnicamente para a atividade a ser exercida, tendo como responsabilidade do empregador fornecer, orientar e exigir sua utilização de forma correta. Os perigos existentes na empresa são de trabalho em altura, espaço confinado, esteiras, câmaras frias e produtos químicos. Deve-se citar que EPI não evita acidente, ele ajuda o indivíduo trazendo proteção e amenização da gravidade dos acidentes, ainda que os mesmos sejam inevitáveis. Por isso a melhor maneira de garantir a segurança é a conscientização. Concluímos que existem perigos que de certa forma podem ser evitados trabalhando de forma segura.

PALAVRAS-CHAVE: EPI; NR 06; SEGURANÇA DO TRABALHO; TRABALHO SEGURO.
\end{abstract}




\title{
ANÁLISE DO CUSTO-EFETIVIDADE DE MEDICAMENTOS ANTIDEPRESSIVOS FORNECIDOS PELA FARMÁCIA MUNICIPAL DE ARAGUARI-MG
}

\author{
DANIEL RODRIGUES MOREIRA CORRÊA, ELIAS ANTÖNIO SOARES FERREIRA, ISABELA PIMENTA \\ PESSÖA, IVANA VIEIRA CUNHA, MARIA LUIZA NASCIUTTI MENDONÇA, HERBERT CRISTIAN DE \\ SOUZA
}

INSTITUTO MASTER DE ENSINO PRESIDENTE ANTÔNIO CARLOS - IMEPAC

danielrmcorrea@yahoo.com.br

Comunicação Oral

Resumo

Área do Conhecimento: Saúde coletiva e bem-estar

De acordo com a OMS (2017), o transtorno depressivo afeta cerca de 322 milhões de pessoas no mundo e 5,8\% da população brasileira. Para o tratamento da depressão, o SUS disponibiliza medicamentos que fazem parte da classe de antidepressivos tricíclicos e dos Inibidores Seletivos da Recaptação de Serotonina. Com o aumento dos custos em saúde, faz-se necessária a avaliação econômica antes da aprovação do medicamento pelas entidades regulatórias, principalmente em países em desenvolvimento, que apresentam recursos limitados. As relações de custo efetividade são um estudo de avaliação econômica que tem como objetivo considerar o fator custo na tomada de decisão quanto as novas drogas ou tecnologias a serem utilizadas, sendo o método mais indicado para se comparar duas ou mais alternativas terapêuticas, diagnósticas ou preventivas, uma vez que permite a análise combinada de benefícios, sejam estes clínicos ou de custos associados, dando acesso a dados claros e objetivos para uma chegar a uma decisão.

O objetivo foi analisar o custo efetividade de medicamentos antidepressivos fornecidos pela Farmácia Municipal de Araguari-MG.

Trata-se de um estudo quantitativo, observacional e transversal. Foi feita uma estimativa de custoefetividade de medicamentos antidepressivos fornecidos pela rede pública municipal de Araguari, por meio de dados fornecidos pela Farmácia Municipal. 0 custo dos medicamentos foi extraído da tabela "Preços Máximos de Medicamentos por Princípio Ativo" atualizada em 2019 da ANVISA. Foi calculado o custo efetividade desses medicamentos utilizando o Preço de Fábrica e a efetividade dos medicamentos encontrada em suas respectivas bulas. Não foi avaliado a prevalência de efeitos colaterais.

A análise mostrou que o custo efetividade da Amitriptilina foi dominante em relação aos outros medicamentos disponíveis, com $\mathrm{R} \$ 1,71$ por dia de tratamento até alcançar sua dose resposta em 30 dias. Entretanto, a Clomipramina possui um custo-efetividade de $\mathrm{R} \$ 1,76$ por dia de tratamento, muito próximo ao da Amitriptilina, porém com vantagem de alcançar sua dose resposta mais rapidamente em, no mínimo, 2 semanas. Por outro lado, a posologia da Clomipramina requer a ingestão do medicamento de 2 a 3 vezes ao dia e está mais sujeita adesão incorreta do paciente ao tratamento, enquanto a Amitriptilina requer a ingestão apenas 1 vez ao dia, diminuindo a chance de falha causada pelo paciente. Por fim, o maior custo efetividade presente no estudo foi a Sertralina com $\mathrm{R} \$ 2,31$ por dia de tratamento até atingir sua doseresposta.

Em vista da importância da análise de custos para melhor aproveitamento dos recursos limitados oferecidos pelo governo, e considerando a chance hipotética de adesão correta do paciente e uma boa efetividade do medicamento, a Amitriptilina é a melhor escolha quando comparado seu custo-efetividade com outros medicamentos disponibilizados na Farmácia Municipal da cidade Araguari. PALAVRAS-CHAVE: ANTIDEPRESSIVOS; AVALIAÇÃO DE CUSTO-EFETIVIDADE; DEPRESSÃO. 


\title{
ANÁLISE DO PERFIL ANTROPOMÉTRICO E DA PRESSÃO ARTERIAL DE REPOUSO EM ATLETAS DE ESCOLINHA DE FUTSAL INFANTO-JUVENIL
}

\author{
MARCELA PAIVA BORGES, CELSO DE ASSIS LEMOS DE MORAIS, GABRIEL SIMÃO MAGALHÃES, \\ JULIO CESAR SAMUEL JUNIOR, MARCO TÚLIO PEREIRA DA SILVA, MAYRA CORREA SANTOS, \\ JAQUELINE PONTES BATISTA
}

INSTITUTO MASTER DE ENSINO PRESIDENTE ANTÔNIO CARLOS - IMEPAC

marcelapaivaborges@gmail.com

Apresentação de Pôster

Resumo

Área do Conhecimento: Saúde coletiva e bem-estar

Introdução: 0 futebol é um dos esportes mais praticados por crianças, jovens e adultos de todo o mundo, além da aptidão física, outro aspecto importante para detecção e promoção de talentos é a composição corporal dos atletas, já que índices elevados da gordura corporal estão associados com o mal condicionamento físico e queda de rendimento na maioria das modalidades. As vantagens no uso das técnicas antropométricas são: significativa relação das medidas an tropométricas com a densidade corporal, obtidas através dos métodos laboratoriais; uso de equipamentos de baixo custo financeiro e a necessidade de pequeno espaço físico; a facilidade e a rapidez na coleta de dados; a não invasividade do método. As modalidades esportivas é uma das intervenções mais propícias para melhoras do desenvolvimento motor e cognitivo de crianças e adolescentes, além de responder positivamente ao perfil antropométrico e cardiovascular destes indivíduos.

Objetivo:analisar os dados antropométricos e cardiovasculares de um grupo de crianças e adolescentes praticantes da modalidade futsal.

Materiais e métodos: Participaram do estudo 13 crianças (10 \pm 1 anos; 42,15 $\pm 11,34 \mathrm{Kg} ; 1,44 \pm 0,07 \mathrm{~m})$ integrantes do projeto de escolinha de futsal do Instituto Master de Ensino Presidente Antônio Carlos (IMEPAC), na cidade de Araguari/MG. Foi efetuada coleta de Pressão Arterial (PA) de repouso com o aparelho esfigmomanometro P.A.MED devidamente calibrado, com os indivíduos na posição sentada, em um ambiente calmo e com 15 minutos de repouso para mensuração da pressão arterial sistólica (PAS) e pressão arterial diastólica (PAD). Os dados antropométricos de peso e altura foram calculados por uma balança digital e estadiômetro, respectivamente. 0 índice de massa corporal (IMC) foi calculado pelas medidas de peso e estatura, de acordo com o IMC = peso $(\mathrm{kg}) /$ altura $^{2}(\mathrm{~cm})$. Os dados foram calculados no programa Excel, e descritos em média e desvio padrão.

Resultados:Obtivemos um valor de 20,31 \pm 4,32 de IMC e uma resposta hemodinâmica de $108 \pm 11$ de PAS e $78 \pm 4$ de PAD. Os valores de IMC para esta faixa etária indicam um valor de sobrepeso de acordo com as Diretrizes Brasileiras de Obesidade Infantil. Já os níveis de pressão arterial encontram-se com os valores normais de acordo com a Sociedade Brasileira de Cardiologia.

Conclusão: Concluímos nossa pesquisa pelos dados coletados que o grupo não apresenta fatores de riscos cardiovasculares pelas suas respostas hemodinâmicas. Porém, deve-se ressaltar que o IMC da maioria não se enquadra com padrão ideal indicando que o futsal é uma boa alternativa para o sistema cardiovascular e que necessita de uma intervenção aditiva como o controle nutricional para alterações no perfil antropométrico.

PALAVRAS-CHAVE: ATIVIDADE FÍSICA, ANTROPOMETRIA, PRESSÃO ARTERIAL, ESPORTE, CRIANÇA. 


\title{
ANÁLISE DO PROGRAMA SAÚDE NA ESCOLA EM ARAGUARI- MG
}

\author{
JOICE SOARES CAMPOS, LÍVIA MARQUES DE OLIVEIRA, MARISLENE PULSENA DA CUNHA NUNES, \\ MICHELLE SANTOS PEIXOTO RODRIGUES, MURILO FRANCO RODRIGUES, LUANA THOMAZETTO \\ ROSSATO
}

NASF-AB/ SECRETARIA MUNICIPAL DE SAÚDE DE ARAGUARI

joicepsicoufu@yahoo.com.br

Apresentação de Pôster

Resumo

Área do Conhecimento: Saúde coletiva e bem-estar

Introdução: O Programa Saúde na Escola (PSE) foi instituído em 2007, sendo uma política pública intersetorial entre o Ministério da Saúde e o Ministério da Educação. Neste programa, as escolas estaduais e municipais da educação pública básica do país são contempladas com temas prioritários, os quais englobam ações de prevenção, promoção e avaliação das condições de saúde dos educandos. Além disso, o PSE tem o intuito de realizar uma mobilização comunitária, envolvendo escola, saúde, estudante e sociedade, objetivando assim, melhorar as condições de saúde dos educandos e educadores, o que impacta diretamente na aprendizagem.

Objetivo: Analisar a prática e o desenvolvimento do PSE no município de Araguari, Minas Gerais, no biênio 2017-2018.

Metodologia: Trata-se de um estudo observacional e descritivo, de corte transversal, do tipo quantitativo. Os dados foram obtidos por meio do Núcleo Ampliado de Saúde da Família e Atenção Básica do município de Araguari-MG, o qual é responsável pela realização das ações do PSE no município. O PSE, no biênio avaliado, disponibilizou doze temas, sendo que, no mínimo, dois deveriam ser trabalhados em cada escola. Dentre estes dois temas, um deles, obrigatoriamente deveria ser ações de combate ao mosquito Aedes aegypti. Além disso, foram pactuadas 20 escolas a serem contempladas pelo programa.

Resultados: No biênio 2017-2018 foram contempladas as 20 escolas do município que foram pactuadas (prioritárias e não prioritárias), incluindo escolas municipais de educação infantil, centros educacionais municipais e escolas estaduais. A faixa etária dos alunos variou de 0 a 18 anos. No total, 5454 alunos foram contemplados pelo programa. Em todas as escolas foram trabalhados três temas dentre os doze recomendados pelo PSE, sendo eles: ações de combate ao mosquito Aedes aegypti; promoção da segurança alimentar e nutricional e da alimentação saudável e combate à obesidade infantil; e promoção das práticas corporais, da atividade física e do lazer nas escolas.

Conclusão: Diante do exposto, verifica-se que o PSE no biênio 2017-2018 alcançou 100\% da meta determinada pelo programa. Assim, destaca-se a importância do desenvolvimento destas ações de promoção e prevenção no âmbito municipal, o qual contribui com saúde dos educandos, educadores, bem como de toda a comunidade adscrita da área de abrangência deste programa.

PALAVRAS-CHAVE: EDUCAÇÃO; SAÚDE; POLÍTICAS PÚBLICAS. 


\title{
ANÁLISE EPIDEMIOLÓGICA DA INCIDÊNCIA DE DENGUE NO MUNICÍPIO DE ARAGUARI-MG
}

\author{
BRUNA APARECIDA DOS SANTOS TONETO, LANO DE SOUSA MOREIRA, ABEL DIB RAYASHI
}

INSTITUTO MASTER DE ENSINO PRESIDENTE ANTÔNIO CARLOS - IMEPAC

brunatoneto@yahoo.com.br

Comunicação Oral

\section{Resumo}

Área do Conhecimento: Saúde coletiva e bem-estar

A dengue é um crescente problema de saúde pública no mundo, principalmente devido a sua virulência e morbimortalidade, com acometimento neurológico, articular e hemorrágico. Até março de 2019 foram registrados 229.064 casos prováveis de dengue no Brasil. No estado de Minas Gerais, até abril de 2019, foram 140.754 casos, sendo 1.735 casos no município de Araguari.

OBJETIVOS

Avaliar a incidência de dengue no município de Araguari-MG.

\section{METODOLOGIA}

Trata-se de um estudo descritivo, retrospectivo e com abordagem quantitativa. A coleta de dados foi realizada através de consulta documental no Datasus e no Boletim Epidemiológico de Minas Gerais. Foram incluídos na pesquisa os casos prováveis de dengue registrados no município de Araguari-MG no período de janeiro de 2016 a abril de 2019. Os dados foram tabulados no software Microsoft Excel@ e passaram por tratamento estatístico descritivo, sendo calculadas a incidência, frequência e percentuais de casos de dengue durante o período avaliado.

\section{RESULTADOS}

No período de janeiro de 2016 a abril de 2019 foram notificados 3248 casos prováveis de dengue no município de Araguari-MG. Desses, 53\% foram registrados em 2019 (n=1735) e 43\% em 2016 (n=1429), os demais anos envolvidos na pesquisa obtiveram um percentual de $4 \%$ dos casos notificados. A incidência da doença no ano de 2016 foi de 1229 casos/100.000 habitantes e de janeiro a abril de 2019 foi de 1486 casos/100.000 habitantes. 0 período de janeiro a julho foi o que apresentou maior número de notificações em todos os anos.

A análise dos resultados mostrou alta incidência de casos de dengue no município de Araguari-MG nos anos de 2016 e 2019, predominantemente durante os primeiros semestres. 0 aumento expressivo dos casos nesses anos relaciona-se, provavelmente, ao aumento da circulação de novos sorotipos do vírus da dengue, sendo em 2019 o sorotipo 2. De janeiro a abril de 2019, a incidência de casos prováveis de dengue na região Sudeste foi de 170,8 casos/100.000 habitantes, enquanto no município de Araguari foi de 1.486 casos/100.000 habitantes.

CONCLUSÃO

Observou-se alta taxa de incidência de dengue no município de Araguari, sendo classificado como de alto risco epidemiológico para a doença. Isso pode estar relacionado à carência de políticas de prevenção efetivas e continuadas, bem como ao compromisso civil da população. Logo, evidencia-se a necessidade de intervenções precoces e de amplo espectro que abordem vários setores da sociedade, de forma incisiva e continuada para o combate efetivo e integral ao vetor. Dessa forma, será possível diminuir o número de casos novos de dengue e prevenir as complicações e óbitos decorrentes da doença.

PALAVRAS-CHAVE: DENGUE; INCIDÊNCIA; PREVENÇÃO DE DOENÇAS. 


\title{
ANÁLISE MICROBIOLÓGICA DOS CELULARES DE ACADÊMICOS DO CURSO DE MEDICINA EM UMA INSTITUIÇÃO DE ENSINO PRIVADA
}

\author{
CIBELLE CRISTINA PAMPLONA LEAL, ANA RAQUEL FERREIRA BORGES, FELIPE DE OLIVEIRA \\ VITORINO, ISADORA MAIRA RODRIGUES DE OLIVEIRA, MARLON REIS ALCÂNTARA, MARIA \\ CLÁUDIA CÂNDIDA RODRIGUES
}

INSTITUTO MASTER DE ENSINO PRESIDENTE ANTÔNIO CARLOS - IMEPAC

cibellepamplona@hotmail.com

Comunicação Oral

Resumo

Área do Conhecimento: Saúde coletiva e bem-estar

Introdução: A importância dos aparelhos celulares, hoje em dia, é inquestionável para a população mundial, principalmente pela facilidade de acesso às informações e à sua praticidade. No entanto, ele também pode ser veículo de transmissão de infecções causadas por bactérias, vírus, entre outros microrganismos. Assim, a forma como são utilizados, pode favorecer essa transmissão, como no contato do aparelho com a boca e pelo empréstimo a outras pessoas. Desse modo, tratando-se de estudantes de medicina, que mantém contato direto com o ambiente ambulatorial e hospitalar, há grande chance de contaminação dos telefones e de propagação de infecções.

Objetivo: Realizar análise microbiológica dos telefones celulares dos acadêmicos do $1^{\circ}$ ao $8^{\circ}$ períodos do curso de medicina do Instituto Master de Ensino Presidente Antônio Carlos (IMEPAC) e em posse dos resultados promover ações de educação em saúde.

Metodologia: Trata-se de um estudo transversal de cunho exploratório referente à população de estudantes do 1a ao 8o períodos matriculados no curso de Medicina do IMEPAC. A amostragem foi do tipo proporcional estratificada por período, sendo os voluntários escolhidos de maneira aleatória. 0 tamanho mínimo amostral foi calculado por meio da equação de Cochran, considerando-se um nível de confiança de 95\% e uma precisão de 5\%. Com isso, obteve-se uma amostra de 190 acadêmicos. Utilizou-se como instrumento de coleta o swab da parte anterior e posterior do celular dos voluntários, após assinatura do Termo de Consentimento Livre e Esclarecido. Em seguida o material foi transportado para o laboratório de microbiologia da instituição, onde se realizou a análise. Em cumprimento com o Conselho Nacional de Saúde, este trabalho foi submetido ao Comitê^ de Ética em Pesquisa local.

Resultados: Dos 190 alunos analisados, até então, 90 tiveram celulares com amostras positivas para

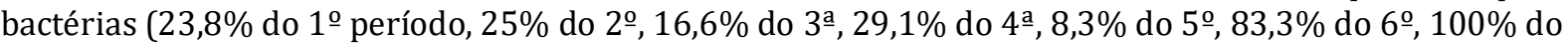
7 o e $100 \%$ do $8^{\circ}$ ). Das amostras, 64 foram positivas apenas no ágar manitol, propício para o crescimento de bactérias Gram-positivas como Staphylococcus aureus, Staphylococcus epidermidis e Bacillus subtillis; 04 apenas no ágar macconkey, meio de cultura destinado ao crescimento de bactérias gram-negativas como Enterobacteriaceae e Pseudomonas aeruginosa, e 22 amostras foram positivas nos dois tipos de ágares.

Conclusão: Os resultados prévios do estudo mostram que nos períodos inferiores, a porcentagem de contaminação dos celulares foi menor se comparada aos períodos do ciclo clínico. Isso é esperado, pois no ciclo clínico os estudantes possuem uma maior vivência em hospitais. Portanto, para evitar a propagação de doenças, é fundamental que os estudantes de medicina sejam incentivados, por todo o curso, a promoverem uma higienização adequada das mãos e celulares, a fim de diminuir a propagação de infecções.

PALAVRAS-CHAVE: ESTUDANTES DE MEDICINA; ANÁLISE MICROBIOLÓGICA; TELEFONE CELULAR. 


\title{
ANTIMICROBIANOS MAIS DISPENSADOS EM ESTABELECIMENTOS DE SAÚDE NO MUNICÍPIO DE ESTRELA DO SUL-MG
}

\author{
VINÍCIUS PÁDUA MARQUES, GEOVANNA KARLA NUNES FONTES, GUSTAVO SANTIAGO \\ RODRIGUES RESENDE, LETÍCIA YUMI DA SILVA OLIVEIRA, LUCAS DE PINHO SILVA, YURI CARDOSO \\ CLAUDOMIRO, RITA ALESSANDRA CARDOSO
}

INSTITUTO MASTER DE ENSINO PRESIDENTE ANTÔNIO CARLOS - IMEPAC

vinipaduam@gmail.com

Apresentação de Pôster

Resumo

Área do Conhecimento: Saúde coletiva e bem-estar

\begin{abstract}
Introdução: As bactérias são parte integral e inseparável da vida na terra, são encontradas em todos os lugares, revestem a pele, as mucosas e cobrem o trato intestinal humanos, sendo a maioria delas inofensivas. Algumas são benéficas para seu hospedeiro e provêm nutrientes ou proteção contra patógenos e doenças, outras são extremamente nocivas, podendo causar doenças infecciosas que sem tratamento podem ser fatais. Vários medicamentos, chamados antimicrobianos, atuam na eliminação desses microrganismos.

Objetivo: 0 objetivo dessa pesquisa foi analisar os principais antimicrobianos dispensados em estabelecimentos de saúde com assistência farmacêutica no município de Estrela do Sul - MG.

Metodologia: Foi aplicado um questionário aos farmacêuticos responsáveis pelos estabelecimentos de saúde, em que foi perguntado "quais os três antibióticos mais dispensados no estabelecimento, sua concentração e forma farmacêutica". A aplicação do questionário foi realizada por um grupo de alunos como parte das atividades das disciplinas de Farmacologia Clínica e Projeto Integrador em Assistência Farmacêutica. Foram visitadas a Unidade Mista de Saúde e a Farmácia Básica Municipal, situadas na cidade de Estrela do Sul e três drogarias, sendo duas na cidade de Estrela do Sul e uma no distrito de Dolearina. Resultados: Em uma das drogarias, os três antibióticos mais dispensados são Amoxicilina, comprimido de $500 \mathrm{mg}$; Cefalexina, comprimido de $500 \mathrm{mg}$ e Azitromicina, comprimido de $500 \mathrm{mg}$. Na segunda drogaria, a Amoxicilina, comprimido de $500 \mathrm{mg}$, também é o antimicrobiano mais dispensado, seguido pela Azitromicina, comprimido de $500 \mathrm{mg}$ e Amoxicilina + clavulanato de potássio, comprimido de $500 \mathrm{mg}+125 \mathrm{mg}$. Na terceira drogaria, os três mais dispensados são Azitromicina, comprimido de $500 \mathrm{mg}$; Amoxicilina, comprimido de $500 \mathrm{mg}$; Amoxicilina + clavulanato de potássio, comprimido de $500 \mathrm{mg}+125 \mathrm{mg}$. Já na Farmácia Básica Municipal, os antibióticos mais dispensados são a Amoxicilina, comprimido de 500mg e Cefalexina, comprimido de $500 \mathrm{mg}$. Na Unidade Mista de Saúde, os antibióticos mais utilizados são Ceftriaxona de 1g, suspensão injetável e Benzilpenicilina benzatina, suspensão injetável 1.200.000UI.

Conclusão: Praticamente os mesmos antimicrobianos são relatados pelos farmacêuticos como os de maior dispensação em drogarias e na Farmácia Municipal, devido ao fato da cidade de Estrela do Sul contar com uma pequena população, os problemas de saúde provavelmente variam menos que em grandes cidades, além disso, a população geralmente é atendida pelos mesmos médicos na atenção básica, favorecendo um padrão de prescrição mais homogêneo. Já na Unidade Mista de Saúde, por se tratar de atendimento em nível hospitalar, prevaleceram prescrições de antimicrobianos na forma injetável.
\end{abstract}

PALAVRAS-CHAVE: BACTÉRIAS; ESTABELECIMENTOS DE SAÚDE; ANTIMICROBIANOS. 


\title{
AS DIFICULDADES ENVOLVIDAS NO PROCESSO DE APRENDIZAGEM DA EQUIPE DE ENFERMAGEM EM UM HOSPITAL DO TRIÂNGULO MINEIRO
}

\author{
JOÃO PAULO OLIVEIRA BRITO, BRUNO FREITAS DA SILVA, DINAMAR CARNEIRO FONSECA, LANA \\ ROBERTA REZENDE NAVES SOUTO, LÚCIA VALÉRIA SILVÉRIO DA COSTA, LÚCIA VALÉRIA SILVÉRIO \\ DA COSTA, VANIA CRISTINA MARTINS DA SILVA, ANA LUCIA COSTA E SILVA E IVANA MELO
}

INSTITUTO MASTER DE ENSINO PRESIDENTE ANTÔNIO CARLOS - IMEPAC

joao.oliveira2007@hotmail.com

Apresentação de Pôster

Resumo

Área do Conhecimento: Saúde coletiva e bem-estar

Introdução: a comunicação é um processo de aprendizagem desenvolvida a partir da interação entre os colaboradores, assumindo uma postura ética de acordo com a missão institucional, não apenas como um prestador de serviços de saúde, mas, sim como um processo de humanização. Durante as observações, percebemos indícios de dificuldades de aprendizagem dos funcionários no processo comunicacional. Nesse sentido, esta pesquisa teve como objetivo analisar os processos de aprendizagem e comunicação no contexto hospitalar. Essa escolha se justifica pelo fato de ser um tema relevante para o bom trabalho em equipe. Metodologia: Conduziram-se entrevistas e ouvidoria com os colaboradores envolvidos na instituição. Os temas relacionados com os métodos relativos ao aprender, foram observados no intuito de correlacionar o aprendizado, suas estruturas, desenvolvimentos e estímulos. Embasados por uma teorização, o projeto inicial foi exposto, analisado e, depois dos levantamentos dos dados, hipóteses de soluções foram apresentadas. Relato da Experiência: foi identificado como proposta de desenvolvimento do trabalho do grupo a questão do "Tratamento Humanizado no Serviço Hospitalar". Contudo, frente às situações encontradas: descontinuidade de projetos, baixo engajamento dos colaboradores, falta de comunicação entre os diversos níveis e entre os profissionais envolvidos na gestão, problemas na operacionalização dos atendimentos, falta de alinhamento das reais diretrizes em termos dos objetivos da instituição no que tange a qualidade do atendimento $\mathrm{x}$ destinação de recursos e de mão de obra para a implementação de ações na execução desses objetivos, compreendeu-se que o foco do trabalho seria "as dificuldades envolvidas no processo de aprendizagem da equipe de enfermagem em um hospital da cidade de Araguari". Resultados: Observou-se a necessidade de estabelecer níveis de gerenciamento entre as funções e o comportamento humanizado, construindo uma aprendizagem hospitalar harmônica. Considerações Finais: Mesmo sem efetuar todas as ações propostas nas hipóteses de solução do problema, podemos concluir com base nos levantamentos realizados, que esse projeto ampliou nossa compreensão sobre a importância do processo de aprendizagem comunicacional, assim como no desenvolvimento e integração de equipe e processos de uma instituição da área hospitalar.

PALAVRAS-CHAVE: HUMANIZAÇÃO, APRENDIZAGEM, COMUNICAÇÃO. 


\title{
AS IMPLICAÇÕES DO NÚCLEO FAMILIAR NO DIREITO DE FAMÍLIA.
}

\author{
LARYSSA LAMARTINE SILVA SOARES, EDUARDO ALVES RESENDE, RODRIGO GUILHERME TOMAZ
}

INSTITUTO MASTER DE ENSINO PRESIDENTE ANTÔNIO CARLOS - IMEPAC

laryssalamartiness@gmail.com

Apresentação de Pôster

Resumo

Área do Conhecimento: Sustentabilidade e Direitos

O presente estudo tratará da forma em que o núcleo e o direito de família evoluiu através do tempo, sendo ressaltado a importância positiva ou negativa de tal evolução.

Quanto ao objetivo do estudo, este se faz na necessidade de que o meio social tem em entender o núcleo familiar e o direito de família a ele atrelado, uma vez que é sabido que a família é o pilar da sociedade através dos séculos, pois nela os indivíduos se deparam com os primeiros valores sociais.

Para alcançar os resultados esperados com o presente estudo, será realizada uma pesquisa usando o método dedutivo, partindo da premissa do geral para o particular, desta forma encontrando a conclusão adequada para a problemática supra.

A família é desde os primórdios da humanidade, o primeiro meio social que o indivíduo se insere, sendo nele, o local para a obtenção da maioria dos valores que este terá.

No passado a imagem que caracterizava a família era basicamente a de um pai, uma mãe e seus filhos, sendo que, o pai era o provedor do sustento de toda a família e a mãe a pessoa incumbida de cuidar da família. Porém este núcleo sofreu forte alteração, principalmente pelo fato de a mulher perquirir vários direitos através do tempo, uma vez que na história, já tivemos momentos em que a mulher simplesmente não tinha a escolha de trabalhar ou cuidar da família, pois era imposto à ela somente os cuidados com os filhos, com a casa e com o marido.

Já nos dias atuais, a mulher busca cada vez mais uma maior equiparação com os homens, ou seja, neste sentido a mudança exercida no núcleo familiar foi arrebatadora, tendo o direito de família que se adequar aos novos tempo e apesar de a igualdade entre homem e mulher, pai e mãe, ainda estar longe da ideal, a igualdade reconhecida até o presente momento trouxe nuances interessantes ao direito de família.

Temos hoje vários modelos de família, tais modelos são derivados do princípio da dignidade da pessoa humana. Hoje este princípio se faz tutelado na nossa Carta magna no art. $1^{\circ}$, III.

Percebe-se que o núcleo familiar antes rígido com as figuras bem determinadas, não seria mais o mesmo, sendo que, todos tem o arbítrio de fazer o que se bem entende, eis que surge na sociedade contemporânea alguns conceitos de famílias como o conceito anaparental, conceito monoparental, conceito de família recomposta e até mesmo um conceito de família unipessoal, cada um destes conceitos possuem perspectivas e peculiaridades únicas, que de fato são inerentes da mudança social através do espaço tempo. Todas as alterações no núcleo familiar apesar de causarem certa estranheza a pessoas mais conservadoras do patriarcado ancestral, são de muita valia para a ordem social, sendo que tal ordem que está em constante evolução para acompanhar os anseios sociais, e que por sorte o núcleo familiar tem acompanhado esta evolução, levando consigo o direito de família à ele atrelado.

PALAVRAS-CHAVE: DIREITO;FAMÍLIA;EVOLUÇÃO. 


\title{
ASSÉDIO SEXUAL E MORAL CONTRA A MULHER NO AMBIENTE DO TRABALHO
}

\author{
AMANDA BARBOSA VENÂNCIO, LARA PERES VIEIRA E SOUSA, RODRIGO GUILHERME TOMAZ
}

INSTITUTO MASTER DE ENSINO PRESIDENTE ANTÔNIO CARLOS - IMEPAC

amandabvenancioo@gmail.com

Apresentação de Pôster

Resumo

Área do Conhecimento: Sustentabilidade e Direitos

Introdução: 0 presente estudo trará o conceito de assédio sexual e moral no ambiente de trabalho, bem como, demonstrar os motivos que levaram uma pessoa a praticar tal ato e apresentar as consequências que essa prática afeta na vítima.

Objetivo: 0 objetivo a ser alcançado refere-se a tentativa de demonstrar como é grave o assédio moral e sexual, considerando que ocasiona transtornos físicos, morais e psicológicos para as vítimas, afetando tanto a atuação no trabalho como relações entre pessoas e no ambiente familiar.

Método: Para a obtenção do resultado pretendido na presente pesquisa, será adotado o método dedutivo. Este método refere-se a um processo de estudo de informações que nos orienta a uma conclusão.

Resultados: 0 assédio moral, qualifica-se pela intenção destinada de menosprezar a vítima. É um processo que tem como objetivo inferiorizar a pessoa que apresenta uma ameaça para o agressor. 0 assédio moral pode ocorrer: por recusa por parte da vítima em ser controlada, inveja da competência da vítima no trabalho por parte do agressor, ou simplesmente pela personalidade do agressor. A agressão acontece com ações que indicam que a liberdade sexual da vítima é moeda de troca para ela ser promovida, ou seja, passar a possui um cargo melhor do que aquele que ela já possui ou sua permanência no emprego. Questiona-se se isso resulta de algum problema psicológico. 0 artigo 223-G da CLT traz como será aplicada a indenização caso o juízo julgue procedente o seu pedido e vemos que é fixado de acordo com o salário da ofendida, podese concluir então que, na maioria das vezes, o agressor irá preferir aquelas que possuem os salários mais baixos para assediá-las. É importante destacar que não pode-se definir o que é assédio apenas pela visão do assediador ou da pessoa assediada, devemos também levar em consideração a cultura daquele local, pois, se em alguns lugares um determinado ato é assédio, em outros pode ser uma coisa normal. 0 assédio gera consequências físicas e psicológicas às vítimas, que interfere não só na vida pessoal, mas também no dia a dia do ambiente de trabalho. Desta forma, as consequências emocionais são mais graves, visto que, os sintomas são de difícil percepção ao meio externo, e que sem o devido tratamento o conjunto de indícios pode gerar uma doença mais grave.

Conclusão: Conclui-se que no tocante ao assédio moral e sexual, percebe-se que não ocorre apenas agressões físicas mas também, palavras agressivas, que podem levar a vítima a sérios problemas psicológicos. Outro fator relevante é que na maioria dos casos, a mulher tem medo ou até mesmo vergonha de denunciar o assediador. Desse modo, seria vantajoso para empresa implantar projetos que incentivassem as vítimas a denunciarem o assédio, como também, punir os agressores, pois, em muitas situações, por haver uma diferença hierárquica entre assediador e assediada, o caso é ignorado. 


\title{
ATENDIMENTO, UMA CULTURA DE JUSTIÇA PARA QUEM BUSCA PELAS FORMAS CONSENSUAIS DE SOLUÇÕES DE CONFLITOS.
}

\author{
ADRIANA AGUIAR ANDRADE, CÉLIA DA CUNHA PEIXOTO, DONNER QUEIROZ
}

INSTITUTO MASTER DE ENSINO PRESIDENTE ANTÔNIO CARLOS - IMEPAC

a3eteles@hotmail.com

Apresentação de Pôster

Resumo

Área do Conhecimento: Sustentabilidade e Direitos

ATENDIMENTO, uma cultura de Justiça para quem busca pelas formas consensuais de soluções de conflitos A presente pesquisa considerou o ambiente de prestação de serviços como contexto de nosso estudo. Em se tratando de ambiente, sua atual classificação transborda a especificação de local, pois está inserido tanto em espaço físico como e/ou digital. É na contextualização do ambiente, de prestação de serviços, que avaliamos a interação deste ambiente moderno, com o processo relacionado ao ATENDIMENTO às pessoas. Sendo esses locais acessíveis, para analisarmos as técnicas de atendimento, desenvolvemos então, este texto, afim de estabelecer um elo entre a disponibilização da cultura dos meios consensuais de soluções de conflito e a qualidade atingida na prática da oferta de atendimento pretendida pelos prestadores de serviços.

Ao avaliarmos a influência da Conciliação e da Mediação, em relação à prática dos atendimentos, nos deparamos com processos dialógicos de ampla negociação, disponíveis tanto em ferramentas de plataformas digitais (como no site "reclame aqui"), bem como voltada para a negociação presencial, alicerçadas em gestões que priorizam as relações de alteridade, as quais são condizentes com um propósito de interferência da conciliação e mediação por práticas associadas aos operadores de Direito.

A problemática gira entorno de que possuímos modernos dispositivos legais para dirimir, mediar, conciliar, negociar diante do surgimento de um conflito, mas eles não são amplamente divulgados e eficazes. Desde o Código de Defesa do Consumidor, considerado avançado por muitos doutrinadores, com procedimentos dialógicos para o melhor atendimento, bem como o marco civil da internet, com prioridade no atendimento digital, até o renomado Novo Código de Processo Civil, com positivação das formas consensuais de soluções de conflito em seu art. $3^{\circ}, \S 3$. Diante de tantas nomenclaturas, adicionadas a tantas outras (SAC, OUVIDORIA, PROCONS.) certificadas pela criação de demais órgãos (PLANDEC, SINDEC, SINACON, CEJUSC), confirmamos que a credibilidade, no suporte dado pela prestadora, não é suficiente para dirimir conflitos se, nesses contextos, os treinamentos para o atendimento não se deslocarem para uma perspectiva de acesso à justiça cidadã, na qual as instruções de formas consensuais de resolução de conflitos interfiram, de fato, na atuação de negociar prontamente. Nossos estudos visam ampliar a discussão dos mecanismos de auto composição, de modo a atingir a sua correlação com o atendimento, logo, percebemos que o campo da negociação não é exclusivamente judicial, e sim social. Essa constatação de negociação efetiva (poderíamos dizer até afetiva, pelo princípio da alteridade) pode ser conquistada através das orientações de um protocolo de atendimento, no qual o acesso aos espaços de mediação sejam interligados e direcionados para, no sentido literal: atender às pessoas.

PALAVRAS-CHAVE: ATENDIMENTO; NEGOCIAÇÃO; ACESSO À JUSTIÇA. 


\title{
ATIVIDADES INSALUBRES QUE AFETAM A POPULAÇÃO
}

\author{
KEVIN TERRA SILVÉRIO, ABSAIR EUSTÁQUIO ROCHA SANTOS, GILSON GOMES DO PRADO, LUIZ \\ EDUARDO ALVES DA SILVA, MATHEUS DA SILVA RODRIGUES, WILLIAM CORRÊA, DANIELA \\ ALMEIDA DANTAS
}

INSTITUTO MASTER DE ENSINO PRESIDENTE ANTÔNIO CARLOS - IMEPAC

keviinterra@gmail.com

Apresentação de Pôster

Resumo

Área do Conhecimento: Saúde coletiva e bem-estar

Introdução: A Norma Regulamentadora que trata das atividades e operações insalubres, ou NR 15, traz consigo o anexo XIV, que prevê quais são os tipos de manipulações que trazem risco biológicos à saúde do trabalhador. Esta pesquisa tem como objetivo buscar soluções para os riscos na área da saúde, especificamente ao perigo do vírus contaminantes influenza. Nos dias atuais há o cuidado feito pela vacinação, que é administrada com suas doses embasadas e respaldadas em bases técnicas, científicas e logísticas. Isto é feito sazonalmente, principalmente em época anterior ao inverno, levando em consideração que a proliferação do vírus é mais comum em temperaturas mais frias. Porém não há o cuidado com os profissionais, ou pode-se dizer que não há treinamento correto ainda, fazendo com que estes possam contrair o vírus por contato direto, passar para outras pessoas fora do ambiente de trabalho e ainda por não haver uma abordagem mais rápida, outros pacientes ter contato com aqueles que estão infectados.

Metodologia: Atualmente, na cidade de Araguari, os casos são tratados nas Unidades Básicas de Saúde (UBS), e em casos mais graves os pacientes são orientados a procurar a Unidade de Pronto Atendimento (UPA). E nestes estabelecimentos todos os casos são tratados simultaneamente, fazendo com que seja ainda mais difícil tomar uma atitude no primeiro contato com o paciente, levando ainda em consideração que a população ainda não é bem informada quanto ao tipo de doença que estão lidando, suas for mas de evitar e como discorrer quando sentirem os primeiros sintomas.

Relato da experiência: Em visita a UPA, pode-se notar que profissionais andam sem seus devidos EPI's para tratar de casos como esses, e os acompanhantes e visitantes também tem livre acesso sem qualquer tipo de proteção, sem esterilização antes da entrada para o ambiente hospitalar, podendo assim ainda levar mais contaminantes para aqueles que estão nos leitos e mesmo a proliferação do vírus por meio daqueles que já estão contaminados.

Considerações finais: Primeiramente para que haja uma melhoria é preciso que os profissionais sejam bem orientados, há a necessidade de autoridades que corrijam o comportamento atual destes, de forma que isso torne-se rotina, para os que estão neste ambiente hoje e aqueles que farão parte um dia. Ainda que locais para isolamento ainda se faz necessário, com os recursos atuais é possível ainda evitar que agrave a saúde da população por pequenos erros.

PALAVRAS-CHAVE: INSALUBRIDADE; SAÚDE; INFLUENZA; ISOLAMENTO. 


\title{
ATIVISMO JUDICIAL E DEMOCRACIA
}

\author{
KEILA CRISTINA MARTINS, MAICON MOURA LEMES, ANNY MARIE SANTOS PARREIRA; DONNER \\ RODRIGUES QUEIROZ
}

INSTITUTO MASTER DE ENSINO PRESIDENTE ANTÔNIO CARLOS - IMEPAC

keilacristinamartins@yahoo.com.br

Apresentação de Pôster

Resumo

Área do Conhecimento: Sustentabilidade e Direitos

0 presente estudo traz uma análise acerca do ativismo judicial, tendo em vista a atuação pró-ativa do Supremo Tribunal Federal que vem ocorrendo de forma recorrente no atual cenário brasileiro e gerado diversas controvérsias, em que se questiona a afronta à separação dos poderes versus a proteção de valores e direitos fundamentais.

PROBLEMAS DE PESQUISA

De que maneira tem se posicionado a doutrina e a jurisprudência com relação ao ativismo judicial e quais seus pontos positivos e negativos?

OBJETIVOS

O objetivo do estudo foi analisar o entendimento doutrinário e jurisprudencial a respeito da crescente atuação do Poder Judiciário sobre os demais poderes e se isso pode de alguma forma gerar insegurança jurídica e colocar em risco a democracia brasileira.

MÉTODO

Como método de pesquisa optou-se pelo dedutivo e como metodologia realizou-se pesquisas bibliográficas com análise da Constituição Federal, legislações, doutrinas e jurisprudências.

RESULTADOS ALCANÇADOS

0 ativismo judicial é tema de grande discussão, parte dos operadores do direito entendem que a omissão dos outros poderes dá ao Judiciário o direito de interferir para o benefício da coletividade. O STF como guardião da Constituição pode e deve ter uma participação mais ampla e intensa para concretização dos valores e fins constitucionais, sendo que isso não traz insegurança jurídica e tampouco fere o princípio da separação dos poderes.

Do outro lado, há os que rebatem esse entendimento alegando que os ministros, muitas vezes, atuam além dos poderes que lhe são conferidos pela ordem jurídica, extrapolando suas competências e atuando em demandas que não cabe a eles resolverem. Um exemplo é a ADI no 3510 que trata das pesquisas com célulastronco embrionárias para fins terapêuticos e que foi julgada improcedente pelo STF.

A repercussão em torno do assunto foi imensa, pois se nem a CF/88 prevê o momento em que a vida se inicia, não seria tarefa do STF estabelecer tal momento. Contudo, a Suprema Corte entendeu que antes dos três meses de gestação não existe vida e que ao embrião congelado é inconcebível dar-lhe os mesmos direitos assegurados a pessoa.

0 posicionamento contrário entende ainda que o ativismo judicial ofende direitos e garantias individuais e abre precedentes perigosos, além de gerar incerteza jurídica.

CONCLUSÃO

Depreende-se da pesquisa realizada que o ativismo judicial no Brasil tem gerado muitas polêmicas, sendo sua aplicação justificada, na grande maioria dos casos, pela necessidade de uma atitude mais rígida dos tribunais com o objetivo de fazer valer os valores e preceitos contidos na CF/88.

Mesmo sendo necessário, em situações excepcionais, para a concretização das normas constitucionais, o ativismo deve sempre apontar para os interesses gerais da sociedade e com a observância do princípio da separação de poderes e do Estado Democrático de Direito.

PALAVRAS-CHAVE: ATIVISMO JUDICIAL; DEMOCRACIA; SEPARAÇÃO DOS PODERES. 


\title{
ATOS DE VIOLÊNCIA: ALUNOS CONTRA PROFESSORES NAS ESCOLAS MUNICIPAIS ARAGUARINAS
}

\author{
CAMILA DINIZ BERNARDES, VALERIA DE SOUSA MAMEDE ALVES, GEILSON NUNES
}

INSTITUTO MASTER DE ENSINO PRESIDENTE ANTÔNIO CARLOS - IMEPAC

camiladiniz26@hotmail.com

Apresentação de Pôster

Resumo

Área do Conhecimento: Sustentabilidade e Direitos

Introdução: 0 presente estudo analisará o aumento de violência nas escolas e o efetivo impacto que a agressão contra os professores no ambiente institucional causam para as organizações da sociedade civil em geral. Igualmente, identificará se a ação violenta é desencadeada como resposta a certos estímulos sociais que integram e contribuem com a manifestação da personalidade humana. Nesta acepção, as possibilidades de enfrentamento do problema com a violência escolar, é que o governo planeje de melhor forma as políticas de comunicação organizacional integradas, com órgãos assistenciais e com a participação das famílias de forma continuada nas instituições escolares.

Objetivo: Frente ao exposto, o objetivo deste trabalho foi analisar a influência do fenômeno social em casos de violência contra professores em Escolas Públicas Municipais de Araguari-MG.

Metodologia: Com a finalidade de contribuir para uma melhor compreensão sobre as ações e fatores que estimulam a manifestação de violência escolar e o desentendimento entre alunos e professores e suas consequências, será utilizado o método dedutivo e a pesquisa quali-quantitativa, onde será incluída a pesquisa qualitativa e quantitativa, pois embora sejam diferentes, elas não se excluem.

Resultados: Foi possível observar, três tipos distintos de violência que acontecem nas escolas. Uma delas acontece quando a escola é o local onde acontecem as violências que se originaram fora da escola e deram vazão dentro da instituição. O segundo tipo é a violência contra a escola, materialmente falando (patrimônio) e o terceiro tipo, é a violência da escola onde as vítimas dependem do tipo de relacionamento estabelecido entre professores e alunos. Neste diapasão, as escolas no Brasil tem sido alvo de constantes de violência, quais sejam: violências físicas, emocionais, verbais, contra o patrimônio e diversas outras. E assim, paulatinamente, a escola vai se distanciando desta visão de zona de aprendizado e respeito outrora tão difundidos e reverenciados. Para que as regras sejam exercidas é necessária a administração e algumas restrições. Existem regras impostas que não são praticadas. Mas este é um problema sociocultural que necessita ser sanado, pois há indivíduos que apresentam dificuldades e certa resistência em cumprir normas por não ter tido como base na infância noções de cumprimento de preceitos. Assim, a violência surge como ato de contestação da ordem estabelecida por meios violentos e até banalizados.

Conclusão: A mediação dos conflitos deve se manifestar através do diálogo e não da violência. 0 resultado positivo da ação educativa do professor para a prevenção da violência na escola depende também da qualificação e capacitação para intervir nos comportamentos agressivos e lidar com os conflitos.

PALAVRAS-CHAVE: ATOS DE VIOLÊNCIA; EDUCAÇÃO; ESCOLA. 


\title{
ATUAÇÃO DO ADVOGADO NO INQUÉRITO POLICIAL EM FACE DA LEI 13.245/2016
}

\author{
JORGE LUIZ DA COSTA PEREIRA, FÁBIO RAFAEL DE OLIVEIRA GOMES, GEILSON NUNES
}

INSTITUTO MASTER DE ENSINO PRESIDENTE ANTÔNIO CARLOS - IMEPAC

jorgeldcp@gmail.com

Apresentação de Pôster

Resumo

Área do Conhecimento: Sustentabilidade e Direitos

INTRODUÇÃO: O presente estudo versará sobre atuação do advogado no inquérito policial em face da lei $13.245 / 16$, pois que o assunto provoca polêmica, de modo que este procedimento administrativo é caracterizado como sigiloso. De acordo com o art. 20 do CPP, a autoridade policial (Delegado de Polícia) tem o dever de assegurar o sigilo necessário à elucidação dos fatos.

OBJETIVO: Em relação ao objetivo a ser alcançado, refere-se à busca em demonstrar que a participação do advogado no inquérito policial se faz necessário para resguardar os direitos e garantias do investigado, assim, buscando a verdade real dos fatos referente ao delito ora investigado. Por fim, uma conclusão do que se consignou na pesquisa.

MÉTODO: Adotou-se o método dedutivo, isto é, apresentar argumentos positivos demonstrando a necessidade de autuação do advogado no inquérito policial, por fim, chegando à conclusão. Utiliza-se a metodologia de pesquisas bibliográficas enfocando a lei, a doutrina e a jurisprudência.

RESULTADOS: 0 tema trás críticas no que tange o acesso do advogado no inquérito policial e o dever do Delegado de Polícia que deve garantir o sigilo da investigação. Nasce à dúvida se atuação do advogado na investigação fere o sigilo, pois que à Autoridade Policial não pode negar o acesso sob pena do cometimento do crime de abuso de autoridade. 0 inquérito policial é um procedimento administrativo preliminar, presidido pelo Delegado de Polícia, tem por objetivo apurar as circunstâncias da autoria e materialidade do crime, também tem caráter informativo que visa auxiliar na instauração da ação penal. 0 delegado de polícia, com base no art. 20 do CPP deve garantir o sigilo da investigação. Por outro bordo, considerando a Lei 13.245/16, aliada a súmula 14 do STF, permite a atuação do advogado na peça investigativa, seja de natureza criminal ou administrativa. Todavia, nos autos sujeitos a sigilo e/ou segredo de justiça, deve o advogado apresentar procuração para o exercício dos direitos de acesso aos autos de investigação.

CONCLUSÃO: Considerando os elementos de informações pesquisados, concluímos que é permitido o acesso do advogado no inquérito policial, visando à garantia do direito de defesa do investigado. Sendo que, dentre os princípios que regem este procedimento administrativo não contempla o principio do contraditório e da ampla defesa que são considerados mais importantes do processo penal. Contudo, a participação do advogado no inquérito policial esta limitado pela autoridade policial (Delegado de Polícia) o qual deverá assegurar o sigilo das provas produzidas para as elucidações dos fatos. Todavia, pode deixar de juntar uma peça aos autos para garantir o sigilo das investigações.

PALAVRAS-CHAVE: INQUÉRITO POLICIAL; SIGILO; ACESSO DO ADVOGADO. 


\title{
AVALIAÇÃO DA DEMANDA CLÍNICA SEGUNDO O PROTOCOLO MANCHESTER DA UNIDADE DE PRONTO ATENDIMENTO EM ARAGUARI - MG
}

\author{
VICTOR COSTA MONTEIRO, DÉBORAH HELENA KICHESE SILVA SANTOS, JUAN FILIPE TEIXEIRA \\ NAUE, MANOELINA LOUIZE QUEIROZ DOS SANTOS, PAULA FLEURY JUBÉ LEAL, RAPHAEL DE SOUSA \\ DANTAS AZARIAS, RENATHA MIRANDA CHAVES TELES, ROSÂNIA EMÍLIA RIBEIRO CUNHA
}

INSTITUTO MASTER DE ENSINO PRESIDENTE ANTÔNIO CARLOS - IMEPAC

victormonteirooto@gmail.com

Comunicação Oral

Resumo

Área do Conhecimento: Saúde coletiva e bem-estar

O protocolo de Manchester é uma classificação de risco utilizada de maneira ampla no território brasileiro. Médicos e enfermeiros ingleses que trabalhavam em unidades de pronto atendimento a luz da necessidade de estratificar os pacientes elaboraram tal protocolo a fim de diminuir a mortalidade durante a espera de atendimento (DINIZ, 2014).

Esse protocolo estratifica os pacientes por cores sendo divido em 5: azul, verde, amarelo, laranja e vermelho. Tais cores dividem os pacientes em risco decrescente, sendo que a cor vermelha sugere atendimento imediato por ser considerado de emergência. A cor laranja indica que o tempo de espera deve ser menor do que 10 minutos e se refere a um atendimento de urgência. A cor amarela, assim como o alaranjado, sugere atendimento de urgência, no entanto, em casos que o paciente pode esperar até 60 minutos. A cor verde designa pacientes de pouca urgência cujo tempo de espera pode chegar a 120 minutos. Os classificados com a cor azul sinalizam pacientes não urgentes e o tempo de espera preconizado é de 240 minutos (ANZILIERO, 2016).

A UPA é uma unidade de pronto atendimento que tem a finalidade de atender urgência e emergência sendo, portanto, classificada como uma unidade de média complexidade que tem seu horário de atendimento estendido por 24 horas inclusive aos finais de semana e pontos facultativos. Em teoria, esse tipo de atendimento deveria priorizar pacientes urgentes e emergentes, no entanto, por ter livre acesso adicionado a resolução rápida e efetiva, a população acaba por utilizar esse serviço de maneira indiscriminada afogando o sistema e gerando longas filas de espera (MEGIER, 2017).

Observando essa superlotação e a desinformação da população sobre a real utilização dos serviços que preconizam urgência e emergência optou-se pela realização de um trabalho que levantasse dados sobre a porcentagem de pacientes em cada estratificação de risco e verificar se o papel atribuído a UPA se cumpre em sua totalidade. E com isso, visou-se analisar os dados estatísticos acerca da quantidade de pacientes atendidos e classificados, de acordo com a classificação de risco do protocolo de Manchester, coletados de uma Unidade de Pronto Atendimento da cidade de Araguari - MG. Com o objetivo de verificar se a UPA, que compõe um nível de gestão secundária da saúde pública, apresenta utilização de seus serviços adequadamente pela população, priorizando os atendimentos de urgência e emergência, tendo como referência as respectivas colorações: AMARELO, LARANJA E VERMELHO.

Diante disso, se o serviço é usado inadequadamente, de forma que não priorize os níveis de gravidade prioritários (urgência e emergência), o sistema fica sobrecarregado e há demora nos atendimentos. 0 que causa transtorno, tanto para a população, que muitas vezes desconhece o sistema, quanto para os profissionais de saúde, que precisam solucionar a grande demanda advinda desse uso inadequado.

PALAVRAS-CHAVE: ATENÇÃO SECUNDÁRIA EM SAÚDE; ATENDIMENTO; PRONTO-SOCORRO. 


\title{
AVALIAÇÃO DA EFICÁCIA DO OUTUBRO ROSA EM UMA UNIDADE BÁSICA DE SAÚDE DA FAMÍLIA DE ARAGUARI-MG
}

\author{
JANAYNA GIULIA SOARES DOS REIS, AMANDA FIGUEIREDO REGES, ANA LUISA SILVA ARAÚJO, \\ GRAZIELLA CRISTINA DUTRA FERREIRA, HELENE RIBEIRO, ISADORA ZUPELLI RODRIGUES, ROSÂNIA \\ EMÍLIA RIBEIRO CUNHA
}

INSTITUTO MASTER DE ENSINO PRESIDENTE ANTÔNIO CARLOS - IMEPAC

janaynagiulia94@gmail.com

Comunicação Oral

Resumo

Área do Conhecimento: Saúde coletiva e bem-estar

INTRODUÇÃO: As ações preventivas em saúde definem-se como intervenções orientadas a evitar o surgimento de doenças específicas, reduzindo sua incidência e prevalência nas populações. Hoje, principalmente diante do aumento nos custos assistenciais, chegou-se ao consenso de que a medicina preventiva pode contribuir não apenas para melhorar a qualidade de vida das pessoas como também para controlar despesas desnecessárias com o tratamento de patologias que podem ser prevenidas, diagnósticas e tratadas precocemente. Assim, devido ao alto custo em níveis de atenção secundária e terciária com tratamentos oncológicos relacionados ao colo de útero, esta pesquisa se justifica por evidenciar a importância do rastreio e diagnóstico precoce feitos através do exame preventivo.

OBJETIVO: Comparar a efetividade da companha Outubro Rosa em relação aos demais meses do ano de 2018, tendo como análise a realização de coleta de citopatológico.

METODOLOGIA: Trata-se de um estudo transversal, descritivo, com abordagem quantitativa, de base populacional, retrospectivo e analítico, que visa avaliar a efetividade da campanha do Outubro Rosa no ano de 2018 comparativamente ao número de coletas de Papanicolau nos demais meses do ano. Foram analisados os números de coletas de citopatológico de mulheres entre 25 e 64 anos, de acordo com as recomendações do Ministério da Saúde para rastreio de câncer de colo uterino, assistidas por uma UBSF, na cidade de Araguari, em Minas Gerais, entre os meses de janeiro à dezembro de 2018. A coleta de dados foi feita por meio do acesso aos registros oficiais de uma UBSF, em Araguari-MG e a randomização foi realizada por meio dos softwares Excel.

RESULTADOS: Foram coletados dados de dois cadernos de registro de exames citopatológicos formulados por uma UBSF, na cidade de Araguari,em Minas Gerais, totalizando 504 exames, sendo 134 coletas no mês de outubro (26,58\%), seguido do mês de setembro (2,89\%), junho $(7,14 \%)$; e agosto e novembro (ambos com $5,75 \%)$.

CONCLUSÃO: Conclui-se, portanto, que o Outubro Rosa é uma campanha efetiva quando comparada aos demais meses do ano de 2018, visto que o maior número de coletas de citopatológico realizadas encontrase nesse mês. Ademais, é notório que a campanha otimiza a presença da mulher para a prevenção e detecção do câncer de colo uterino, além de promover a prevenção primária e o conhecimento da população sobre os fatores de risco e importância do diagnóstico precoce.

PALAVRAS-CHAVE: CITOPATOLÓGICO; OUTUBRO ROSA; EXAME PREVENTIVO; CÂNCER DE COLO UTERINO. 


\title{
AVALIAÇÃO DA POTÊNCIA DE MEMBROS SUPERIORES EM ATLETAS DE CATEGORIAS DE BASES DO MANCHA ESPORTE CLUBE NO PERÍODO DE PRÉ-TEMPORADA
}

\author{
CICERO FELIPE DE CALDAS FELIX, ISADORA SILVERIO DE OLIVEIRA, LUCAS MATEUS ALVES DE JESUS, \\ RAFAEL LIMA DA SILVA, HUGO RIBEIRO ZANETTI, DANIELLE FERNANDES ALVES
}

INSTITUTO MASTER DE ENSINO PRESIDENTE ANTÔNIO CARLOS - IMEPAC

caldascicero@gmail.com

Apresentação de Pôster

Resumo

Área do Conhecimento: Saúde coletiva e bem-estar

Introdução: 0 futebol é um dos esportes coletivos mais praticados no Brasil e em todo o mundo, com característica predominantemente aeróbico, sendo que este esporte requer sempre um bom condicionamento físico dos atletas. Torna-se importante verificar as capacidade físicas durante a formação dos atletas, uma vez que, estas compõem a formação integral do atleta. Nas categorias de base existe a necessidade de diversificar o treinamento para ocasionar as devidas adaptações físicas para tal. Objetivo: Avaliar da potência de membros superiores em atletas de categorias de bases do Mancha Esporte Clube no período de pré-temporada. Metodologia: Trata-se de um estudo transversal descritivo realizado com atletas das categorias pré-mirim (10 e 11 anos), mirim (12 e 13 anos), infantil (14 e 15 anos) e juvenil (16 e 17 anos) de base do Mancha Esporte Clube da cidade de Araguari/MG no período de pré-temporada e afim de avaliar a potência de membros superiores utilizou-se o teste de arremesso de medicine ball. Para realizar 0 teste, $\mathrm{o}$ atleta foi orientado ficar sentado com as costas apoiadas em uma cadeira, com as pernas unidas e segurando uma bola de medicine ball de 3 quilogramas junto ao peito e com cotovelos flexionados. Após o avaliador dar o comando de "já", o atleta lançou à bola para a maior distância possível, sendo que foi contado a distância a partir de onde a bola tocou primeiramente o solo. Foram realizadas três tentativas e considerada como válida aquela que percorreu maior distância. Os valores estão expressos em média \pm desvio-padrão. Resultados: Foram avaliados 97 atletas sendo 17 atletas pré-mirim, 38 atletas mirim, 33 atletas infantil e 14 atletas juvenil. A categoria pré-mirim apresentou 2,28 \pm 0,65 metros, a categoria mirim obteve 2,43 \pm 0,24 metros, a categoria infantil realizou 3,01 $\pm 0,55$ metros e a categoria juvenil foi de 3,79 \pm 0,68 metros. Conclusão: Embora os membros superiores não sejam tão utilizados para a prática do futebol, o teste tem uma grande importância na avaliação de goleiros, pelo fato da destreza da potência de membros superiores serem fundamentais para o bom desempenho durante as partidas. Sendo assim prescrever treinamentos específicos para a melhor performance da potência de goleiros durante a prétemporada, tem uma grande importância para o decorrer da temporada. Desta forma, torna-se importante a mensuração da potência, uma vez que, é uma capacidade física treinável.

PALAVRAS-CHAVE: ATLETAS DE FUTEBOL, POTÊNCIA DE MEMBROS SUPERIORES, CATEGORIAS DE BASE. 


\title{
AVALIAÇÃO DA RESISTÊNCIA ABDOMINAL EM ATLETAS DE FUTEBOL DAS CATEGORIAS DE BASE DO MANCHA ESPORTE CLUBEDE ARAGUARI/MG NO PERÍODO DE PRÉ-TEMPORADA
}

\author{
GEOVANA FERNANDES PEREIRA, AMANDA NOGUEIRA DE OLIVEIRA, BRUNA DE FÁTIMA PEREIRA \\ COELHO, HUGO RIBEIRO ZANETTI, DANIELLE FERNANDES ALVES
}

INSTITUTO MASTER DE ENSINO PRESIDENTE ANTÔNIO CARLOS - IMEPAC

geovanapereira14@hotmail.com

Apresentação de Pôster

Resumo

Área do Conhecimento: Saúde coletiva e bem-estar

Introdução: 0 futebol como um esporte complexo, exige do jogador o desenvolvimento de múltiplas capacidades físicas, motoras e psíquicas. Este pode aumentar a força dos músculos abdominais resultando em uma boa movimentação, manutenção da posição ereta da coluna, colabora com os músculos do dorso nos movimentos do tronco e aumenta a eficiência respiratória. Além disso, torna-se importante a avaliação da resistência muscular do jogado o qual pode aumentar e/ou diminuir a performance esportiva.Objetivo: Avaliar a resistência abdominal de atletas de futebol das categorias de base do Mancha Esporte Clube da cidade de Araguari/MG no período de pré-temporada. Metodologia: Trata-se de um estudo transversal descritivo realizado com atletas das categorias pré-mirim (10 e 11 anos), mirim (12 e 13 anos), infantil (14 e 15 anos) e juvenil (16 e 17 anos) de base do Mancha Esporte Clube da cidade de Araguari/MG no período de pré-temporada e afim de avaliar a resistência abdominal foi utilizado o teste de resistência muscular localizada. 0 teste consistiu em realizar a maior quantidade de flexão de tronco em um minuto e, para isso, o atleta foi orientado a estar na posição deitada em decúbito dorsal, joelhos fletidos em 90 graus, planta dos pés tocando no solo, pés fixados no chão e mãos na nuca. Ao comando de "já" do avaliador o atleta realizou a flexão do tronco até encostar os cotovelos nos joelhos, voltando à posição inicial, o máximo de vezes que conseguisse, podendo descansar entre as repetições caso precisasse. Ao final, contou-se a quantidade de repetições realizadas no tempo avaliado. Os valores estão expressos em média \pm desvio-padrão. Resultados: Foram avaliados 97 atletas sendo 17 atletas pré-mirim, 38 atletas mirim, 33 atletas infantil e 14 atletas juvenil. Encontrou-se que os atletas pré-mirim apresentam resistência de 31,8 \pm 5,7 movimentos, os atletas mirim tinham resistência de $29 \pm 7,1$ movimentos, os atletas infantis obtiveram $31,4 \pm 5$ movimentos e os atletas juvenis possuíam 30,7 \pm 6,2 movimentos. Conclusão:A partir do estudo é possível observar o desenvolvimento dos atletas de futebol das categorias de base do Mancha Esporte Clube e, principalmente, avaliar a resistência abdominal dos mesmos. Deste modo, com a obtenção dos dados, pode-se examinar o crescimento do atleta e passar um treinamento específico para determinada habilidade que não esteja de acordo com os parâmetros adequados.

PALAVRAS-CHAVE: RESISTÊNCIA ABDOMINAL,ATLETAS DE FUTEBOL, FORÇA MUSCULAR. 


\title{
AVALIAÇÃO DE AGILIDADE DOS ATLETAS DA CATEGORIAS DE BASES DO MANCHA ESPORTE CLUBE NO PERÍODO DE PRÉ- TEMPORADA
}

\author{
LUCAS MATEUS ALVES DE JESUS, CÍCERO FELIPE DE CALDAS FELIX, ISADORA SILVERIO OLIVEIRA, \\ RAFAEL LIMA DA SILVA, HUGO RIBEIRO ZANETTI, DANIELLE FERNANDES ALVES
}

INSTITUTO MASTER DE ENSINO PRESIDENTE ANTÔNIO CARLOS - IMEPAC

lucas.obig@gmail.com

Apresentação de Pôster

Resumo

Área do Conhecimento: Saúde coletiva e bem-estar

Introdução: Nas categorias de bases os atletas que planejam ter um bom rendimento no futebol necessitam apresentar aprimoramento da agilidade e velocidade que são componentes neuromusculares. A agilidade irá destingir a posição em campo entre outras determinantes como a capacidade de aprendizagem dos fundamentos desse esporte que é tão visado pelos atletas atualmente, e que muitos ficam de fora por limitações nesse quesito que por sinal será testado e após o teste um resultado obtido poderá trazer uma resposta para aqueles que precisam melhorar neste ponto.Objetivo: Avaliar a agilidade de atletas das categorias de base do Mancha Esporte Clube da cidade de Araguari/MG no período de prétemporada.Metodologia: Trata-se de um estudo transversal descritivo realizado com atletas das categorias pré-mirim (10 e 11 anos), mirim (12 e 13 anos), infantil (14 e 15 anos) e juvenil (16 e 17 anos) de base do Mancha Esporte Clube da cidade de Araguari/MG no período de pré-temporada e para avaliar a agilidade foi aplicado o teste de ShuttleRun que consiste no atleta realizar um percurso de ida e volta em um espaço de 9,14 metros. Ao sinal de "já" do avaliador, o atleta foi orientado a sair do local de largada e ir o mais rápido possível até o final do percurso, passar os dois pés pela linha final do percurso, e voltar novamente para linha de largada e repetir novamente o processo. Ao final deste percurso, o avaliador anotou o tempo gasto por cada atleta para realizar o percurso. Os dados estão expressos em média \pm desvio-padrão. Resultado: Foram testados 97 atletas sendo eles 17 atletas pré-mirim, 38 atletas mirim, 33 atletas infantil e 14 atletas juvenil. Em relação aos tempos no teste ShuttleRun, os atletas pré-mirim obtiveram tempo de $11,8 \pm$ 1,37 segundos; os atletas mirim apresentaram tempo de 10,5 \pm 1,68 segundos; os atletas infantil tiveram tempo de 9,90 $\pm 0,85$ segundos e os atletas juvenil tempo de 9,4 $\pm 0,48$ segundos. Conclusão: A partir da metodologia aplicada e dos resultados encontrados, pode-se concluir que o teste de Shuttle Run deve ser aplicado nas categorias de bases afim de servir como parâmetro para prescrição do treinamento adequado para estes atletas das categorias de bases. Além disso, sabe-se que a agilidade é um fator fundamental na prática do futebol e deve ser constantemente avaliado.

PALAVRAS-CHAVE: AGILIDADE, FUTEBOL, ATLETAS. 


\title{
AVALIAÇÃO DE POTÊNCIA DE MEMBROS INFERIORES EM ATLETAS DE CATEGORIAS DE BASES DO MANCHA ESPORTE CLUBE NO PERÍODO DE PRÉ
}

\author{
RAFAEL LIMA DA SILVA, CÍCERO FELIPE DE CALDAS FELIX, ISADORA SILVERIO DE OLIVEIRA, LUCAS \\ MATEUS ALVES DE JESUS, HUGO RIBEIRO ZANETTI, DANIELLE FERNANDES ALVES
}

INSTITUTO MASTER DE ENSINO PRESIDENTE ANTÔNIO CARLOS - IMEPAC

rafaellook_2005@hotmail.com

Apresentação de Pôster

Resumo

Área do Conhecimento: Saúde coletiva e bem-estar

Introdução: 0 futebol é um dos esportes mais praticados mundialmente. Ano após ano, crianças ainda crescem com o sonho de se tornarem jogadores de futebol e, na cidade de Araguari/MG não é diferente. Sabendo disso, existe a necessidade de treinar as capacidades físicas dos atletas das categorias de base, uma vez que, estas são de extrema importância para o desenvolvimento do atletas. Além disso, o futebol exige que os atletas apresentem potência de membros inferiores seja para o ato de chutar e de saltar para cabecear a bola. Objetivo: Avaliar a potência de membros inferiores dos atletas da categoria de base do Mancha Esporte Clube no período de pré-temporada. Metodologia: Trata-se de um estudo transversal descritivo realizado com atletas das categorias pré-mirim (10 e 11 anos), mirim (12 e 13 anos), infantil (14 e 15 anos) e juvenil (16 e 17 anos) de base do Mancha Esporte Clube da cidade de Araguari/MG no período de pré-temporada e, afim de avaliar a potência dos membros inferiores, utilizamos o teste de salto horizontal e salto vertical. 0 primeiro teste consiste em o atleta, partindo de uma linha demarcada, executar um salto para a frente, podendo utilizar o movimento dos braços para aumentar o impulso e o avaliador marcar a distância da linha de salto até a marca deixada pelo calcanhar do atleta. 0 segundo teste consiste no atleta saltar para cima, alcançando a maior altura que conseguir. Todos os atletas realizaram três tentativas em cada teste e a melhor marca foi considerada pelo avaliador como resultado válido. Os dados estão expressos em média \pm desvio-padrão. Resultados: Foram avaliados 97 atletas sendo 17 atletas prémirim, 38 atletas mirim, 33 atletas infantil e 14 atletas juvenil. Em relação ao salto horizontal foi verificado que os atletas pré-mirim tiveram 1,49 $\pm 0,21$ metros; os atletas mirim obtiveram 1,64 $\pm 0,18$ metros; os atletas infantil alcançaram 1,79 $\pm 0,2$ metros e os atletas juvenil possuíram $2 \pm 0,16$ metros. Em relação ao salto vertical, foi encontrado que os atletas pré-mirim tiveram 2,28 $\pm 0,2$ metros; atletas mirim obtiveram $2,40 \pm 0,14$ metros; os atletas infantil alcançaram 2,57 $\pm 0,15$ metros e os atletas juvenil possuíram 2,73 \pm 0,1 metros. Conclusão: Sabendo que pare se praticar futebol existe a necessidade do uso predominante dos membros inferiores, pode-se concluir que, em pré-temporada, o teste dos membros inferiores mostra o quão forte estão os membros inferiores dos atletas, para suportar toda a tensão muscular gerada sobre seus membros, e evitando assim futuras lesões.

PALAVRAS-CHAVE: FUTEBOL, POTENCIA, ATLETAS. 


\title{
AVALIAÇÃO DO CONSUMO MÁXIMO DE OXIGÊNIO EM ATLETAS DE CATEGORIAS DE BASES DO MANCHA ESPORTE CLUBE NO PERÍODO DE PRÉ-TEMPORADA
}

\author{
ISAÍAS JOSÉ FERNANDES, IGOR ALVES GOMES OLIVEIRA , RAFAEL DA SILVA JORGE, HUGO RIBEIRO \\ ZANETTI, DANIELLE FERNANDES ALVES
}

INSTITUTO MASTER DE ENSINO PRESIDENTE ANTÔNIO CARLOS - IMEPAC

isaiasjose7096@gmail.com

Apresentação de Pôster

Resumo

Área do Conhecimento: Saúde coletiva e bem-estar

Introdução: 0 futebol é um dos esportes mais tradicionais e disseminados pelo mundo além de ser um dos mais praticados pela população brasileira. Este esporte caracteriza-se por demandas energéticas intermitentes, sendo a maior parte do tempo suprida pelo metabolismo aeróbico. Um método válido para averiguar a eficiência do metabolismo aeróbico em atletas de futebol consiste no teste do consumo máximo de oxigênio (VO2máx), no qual verifica-se a capacidade do corpo realizar a captação, transporte e utilização do oxigênio para geração de energia. Sabendo dessas informações, é aconselhável a mensuração desta variável em atletas de futebol.Objetivos: Avaliar o V02máx de atletas das categorias de base do Mancha Esporte Clube da cidade de Araguari/MG no período de pré-temporada. Metodologia: Trata-se de um estudo transversal descritivo realizado com atletas das categorias pré-mirim (10 e 11 anos), mirim (12 e 13 anos), infantil (14 e 15 anos) e juvenil (16 e 17 anos) de base do Mancha Esporte Clube da cidade de Araguari/MG no período de pré-temporada. Para mensurar o V02máx foi utilizado o teste de Cooper de 12 minutos, no qual consiste em percorrer a maior distância nos 12 minutos. 0 V02máx foi estimado pela fórmula de Cooper [V02máx = (distância - 504) / 45]. Antes do teste, todos os atletas foram orientados trotar/correr durante o teste e apenas pararem ao final do tempo e, além disso, foram informados do tempo de teste a cada dois minutos. Ao final do teste, os avaliadores calcularam a distância percorrida por ca da atleta. Por se tratar de um estudo descritivo, os valores estão expressos em média \pm desvio-padrão e separados por categorias. Resultados: Foram avaliados 97 atletas sendo 17 atletas pré-mirim, 38 atletas mirim, 33 atletas infantil e 14 atletas juvenil. Foi observado que os atletas pré-mirim apresentam V02máx de 33,6 \pm 9,49 ml.kg.min-1, os atletas mirins de $45 \pm 11,9$ ml.kg.min -1 , os atletas infantis de 45,7 $\pm 12,72$ ml.kg.min-1 e os atletas juvenil de 51,1 $\pm 7,43$ ml.kg.min-1. Conclusão: Sabendo da importância do metabolismo aeróbico para a prática do futebol, conclui-se que, no período de pré-temporada, a mensuração do V02max é importante para a prescrição dos treinamentos físicos e, ademais, verificar os níveis de resistência e condicionamento físico dos atletas.

PALAVRAS-CHAVE: VO2 MÁX, TESTE DE COOPER, ATLETAS DE FUTEBOL. 


\title{
AVALIAÇÃO DO PERFIL ANTIMICROBIANO UTILIZADO EM HOSPITAIS E DROGARIAS
}

\author{
SAMUEL JUSTINO BARBOSA DA CONCEIÇÃO, ARIANA INGRID BARBOSA COSTA, DIOGO DE SOUSA \\ ROSA, KAREN CRISTINA DE OLIVEIRA, MAHARA VIEIRA MIRANDA, MAISA PEREIRA SANTANA, \\ MOISÉS ANDRÉ ALVES, RITA ALESSANDRA CARDOSO
}

INSTITUTO MASTER DE ENSINO PRESIDENTE ANTÔNIO CARLOS - IMEPAC

leumas.conceicao@hotmail.com

Apresentação de Pôster

Resumo

Área do Conhecimento: Responsabilidade, Tecnologia e Ciência

Introdução: Antes do advento dos antimicrobianos, a guerra entre as bactérias e a humanidade era desleal, muitas epidemias assolaram o mundo e dizimaram milhares de pessoas por falta de tratamento e de conhecimento acerca dos organismos patogênicos e mecanismos das doenças. Antimicrobianos são compostos naturais, chamados de antibióticos, sintéticos ou semissintéticos, intitulados quimioterápicos, capazes de inibir o crescimento de bactérias ou matá-las. São classificados como bactericidas, quando causam a morte da bactéria, ou bacteriostáticos, quando promovem a inibição do crescimento microbiano. Os antimicrobianos estão entres os medicamentos de maior importância clínica terapêutica e com maior dispensação tanto em hospitais como em drogarias.

Objetivo: Avaliar as características e a diferença no perfil de antimicrobianos dispensados em hospitais e drogarias na cidade de Araguari.

Metodologia: A pesquisa foi realizada por meio de um questionário de investigação científica aplicado por discentes do Curso de Farmácia aos farmacêuticos responsáveis técnicos por drogarias e hospitais da cidade de Araguari. Esse trabalho está vinculado às disciplinas de Farmacologia Clínica e Projeto Integrador em Assistência Farmacêutica do Curso de Farmácia do Imepac Araguari. 0 questionário levantou as seguintes informações em três hospitais e seis drogarias: tipo de estabelecimento, antimicrobianos mais dispensados, concentração e forma farmacêutica.

Resultados: Com a pesquisa descritiva foi possível observar que existe diferença no perfil de dispensação de antimicrobianos em drogarias e hospitais. Nas drogarias prevalece a dispensação de medicamentos administrados por via oral, provavelmente em decorrência da comodidade e segurança da utilização dessa via. Ao contrário dos hospitais, em que a maioria dos antimicrobianos mais utilizados estão em formas farmacêuticas para administração por via parenteral. A maior prevalência no uso de medicamentos por via intravenosa comparada ao uso dos antimicrobianos por via oral nas unidades hospitalares justifica-se pela dificuldade do uso oral em decorrência de necessidades terapêuticas dos usuários: pacientes com dificuldade de deglutição, inconscientes, com vômitos ou diarreia, necessidade de biodisponibilidade mais rápida, maior ou mais previsível, minimizar possibilidade de interações medicamentosas decorrentes da via de administração ou necessidade de antimicrobianos disponíveis somente para administração parenteral.

Conclusão: Com o estudo foi possível compreender algumas especificidades apresentadas pelo público atendido por cada tipo de estabelecimento de saúde e o impacto sobre a seleção do antimicrobiano e respectiva forma farmacêutica.

PALAVRAS-CHAVE: ANTIMICROBIANOS; DROGARIAS E HOSPITAIS; FORMAS FARMACÊUTICAS. 


\title{
AVALIAÇÃO DO USO DE FIBRAS PARA REFORÇO DE CONCRETOS
}

\author{
RAPHAEL FONSECA DIAS, CRISTIANO EUSTÁQUIO GUIMARÃES , EDUARDO FÉLIX BRAGA ALVES , \\ HENRIQUE FERNANDES DA SILVA,
}

INSTITUTO MASTER DE ENSINO PRESIDENTE ANTÔNIO CARLOS - IMEPAC

raphael.dias@imepac.edu.br

Apresentação de Pôster

Resumo

Área do Conhecimento: Responsabilidade, Tecnologia e Ciência

\begin{abstract}
Introdução: 0 concreto possui uma série de características que lhe garantem o posto de material estrutural mais utilizado no mundo. Entre as principais vantagens, pode-se listar o baixo custo e a capacidade de se adequar a variadas condições de produção, além de possibilitar infinitas variações de forma para as peças moldadas. Apesar disso, o concreto apresenta também várias limitações, como a baixa relação resistência/peso e o fato de ter sua qualidade aferida apenas depois que a peça estrutural foi produzida. No entanto, nos últimos anos, surgiu uma nova possibilidade de reforço do concreto através do uso de fibras. Objetivo: O projeto tem como objetivo avaliar e explorar as vantagens e limitações do uso de fibras como reforço do concreto estrutural.

Metodologia: Trata-se de uma pesquisa qualitativa e exploratória sobre o uso de fibras no reforço de concreto estrutural. Busca-se o entendimento sobre o comportamento das fibras em contato com a matriz de concreto, denominada de interação fibra-matriz. A pesquisa também averiguou os diversos tipos de fibras utilizadas como reforço, tais como as de vidro, naturais e de aço, pontuando as principais características que essas fibras precisam ter, para um bom desempenho do compósito.

Resultados: Observou-se que a interação fibra-matriz é influenciada pelo fator de forma ou de aspecto das fibras (relação entre o comprimento da fibra e seu diâmetro), ancoragem das fibras na matriz, resistência à tração das fibras, resistência da ligação entre as fibras e a matriz, teor de fibras incorporado e o comprimento da fibra embebido na matriz de concreto quando a matriz se encontra fissurada. Uma das características do reforço proporcionado pelas fibras é o fato de estas se distribuírem aleatoriamente no material, reforçando toda a peça, e não uma determinada posição, como ocorre com as armaduras convencionais.

Conclusão: Não há consenso de que o Concreto Reforçado com Fibras (CRF) venha a ser a solução que resolverá todos os problemas de construção de obras de infraestrutura. Na verdade, ainda falta embasamento técnico de muitos especificadores e aplicadores brasileiros, o que é agravado pela carência de referências normativas a respeito do assunto. Esta situação pode ser explicada, em parte, pelo fato de haver poucos pesquisadores brasileiros atuando de maneira sistemática nessa área. Além disso, há uma grande dificuldade de transferência dos resultados de pesquisa para o meio produtivo. Atualmente, a prática de utilização do CRF no Brasil pode ser descrita como uma atividade basicamente empírica, pois é muito frequente a utilização de teores fixos de fibras e a total ausência de procedimentos de controle da qualidade do compósito.

Palavras-chave: Concreto reforçado com fibras; interação fibra-matriz; tecnologia.
\end{abstract}

PALAVRAS-CHAVE: CONCRETO REFORÇADO COM FIBRAS; INTERAÇÃO FIBRA-MATRIZ; TECNOLOGIA. 


\title{
AVALIAÇÃO TÉCNICA DA FABRICAÇÃO DE BLOCOS DE SOLO- CIMENTO NA ONG AÇÃO MORADIA - UBERLÂNDIA -MG
}

\author{
RAPHAEL FONSECA DIAS, FRANCES WILLIAM DA SILVA, ISAAC ELIAS PEIXOTO, LUCAS AMORIM \\ KOZIEVITCH, PEDRO PAULO GREGOL JUNIOR,
}

INSTITUTO MASTER DE ENSINO PRESIDENTE ANTÔNIO CARLOS - IMEPAC

raphael.dias@imepac.edu.br

Apresentação de Pôster

Resumo

Área do Conhecimento: Educação para Desenvolvimento Sustentável

Introdução: Os tijolos de solo-cimento têm grande potencial para utilização em habitações de interesse social. A possibilidade de sua fabricação sem a necessidade de queima e a disponibilidade extensiva de solo favorecem a utilização de mão de obra local, sem experiência, em agrupamentos voluntários ou não, organizando-os em torno de prensas hidráulicas com o objetivo de produzir tijolos para suas próprias casas. Um dos problemas dessa prática é a falta de uniformidade e de qualidade dos tijolos, devido à variação dos solos disponíveis em cada momento, as misturas obtidas e a energia de compactação, dentre outras.

Objetivo: 0 projeto de diagnóstico e avaliação técnica na produção de blocos de solo-cimento tem por objetivo analisar o desenvolvimento atual da fabricação dos mesmos, pela ONG Ação Moradia, e propor procedimentos que promovam melhorias no processo, frente à normalização brasileira.

Metodologia: Inicialmente, foram coletadas informações a respeito do processo de produção na ONG, dos materiais utilizados e sua origem, bem como da mão-de-obra atuante. A fim de confirmar as informações coletadas em campo e verificar o desempenho dos lotes de blocos de solo-cimento, realizaram-se ensaios de determinação da resistência à compressão de amostras coletadas no local de fabricação. Finalizados os ensaios, os resultados obtidos foram utilizados para propor melhorias no sistema de produção, com o objetivo de aumentar a uniformidade dos produtos fabricados e o desempenho adequado dos tijolos.

Resultados: A fábrica de blocos de solo-cimento da Ação Moradia, de acordo com os ensaios realizados no laboratório da Universidade Federal de Uberlândia, atende às indicações normativas. As porcentagens mínimas de areia e argila do solo, bem como, os índices de consistência são adequados para a fabricação. A resistência à compressão e absorção de água dos blocos também foram verificados e atendem as recomendações das normas brasileiras.

Conclusão: Revendo o processo de fabricação, bem como o traço utilizado, realizando treinamento da mão de obra e maior inspeção dos materiais e dos produtos, a Ação Moradia poderá, com certeza, aperfeiçoar e otimizar a produção, não somente aumentando o lucro, mas visando a qualidade dos blocos e ajudando as famílias carentes por ela atendidas. Sugere-se como estudos posteriores a realização do ensaio de durabilidade por molhagem e secagem e a adição de resíduos da construção civil, como granito e cerâmica, na fabricação dos blocos. 0 processo de cura da fábrica também precisa ser estudado. Recomenda-se fazer a cura dos blocos, parte do lote no laboratório e outra parte na própria fábrica para comparação dos resultados obtidos.

Palavras-chave: Solo-cimento; fabricação de tijolos; controle de qualidade.

PALAVRAS-CHAVE: SOLO-CIMENTO; FABRICAÇÃO DE TIJOLOS; CONTROLE DE QUALIDADE. 


\title{
BEM-ESTAR ANIMAL: UM CONCEITO CONHECIDO E APLICADO OU AINDA MERAMENTE SUPERFICIAL?
}

\author{
GABRIELY LOURENÇO LEITE DE SOUSA, FERNANDA SOUSA ALEIXO, RAFAEL QUIRINO MOREIRA
}

INSTITUTO MASTER DE ENSINO PRESIDENTE ANTÔNIO CARLOS - IMEPAC

gaby.lourencols@hotmail.com

Comunicação Oral

Resumo

Área do Conhecimento: Saúde coletiva e bem-estar

Introdução: O bem-estar animal refere-se a um indivíduo em um completo estado de saúde física e mental, variando em uma escala de muito bom a muito ruim. Para mensurá-lo existem as cinco liberdades (nutricional, sanitária, comportamental, psicológica e ambiental).

Objetivo: Verificar o nível de conhecimento das pessoas sobre o bem-estar animal.

Metodologia: Desenvolveu-se a pesquisa em Araguari, com auxílio de 75 questionários com 16 perguntas (sim ou não) sendo apenas discursiva a número quatro. Considerou-se dois grupos: 40 estudantes de medicina veterinária (2ํㅜ $3^{\circ}$, 6ํㅜ e 7ํㅜ períodos) do IMEPAC e 35 não estudantes, com questões sobre bemestar, cinco liberdades, prática da eutanásia, cirurgias estéticas em animais, legislação de crimes ambientais (Lei no 9.605/1998 que proíbe maus tratos aos animais incluindo cirurgias estéticas), enriquecimento ambiental, abate humanitário, bem-estar de animais de produção e sua interferência na qualidade de alimentos de origem animal, utilização de animais em experimentação científica, alta densidade de frangos, debicagem (corte de bico necessário para minimizar conflitos entre as aves) e utilização de gaiolas para poedeiras.

Resultados: Do total de 40 entrevistados, estudantes de medicina veterinária, obteve-se como resultados positivos todos conhecerem sobre bem-estar (100\%), concordarem com a eutanásia em casos de sofrimento extremo do animal (discursiva), discordarem de cirurgias estéticas (92,5\%), conhecerem sobre abate humanitário $(72,5 \%)$ e interferência do bem-estar animal em alimentos (100\%). Como pontos negativos desconhecerem a alta densidade $(72,5 \%)$, se oporem à debicagem $(65 \%)$ e desconhecerem a legislação de crimes ambientais (52,5\%).

Dos não estudantes, obteve-se como bons resultados a maioria conhecer sobre bem-estar $(68,5 \%)$, aprovarem eutanásia em casos de doenças incuráveis (discursiva), discordarem de cirurgias estéticas (83\%), aplicarem bem-estar aos animais de produção (97\%) e entenderem que este altera a qualidade dos alimentos de origem animal $(85,7 \%)$, concordarem com o uso de animais em experimentos científicos $(51,5 \%)$ e discordarem do uso de gaiolas (83\%). Como negativos desconhecerem as cinco liberdades $(88,5 \%)$, legislação de crimes ambientais (80\%), enriquecimento ambiental (63\%), abate humanitário $(74,3 \%)$, densidade de frangos $(77,2 \%)$ e discordarem da debicagem $(80 \%)$.

Conclusão: Os estudantes de medicina veterinária possuem boa percepção sobre bem-estar, exceto nas questões de avicultura, todavia eles ainda não cursaram tal disciplina. Para os não estudantes, poderiam ser feitas divulgações do assunto, visto que a maioria não sabia sobre bem-estar. Ambos os grupos desconheciam a legislação de crimes ambientais.

PALAVRAS-CHAVE: BEM-ESTAR ANIMAL; ENRIQUECIMENTO AMBIENTAL; EXPERIMENTO CIENTÍFICO. 


\title{
CASOS BRUMADINHO E MARIANA: PERSPECTIVA LEGALISTA AO BEM JURÍDICO AMBIENTAL PENALMENTE TUTELADO.
}

\author{
EDMAR MORAIS DE OLIVEIRA, JEOVANE VIEIRA JÚNIOR, LUCAS VINÍCIUS DE SOUSA, OSMAR \\ PEIXOTO MENDES JÚNIOR, GEILSON NUNES
}

INSTITUTO MASTER DE ENSINO PRESIDENTE ANTÔNIO CARLOS - IMEPAC

edmar_mdo@hotmail.com

Comunicação Oral

Resumo

Área do Conhecimento: Sustentabilidade e Direitos

Introdução: Os desastres nas mineradoras VALE em Brumadinho e SAMARCO em Mariana, cidades em Minas Gerais, configuram as piores tragédias ambientais no cenário pátrio. Objetivo: Sendo assim, objetivase elucidar à luz do Ordenamento Jurídico brasileiro, os aspectos inerentes às sanções penais, quando da aferição do injusto penal.

Metodologia: 0 presente estudo sucedeu-se por meio de referencial teórico, em pesquisas concernentes ao Direito Penal Ambiental. Pôde-se também, minuciar a evolução legislativa do ordenamento jurídico Pátrio, a doutrina especializada e a jurisprudência atualizada, quanto a responsabilização das pessoas jurídicas, dadas as condutas lesivas ao meio ambiente.

Resultados: Precedente a análise nacionalista, deve-se considerar a Declaração de Estocolmo sobre o Meio Ambiente Humano, resultante da Conferência das Nações Unidas de 1972, como o gênesis para uma legislação ambiental, por apresentar princípios para um desenvolvimento econômico não predatório, que vise a preservação dos recursos naturais, sobretudo os não renováveis. No Brasil, publicou-se em 1981 a Política Nacional do Meio Ambiente, Lei n.ำ 6.938, implementando e estabelecendo políticas e objetivos para o Direito Ambiental. Ressalta-se que anterior a sua edição, a legislação guardava pouca preocupação com a preservação, a exemplo, o Código de Caça, Lei n.o 5.197/67. Posteriormente recepcionada pela Constituição de 1988, diploma por meio do qual se conferiu no artigo 225 especial relevância ao meio ambiente e inovou ao prever a responsabilidade penal e administrativa, ademais da cível à pessoa jurídica. Em 1998, a Lei n.o 9.605 dispôs quanto as sanções penais e administrativas às pessoas jurídicas, derivadas de condutas e atividades lesivas ao meio ambiente. O Decreto n. $3.179 / 99$, foi revogado pelo Decreto n. $0.514 / 08$ que disciplina quanto as infrações e sanções administrativas, ocorre que, por escopo, buscava regulamentar a

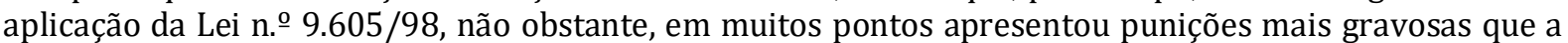
própria lei em regulamentação, sendo então, alterado e acrescido pelo Decreto n.o 6.686/08. Mister destacar que permanecem vigentes tanto o decreto, quanto a lei, incidindo em relação à mesma conduta. Conclusão: Conclui-se que, o Brasil possui uma apropriada legislação ambiental, compondo um sólido arcabouço legal, todavia, demasiado esparso. Demanda-se assim, sua unificação, de modo a descomplexificar sua aplicação e uma melhor atuação dos entes administrativos, que por meio de uma antecedente fiscalização, em observância a ampla defesa, e quando necessário, atuem na punição. Dessa forma, delega-se ao Direito Penal, o cumprimento de seu papel, qual seja, a aplicação das sanções penais existentes em uma atuação repressiva, como ultima ratio e, na prevenção geral negativa, de modo a se evitar situações, tais quais, as ocorridas em Brumadinho e Mariana/MG.

PALAVRAS-CHAVE: BRUMADINHO E MARIANA; DIREITO PENAL AMBIENTAL; RESPONSABILIDADE JURÍDICA. 


\section{CLASSIFICAÇÃO DE CUSTOS QUANTO À VARIEDADE (FIXOS E VARIÁVEIS)}

VICTOR LUCIO DA SILVA SILVANO, NIKE ANDERSON DA SILVA SILVANO, CAIRO HENRIQUE BORGES

INSTITUTO MASTER DE ENSINO PRESIDENTE ANTÔNIO CARLOS - IMEPAC

victorluciosilvasilvano@gmail.com

Comunicação Oral

Resumo

Área do Conhecimento: Responsabilidade e Negócios

Segundo Roberto et al (2018), atualmente as empresas passam por um momento de muita competitividade e para se manterem no mercado lançam mão de estratégias que consiga alinhar o ambiente interno com o ambiente externo, a fim de se tornarem flexíveis para entenderem e se adaptar às mudanças do mercado. Uma empresa precisa ser capaz de se atualizar, buscando a otimização de seus recursos físicos, humanos e tecnológicos, para ter participação eficiente no mercado e vencer a concorrência.

Há a necessidade de formatar preços que sejam competitivos e que tragam lucro para a organização, necessitando assim de uma boa gestão de custos, que seja capaz de minimizar todos ou a grande maioria dos custos envolvidos nos processos da atividade da empresa e maximizar os resultados.

A gestão de custos se torna importante por se tornar a responsável por medir, controlar e produzir informações gerenciais para a tomada de decisão.

Para Martins (2010) na medida em que a empresa cresce a gestão de custos passa a ser cada vez mais requisitada, pois auxilia no controle e gera informações aos gestores para que se tornem conhecidos os gastos da empresa e decida de forma eficaz estratégias para maximizar o desempenho da empresa.

As informações geradas identificam os gastos de acordo com cada produto e se tornam fáceis de mensurar se é viável ou não produzir certos produtos dentro do mix de um segmento industrial.

Martins (2010) ainda afirma que é crucial saber o gasto real por produto, para saber se um determinado produto é rentável ou não rentável para o resultado global da empresa.

A complexidade da análise de custo requer um bom gerenciamento de custos, para Bornia (2010), o aumento nas atividades das empresas e o alto nível de complexidade no sistema produtivo notaram que as informações fornecidas pela gestão de custos são extremamente úteis ao auxílio gerencial, ajudando a gerência de duas maneiras, no auxílio ao controle e à tomada de decisão.

A gestão é importante para que se tenha mensurado os custos de forma correta, e assim poder criar um planejamento a partir da base de dados das informações levantadas, e realizar ações para que possam aperfeiçoar os possíveis gargalos, para a eficácia deste gerenciamento se faz necessário à presença de profissionais capacitados, para que façam a mensuração de forma correta e principalmente, interprete os dados e tome as decisões de forma precisa.

Como o mercado não para de impor melhorias contínuas nas empresas, torna-se um requisito indispensável nas organizações os indicadores que auxiliem na tomada de decisão.

Reconhecendo a importância do principal indicador, que é a análise de custo, e a influência que a mesma tem quando é bem feita, entende-se o porquê ele está presente em quase todas as organizações.

PALAVRAS-CHAVE: GESTÃO DE CUSTOS, CUSTOS FIXOS, CUSTOS VARIÁVEIS. 


\title{
COLORINDO A APRENDIZAGEM NOS DIVERSOS ESPAÇOS DA EDUCAÇÃO ESCOLAR: RE-SIGNIFICANDO A SALA DE AULA
}

\author{
OSÉIAS CARNEIRO AMORIM, JOSIELE MOREIRA CÂNDIDO, ANA LÚCIA COSTA E SILVA E MARIA \\ TERESA DE BEAUMONT
}

INSTITUTO MASTER DE ENSINO PRESIDENTE ANTÔNIO CARLOS - IMEPAC

oseiaspedagogo03@gmail.com

Apresentação de Pôster

Resumo

Área do Conhecimento: Educação para Desenvolvimento Sustentável

\begin{abstract}
Introdução: Como melhorar o espaço de sala de aula, para que os alunos percebam o ambiente mais interessante e aconchegante? A partir dessa indagação desenvolveu-se esse projeto, corroborando com Marquezan et al. (2003) que afirma que o ambiente escolar se apresenta como um espaço multicultural e de múltiplos saberes, que tem como finalidade favorecer a socialização entre educandos e proporcionar uma aprendizagem significativa. Deparamo-nos, em nosso local de observação, com salas de aula que não estimulavam a aprendizagem, inclusive por falta de manutenção adequada e uso de materiais de ensino que não faziam com que o olhar do aluno fosse voltado para o interesse em aprender e se desenvolver. Objetivo: melhorar o ambiente de aprendizagem, usando a sala de aula; para o desenvolvimento da educação, além de apresentar formas do professor trazer para esse ambiente a ludicidade, visando aulas dinâmicas, aprendizagem significativa e que acima de tudo o aluno seja indivíduo ativo em todo o processo. Metodologia: realizamos as observações e concluímos que há salas de aulas com aspectos que não proporcionam, aos alunos, um olhar curioso, ludicidade necessária para inseri-los em sua aprendizagem e autonomia. Salas com paredes sujas, sem porta, carteiras muito rabiscadas, armários de utilização da classe e professor desmotivado; faltam cores alegres que ajudem no desenvolvimento dessas crianças. Usamos um questionário com 5 perguntas para alunos e professores da escola acerca do ambiente da sala de aula e preparamos materiais para utilização na execução do projeto. A partir das respostas re cebidas, foi mais fácil orientarmo-nos sobre como auxiliar alunos e colaboradores da escola. Relato da Experiência: 0 grupo começou a dar forma ao projeto, colocando em prática e dando forma aos materiais que pretendiam utilizar. Iniciou-se a pintura em pneus com as crianças, orçamentos de materiais, preparo dos materiais que íamos usar na sala referência, verificação dos valores de tintas, nichos, armário, quadro branco, buscar patrocínio e pintura nos caixotes. Chegar nessa fase de começar a experimentar aquilo que desejamos no projeto, deu mais ânimo, nos colocou mais envolvidos e conseguimos dar forma aos nossos sonhos. Resultados: A professora apoiou e achou de grande importância a iniciativa desse projeto, concordando que a melhoria do ambiente despertou nos alunos mais interesse às aulas, melhor aprendizagem e desenvolvimento deles. Tivemos para a sala de aula nova pintura, a porta, o quadro e os painéis elaborados em EVA. Falamos sobre a importância da manutenção e zelo constante do ambiente, com os alunos, e sobre a conscientização das outras turmas em ajudar a manter a sala limpa e agradável para todos que a utilizam. Considerações Finais: Esperamos que essa sala sirva de referência para as outras turmas, e que algum grupo se interesse pelo trabalho iniciado, dando continuidade ao que já teve o pontapé inicial.

PALAVRAS-CHAVE: OBSERVAÇÃO; APRENDIZAGEM, SALA DE AULA, FORMAÇÃO.
\end{abstract}




\title{
COMO DESENVOLVER A PERSONALIDADE HUMANA DE CRIANÇAS INSERIDAS EM MEIO AMBIENTE INSALUBRE
}

\author{
RAFAELA DOS ANJOS RIBEIRO
}

UNIVERSIDADE FEDERAL DO PARANÁ

rafaelaanjosr@gmail.com

Comunicação Oral

Resumo

Área do Conhecimento: Agenda 2030 e os Objetivos de Desenvolvimento Sustentável

Introdução: Em nível mundial, o índice de morte de crianças atribuídas ao ambiente é bastante elevado, isso resulta da falta de saneamento básico, da poluição atmosférica, além das ameaças ambientais emergentes acometidas pelo lixo eletrônico, dentre outros fatores. Esse impacto proporciona reflexões com relação à formação da personalidade humana infantil, considerando àquelas que vivem em regiões ambientais poluídas. Logo, como seria possível desenvolver na criança que vive em meio ambiente insalubre a sua personalidade em prol de torná-la uma cidadã consciente? Sabe-se que o direito ao meio ambiente ecologicamente equilibrado é um direito de todos, previsto na Carta Magna em seu artigo 225, entretanto é uma realidade distante para algumas pessoas em especial, crianças que sofrem consequências irreversíveis. Objetivo: Apresentar como é possível desenvolver a personalidade humana de crianças que vivem em meio ambiente insalubre. Metodologia: Foi utilizado o método dedutivo baseado nos estudos bibliográficos das Leis Sistêmicas de Bert Hellinger, bem como a Teoria dos Sistemas, A Improbabilidade da Comunicação e a Comunicação Ecológica de Niklas Luhmann. Resultados: A comunicação é o elo entre os seres humanos, elemento diferenciador de nossa espécie, tendo como base a consciência, essas se complementam. A teoria luhmanniana da comunicação, aborda sobre a autopoiesis, como um sistema de estruturas e produção de componentes, assim o pensamento do autor Niklas Luhmann é eficaz para a compreensão e contribuição da proposta temática, prevendo como resultado que as mudanças internas da personalidade da criança deve ser conscientizada por meio da comunicação, de modo a assegurar a sua sobrevivência no meio em que habita, para o alcance do seu direito ao desenvolvimento sustentável. A comunicação intersistêmica é importante, pois gera efeitos capacitantes com relação a própria existência do sistema, ou seja, a improbabilidade transita para a probabilidade da comunicação. Como complementação da formação da personalidade da criança, o trabalho desenvolvido pelo psicoterapeuta Bert Hellinger, traz um importante olhar e pensamento na Lei da Hierarquia/Ordem, a qual diz que "aqueles que primeiro veio tem precedência sobre os demais", no entanto isso permeia a importância da conscientização de que a criança é parte integrante do meio ambiente, quando ampliada a sua consciência nesse aspecto, facilita-se a compreensão e a comunicação para a sua formação enquanto um ser humano consciente. Conclusão: Isto posto, o desenvolvimento da personalidade humana da criança dar-se-á por meio da comunicação educativa, de modo a criar formas adaptativas para a superação das dificuldades de viver em ambientes insalubres, ensinando que a sua sobrevivência é parte de um processo que deve ser harmonizado e conscientizado, afinal a criança é parte da própria natureza em sua diversidade e universalidade.

PALAVRAS-CHAVE: CRIANÇA. COMUNICAÇÃO ECOLÓGICA. CONSTELAÇÕES FAMILIARES. TEORIAS SISTÊMICAS. 


\title{
COMO OS COMPULSORES PODEM AUXILIAR NA APRENDIZAGEM POR MEIO DOS TREINAMENTOS ORGANIZACIONAIS
}

\author{
FERNANDA BERALDO BARBOSA, DANILO FARIA DE MOURA
}

FACULDADE PITÁGORAS DE UBERLÂNDIA

beraldo.fernanda@gmail.com

Comunicação Oral

Resumo

Área do Conhecimento: Responsabilidade e Negócios

Introdução: 0 desenvolvimento de pessoas passa por grandes transformações. Quando o foco é ensinar adultos, muitas vezes a ação de transmitir conhecimento se esbarra em resistências pessoais e paradigmas difíceis de serem quebrados. Um cenário desafiador para profissionais de talentos humanos que buscam, em suma, aperfeiçoar o indivíduo para que ele gere resultados para si mesmo e para as corporações. Duas descobertas do mundo moderno são a chave para abrir a porta dessas mentes e ressignificar a forma de aprender e ensinar: a primeira diz respeito ao conhecimento da personalidade de cada indivíduo, por meio da teoria Análise Transacional; a segunda é a metodologia 6 D’s (As 6 Disciplinas que transformam a educação) uma grande revolução no ensino de adultos.

Objetivo: A pesquisa deseja comprovar que os treinamentos podem ser personalizados. Por meio de testes é possível detectar o Compulsor de cada indivíduo e traçar a personalidade do mesmo e também sua curva de aprendizagem. Somando a essa descoberta a metodologia 6Ds é possível criar e aplicar treinamentos que tragam retornos rápidos e financeiramente mais sustentáveis para as organizações.

Metodologia: Trata-se de uma pesquisa qualitativa, que faz uso de duas importantes teorias, uma referente ao conhecimento da personalidade de cada indivíduo, denominada teoria Análise Transacional (Berne, 1985), em que é possível detectar, com testes individuais, os cinco traços de personalidades, denominados Compulsores: Seja Perfeito, Seja Forte, Seja Apressado, Seja Esforçado e Seja Agradável. A segunda é a metodologia 6 D’s (As 6 Disciplinas que transformam a educação), elas englobam um completo processo, que abrange desde a forma de comunicação com as pessoas à adequação do ambiente corporativo, onde essas pessoas estão inseridas.

Resultado: Treinar pessoas as levará à diferentes níveis de conhecimento, mas também de atuação. Grande parte dos conteúdos programáticos dos treinamentos procuram mudar atitudes conservadoras por atitudes inovadoras, que poderão melhorar o trabalho em equipe e desperta a criatividade dos indivíduos. Aliar a metodologia 6D's aos traços de personalidade, que considera o conhecimento empírico de cada pessoa levará os treinamentos a novos patamares.

Conclusão: 0 treinamento é um esforço contínuo desenhado para melhorar a atividade das pessoas e, consequentemente, o desempenho organizacional. A Metodologia 6D's, contempla uma man eira prática de ensinar adultos, visto que contempla a vivência de cada pessoa. Somado a esse entendimento os cinco traços de personalidades, denominados Compulsores, tornam-se um instrumento valioso na construção e elaboração dos treinamentos. É como ensinar com a ciência de como o indivíduo conseguirá aprender. Os ganhos serão reais e palpável.

PALAVRAS-CHAVE: COMPULSORES; TREINAMENTOS; EDUCAÇÃO; PERSONALIDADE; APRENDIZAGEM. 


\title{
COMPARAÇÃO DAS CAPACIDADES FÍSICAS ENTRE ATLETAS DE DIFERENTES CATEGORIAS DO MANCHA ESPORTE CLUBE NO PERÍODO DE PRÉ-TEMPORADA
}

\author{
IGOR ALVES GOMES OLIVEIRA, ISAÍAS JOSÉ FERNANDES, RAFAEL DA SILVA JORGE, DANIELLE \\ FERNANDES ALVES, HUGO RIBEIRO ZANETTI
}

INSTITUTO MASTER DE ENSINO PRESIDENTE ANTÔNIO CARLOS - IMEPAC

igoralves1910@hotmail.com

Apresentação de Pôster

\section{Resumo}

Área do Conhecimento: Saúde coletiva e bem-estar

\begin{abstract}
Introdução: 0 futebol é um dos esportes mais acompanhados do mundo e o mais popular no Brasil, com sua origem milenar e registros antigos do seu surgimento. Por ser um esporte com predominância aeróbica e de característica coletiva, possui uma demanda energética alta. Existe alguns testes para mensurar como se encontra os atletas em relação a parte física como por exemplo o teste de capacidade aeróbica máxima (V02máx), agilidade, resistência abdominal (RA), potência de membros superiores (PMMSS) e flexibilidade de tornozelo (FT). Objetivo: Comparar as capacidades físicas entre atletas de diferentes categorias do Mancha Esporte Clube da cidade de Araguari/MG no período de pré-temporada. Métodos: Trata-se de um estudo transversal realizado com atletas das categorias pré-mirim (10 e 11 anos), mirim (12 e 13 anos), infantil (14 e 15 anos) e juvenil (16 e 17 anos) de base do Mancha Esporte Clube da cidade de Araguari/MG no período de pré-temporada. Para mensurar o V02máx foi utilizado o teste de Cooper, a agilidade foi mensurada pelo teste de Shuttle Run, a RA foi verificado pelo teste de resistência muscular localizada, PMMSS foi realizado com o teste de arremesso de medicine ball e a flexibilidade foi analisada pelo teste de sentar e alcançar. A normalidade dos dados foi verificada pelo teste de Shapiro-Wilk e, posteriormente, foi utilizado o teste de análise de variância (ANOVA) de uma entrada para verificar diferenças entre as categorias, tendo nível de significância quando p<0,05. Resultados: Foram avaliados 97 atletas sendo 17 atletas pré-mirim, 38 atletas mirim, 33 atletas infantil e 14 atletas juvenil. Observou-se que a categoria prémirim apresentou menor V02máx comparado às categorias infantil $(p=0,02)$ e juvenil $(p=0,003)$. Encontrou-se que a categoria pré-mirim apresentou menor agilidade comparada às demais $(p<0,001) \mathrm{e}$, além disso, a categoria mirim apresentou diferença comparado à juvenil $(p=0,04)$. Foi encontrado que as categorias pré-mirim e mirim apresentaram diferença em relação às categorias infantil e juvenil $(p<0,01)$ e, ademais, a categoria juvenil foi significativamente diferente da categoria infantil $(p<0,001)$. Em relação ao FT encontrou-se que a categoria mirim foi diferente da categoria juvenil $(\mathrm{p}=0,02)$. Não houve diferença da RA. Conclusão: Conclui-se que as capacidades físicas são diferentes entre as categorias, podendo ser explicado, principalmente pela idade e desenvolvimento biológico dos atletas.

PALAVRAS-CHAVE: CAPACIDADE FÍSICA, FUTEBOL, ATLETAS.
\end{abstract}




\title{
CONCILIAÇÃO E MEDIAÇÃO NO NOVO CÓDIGO DE PROCESSO CIVIL
}

\author{
ANA VITÓRIA PINTO DE PAULA, LETÍCIA VIERA QUEIROZ,
}

INSTITUTO MASTER DE ENSINO PRESIDENTE ANTÔNIO CARLOS - IMEPAC

anavitoria2605@hotmail.com

Apresentação de Pôster

Resumo

Área do Conhecimento: Sustentabilidade e Direitos

INTRODUÇÃO: O presente estudo tratará da Conciliação e Mediação como forma de solução de conflitos nas ações relacionadas ao Direito de Família, o que levou o legislador a prever um procedimento especial nas ações de família, e como essa previsão ocorre na prática. Desse modo, procurará demonstrar o que é essa forma de solucionar litígios, bem como analisar os efeitos positivos e negativos diante dos princípios do Direito de Família.

PROBLEMA DA PESQUISA: Considerando que a Conciliação e a Mediação fazem parte de um novo procedimento para se tramitar o processo concernente às ações de família, o problema desta pesquisa é: De que forma a Conciliação e Mediação podem facilitar a resolução das ações de família, tanto do ponto de vista do princípio da celeridade quanto das questões psicossociais que envolvem os litígios familiares?

OBJETIVO: Quanto ao objetivo a ser alcançado, refere-se à tentativa de demonstrar o quão é importante tratar de forma diferenciada e harmônica os litígios de cunho familiar, haja vista ser uma entidade de grande importância, considerada pela Constituição Federal como base da sociedade, de forma que essas lides possam ser resolvidas da melhor forma possível e proporcionando a preservação dos laços que ainda possam ser mantidos.

MÉTODO: Para a obtenção dos resultados almejados na presente pesquisa será adotado o método dedutivo, a partir de argumentos gerais para argumentos particulares, de forma a alcançar os resultados propostos na problemática em tela e, por conseguinte, uma conclusão do que se consignou na pesquisa.

RESULTADOS ALCANÇADOS: De acordo com o Código de Processo Civil as ações de divórcio, separação, reconhecimento e extinção da união estável, pedido de guarda, visitação e filiação, todos quando não houver consenso entre as partes envolvidas. Tanto a conciliação quanto a mediação se baseiam no princípio da autonomia da vontade. A mediação ocorre quando há vinculo anterior entre as partes, onde é oferecido um ambiente e oportunidade adequados para se chegar a uma solução, que geralmente decorre de uma relação continuada. Já na conciliação, ocorre quando as relações são ocasionais, de modo que, o conciliador atuará como um terceiro desinteressado que objetiva a aproximação dos interesses em jogo, desempenhando um papel de facilitador, para que ambas as partes saiam satisfeitas, com a concessão e benefício de todos os polos.

CONCLUSÃO: Conclui-se então que foi uma mudança inovadora a trazida pelo Código de Processo Civil e que somente agregou pontos positivos, o fato de serem obrigatórias as audiências de mediação e conciliação nas ações de família. Vale ressaltar que não é obrigatório se chegar a solução do conflito, de modo que, persistindo, o processo poderá seguir seu curso na forma contenciosa, e a partir daí passa a seguir todo o procedimento de praxe.

PALAVRAS-CHAVE: DIREITO; FAMILIA; CIVIL. 


\title{
CONHECIMENTO DO HIPERTENSO SOBRE A DOENÇA:ADESÃO AO TRATAMENTO E IMPACTOS
}

\author{
THAYS BENTO DOS SANTOS, AMANDA NAVES NUNES, ANA LUISA SIROTHEAU CORRÊA ALVES, \\ CAROLINY GONZAGA MARQUES, MARIANE RESENDE DAVID, MARINA RODRIGUES DE ARAUJO \\ AVILA, NATHÁLIA TEIXEIRA SOUSA E BRAGANTI, THAIS HELENA PARO NEME, HERBERT CRISTIAN \\ DE SOUZA
}

INSTITUTO MASTER DE ENSINO PRESIDENTE ANTÔNIO CARLOS - IMEPAC

bento_thays@yahoo.com

Comunicação Oral

Resumo

Área do Conhecimento: Saúde coletiva e bem-estar

Introdução: A Hipertensão Arterial Sistêmica (HAS) é uma doença crônica, que requer muitos cuidados de seus portadores, como mudanças no estilo de vida, adesão aos medicamentos, hábitos alimentares, atividades e físicas, dentre outros. 0 conhecimento sobre a doença é um importante fator no seguimento terapêutico e este deve ser avaliado pelos profissionais de saúde para a condução do cuidado. Visando mensurar o conhecimento de adultos

sobre hipertensão arterial, aplicou-se o questionário ENCHAS em idosos hipertensos do programa Araguari Ativa.

Objetivo: Avaliar o conhecimento sobre hipertensão de idosos hipertensos atendidos pelo programa Araguari Ativa por meio d o a Versão brasileira da Escala de Nível de Conhecimento sobre Hipertensão Arterial Sistêmica (ENCHAS)

Revisão da literatura: A adesão ao tratamento e o conhecimento dos portadores de hipertensão arterial mostraram-se reduzidos, sendo essa baixa adesão relacionada à complexidade da esquematização de dosagem medicamentosa, aos efeitos colaterais dos fármacos e à incompreensão da doença. Por se tratar de uma patologia silenciosa e progressiva, há a necessidade de terapêutica anti-hipertensiva, além da mudança de hábitos dos indivíduos, sobretudo dos etilistas, obesos, sedentários e tabagistas. Tais transformações potencializam a prevenção de consequências em longo prazo, como lesão de órgãos -alvo, e a redução da mortalidade.

Metodologia: A presente investigação trata-se de um estudo transversal, onde foi aplicada a Versão brasileira do ENCHAS ( 6 domínios, com pontuação total de 22 pontos) e um questionário sócidemográfico (com informações sobre, sexo, idade, nível de instrução, tempo de diagnóstico de HAS, renda, ocupação laboral e estado conjugal) em portadores de HAS presentes durante uma das sessões de atividades físicas orientadas no programa Araguari Ativa, após a assinatura do TCLE. A Análise dos dados foi feita pela estatística descritiva (mediana, percentis), após o teste de normalidade se Shapiro-Wilk indicar que os dados não apresentam, distribuição normal. A confiabilidade da consistência interna foi feita pelo alfa de Cronbach e o nível de significância foi de $\mathrm{P}<0,05$.

Resultados: Até o momento foram coletados 9 protocolos e a idade média dos sujeitos foi de 68 anos (p25 $=55,00$ e p75=71,50) predominância do sexo feminino 8,00 $(88,90 \%)$ e com nível de estudos mais frequente ensino fundamental incompleto $4,00(44,40 \%)$, aposentados $6,00(66,70 \%)$, casados ou em união estável 7,00 (77,80\%) com renda entre 2 a 4 salários mínimos 7,00 (77,80\%). A confiabilidade do ENCHAS variou entre 0,48 á 0,66 em seus domínios. Nos 6 domínios do ENCHAS os resultados tiveram mais de 50\% de acertos e a mediana do escore total foi de $19,00(\mathrm{p} 25=14,00$ e p75=21,00).

Conclusão: Conclui-se que o ENCHAs foi confiável e evidenciou que os pacientes atendidos pelo programa Araguari Ativa têm bons conhecimentos sobre a HAS.

PALAVRAS-CHAVE: HIPERTENSÃO; CONHECIMENTO; DOENTE. 


\title{
CONSCIENTIZAÇÃO SOBRE A IMPORTÂNCIA DA RECICLAGEM EM UMA POPULAÇÃO CARENTE DE ARAGUARI- MG
}

\author{
KAROLLYNE FRANCISCO PRADO, BARBARA MOURA MEDEIROS , BARBARA OLIVEIRA RODRIGUES \\ DO NASCIMENTO, DEBORA ALVES SICARI, GABRIELA PEREIRA BATISTA, MARCUS JAPIASSU \\ MENDONÇA ROCHA, MELISSA MARIANE DOS REIS
}

INSTITUTO MASTER DE ENSINO PRESIDENTE ANTÔNIO CARLOS - IMEPAC

karollyneprado@hotmail.com

Apresentação de Pôster

Resumo

Área do Conhecimento: Educação para Desenvolvimento Sustentável

INTRODUÇÃO: Lixo é tudo aquilo não tem utilidade e é jogado fora. Muitos dos resíduos que vão para ele podem ser destinados à reciclagem, em que lixos orgânicos e inorgânicos são reaproveitados, reduzindo a agressão ao meio ambiente. Diante disso, a reciclagem do lixo é importante e deve ser incentivada. Dessa forma, objetivando-se analisar como é feito o descarte de lixo em bairros carentes de Araguari - Minas gerais (MG), foi realizada uma pesquisa com a população do bairro São Sebastião. Após análise dos dados obtidos pode-se intervir por meio da conscientização sobre a importância da reciclagem nessa população.

METODOLOGIA: 0 estudo fundamentou-se na metodologia da problematização baseada no Arco de Maguerez. Iniciou-se com a observação da realidade e o levantamento dos pontos chaves, sobre o descarte de lixo no Bairro São Sebastião na cidade de Araguari. Em seguida, foram realizadas 51 visitas domiciliares, com aplicação de questionário confeccionado pelos próprios pesquisadores, contendo perguntas sobre como é feito o descarte de lixo. Além disso, foi entregue e assinado por todos os participantes um termo de consentimento livre e esclarecido, respeitando a privacidade por meio da coleta individual de dados, com o direito de desistir a qualquer momento da participação do estudo. Depois da análise dos dados, a intervenção foi realizada em uma creche, no mesmo bairro, a fim de ensinar as crianças a realizar a separação e descarte correto dos resíduos sólidos. Esta etapa também foi autorizada pelos pais, que assinaram o termo de consentimento livre e esclarecido em 2 vias.

RELATO DE EXPERIENCIA: A partir da observação da grande quantidade de lixo espalhados pelas ruas, foi levantada a questão do descarte seletivo. E com isso, realizamos visitas domiciliares e percebemos uma grande desinformação a respeito do assunto. Os dados obtidos evidenciaram que a maioria dos resíduos são descartados por meio da coleta municipal, mas não há coleta seletiva. Com base nisso, foi realizada uma ação de conscientização com as crianças de 2 a 5 anos da Creche Inês Vasconcelos de Paiva Neves, objetivando-se sensibilizá-las sobre a importância da coleta seletiva e do descarte correto de lixo e, ensinálas sobre preservação do meio ambiente e a diminuição de doenças decorrentes do lixo. Optou-se pela encenação de uma peça de teatro, em que crianças descartam resíduos de forma irregular e um professor lhes ensina como separar o lixo para a coleta seletiva.

CONSIDERAÇÕES FINAIS: Foi possível perceber que campanhas de incentivo à separação dos resíduos sólidos são cada vez mais comuns. Porém, sem adesão populacional significativa. Dessa forma, iniciando a conscientização na infância, acredita-se que os resultados serão mais positivos já que proporcionarão conhecimentos à criança e à toda família. Embora o trabalho só tenha abrangido a população de um bairro, há o objetivo de que continuemos o trabalho em outras regiões.

PALAVRAS-CHAVE: CONSCIENTIZAÇÃO. CRIANÇAS. LIXO. RECICLAGEM. 


\title{
CONSEQUÊNCIAS DO EXCESSO NA JORNADA DE TRABALHO
}

\author{
CLEBER FRANCISCO MEDEIROS, FELIPE DE OLIVEIRA SIMÃO, RODRIGO GUILHERME TOMAZ
}

INSTITUTO MASTER DE ENSINO PRESIDENTE ANTÔNIO CARLOS - IMEPAC

clebermedeiros.adm@hotmail.com

Apresentação de Pôster

Resumo

Área do Conhecimento: Sustentabilidade e Direitos

O presente estudo tratará dos malefícios ocasionados pelo excesso na jornada trabalhista, para demonstrar que uma excessiva carga horária de trabalho deixa de ser benéfica à relação trabalhista.

PROBLEMA DE PESQUISA

Considerando que a jornada de trabalho está inserida dentro de um contexto jurídico-social, a problemática desta pesquisa é questionar: a exploração exacerbada de horas extras pelo empregador é de fato beneficial aos rendimentos da empresa?

OBJETIVO

Com fundamento nos princípios constitucionais, a legislação trabalhista vigente e estudos recentemente realizados, pretende-se ver de que maneira a análise sintática dos fatos empregatícia poderá contribuir de forma eficaz com a gestão de horas e jornada de trabalho.

MÉTODO

Foi utilizado o método dedutivo para a realização do trabalho, sendo performadas experiências reais com o tema, além da busca de pesquisa sobre o tema apresentado, bem como a utilização de doutrinas.

RESULTADOS ALCANÇADOS

Ainda é observável em muitas relações trabalhistas desrespeito ao princípio dignidade da pessoa humana. Um exemplo observável é o do excesso da jornada de trabalho, onde empregadores, com vistas apenas no lucro, e em desprezo aos princípios do direito do trabalho se utilizam de forma excessiva do instituto da hora extra. 0 empregado também abusa muito desta prática, na maioria das vezes para tentar obter uma renda maior. Entretanto, estudos recentes têm demonstrado que esta prática pode na verdade via a ser prejudicial para a relação empregatícia, eis que é notória queda na qualidade, no desempenho organizacional e na saúde do profissional, e, consequentemente, queda de faturamento e rendimento da empresa.

Em estudo realizado pelo The American Institute of Stress chegou-se à conclusão de que a jornada excessiva de trabalho pode trazer diversos malefícios à saúde o operário, ou seja, o problema não é meramente econômico.

A CLT estabelece severos limites quanto à fixação da jornada de trabalho, os quais quando desrespeitados pelo trabalhador são causa de pedir em diversas ações trabalhistas. Afora o fato do absurdo preço das horas extras.

Melhor solução para o problema seria a contratação de profissionais que possuam técnica para elaboração de análise de resultados, de maneira a ser possível verificar se seus operários estão sendo afetados pela quantidade de horas trabalhadas, de maneira a comprometer o faturamento da empresa.

PALAVRAS-CHAVE: TRABALHO CONGRESSO. 


\title{
CONSOLIDAÇÃO E ACOLHIMENTO DO DIREITO INTERNACIONAL DOS DIREITOS HUMANOS
}

\author{
LUKIÃ MENDES SILVA, SUNAMITA ALVES DO ALDO PEREIRA, WOILLE AGUIAR BARBOSA
}

INSTITUTO MASTER DE ENSINO PRESIDENTE ANTÔNIO CARLOS - IMEPAC

kialulm@gmail.com

Apresentação de Pôster

Resumo

Área do Conhecimento: Sustentabilidade e Direitos

O Direito Internacional dos Direitos Humanos, nos últimos anos, tem obtido relevante repercussão internacional multidisciplinar propagando medidas protetivas básicas à dignidade da pessoa humana através de instrumentos internacionais, inclusive, legitimando-se com relevante impacto legislativo em várias Constituições e normas infraconstitucionais modernas

OBJETIVOS

Através desta se indagará como e quando a matéria dos Direitos Humanos logrou atingir o âmbito de ação e pensamento do Direito Internacional e quais são seus efeitos dentro dos domínios pátrios mundiais.

METODOLOGIA

A presente pesquisa passará pelo método dedutivo que, a partir de argumentos gerais, passarão ao debate específico, buscando-se, assim, alcançar as respostas da pesquisa. Para tanto, utilizar-se-á de pesquisa, essencialmente, bibliográfica e documental.

RESULTADOS ALCANÇADOS

Ferreira Júnior (2006, p. 43) entende que "a proteção internacional dos Direitos Humanos surge no fim da Segunda Guerra Mundial, com a criação em 1945 da Organização das Nações Unidas - ONU." Outros diversos atos e fatores históricos, tais como, o nazismo, o fascismo e o comunismo, a fundação da Organização Internacional do Trabalho - OIT, em 1919, a adoção da Declaração Universal dos Direitos Humanos em 1948 e a política internacional no período de Guerra Fria (1947-1991), entre outros variados acontecimentos, encorajaram sua evolução e extensão. Uma vez adotado o Direito Internacional, pela regra interna do país assinante, aquela norma passa a ser considerado como parte desta, projetando a liberação do ser humano de possíveis vícios do direito nacional pátrio. Em virtude de tais fatos mencionados, os Estados foram provocados a reforçarem seus desempenhos, tanto em suas estratégias internas, como em suas agendas internacionais, para fortalecerem suas politicas e garantias à vida, liberdade de expressão, desenvolvimento, meio ambiente sustentável, alimentação, educação e redução da pobreza e trabalho precário, entre outros. Desta maneira, aprecia-se que houve o afastamento da antiga abordagem central do Direito Internacional clássico, ou tradicional, na qual o Estado absoluto, todo-poderoso, encontrava-se apartado da causa humana.

CONCLUSÃO

Entende-se que, os direitos humanos essenciais ao homem não derivam de nacionalidade ou Estado, mas sim da mera qualidade de ser humano. Os atos e omissões do Estado ficam sujeitos à fiscalização e controle de diversas instituições e mecanismos internacionais de proteção dos direitos humanos. Evidencia-se, que os cidadãos passam a ser titulares, além dos direitos internos pátrios, de direitos internacionais ratificados, além de serem reconhecidos como indivíduos com acesso à justiça Internacional.

REFERÊNCIAS

FERREIRA JÚNIOR, Lier Pires (coord.). Direitos humanos \& direito internacional. Curitiba: Jurúa, 2006. 400 p.

PALAVRAS-CHAVE: DIREITO INTERNACIONAL; DIREITOS HUMANOS; ESTADO; 


\title{
CONSTRUÇÕES COM PAINÉIS MONOLÍTICOS DE EPS
}

\author{
MARCOS PAULO DE BORBA ALVES, BRUNO PORTELA BARBOSA FILHO, DOUGLAS ALVES TEIXEIRA, \\ RAPHAEL FONSECA DIAS
}

INSTITUTO MASTER DE ENSINO PRESIDENTE ANTÔNIO CARLOS - IMEPAC

marcoosp.alves@gmail.com

Apresentação de Pôster

Resumo

Área do Conhecimento: Responsabilidade, Tecnologia e Ciência

Introdução: Estabilizando-se no ramo da construção por sua inovação, eco-eficiência e tecnologia, o método construtivo com painéis de EPS (Poliestireno Expandido, conhecido como isopor $囚$ ) e telas eletro soldadas surgiu na Itália por volta dos anos 70 e 80, sendo implantado em diversos países, chegando ao Brasil nos anos 90, submetendo-se a análises do IPT (Instituto de Pesquisas Tecnológicas de São Paulo) apresentando resultados satisfatórios. Este método fora criado no intuito de suprir e cumprir com os quesitos técnicos, construtivos e climáticos de sua região (onde fora desenvolvido), atendendo também a solicitações estruturais críticas, como regiões com risco de abalos sísmicos. Apesar de não haver circunstâncias tão desfavoráveis no Brasil, este processo construtivo se adequou satisfatoriamente com a aplicação em formas arquitetônicas variadas. Este processo construtivo constitui-se na utilização de painéis em EPS, em substituição aos tijolos (blocos cerâmicos de alvenaria) nas construções de alvenaria convencional, se tornando uma construção leve, sendo recicláveis e reaproveitáveis.

Objetivo: Avaliar tecnicamente o método construtivo com painéis monolíticos de EPS na área da engenharia civil, analisando o método em relação aos custos-benefícios, vantagens e desvantagens.

Metodologia: Trata-se de uma pesquisa qualitativa, exploratória referente a construções em painéis monolíticos de poliestireno expandido (EPS), onde, de acordo com uma pesquisa realizada em 2014 pela Plastivida, Instituto Socioambiental de Plásticos, 34,5\% do EPS pós-uso é reciclado no Brasil e o principal mercado para ele é a construção civil. O EPS se torna vantajoso por atuar como isolante térmico, por ser leve (facilitando seu manuseio na hora da construção, diminuindo os esforços nas fundações, etc...), livre de $\mathrm{CO}^{2}$, mais barato, $100 \%$ reciclável, mais fácil para a decoração dos edifícios e por utilizar menos água que a argamassa.

Resultados: O EPS é, principalmente, empregado em lajes e paredes. As paredes de EPS se tornam mais ecológicas, uma vez que dispensam o uso de pilares e vigas, evitando o desperdício com a madeira e escoramento das vigas, além de requerer menos materiais como o ferro e o cimento. Estes painéis de EPS apresentam economia de tempo e mão de obra, resistência mecânica, eficiências térmica e acústica.

Conclusão: As construções em painéis monolíticos de poliestireno expandido (EPS), são uma boa opção na decisão de uma construção, seja uma casa ou um edifício. Este processo construtivo constitui-se na utilização de painéis em EPS, em substituição aos tijolos (blocos cerâmicos de alvenaria) nas construções de alvenaria convencional, se tornando uma construção leve, reduzindo os gastos por exemplo em sua fundação, sendo recicláveis e reaproveitáveis.

PALAVRAS-CHAVE: PAINÉIS EM EPS; POLIESTIRENO EXPANDIDO; PROCESSO CONSTRUTIVO. 


\title{
CONTABILIDADE AMBIENTAL: UM ESTUDO SOBRE AS NORMAS REGULAMENTADORAS
}

\author{
MILENA ABREU RESENDE, PIETRA VITOR SILVA, RAYANNE SILVA BARBOSA
}

INSTITUTO MASTER DE ENSINO PRESIDENTE ANTÔNIO CARLOS - IMEPAC

milenaresende@yahoo.com.br

Apresentação de Pôster

Resumo

Área do Conhecimento: Responsabilidade e Negócios

Introdução (Contextualização): No Brasil a discussão de temas ambientais está cada vez mais presente nas diferentes esferas sociais, o que aumenta a consciência nacional da importância da preservação do meio ambiente. Dessa forma, a preocupação com questões ambientais é crescente em todos os ramos de atuação dentro do mercado de trabalho. A contabilidade é uma ferramenta fundamental para auxiliar os administradores e gestores na gestão empresarial, portanto o conhecimento dos profissionais acerca de temas e normas ambientais é fundamental para um crescimento sustentável da empresa. Pode-se considerar que a Contabilidade Ambiental é uma é fundamental para auxiliar no controle das variáveis ambientais das organizações. Atualmente, observa-se a necessidade de um maior aprofundamento nos estudos relacionados às Normas Contábeis que regulamentam a Contabilidade Ambiental das empresas no âmbito da formação acadêmica. Por isso, o objetivo é a apresentação e discussão das Normas Brasileiras de Contabilidade (NBC) que orientam e trata da evidenciação contábil ambiental para os futuros profissionais de contabilidade, o que irá permitir aos alunos de graduação uma melhor compressão sobre a estrutura que regulamenta a profissão em toda sua amplitude. Utilizou-se a pesquisa documental como metodologia, com o intuito de aprofundar o estudo no tema e apresentar as normas regulamentadoras que possam, futuramente, auxiliar profissionais da contabilidade de forma simplificada e pratica.

Relato da experiência: A pesquisa documental, enquanto método de investigação social tem um caráter compreensivo com enfoque mais expositor, essa característica exige do pesquisador uma capacidade reflexiva e crítica não só do estudo, mas sim de todo seu contexto social. O Conselho Federal de Contabilidade (CFC) por meio de suas atribuições aprovou a NBC T 15 que trata da Demonstração das Informações de Natureza Sócio Ambiental, e estabelece os procedimentos para a evidenciação das informações sócio ambiental. Essa Demonstração ainda não é obrigatória, mas se inserida pela empresa deverá obedecer aos procedimentos determinados da NBC T 15. 0 estudo possibilitou o conhecimento da NBC T 15 que regulamenta as informações social e ambiental da Contabilidade Ambiental. Considerações finais: É importante ressaltar que a Contabilidade Ambiental não é uma nova forma de contabilização, mas sim um modelo de aplicações de técnicas e registros aplicados aos controles e registros da Gestão Ambiental. Pode-se destacar também a falta de conhecimento dos profissionais e das empresas sobre os benefícios da aplicação da Contabilidade Ambiental, que de forma generalizada utilizam as mesmas apenas para amenizar danos de produção. 0 estudo e evidenciação das informações ambientais influenciam na organização de recursos que podem ter grande impacto na saúde financeira e publica das empresas.

PALAVRAS-CHAVE: CONTABILIDADE AMBIENTAL; NBC T 15; RESPONSABILIDADE SOCIAL. 


\title{
CORRELAÇÃO DAS CAPACIDADES FÍSICAS DOS ATLETAS DA CATEGORIA DE BASE DO MANCHA ESPORTE CLUBE DA CIDADE DE ARAGUARI/MG.
}

\author{
AMANDA NOGUEIRA DE OLIVEIRA, BRUNA DE FÁTIMA PEREIRA COELHO, GEOVANA FERANDES \\ PEREIRA, HUGO RIBEIRO ZANETTI, DANIELLE FERNANDES ALVES
}

INSTITUTO MASTER DE ENSINO PRESIDENTE ANTÔNIO CARLOS - IMEPAC

amandanog53@gmail.com

Apresentação de Pôster

\section{Resumo}

Área do Conhecimento: Saúde coletiva e bem-estar

\begin{abstract}
Introdução: A prática regular do esporte futebol tem sido amplamente disseminada em todo o mundo. Dessa forma milhões de pessoas, principalmente crianças e adolescentes, tem praticado este esporte buscando se tornar um jogador profissional de sucesso. Nesse sentido, faz-se necessário a avaliação das capacidades físicas que compõem este esporte e, a partir desses resultados, melhorar o planejamento e prescrição dos treinamentos aplicados para estes atletas. Objetivo: Correlacionar as capacidades físicas dos atletas da categoria de base do Mancha Esporte Clube da cidade de Araguari/MG. Metodologia : Trata-se de um estudo transversal, quantitativo e descritivo realizado com atletas das categorias pré-mirim (10 e 11 anos), mirim (12 e 13 anos), infantil (14 e 15 anos) e juvenil (16 e 17 anos) de base do Mancha Esporte Clube da cidade de Araguari/MG no período de pré-temporada e, para avaliar as capacidades físicas, foram aplicados testes validados e específicos para tal finalidade. Para correlacionar as variáveis foram utilizados os resultados provenientes dos testes de consumo máximo de oxigênio (VO 2máx ) que foi realizado por meio do teste de Cooper de 12 minutos, teste de agilidade (AG) que foi verificado pelo teste de Shuttle Run, teste de resistência abdominal (RA) que foi realizado pelo teste de resistência muscular localizada, teste de potência de membros superiores (PMMSS) verificado pelo teste de arremesso de medicine ball e a flexibilidade (FL) que foi mensurada pelo teste de sentar e alcançar e, além disso, foi analisado a composição corporal (CC) teste de índice de massa corporal [IMC = massa corporal / estatura 2 ]. Foi utilizado o teste de correlação de Pearson (r), tendo nível de significância quando $\mathrm{p}<0,05$. Resultados: Foi encontrado que o V0 2máx apresentou correlação com a PMMSS $(r=0,29)$ e agilidade $(r=0,25)$. A AG correlacionou-se com a PMMSS $(r=0,38)$. A PMMSS correlacionou-se com o IMC $(r=0,5)$. Conclusão: A partir da metodologia adota e dos resultados encontrados, conclui-se que a avaliação das capacidades, principalmente, o V02máx é capaz de correlacionar-se com variáveis que são utilizadas durante a prática do futebol. Dessa forma, deve-se explorar tais variáveis para que os atletas consigam desenvolver o máximo de performance, devendo ser aprimoradas durante todo o período de temporada de uma equipe de futebol.

PALAVRAS-CHAVE: CAPACIDADE FÍSICA, FUTEBOL, ATLETAS.
\end{abstract}




\title{
CRIPTOCOCOSE CANINA: RELATO DE CASO
}

\author{
PATRICIA ADANIA DE OLIVEIRA, AMANDA CAETANO VIEIRA, ANGELICA LANDA DA SILVA, EMILLY \\ APARECIDA DA SILVA, KAMILA DE FREITAS LIMA, DANIELLE VITORINO MORAES
}

INSTITUTO MASTER DE ENSINO PRESIDENTE ANTÔNIO CARLOS - IMEPAC

paty_adania@hotmail.com

Apresentação de Pôster

Resumo

Área do Conhecimento: Saúde coletiva e bem-estar

Introdução: A criptococose é uma doença fúngica sistêmica, de distribuição mundial, causada por fungos do gênero Cryptococcus. A manifestação dos sinais clínicos e a disseminação da infecção depende da imunidade do hospedeiro. A ocorrência da doença pode ser considerada pouco frequente, comparadas outras enfermidades fúngicas como esporotricose e dermatofitose. A transmissão ocorre por inalação de microorganismos em locais contaminados por fezes de aves, em especial pombos que favorecem a manutenção e a permanência do agente no ambiente. Objetivou-se com esse relato, elucidar as manifestações clínicas da doença que pode oferecer riscos não só a saúde animal, mas também a saúde pública, considerando que a criptococose é uma zoonose.

Metodologia: Para o estudo deste caso clínico foi inicialmente realizada uma pesquisa bibliográfica e a metodologia apresentada refere-se ao relato de caso, cujo paciente estudado é um cão do sexo masculino, de um ano de idade, raça maltês, atendido em uma clínica veterinária. Os dados utilizados na pesquisa foram da anamnese, exames laboratoriais e exames de imagem. Este relato de caso foi autorizado pelos tutores do paciente, uma vez que a identificação do mesmo fosse preservada, respeitando questões éticas.

Relato da experiência: $\mathrm{O}$ animal foi atendido em uma clínica na cidade de Araguari-MG, apresentando apatia, prostração e fadiga. Ao exame físico constatou-se febre de $39,7^{\circ} \mathrm{c}$, apatia, mucosas normocoradas, animal muito magro, pesando 3,5kg e com score corporal 2, sem sinais de dor a palpação na região abdominal. Durante a palpação abdominal foi possível sentir uma massa na região caudal ao fígado. Foram realizados hemograma e ultrassonografia. A análise do hemograma mostrou monocitose, aumento de bastonetes, eosinopenia e linfopenia. . O exame de imagem mostrou alterações sonográficas em alças intestinais de formato oval, com presença de gases no intestino e motilidade diminuída, evidenciando também presença de conteúdo com ecogenicidade mista. O animal foi submetido ao procedimento de laparotomia exploratória, com enterectomia na qual foram retirados duas massas de $3,38 \mathrm{~cm}$ e $2,79 \mathrm{~cm}$, totalizando a retirada de $10 \mathrm{~cm}$ do segmento intestinal. Após a cirurgia foi realizada transfusão sanguínea, pois no hemograma pós cirúrgico houve queda de $50 \%$ do hematócrito. No dia seguinte ao procedimento cirúrgico o animal veio ao óbito. 0 material coletado foi encaminhado para a biópsia, com diagnóstico conclusivo de criptococose.

Considerações finais: Conclui-se que, apesar da criptococose intestinal em cães ser considerada rara, recomenda-se a inclusão nos diagnósticos diferenciais. Estudos epidemiológicos sobre o Criptococcus neoformans são indispensáveis à identificação de microfocos desse fungo, facilitando a adoção de medidas preventivas como o controle de portadores.

PALAVRAS-CHAVE: CRIPTOCOCOSE, CACHORRO, PATOLOGIAS FÚNGICAS, ZOONOSES, AVES. 


\title{
CRITÉRIOS DE SUBSTITUIÇÃO DE DORMENTES DE MADEIRA
}

\author{
MARCIO CAIXETA TEIXEIRA, DAVID DE SOUZA MATOS, JONNATHA DENNIS BATISTA FERREIRA, \\ SHIRLEY APARECIDA OLIVEIRA SANTOS, THAYNÁ ALVIM DE MELO, GEORGE WILTON \\ ALBUQUERQUE RANGEL
}

INSTITUTO MASTER DE ENSINO PRESIDENTE ANTÔNIO CARLOS - IMEPAC

eng.caixeta@icloud.com

Apresentação de Pôster

Resumo

Área do Conhecimento: Responsabilidade, Tecnologia e Ciência

Introdução: A falta de literatura específica para a manutenção de via permanente fez com que as empresas, através da experiência dos antigos funcionários, se adequassem baseando-se nas antigas literaturas de construção ferroviária, gerando documentos técnicos empresariais para manutenção de via permanente. Esta, por sua vez, é de suma importância, desde o ponto de vista humano, ao financeiro. A principal causa das Ocorrências Ferroviárias é inerente a má conservação da via, portanto, faz-se necessário ter um controle eficiente, de qualidade, e com o menor impacto possível.

Objetivo: O objetivo deste trabalho foi avaliar os critérios de manutenção de dormentes da via permanente ferroviária.

Metodologia: Trata-se de uma pesquisa que envolve a revisão dos critérios relevantes para a substituição e manutenção de dormentes. A premissa básica da manutenção de dormentes é a sua substituição, porém, a grande dúvida é quando ela ocorrerá. Os dormentes de aço ou de concreto serão substituídos assim que sejam identificadas suas avarias, normalmente, nos dormentes de concreto ocorrerá o rompimento do concreto em função de excesso de vibração, já os de aço, ocorre esmagamento das fixações e oxidação do dormente. Porém uma variável é utilizada na substituição dos dormentes de madeira, a taxa máxima de dormentação inservível, que define qual a quantidade de dormente inservível pode haver em seqüência. Critério este, baseado em cumprimento de recomendações da ANTT que varia de acordo com o volume de transporte, geometria ferroviária e estrutura de via permanente. Portanto, será analisada a periodicidade das substituições e uma analise critica sobre o critério de dormentes podres em seqüência.

Resultados: Com base nesses dados, as ferrovias administram os recursos ao máximo. Do ponto de vista de gestão, planejamento e controle da manutenção, quando se há recursos financeiros para substituição de todos estes dormentes identificados, seria importante que se fizesse, porém com os recursos direcionados à manutenção, as empresas adotam que será seguro trafegar com a taxa de dormentes podres descritas em cada situação. Mas, a melhor situação, tanto para engenharia, quanto para manutenção e levando-se em consideração que toda via haverá dormentes podres, seria manter a linha com taxa de dormentação inservível próxima de zero em todas as linhas.

Conclusão: 0 fornecimento do dormente de madeira é o maior problema enfrentado pelas empresas ferroviárias, que apesar de ter um baixo custo de aquisição à periodicidade de troca é muito alta. Com o intuito de resolver essa questão, estuda-se a substituição de parte dos dormentes de madeira (fixação elástica) por dormentes de aço ou concreto em curvas, que são locais de maior solicitação das tensões, é economicamente viável em longo prazo, devido à longa vida útil do dormente e a confiabilidade que ele trará à via.

PALAVRAS-CHAVE: FERROVIA, MANUTENÇÃO, VIA PERMANENTE, DORMENTE. 


\title{
CUSTO MÉDIO DE UMA ANGIOPLASTIA PELO SISTEMA ÚNICO DE SAÚDE EM UM HOSPITAL DE UBERLÂNDIA-MG
}

\author{
NEIDE ALVES ALMEIDA ALVARENGA, AMANDA FERRAZ GARCIA, CAMILA PEREIRA FERNANDES, \\ CAROLINE PEREIRA FERNANDES, MÁRCIO ANTÔNIO DE PÁDUA GUIMARÃES NETO, VITÓRIA \\ SANTANA DE AZEVEDO CARDOSO, CÉSAR ANTONIO DE OLIVEIRA
}

INSTITUTO MASTER DE ENSINO PRESIDENTE ANTÔNIO CARLOS - IMEPAC

neidealvarenga2012@hotmail.com

Apresentação de Pôster

Resumo

Área do Conhecimento: Gestão de recursos econômicos (naturais)

INTRODUÇÃO: O Infarto Agudo do Miocárdio - IAM, conhecido como ataque cardíaco ou enfarte agudo do miocárdio, caracteriza-se pela interrupção do fluxo sanguíneo em uma das artérias coronarianas que irrigam o coração, o que pode levar o infartado à óbito. Mediante análise de cada caso de IAM, pode-se optar pela intervenção percutânea - angioplastia coronariana transluminal percutânea (ACTP), levando-se em consideração o grau de angina, função ventricular, carga isquêmica e anatomia da coronária.

OBJETIVO: 0 objetivo da pesquisa é conhecer o custo médio total de uma angioplastia em um hospital universitário de Uberlândia-MG, desde a internação inicial até a alta do usuário SUS.

METODOLOGIA: Trata-se de um estudo descritivo de série temporal, baseado nos dados secundários fornecidos por um dos gestores de custos, versando sobre os gastos dispendidos com o procedimento cirúrgico angioplastia em um hospital universitário de Uberlândia-MG. Foram considerados os dados de custos do pré-operatório, per-operatório e pós-operatório.

RESULTADO: Através do DATASUS, foi gerada uma média de R $\$ 186,05$, sobre o total de 672 procedimentos, realizados no período de julho a novembro de 2017. Custos pré-operatórios - por angioplastia estimado A limpeza dos $176,78 \mathrm{~m}^{2}$ da sala hemodinâmica representa uma média de $R \$ 23,15$, considerando uma limpeza por procedimento. Energia, gastos totais de $\mathrm{R} \$ 550.000,00$. O consumo de energia na hemodinâmica representa 2,45\% desse gasto, totalizando $\mathrm{R} \$ 13.475,00$ rateados pelo numero de procedimentos. Energia gasta no procedimento R \$ 80,20. Depreciação da máquina (12 anos de vida útil), custo de $\mathrm{R} \$ 2.000 .000,00$. Máquina utilizada no procedimento $\mathrm{R} \$ 82,70$. Custos per-operatórios: material utilizado na cirurgia $\mathrm{R} \$ 2.464 .01$; Equipe $\mathrm{R} \$ 769,27$ (foram calculados dividindo a soma de todos os salários dos profissionais envolvidos no procedimento, como médicos, enfermeiros, técnicos em enfermagem e secretárias). Manutenção hemodinâmica $\mathrm{R} \$ 71,42$ (terceirizada, custa $\mathrm{R} \$ 12.000,00$, sendo rateado pelo numero de procedimentos). Roupas hemodinâmica $\mathrm{R} \$ 9,34$. 0 cálculo das roupas foi feito baseado no pedido de vestimentas, totalizando $\mathrm{R} \$ 1.570,00$ por procedimentos realizados. Custos pós operatórios Exames (Hemograma, ECG) R\$ 30,00 (média). Diária quarto/enfermaria R\$300,00; Diária UTI R\$1.50 0,00 Somatório de todos os custos R $\$ 5.330,09$. Receita SUS R $\$ 5.644,72$

CONSIDERAÇÕES FINAIS: 0 custo da diária na UTI é de aproximadamente $1.500,00$ e o SUS repassa R\$ 500,00 , havendo um déficit de $\mathrm{R} \$ 1.000,00$ na diária. Porém, a partir da observação das de spesas nos momentos pré-operatório, per-operatório e pós-operatório, verificou-se que o repasse do SUS e o valor despendido pelo prestador de serviço são correspondentes.

PALAVRAS-CHAVE: HEMODINÂMICA, GESTÃO HOSPITALAR, CUSTO E ANGIOPLASTIA. 


\title{
DESCARTE DE MEDICAMENTOS E SEU IMPACTO SOCIOAMBIENTAL NA CIDADE DE OUVIDOR-GO
}

\author{
MATHEUS ANTONIO PEREIRA, SAMPERSON LUCIO PACHECO, LEONARDO GOMES PEIXOTO
}

INSTITUTO MASTER DE ENSINO PRESIDENTE ANTÔNIO CARLOS - IMEPAC

matheus_a.pereira@hotmail.com

Apresentação de Pôster

Resumo

Área do Conhecimento: Saúde coletiva e bem-estar

Introdução: No Brasil não há um Programa Nacional de Recolhimento de Medicamentos Vencidos. Fica a cargo de cada comunidade realizar o seu programa de descarte. Os medicamentos são produtos farmacêuticos tecnicamente obtidos ou elaborados com finalidade profilática, curativa, paliativa ou para fins de diagnósticos. Seu consumo deve estar em condições adequadas e dentro do prazo de validade. Após expirar o prazo de validade os medicamentos vencidos devem ser inutilizados e descartados para evitar problemas relacionados como intoxicações, uso sem necessidade ou sem indicação, falta de efetividade, reações adversas, poluição do meio ambiente, entre outros.

Objetivo: Avaliar o conhecimento do programa de descarte de fármacos de uma população de Ouvidor - GO. Compreendendo como ocorre o armazenamento de fármacos não vencidos e vencidos e como é o procedimento para o descarte destes fármacos.

Metodologia: Trata-se de um estudo qualitativo, quantitativo e descritivo de descarte de medicamentos e resíduos farmacêuticos tanto líquidos, quanto sólidos nas UBSF e residentes de Ouvidor - GO. Foi aplicado um questionário para avaliar como as pessoas realizam o descarte dos medicamentos. Este formulário foi baseado no artigo Diretrizes para um Programa de Recolhimento de Medicamentos Vencidos no Brasil. Foram entrevistados 30 voluntários $(10 \mathrm{~h}$ e $20 \mathrm{~m})$. Antes da aplicação do questionário, o trabalho foi apresentado e discutido com cada voluntário. E o mesmo foi respondido de forma livre-esclarecido.

Resultados: A análise dos nossos resultados mostrou que 50\% dos entrevistados conhecem o programa de descartes da comunidade, sendo que as mulheres $(60 \%)$ conhecem mais o programa quando comparado com os homens (30\%). Além disso, nossos resultados mostraram que todos os homens guardam os fármacos antes do vencimento enquanto as mulheres descartam, e que $80 \%$ das mulheres levam as embalagens para o descarte. Após o vencimento e antes do descarte os homens acondicionam os fármacos no armário independente da forma medicamentosa, já as mulheres guardam no armário (60\%) e geladeira (41\%). Todos os homens descartam os fármacos vencidos na pia, enquanto $40 \%$ das mulheres descartam na pia ou no lixo comum. Se os fármacos utilizarem aparatos perfuro-cortantes (como agulhas) todos descartam no lixo comum.

Conclusão: A partir das análises dos resultados concluímos que as mulheres possuem um maior conhecimentos do programa de descartes e da forma como estes medicamentos devem ser armazenados e descartados quando comparado com os homens. Assim, o descarte correto dos fármacos pode diminuir o uso indiscriminado sem prescrição diminuindo assim a contaminação/intoxicação pelo mau uso de medicamentos vencidos.

PALAVRAS-CHAVE: MEDICAMENTOS; DESCARTE; FÁRMACOS VENCIDOS; RESÍDUOS DE SAÚDE. 


\title{
DESCARTE DE MEDICAMENTOS: CONDUTA DE PACIENTES ATENDIDOS PELA FARMÁCIA MUNICIPAL DE ARAGUARI (MG)
}

\author{
THAIS CAMPOS DUARTE, DAYANE CRISTINA DE PAIVA RAMOS, HERBERT CRISTIAN DE SOUZA, \\ MARCELO CARVALHO, LUIZ DUARTE ULHÔA ROCHA JÚNIOR, RITA ALESSANDRA CARDOSO
}

INSTITUTO MASTER DE ENSINO PRESIDENTE ANTÔNIO CARLOS - IMEPAC

thaiscampos.mg@gmail.com

Apresentação de Pôster

Resumo

Área do Conhecimento: Saúde coletiva e bem-estar

Introdução: Medicamento é o produto farmacêutico tecnicamente obtido ou elaborado com finalidade profilática, curativa, paliativa ou para fins de diagnósticos. Nos domicílios, muitos dos medicamentos não são consumidos por completo, gerando sobras que acabam sendo descartadas com o lixo doméstico ou no esgoto comum, ou são armazenados para um possível consumo posterior. Essa conduta representa riscos para a saúde individual e coletiva, bem como podem levar à contaminação do solo e água, com graves impactos sobre o meio ambiente.

Objetivo: Analisar a conduta dos pacientes atendidos pela Farmácia Municipal de Araguari (MG) com relação ao descarte de medicamentos.

Metodologia: Trata-se de uma pesquisa exploratória, prospectiva, com análise qualitativa e quantitativa, em que foi utilizado um questionário autoaplicável, construído pelos autores e respondido individualmente por 300 pessoas enquanto suas receitas eram aviadas na Farmácia Municipal de Araguari (MG). 0 questionário contem questões acerca de dados sociodemográficos e perguntas específicas a respeito dos hábitos de descarte de medicamentos pelo usuário.

Resultados: Observou-se que 64\% da amostra eram do sexo feminino, 56\% dos participantes afirmaram possuir ensino médio, enquanto $31,3 \%$ possuíam ensino fundamental e os demais declararam ensino superior ou pós-graduação. Devido à metodologia da pesquisa, em que se utiliza um questionário autoaplicável, participaram somente voluntários alfabetizados. 42,3\% dos respondentes afirmaram jogar as sobras de medicamentos no lixo comum. Dentre os que não jogam no lixo comum, somente 16,7\% levam para uma farmácia ou drogaria e 42,3\% costumam levar para postos de saúde, houve também aqueles que informaram descartar na pia, no vaso sanitário ou queimar. Dentre os participantes, 28 faziam uso de insulina, quando questionados sobre a forma que faziam o descarte das seringas e agulhas, 42,9\% informaram que colocam em frasco rígido e jogam no lixo comum, 28,6\% reencapam as agulhas e jogam no lixo comum e 28,6\% colocam em frasco rígido e encaminham para a unidade de saúde. Quando questionados sobre o hábito de conferir o prazo de validade dos medicamentos armazenados em casa, $83,7 \%$ afirmaram ter esse hábito, $13,0 \%$ disseram que conferem somente às vezes e 3,3 admitiram não conferir. Em relação aos medicamentos vencidos, $76 \%$ dos participantes afirmam não continuar usando, $18,3 \%$ admitiram que às vezes continuam usando e 5,7\% afirmam que usam os medicamentos mesmo após o vencimento.

Conclusão: Uma grande parcela dos participantes informou descartar as sobras de medicamentos de maneira incorreta. Dentre os usuários de insulina, a maioria informou manejo inadequado dos resíduos perfurocortantes. Portanto, há a necessidade de ações educativas visando à mudança desses hábitos, para tanto, políticas públicas devem ser implementadas nesse sentido. PALAVRAS-CHAVE: RESÍDUOS SÓLIDOS; MEDICAMENTOS; DESCARTE. 


\title{
DIAGNÓSTICO DO RACIOCÍNIO LÓGICO MATEMÁTICO ENTRE ALUNOS DO $1^{\circ}$ PERÍODO DO CURSO DE PEDAGOGIA NO ANO DE 2017
}

\author{
LEANDRA MENDES DO VALE, ANA LÚCIA COSTA E SILVA, MARIA TERESA DE BEAUMONT,
}

INSTITUTO MASTER DE ENSINO PRESIDENTE ANTÔNIO CARLOS - IMEPAC

leandramvale@gmail.com

Apresentação de Pôster

Resumo

Área do Conhecimento: Agenda 2030 e os Objetivos de Desenvolvimento Sustentável

Introdução: Em 2017, o curso de Pedagogia contava, em seu primeiro período, com o conteúdo curricular Lógica e Pensamento Crítico, cujo ementário apresentava a introdução à lógica e ao raciocínio lógico como instrumentos do saber, para a busca do conhecimento e crítica, além do estudo da argumentação baseada em provas e raciocínio lógico a fim de estimular os alunos a compreenderem e raciocinarem sobre o que era proposto, organizando seu pensamento e não somente memorizando e aplicando fórmulas. As atividades propostas utilizavam ferramentas auxiliares, como: palitos de madeira, imagens que exigiam a observação, raciocínio, construção de padrões gerais, análise de sequências numéricas e domínio das operações aritméticas básicas.

Objetivo: diagnosticar previamente a habilidade de raciocínio lógico matemático da turma, por meio de cinco exercícios objetivos.

Metodologia: Pesquisa quantitativa e exploratória, buscando diagnosticar o nível de raciocínio lógico matemático, cujo levantamento foi realizado com 58 alunos, sendo 89,7\% do sexo feminino, 67,2\% com faixa etária entre 18 e 22 anos, 89,7\% cursando a sua primeira graduação, 27,6\% havia terminado o ensino médio em dezembro de 2016 e 24,1\% havia terminado o ensino médio há mais de 7 anos. Investigou-se, portanto, o nível de raciocínio lógico matemático destes alunos com cinco exercícios objetivos, sendo que três eram considerados de nível fácil, um de nível médio e um de nível difícil.

Resultados: Observou-se que apenas em um exercício de nível fácil 74,4\% obteve resultado satisfatório, tratando-se de uma habilidade simples de análise de imagem, acréscimo de elementos semelhantes e contagem. Os outros exercícios de nível fácil eram semelhantes ao anterior, ou seja, a habilidade de raciocínio exigida era a mesma e obteve-se em um deles 48,09\% de acerto e no outro apenas 32,4\%. Já no exercício de nível médio, a habilidade exigida era semelhante aos de nível fácil, acrescentando-se mais elementos de análise e cálculos, não exigindo apenas contagem e sim, a aplicação das operações aritméticas básicas, como soma e multiplicação, e apenas 23,7\% conseguiram êxito na solução. No exercício de nível difícil, que exigia as mesmas habilidades do de nível médio, acrescentando-se a habilidade de reconhecimento de sequências numéricas, 15,4\% conseguiram desenvolver a solução.

Conclusão: Os resultados nos mostram que apenas $27,6 \%$ dos alunos haviam terminado o ensino médio recentemente e em apenas um exercício de nível fácil obteve-se resultado satisfatório. 0 diagnóstico confirmou que algumas habilidades devem ser diagnosticadas e resgatadas antes da aplicação de conteúdos curriculares para que o docente as tenha como norteador do processo de ensino-aprendizagem, avaliando o nível de dificuldade que deve empenhar em suas aulas para que consiga atingir os objetivos propostos no planejamento.

PALAVRAS-CHAVE: LÓGICA; MATEMÁTICA; RACIOCÍNIO. 


\title{
DIFERENÇA TRIBUTÁRIA NA COMPRA DE PRODUTOS FORA DO ESTADO DE PRODUÇÃO
}

\author{
EDUARDO MARCONDES BONDEZAN, ALBERT MEIRA VIEIRA JUNIOR, ANDRÉ ARRUDA MOREIRA \\ DE AGUIAR PEREIRA , GABRIEL CASTRO CARVELO, MATHEUS VIEIRA ÁVILA, FABIANO JOSÉ LUCAS \\ DOS SANTOS
}

INSTITUTO MASTER DE ENSINO PRESIDENTE ANTÔNIO CARLOS - IMEPAC

embondezan@gmail.com

Apresentação de Pôster

Resumo

Área do Conhecimento: Responsabilidade e Negócios

Tendo em vista o desenvolvimento de um trabalho de pesquisa utilizando a Metodologia da Problematização com o Arco de Maguerez, escolhemos como campo de observação da realidade a empresa Castelo Sobremesas LTDA. Tal escolha se deve pela facilidade de obtenção dos dados da empresa por meio de um dos integrantes do grupo.No campo investigado, notamos que a empresa Castelo Sobremesas LTDA, possui um alto valor de tributação na compra de produtos fora do estado, devido à alta carga de substituição tributária que incide sobre os produtos comprados fora do estado de Minas Gerais, o qual é o estado onde a empresa se encontra.Foram feitos os levantamentos através de entrevistas com o Diretor da empresa e o contador responsável. Obtivemos dessa forma os valores referentes a tributação, valor do imposto pago, custo atribuídos aos produtos, margem de contribuição e custos com a logística da empresa. Dessa forma, as observações nos conduziram ao delineamento do seguinte problema de investigação: Alto valor pago de tributos na compra de mercadorias fora do estado de produção. O ICMS é um imposto que incide sobre todas as etapas da cadeia comercial, onde o imposto é gerado quando o fabricante vende a mercadoria ao atacadista, quando este repassa ao varejista e quando o varejista vende ao consumidor final. Caracteriza-se pelo fato de as legislações estaduais atribuírem o recolhimento a um só contribuinte que esteja vinculada a cadeia produtiva. Com previsão no art. 6ํ da Lei Complementar Federal no7/1996, a lei estadual pode atribuir a um só contribuinte a responsabilidade de recolher o imposto devido por outra, colocando-o na condição de substituto. Mas não é somente um recolhimento antecipado das futuras transações, pois mesmo se o fato gerador futuro não acontecer o contribuinte deverá recolher o imposto como se devido fosse.No caso da substituição tributária o pagamento do imposto é feito referente a operações presentes e futuras, ou seja, um determinado contribuinte tem a responsabilidade de recolher o imposto referente a sua própria operação de venda, e também as operações que a mercadoria passou anteriormente ou passará posteriormente até chegar no consumidor final. Compreendemos que estudar mais profundamente sobre este tema buscando possíveis soluções para esse problema, contribuirá para um melhor entendimento de tributação e para a visão da realidade tributária de nosso país. Sob o ponto de vista dos/as sócios, com uma menor contribuição de encargos tributários.

PALAVRAS-CHAVE: EXISTÊNCIA DE SUBSTITUIÇÃO TRIBUTÁRIA NO ESTADO DE MINAS GERAIS E OU NO ESTADO DE GOIÁS; FALTA DE PLANEJAMENTO TRIBUTÁRIO; ESTRUTURA INFORMAL DO PLANEJAMENTO PARA ELISÃO FISCAL, SONEGAÇÃO E FRAUDE, CUSTO DE PRODUÇÃO; LOGÍSTICA NA TRANSFERÊNCIA DA INDÚSTRI. 


\title{
DIREITO URBANISTICO E SUAS CONSEQUENCIAS NOS CENTROS POPULACIONAIS
}

\author{
JESSICA BORGES DE MORAIS, ANA CAROLINA DE OLIVEIRA LIMA, GEILSON NUNES
}

INSTITUTO MASTER DE ENSINO PRESIDENTE ANTÔNIO CARLOS - IMEPAC

jeh.bmorais@hotmai.com

Apresentação de Pôster

Resumo

Área do Conhecimento: Sustentabilidade e Direitos

Introdução: O presente estudo mostrará como o Direito Urbanístico vem para trazer uma melhoria na manutenção na vida de uma comunidade em geral e, ainda como a urbanização de uma forma desenfreada vem junto de grandes problemas de cunho social, bem como, se for feito o crescimento de determinado centro populacional, de uma forma organizada e estruturada traz incontáveis benefícios na condição de vida humana na sociedade em questão.

PROBLEMA DE PESQUISA: Considerando a realidade social no Brasil, e como vem sendo desorganizada o planejamento do crescimento e desenvolvimento urbano nos municípios, o problema desta pesquisa é indagar: De que maneira o Direito Urbanístico é útil para a manutenção da ordem, e como o plano diretor e o estatuto da cidade, tendo base na política urbana tratada na Constituição Federal 1988, para ajudar nesta manutenção, e não somente no social, como também na tutela do patrimônio histórico, cultural e paisagística dos centros populacionais?

OBJETIVO: Quanto ao objetivo a ser alcançado, refere-se à tentativa de demostrar como o desenvolvimento urbano de modo desenfreado traz consequências na manutenção dos centros populacionais, e ainda, que se desenvolver o plano diretor no município, bem como, um crescimento planejado e controlado, traz benefícios para uma comunidade, em uma gama maior demostrar como a educação, cultura, segurança, saúde, entre outros, será melhorado com o estatuto da cidade junto com o Direito Urbanístico.

MÉTODO:Para se conseguir alcançar os objetivos designados nesta pesquisa será utilizado o método dedutivo, obtidos através de argumentos gerais sobre o assunto tratado evoluindo para argumentos particulares, alcançando os resultados, apresentado como problemática e, assim, se ter uma conclusão na pesquisa.

RESULTADOS ALCANÇADOS: Deve-se falar antes de tudo sobre o conceito de urbanização e como este é tratado e ligado diretamente com o conceito de cidade, é uma forma difícil de qualificar, vindo de uma conexão entre as necessidades, da sociedade em uma aglomeração um determinado espaço geográfico.

A urbanização é o termo empregado para definir o processo de crescimento dos centros urbanos em escalpas superiores aos centros populacionais rurais, este fenômeno é uma das principais características da industrialização e com isso vem consequentemente grandes problemas sociais

0 direito urbanístico é encontrado de forma genérica na Constituição Federal de 1988, como no art. 182, onde é encontrado o princípio da função social da propriedade e das cidades, nos arts. 5ํㅜ, inciso XXIII e 170, inciso III, estes princípios serão trabalhados no plano diretor das cidades.

PALAVRAS-CHAVE: CENTROS URBANOS; DIREITO URBANÍSTICO; ÊXODO; PLANO DIRETOR; URBANIZAÇÃO. 


\title{
DIREITOS FUNDAMENTAIS NO ESTADO DEMOCRÁTICO DE DIREITO E A REALIDADE DAS COTAS RACIAIS
}

\author{
DORIS MARRA RODRIGUES, PAULO ROBERTO DE OLIVEIRA SANTOS
}

INSTITUTO MASTER DE ENSINO PRESIDENTE ANTÔNIO CARLOS - IMEPAC

dorismarra@hotmail.com

Apresentação de Pôster

\section{Resumo}

Área do Conhecimento: Sustentabilidade e Direitos

\begin{abstract}
Introdução: A inclusão no ensino superior por cotas raciais, implantada através de políticas afirmativas, procura tratar os desiguais de forma equitativa, com a finalidade de propiciar um diferencial para uma população que, com frequência, encontra-se à margem da sociedade, como reflexo de um passado marcado por muitas divisões. Os direitos fundamentais elencados na CF/88 asseguram a dignidade da pessoa humana e por consequência uma sociedade mais justa e com menos desigualdade. Tal política desencadeia discussões favoráveis e contra, como em vários outros campos, sendo assim necessário um melhor conhecimento para situá-la corretamente em nosso contexto.

Objetivo: Frente ao exposto, o objetivo deste trabalho é, pela via do entendimento dos elementos jurídicos da política afirmativa de cotas raciais, discorrer acerca dos seus pontos positivos e negativos, na perspectiva de eventual reforço à exclusão.

Metodologia: Trata-se de uma pesquisa doutrinária, qualitativa, exploratória e retrospectiva, buscando identificar a origem e motivação da implantação da política de cotas raciais, conhecendo de perto a realidade do contexto na educação desde o ensino fundamental até o ensino superior. A investigação foi feita através de visitas em escolas públicas de ensino fundamental, médio e superior, buscando identificar como em cada uma das etapas estão parte da população que pode ser contemplada com tal política, como a vislumbram e utilizam.

Resultados: Até o presente momento, é possível notar que, quando se fala de inclusão por cotas raciais, há um preconceito arraigado tanto por pessoas que não tem como usufruírem de tal mecanismo quanto as que podem ser inclusas. Atualmente, os estudantes ingressos no ensino superior através de cotas, muitas vezes são discriminados e alvo de críticas e preconceitos. Não pode ser deixado de lado que, desde a implantação desta política afirmativa, houve pessoas se valendo de tal mecanismo de forma incorreta, ocasionando um descrédito e tornando-se alvo de questionamentos na esfera judiciária.

Conclusão: A política de cotas raciais, mesmo visando inclusão mais eficaz e o exercício da dignidade da pessoa humana de um nicho da população que sofre consequências de um passado marcado por discriminação e desigualdade, merece ser enfrentada no campo da Ciência do Direito, por conta da sua importância social.

Professor orientador: Paulo Roberto de Oliveira Santos

Instituição vinculada: IMEPAC Araguari
\end{abstract}

PALAVRAS-CHAVE: POLÍTICA AFIRMATIVA. COTAS RACIAIS. DIGNIDADE DA PESSOA HUMANA. 


\title{
DISPENSAÇÃO DE ANTIMICROBIANOS EM DROGARIAS PRÓXIMAS A HOSPITAIS DE ARAGUARI
}

\author{
JOÃO GABRIEL RODRIGUES DE ANDRADE, ANTONIO FELLIPE DE ASSUNÇÃO MENDES, GEOVANNA \\ ROSA GOMES RIBEIRO, HENDRIX LEITE SOUSA BORGES DE CARVALHO, SAMUEL PHELIPE DE \\ FREITAS SILVA, RITA ALESSANDRA CARDOSO
}

INSTITUTO MASTER DE ENSINO PRESIDENTE ANTÔNIO CARLOS - IMEPAC

andrade.j.gabriel@gmail.com

Apresentação de Pôster

Resumo

Área do Conhecimento: Saúde coletiva e bem-estar

\begin{abstract}
Introdução: Os fármacos antimicrobianos foram e ainda são uma das maiores descobertas da humanidade, mudaram por completo o modo de vida dos seres humanos, aumentando sua expectativa de vida, tornandose um dos pilares que permitiram a constituição das sociedades como as conhecemos atualmente. A análise do perfil de utilização de antimicrobianos permite a correlação com as infecções mais prevalentes em uma determinada região e qual poderá ser a taxa de bactérias resistentes a antimicrobianos de tal localidade. Objetivo: 0 objetivo deste estudo foi analisar os antibióticos mais dispensados em drogarias próximas aos maiores hospitais de Araguari - MG.

Metodologia: Trata-se de uma pesquisa qualitativa, exploratória de âmbito municipal, que busca conhecer como é a dispensação de antibióticos em drogarias próximas a hospitais de Araguari - MG. Através da visita a essas drogarias, em contato com o farmacêutico responsável técnico, um breve questionário foi aplicado, que consistia em identificar quais são os três antibióticos de maior dispensação naquele estabelecimento. $\mathrm{O}$ projeto foi desenvolvido como trabalho discente efetivo da disciplina Projeto Integrador $\mathrm{V}$, do Instituto Master de Ensino Presidente Antônio Carlos. Todos os farmacêuticos entrevistados concordaram em participar, assinaram o Termo de Consentimento Livre e Esclarecido e terão sua identidade preservada. Resultados: Observa-se que nas três drogarias pesquisadas, os antimicrobianos mais dispensados seguiram um padrão que se repetiu em todos os estabelecimentos. Em 100\% das drogarias, a Amoxicilina foi citada como o antimicrobiano mais dispensado, com muitas prescrições para quadros de infecção nas vias aéreas superiores. O segundo mais dispensado é a Azitromicina, também muito prescrito para o quadro de infecção nas vias aéreas superiores, especialmente em quadros de sinusite. 0 terceiro é a Cefalexina, sendo que os farmacêuticos afirmaram observar que muitas prescrições são para tratamento de quadros relacionados à pele, coadjuvante no tratamento de feridas ou pós-operatório.

Conclusão: Os três antimicrobianos mais dispensados nas drogarias próximas a hospitais de Araguari são medicamentos presentes na relação de medicamentos essenciais, consolidando uma perspectiva de racionalização da prescrição considerando vários aspectos, como custo acessível, as condições mais comuns de serem tratadas, a gravidade do quadro clínico e apresentações que favorecem a adesão ao tratamento pelo paciente.
\end{abstract}

PALAVRAS-CHAVE: ANTIBIÓTICOS; DISPENSAÇÃO; DROGARIAS. 


\title{
DISPENSAÇÃO DE ANTIMICROBIANOS PELOS FARMACÊUTICOS NAS DROGARIAS CENTRAIS DE ARAGUARI (MG).
}

\author{
LUCAS BARBOSA VISO, ANDRESSA FREITAS DA SILVA, JESSICA MENDES, KAROLAYNE DOS SANTOS \\ BORGES, MARIANA FERREIRA DE ALMEIDA, YASMIN MARIA DUARTE POVOA, RITA ALESSANDRA \\ CARDOSO
}

INSTITUTO MASTER DE ENSINO PRESIDENTE ANTÔNIO CARLOS - IMEPAC

lucasviso@hotmail.com

Apresentação de Pôster

Resumo

Área do Conhecimento: Saúde coletiva e bem-estar

\begin{abstract}
Introdução: 0 uso não racional de antimicrobianos tem causado o surgimento de bactérias resistentes a esses fármacos. 0 controle da dispensação desses medicamentos em drogarias é de responsabilidade do farmacêutico, sendo necessária, inclusive, a retenção das receitas quando medicamentos contendo essas substâncias são dispensados. Os antimicrobianos são compostos naturais ou sintéticos capazes de inibir o crescimento ou causar a morte de bactérias. Quando de origem natural são denominados antibióticos. 0 objetivo deste trabalho foi pesquisar junto aos farmacêuticos responsáveis técnicos por drogarias da região central da cidade de Araguari, quais os antimicrobianos mais comercializados bem como as dúvidas apresentadas e as orientações prestadas aos pacientes.

Metodologia: Pesquisa realizada no mês de abril de 2019, por alunos do Curso de Farmácia, como parte das atividades da disciplina Projeto Integrador V, quando os alunos aplicaram um questionário ao farmacêutico responsável técnico pelas maiores drogarias da região central de Araguari, avaliando quais os antibióticos mais dispensados para a população e orientações prestadas no momento da dispensação.

Relato da experiência: Primeiramente, quando chegamos nas drogarias, conversamos com o atendente/balconista solicitando atendimento pelo farmacêutico, rapidamente fomos direcionados ao profissional, a quem nós nos apresentamos e informamos o motivo da visita. Dentre as 05 drogarias visitadas, em 04 delas, os farmacêuticos foram cordiais, esclareceram todas nossas dúvidas e preencheram o questionário com absoluta presteza. Apenas em uma drogaria não fomos tão bem recebidos, provavelmente devido ao fluxo intenso na drogaria naquele momento. 0 antibiótico mais dispensado em todos os 05 estabelecimentos é a Amoxicilina 500mg. 0 segundo antibiótico mais dispensado é a Cefalexina $500 \mathrm{mg}$ em quatro drogarias e o terceiro antibiótico mais dispensado é a Azitromicina $500 \mathrm{mg}$ em três drogarias, sendo todos eles na forma de comprimidos para administração por via oral. Todos esses antimicrobianos são indicados para tratamento de infecções bacterianas. Os farmacêuticos informaram que a maior procura dos pacientes por orientações do farmacêutico em relação aos antibióticos é devida a dúvidas quanto à posologia, em função da prescrição médica ilegível ou mesmo ausência da posologia na prescrição. Os farmacêuticos informaram que, nessas oportunidades, também alertam quanto à necessidade do cumprimento de todo o período de tratamento para que não haja desenvolvimento de resistência.

Considerações finais: 0 desenvolvimento do projeto foi de grande valor e aprendizado para o grupo, pois os farmacêuticos nos mostraram a importância de dispensar corretamente os antimicrobianos, de uma boa comunicação com os pacientes, do correto controle do receituário, além da responsabilidade pela promoção do uso racional de medicamentos.
\end{abstract}

PALAVRAS-CHAVE: ASSISTÊNCIA FARMACÊUTICA; ANTIBIÓTICOS; ANTIMICROBIANOS; DISPENSAÇÃO. 


\title{
DOCÊNCIA ORIENTADA: RESPONSABILIDADE SOCIAL E PRÁTICA PROFISSIONAL
}

\author{
VALÉRIA ALVES DA SILVA ROSA, MARIA LUIZA DE BORBA ALVES, ORDALHA JORDANA DA SILVA \\ REIS, VALÉRIA ALVES DA SILVA ROSA
}

INSTITUTO MASTER DE ENSINO PRESIDENTE ANTÔNIO CARLOS - IMEPAC

alvesvaleria169@gmail.com

Comunicação Oral

Resumo

Área do Conhecimento: Agenda 2030 e os Objetivos de Desenvolvimento Sustentável

Introdução: Aprende-se a ser professor em diferentes espaços e tempos. A pesquisa trata de algumas reflexões construídas acerca de uma experiência de aprendizagem na área de alfabetização, realizada em uma escola pública da cidade de Araguari. Toma-se como referência parte de uma pesquisa sobre as contribuições da docência Orientada num projeto de formação de professores, o projeto Docência Orientada tornou-se "lugar de aprendizagem" a partir de uma experiência de trabalho compartilhado entre a professora orientadora, professora co-orientadora e acadêmica da graduação do curso de Pedagogia do Imepac.

Objetivo: Frente ao exposto, o objetivo deste trabalho é apresentar os resultados parciais da pesquisa realizada

Metodologia: Trata-se de uma pesquisa ação, nesta perspectiva fundamentamos a construção de ações que sejam norteadoras e auxiliadoras da realização desta pesquisa a qual se configura também enquanto intervenção sobre a realidade observada, à medida que o aluna/estagiária juntamente com a orientadora e co-orientadora terão acesso às documentações necessárias para análise da realidade educacional dos alunos por meio do: PPP - Proposta Político Pedagógica da instituição, o Currículo escolar da Educação Básica referente aos anos de atendimento, os diários de classe, boletins de notas, resultados de avaliações externas e internas e as próprias sondagens de escrita a ser realiza com os alunos participantes do projeto. Resultados: A pesquisa e intervenção estão em andamento, contudo, neste período de oito meses, percebese que das oito crianças pesquisadas, $75 \%$ tiveram um avanço significativo nos aspectos de leitura e escrita, as intervenções realizadas favoreceram o desenvolvimento do processo de aprendizagem, melhorando significativamente os índices de aproveitamento das crianças nas provas e avaliações propostas na escola. Desse grupo, 25\% dos alunos não tiveram o avanço esperado, realizou-se uma nova sondagem e a partir dos resultados modificou-se as ações de intervenção, priorizando principalmente os aspectos relativos à alfabetização inicial.

Conclusão: Os maiores percentuais nesses alunos atendidos confirmam que, entre outros fatores, a intervenção adequada e o atendimento individualizado contribuem de forma significativa para 0 desenvolvimento e aprendizagem das crianças. Esses achados são amplamente conhecidos e discutidos na literatura.

PALAVRAS-CHAVE: DOCÊNCIA ORIENTADA, ALFABETIZAÇÃO, APRENDIZAGEM. 


\title{
DUPLA PATERNIDADE DO REGISTRO CIVIL
}

\author{
GABRIEL JORDÃO DE CARVALHO, BIANCA LAURA DUTRA, WOILLE AGUIAR BARBOSA
}

INSTITUTO MASTER DE ENSINO PRESIDENTE ANTÔNIO CARLOS - IMEPAC

gabrielzinhojordao@hotmail.com

Apresentação de Pôster

Resumo

Área do Conhecimento: Sustentabilidade e Direitos

\section{INTRODUÇÃO}

O ramo do direito de família, começou a ser mais sentimentalista adotando outros critérios para estabelecer a paternidade dos filhos, antes possuía um caráter patrimonialista, e hoje passou a vincular outros caráteres, em virtude de haver uma evolução nos pensamentos jurídicos relacionados a determinados assuntos envolvendo uma nova visão do âmbito familiar, buscando-se os laços de afetividade, amor e respeito, podendo usar como exemplos de evolução a parentalidade afetiva e a dupla parentalidade.

PROBLEMA DE PESQUISA

No presente trabalho podemos perceber como sendo a problemática, a evolução dinâmica do direito ocorre como deveria? É rápida ou lenta? O legislativo cumpriu seu papel?

OBJETIVO

Quanto ao objetivo a ser alcançado, trata-se da tentativa de mostrar as mudanças na sociedade com relação a dupla paternidade, deixando claro que ainda falta muito a ser discutido pelos tribunais e poder legislativo para que os pais tenham este direito efetivado.

MÉTODO

0 método utilizado com objetivo de explanar o assunto referido no presente resumo, foi o dedutivo, trazendo argumentos de mestres e doutorandos em direito para argumentos particulares a partir de doutrinas e textos argumentativos, concluindo assim as implicações encontradas na problemática e por subsecutiva uma conclusão que se assinalou na pesquisa.

RESULTADOS ALCANÇADOS

Para uma pessoa conseguir o direito da dupla paternidade foi necessário que o IBDFAM - Instituto Brasileiro de Direito de Família defendesse a tese de que "a posse de estado de filho podia constituir paternidade" várias vezes em congressos. Sendo que o Poder Legislativo já poderia ter criado uma lei trazendo tais mudanças tão recorrentes nas utilidades, e não jogar toda a problemática para o âmbito do Poder Judiciário como é feito. Devendo também os tribunais, e os órgãos responsáveis pelas mudanças relacionadas ao direito manifestarem sua opinião consolidada sobre tal assunto de forma mais rápida, o que levou cerca de anos para se consolidar, sem ser necessário que casos concretos cheguem até suas mãos.

Atualmente o Conselho Nacional de Justiça (CN)), regulamenta o efetivo reconhecimento extrajudicial da dupla paternidade, após, já existirem decisões dos tribunais brasileiros, que tiveram de resolver varias casos, e consolidaram assim suas respectivas opiniões e entendimentos, permitindo então que tal registro seja realizado em cartórios, sem haver necessidade do magistrado para intervir nos casos concretos.

PALAVRAS-CHAVE: FAMÍLIA, PATERNIDADE, REGISTRO. 


\title{
ECOGEOMETRIA: MATEMÁTICA COM MATERIAIS RECICLADOS
}

\author{
MARCOS VINÍCIUS GUIMARÃES FERREIRA, VALÉRIA ALVES DA SILVA ROSA
}

INSTITUTO MASTER DE ENSINO PRESIDENTE ANTÔNIO CARLOS - IMEPAC

kozovskim@gmail.com

Comunicação Oral

Resumo

Área do Conhecimento: Educação para Desenvolvimento Sustentável

Introdução (Contextualização): A proposta do Projeto Integrador foi o de levamos uma proposta de multidisciplinaridade que integrasse GEOMETRIA, SUSTENTABILIDADE e TECNOLOGIA. A atividade foi desenvolvida em uma escola Municipal de Ensino Fundamental e foi uma construção coletiva entre nós, os alunos da escola e seus professores de acordo com uma sequência didática elaborada. Objetivo 0 objetivo principal foi refletir como os materiais recicláveis podem contribuir para um mundo melhor na perspectiva do desenvolvimento sustentável, discutiu-se com os alunos acerca da SUSTENTABILIDADE e usando como suporte teórico a metodologia do ensino da matemática (geometria) e a tecnologia, foi possível mostrar como materiais que iriam para o lixo poderiam ser reutilizados, reaproveitados, reciclados, etc. no sentido de evitar uma degradação ambiental pela depredação consumista. Metodologia: Atividade práticas para o ensino de sustentabilidade com uso de materiais recicláveis. Abordando necessidade de ser um tema trabalhado em todas as disciplinas. Fez-se o uso de materiais que estão sempre presentes em nosso cotidiano como: caixas, garrafas pet, latas, bobinas e outras. Buscou-se primeiro a conscientização através do filme WALL-E seguindo de roda de conversa onde sondou-se qual o conhecimento a respeito desse tema e deu-se sequência através de oficinas na execução de atividades lúdicas trabalhando as formas geométricas e a coleta seletiva. Relato da experiência: A partir do objetivo proposto, foi utilizado materiais recicláveis e, com base na interdisciplinaridade entre Geometria, Sustentabilidade e Tecnologia, foram desenvolvidas oficinas para confecção de objetos utilizando os materiais, recicláveis e/ou reutilizáveis, sempre associando a figuras geométricas. 0 objetivo principal era despertar conhecimento para tais questões e exercitar a cidadania, inteirando-os de problemas sociais e da importância da mudança de hábitos em seu contexto referente ao desenvolvimentos sustentável. Considerações finais: Aprendeu-se muito com o tema proposto, sendo de grande valia para nós enquanto experiência acadêmica enriquecedora e determinante para a construção de um bom pedagogo. Acredita-se, ainda, ter contribuído muito com a instituição que, gentilmente nos cedeu o espaço, dando liberdade para execução da proposta, o que refletiu também a credibilidade da instituição à qual está se profissionalizando. As professoras que acompanharam o processo, relataram do entusiasmo das crianças e da alegria de todos em participarem de cada atividade deixando claro que sentiram motivadas e também conscientes de sua importância na construção de cada indivíduo em sua totalidade. Espera-se por novas oportunidades em dar continuidade a esse projeto, pois sabemos que nada tem seguimento apenas com verbalismo e ativismo.

PALAVRAS-CHAVE: GEOMETRIA, SEQUÊNCIA DIDÁTICA, SUSTENTABILIDADE E TECNOLOGIA. 


\title{
EDUCAÇÃO AMBIENTAL DESENVOLVIDA PELO PROGRAMA GIRA SOL
}

\author{
SÍLVIA HELENA FERNANDES SOUSA, ALINE FERNANDES HIPÓLITO
}

SECRETARIA MUNICIPAL DE EDUCAÇÃO

shfsousa@hotmail.com

Comunicação Oral

\section{Resumo}

Área do Conhecimento: Educação para Desenvolvimento Sustentável

Introdução e objetivo: A vida no planeta Terra acontece em meio a uma série de fatores e condições: água, clima, variedade e diversidade biológica, integração de todos os sistemas. Mas, todos esses fatores estão sendo alterados, provocando o desequilíbrio no Planeta. A preservação do meio ambiente é condição essencial para a sobrevivência de todos nós. A conscientização atrelada à ação é a única forma de mudar essa situação. Por esse motivo desde 1997, o Programa de Educação Ambiental Gira Sol da Secretaria Municipal de Educação trabalha com afinco na luta em defesa do meio ambiente, objetivando sensibilizar, mobilizar, conscientizar e provocar atitudes proativas de toda a clientela estudantil e população. 0 Programa contempla os eixos temáticos energia, água, cerrado, fauna e flora, degradação do solo, atmosfera e crescimento, lixo e miséria.

Metodologia: O programa trabalha com a confecção de materiais pedagógicos, além de palestras, teatros, entre outras atividades relacionadas aos cuidados ao meio ambiente, que são disponibilizadas e realizadas com todas as escolas municipais e estaduais e os Centros Municipais de Educação Infantil da cidade de Araguari-MG. Ressaltamos a urgente necessidade de políticas públicas sérias, debates, e ações em torno da questão ambiental. E destacamos que é preciso disseminar entre as crianças, jovens e adultos uma nova consciência e novas atitudes quanto à sobrevivência no planeta Terra. A escola é um espaço fundamental para exercitar essas preocupações. Por isso, a educação ambiental precisa ser feita de forma interdisciplinar, intervindo e influindo nas mais diferentes áreas do conhecimento humano.

Resultados: É essencial destacar que o resultado do trabalho de educação ambiental é a logo prazo, mas hoje já podemos perceber mudanças de comportamento de vários educandos, com as atividades permanentes desenvolvidas nas instituições de ensino. E o papel do professor é fundamental para trabalhar a educação ambiental de forma efetiva, para garantir uma melhor qualidade de vida hoje e para as futuras gerações.

Conclusão: É preciso acabar com a impunidade que ainda acoberta e protege os responsáveis pelos fracassos de muitas iniciativas lúcidas preservacionistas fazendo-os reparar os malefícios causados ao meio ambiente. Essa posição é necessária e condição indispensável para se colocar a questão ecológica numa perspectiva de corresponsabilidade entre indivíduos e sociedade.

PALAVRAS-CHAVE: CONSCIENTIZAÇÃO, MEIO AMBIENTE, EDUCAÇÃO AMBIENTAL. 


\section{EDUCAÇÃO E SUSTENTABILIDADE NO CURSO DE PEDAGOGIA: DICAS PARA O USO CONSCIENTE DO ESPAÇO NOSSO DE CADA DIA}

ANA LUCIA COSTA E SILVA, MIRNA GERTRUDES RIBEIRO OLIVEIRA,

INSTITUTO MASTER DE ENSINO PRESIDENTE ANTÔNIO CARLOS - IMEPAC

anaciacosta332@gmail.com

Comunicação Oral

Resumo

Área do Conhecimento: Educação para Desenvolvimento Sustentável

Introdução: temos consciência da necessidade do uso adequado dos recursos disponíveis, mas nem sempre somos conscientes de nossas ações. Nesse sentido, analisando o curso de licenciatura como a Pedagogia, é imperativo que se trabalhe esse repensar do cuidado com o ambiente tanto humano quanto contextual, para que as gerações -atuais e futuras- responsabilizem-se por esse cuidado. A escolha desta proposta surgiu na disciplina "Projeto Integrador: Educação ecológica e escola sustentável", pela necessidade de sensibilizar os alunos para importância do seu papel junto aos pares e nos locais onde atuam para o desenvolvimento sustentável dentro das dimensões sociais da educação. Desse modo, a atividade desenvolvida junto aos alunos do sexto período tinha como objetivo apresentar a resolução de forma criativa para um problema real, constituindo-se em um desafio cognitivo, cuja solução demandasse pesquisa, extensão e estudo na área da educação ambiental, em espaços escolares e não escolares, utilizando as tecnologias contemporâneas de informação e comunicação, para trabalhar sensibilização e conscientização sobre ações sustentáveis. Metodologia: 0 projeto foi desenvolvido em uma turma de 42 acadêmicos do curso de Pedagogia de ima instituição de ensino privada do município de Araguari (MG) e constou de oficinas, realizadas em parceria com a professora de Metodologia do Ensino de Ciências e da construção de dicas de sustentabilidade, atividade inserida na metodologia do arco de Maguerez como uma das propostas de resolução do problema acerca da sustentabilidade. Relato da experiência: após a oficina junto a professora de metodologia e delimitação da proposta de trabalho junto as alunas, a turma foi dividida em grupos e orientada a utilizar o aplicativo CANVA para criar dicas que fossem compartilhadas nas redes sociais dos grupos da sala bem como, junto a instituição de ensino, via grupos de whatsapp, além de serem inseridas no status de cada aluno da sala. A proposta foi colocada em prática, pois não seria adequado realizar uma atividade extramuros e não cuidar do próprio ambiente de formação. As dicas deveriam ser de caráter prático e/ou reflexivo e, ao final, foram apresentadas no formato de e-book de dicas. Considerações finais: A realização deste projeto foi de grande valor para a formação acadêmica dos alunos, visto que proporcionou experiências favoráveis ao crescimento profissional no âmbito de sua formação e permitiu que conhecimento teórico-prático, sobre ações eficazes acerca da sustentabilidade, fosse colocado em pauta e executado nos diversos contextos, refletindo em sua atuação profissional junto aos alunos sob sua responsabilidade. 


\title{
EDUCAÇÃO EM SAÚDE NO PUERPÉRIO: O PAPEL DO ENFERMEIRO NA ATENÇÃO PRIMÁRIA
}

\author{
JOÃO PAULO ASSUNÇÃO BORGES, LARISSA CAROLYNE VELOSO DE FREITAS GUILHERME, JOÃO \\ PAULO ASSUNÇÃO BORGES
}

INSTITUTO MASTER DE ENSINO PRESIDENTE ANTÔNIO CARLOS - IMEPAC

enf_joaopaulo@yahoo.com.br

Apresentação de Pôster

Resumo

Área do Conhecimento: Saúde coletiva e bem-estar

Introdução: No âmbito da Atenção Primária à Saúde (APS) são realizadas diversas ações voltadas aos diferentes ciclos de vida, dentre eles o período puerperal. 0 acompanhamento da mulher e da criança durante o Puerpério está entre os principais eixos do cuidado Materno-infantil. Nesta abordagem, as práticas de Educação em Saúde são ferramentas importantes utilizadas pelo enfermeiro e vão além da transmissão de informações, buscando compartilhar vivências e experiências entre profissionais e comunidade, bem como produzindo mudanças de pensamento e comportamento na puérpera, aprimorando o desempenho materno no auto-cuidado e no cuidado com a criança. Objetivos: identificar e apresentar as evidências científicas mais atuais sobre a importância da Educação em Saúde direcion ada à puérpera realizada nas unidades de APS. Métodos: trata-se de um estudo do tipo revisão de literatura, descritivo, baseado em artigos científicos, publicados nos últimos dez anos. Os artigos foram obtidos por meio de busca avançada na base de dados Biblioteca Virtual de Saúde, utilizando os descritores em Ciências da Saúde: atenção primária, educação em saúde, puerpério e enfermagem. A seguir, foram analisados e extraídas as informações primárias acerca do tema de interesse da pesquisa. Resultados: Encontrou-se que o enfermeiro tem o papel de prestar cuidado direto por meio de ações assistenciais, preventivas e educativas na APS, englobando um conjunto de ações de saúde, no âmbito individual e coletivo. As mulheres durante o puerpério requerem acompanhamento sistematizado devido às particularidades dos seus cuidados. A literatura aponta que a Educação em Saúde deve abordar as mudanças emocionais e corporais vivenciadas pelas mães, além do enfoque reducionista do cuidado biológico. A mulher-mãe deve ser avaliada de um modo individualizado, sistematizado e humanizado valorizando sua subjetividade. Identificou-se ainda que a prática educativa realizada pelos enfermeiros utiliza diversas estratégias, sendo os grupos e palestras as mais comuns. Os principais temas apontados nas ações são os cuidados com recémnascido, orientações relativas à amamentação e à alimentação da nutriz. Também foi evidenciada a escassez de ações educativas sobre o auto-cuidado da puérpera no pós-parto imediato e tardio. Conclusão: Esta pesquisa contribuiu para conhecer as práticas de Educação em Saúde voltadas para o puerpério desenvolvidas por enfermeiros na APS. É necessário que o enfermeiro esteja atento às necessidades das puérperas na construção do conhecimento e a sua prática educativa valorize o saber social das mulheres, promovendo a saúde do binômio mãe-filho durante o puerpério e melhorando a qualidade de vida durante a maternidade.

PALAVRAS-CHAVE: EDUCAÇÃO EM SAÚDE; ATENÇÃO PRIMÁRIA À SAÚDE; PUERPÉRIO; ENFERMAGEM. 


\title{
EFEITO DA CAPOTERAPIA SOBRE OS COMPONENTES DA CAPACIDADE FÍSICA DE IDOSAS NÃO INSTITUCIONALIZADAS
}

\author{
MARIELY CAROLINE DA SILVA PACHECO, HUGO RIBEIRO ZANETTI, ALEXANDRE GONÇALVES
}

INSTITUTO MASTER DE ENSINO PRESIDENTE ANTÔNIO CARLOS - IMEPAC

maripacheco13@hotmail.com

Apresentação de Pôster

\section{Resumo}

Área do Conhecimento: Saúde coletiva e bem-estar

\begin{abstract}
Introdução: 0 envelhecimento é um processo natural do ser humano, que leva a alterações estruturais e funcionais do organismo, a quais acarretam diminuição das capacidades físicas, com comprometimento das atividades da vida diária. Nessas condições a prática de exercícios físicos é uma forma de prevenir e tratar estas alterações funcionais provenientes do processo de envelhecimento. Além dos métodos tradicionais de exercícios, atualmente métodos alternativos começam a ser aplicados para tais fins. A capoterapia tem uma grande possibilidade de desenvolver os componentes da saúde, resistência aeróbica, força muscular, flexibilidade e composição corporal dos indivíduos, proporcionando melhorias capacidade funcional de idosos. Objetivo: 0 objetivo deste estudo foi analisar a influência da capoterapia sobre os componentes da capacidade física de idosas não institucionalizadas. Método: Participaram da pesquisa vinte e duas idosas com idade mínima de sessenta anos de idade que frequentavam o projeto capoterapia na área de abrangência do Centro de Convivência/Unidade Taguatinga-DF. A atividade foi aplicada em um período de nove semanas as terças e quintas das oito as nove horas da manhã com duração de sessenta minutos, totalizando dezoito aulas entre julho e setembro de 2016. As capacidades físicas foram avaliadas através dos testes de flexão de antebraço, levantar e caminhar 2,44m, sentar e levantar da cadeira. Todos os testes foram realizados pré e pós intervenção. Para análise estatística dos resultados foi utilizado o teste teste tstudent, com nível de significância > 0.05. Resultados: Todos os dados obtidos pelos testes para as capacidades físicas de força e resistência muscular de membros superiores e inferiores (flexão de antebraço; sentar e levantar da cadeira, respectivamente) e mobilidade, velocidade e equilíbrio dinâmico (teste de levantar e caminhar $2.44 \mathrm{~m}$ ) aplicados após as nove semanas de intervenção foram, significativamente, maiores que aqueles obtidos pelos mesmos testes pré intervenção. Conclusão: De acordo com o resultados obtidos e metodologia aplicada pode-se concluir que um programa de a nove semanas de capoterapia aplicada duas vezes por semana foi eficaz para melhoria das capacidades físicas de idosas não institucionalizadas.

PALAVRAS-CHAVE: IDOSAS; CAPOTERAPIA; CAPACIDADE FÍSICA.
\end{abstract}




\section{EFEITOS DA EMBRIAGUEZ NO TRABALHO E O RISCO DE RESCISÃO CONTRATUAL POR JUSTA CAUSA}

ROSALIA MARIANA DO VALE CABRAL, WEBER GABRIEL RESENDE, RODRIGO GUILHERME TOMAZ

INSTITUTO MASTER DE ENSINO PRESIDENTE ANTÔNIO CARLOS - IMEPAC

rosaliakbral@hotmail.com

Apresentação de Pôster

Resumo

Área do Conhecimento: Sustentabilidade e Direitos

O presente estudo buscará demonstrar os efeitos da embriaguez no contrato de trabalho perante a rescisão contratual por justa causa por culpa do empregado.

Considerando a embriaguez ser um fato recorrente na sociedade, o problema desta pesquisa é perquirir: Quais as possíveis consequências que a embriaguez pode gerar no contrato de trabalho em relação à rescisão contratual?

OBJETIVO

Quanto ao objetivo, refere-se à tentativa de mostrar a atitude que o empregador deverá ter perante o caso concreto onde o funcionário apresentar sintomas de embriaguez no trabalho, através da análise do art. 482, alínea f da Consolidação das Leis do Trabalho (CLT).

MÉTODO

Para o alcance dos resultados esperados na atual pesquisa será seguido o método dedutivo, a partir de um contexto geral para contextos particulares.

RESULTADOS

Buscando a resolução do conflito proposto encontramos que o empregado que aparece embriagado no serviço, conforme art. 482, alínea f da CLT, poderá ser dispensado por justa causa, porém, a doutrina te m aprofundado tal entendimento.

A embriaguez pode ser dividida em ocasional e crônica, esta considerada como uma dependência química, ou seja, alcoolismo conforme classifica Passagli (2011, p.83). Quando se tratar de embriaguez ocasional (em serviço) poderá ser motivo de demissão por justa causa, desde o primeiro fato ocorrido. Porém, tratandose de alcoolismo o empregador deverá enviar o funcionário para tratamento médico suspendendo o contrato de trabalho enquanto ele estiver afastado pela Previdência Social.

0 alcoolismo é considerado uma síndrome de dependência do álcool conforme está disposto na Classificação Internacional de Doenças, CID-10 F-10 (OMS, 2009, p.316), ou seja, uma patologia que causa compulsão e induz o indivíduo a consumir de maneira descontrolada o álcool, fazendo-o perder todo o discernimento.

Quando se tratar de dependência química, o empregador não poderá dispensar o empregado por justa causa por se tratar de ato de discriminação bem como ato abusivo (DELGADO, 2018, p. 1426).

CONCLUSÃO

O empregado acometido de alguma doença necessita de atenção especial e de ter assegurado seu benefício perante a Previdência Social. Sendo assim, o art. 482, alínea f, da CLT, é discriminatório por tratar o alcoólatra com a punição mais severa, justa causa, e não com tratamento como é oferecido para outras doenças. 


\title{
EFEITOS DO BARBATIMÃO NA CICATRIZAÇÃO EM EQUINOS
}

\author{
ROGERS FERNANDES VIEIRA, GILSON ÁVILA DE ANDRADE, GUILHERME MEROLA MARQUES, \\ MARCOS VINÍCIOS MENDES DE SOUZA, MARIA DE FÁTIMA SOUSA SQUISSATO , THIAGO \\ ABRANCHES SILVA, DANIELLE VITORINO MORAES
}

INSTITUTO MASTER DE ENSINO PRESIDENTE ANTÔNIO CARLOS - IMEPAC

rogersfv@hotmail.com

Apresentação de Pôster

Resumo

Área do Conhecimento: Responsabilidade, Tecnologia e Ciência

Introdução: O desafio em promover uma cicatrização por segunda intenção (aberta) é substituir a precisão pela velocidade de reparo, seguindo as fases na ordem inflamatória, proliferativa e manutenção. Assim sendo, o artigo tem por objetivo fazer uma revisão por relatar a utilização do barbatimão (Stryphnodendron Barbatiman) e mostrar as vantagens do fitoterápico utilizado na estrutura fisiológica e anatômica de ferimentos em equinos.

Metodologia: 0 trabalho foi desenvolvido através do acompanhamento do caso de um acidente com uma potra de 9 meses, a qual sofreu laceração cutânea e muscular profunda em um acidente físico. Após cirurgia de reconstituição o tratamento foi todo feito com a administração tópica do chá de barbatimão.

Relato da experiência: A potra foi atendida por um médico veterinário, que se deparando com uma grande lesão na região da escápula/úmero com laceração muscular profunda, já contaminado pela utilização de medicamentos aerossol, repelente, e cicatrizantes, com claudicação e arrastando o membro acometido. 0 proprietário pediu que suturasse mesmo consciente dos riscos devido à contaminação instalada na ferida. No terceiro dia após o procedimento começou um processo de necrose na sutura ocorrendo em seguida a deiscência dos pontos. No oitavo dia a lesão já estava completamente aberta e a musculatura novamente exposta, com a vantagem de ter preservado as transfixações e aproximação muscular, tendo ocorrido somente o rompimento da pele. A partir desse fato o médico veterinário então sugeriu a utilização da erva (barbatimão) em infusão no tratamento da ferida. Os curativos eram feitos através da assepsia do ferimento com água corrente e detergente neutro debridando toda ferida , aplicava-se a clorexidina e deixava por alguns minutos, depois se retirava com água corrente, secava-se com gaze e aplicava o chá de barbatimão, extraído da casca através da fervura em água filtrada por aproximadamente $20 \mathrm{~min}$. Solução rica em tanino, sua combinação com alcalóides, saponinas, flavonóides tem ação antisséptico, anti-inflamatório, antiedematogênico, antioxidante, adstringente, analgésico, cicatrizante e antimicrobiano. Em seguida passavase unguento nos bordos da ferida, intercalando a cada três dias a utilização do unguento spray (UNGÜENTO PLUS AEROSOL $囚$, contendo a cada 100g : Óxido de Zinco - 25,0g Permetrina - 0,5g Excipiente Propelente: Butano q.s.p - 100,0g). 0 procedimento foi realizado diariamente. 0 barbatimão foi utilizado durante todo tratamento, enquanto apresentava o tecido vivo sem o fechamento total da pele. Do primeiro dia de atendimento até a cicatrização total da ferida foram absolutos 64 dias. Final do tratamento.

PALAVRAS-CHAVE: EQUINOS, FERIDAS, CICATRIZAÇÃO, FITOTERÁPICO, BARBATIMÃO. 


\title{
EJA: O DESPERTAR DO ENCANTO PELA LEITURA
}

\author{
SARA CRISTINA FERNANDES DE SOUSA, CARLA PATRÍCIA CARRIJO, JOYCE EMANUELE AVELINO \\ DE MORAIS, RAFAELA HONÒRIA DE ALMEIDA, RAQUEL APARECIDA GOMES EVARISTO, PROF. ${ }^{a}$ M. $^{a}$ \\ ANA LÚCIA COSTA E SILVA
}

INSTITUTO MASTER DE ENSINO PRESIDENTE ANTÔNIO CARLOS - IMEPAC

sarafersousa1807@gmail.com

Apresentação de Pôster

Resumo

Área do Conhecimento: Educação e Inclusão

Introdução: A Educação de Jovens e Adultos (EJA) é uma modalidade de ensino destinada a alunos que por algum motivo não cursaram ou concluíram a Educação Básica na "idade certa" tendo por finalidade propiciar o desenvolvimento integral do aluno, prepará-lo para o acesso às competências básicas, facilitando sua inserção no mundo do trabalho. Infelizmente, a EJA enfrenta muitos desafios: acúmulo de funções, falta de apoio familiar, desmotivação dos discentes e dos professores, ausência de comprometimento dos estudantes, problemas sociais. Ademais, os educandos possuem uma grande dificuldade em ortografia, interpretação, produção textual e na própria leitura. Essas problemáticas são advindas pela carência do hábito de ler. Objetivo: minimizar as problemáticas citadas relacionadas à carência do hábito da leitura das turmas $8^{\circ}$ e 9o anos da EJA de uma escola da rede pública estadual, da cidade de Araguari-MG, por meio de atividades e dinâmicas. Metodologia: na tentativa de minimizar os problemas desses alunos, realizamos dinâmicas de grupo para trabalharmos as relações interpessoais, autoestima, otimismo, criatividade, criticidade e a individualidade de cada discente. Além das dinâmicas de grupo, utilizamos leituras para incitar a produção de textos com foco no gênero literário poesia, a partir da técnica "palavra puxa palavra", adiante foram realizados momentos para a leitura das próprias composições textuais. Importante destacar que a realidade e experiência de vida de cada educando também foram consideradas dentro das atividades propostas. Resultados: Foi possível observar que com metodologias adequadas, estímulo a leitura e a produção textual, pudemos chegar a resultados satisfatórios e otimistas, superando as expectativas. A partir desses incentivos obtivemos poemas lindos, críticos e ricos em vivências, os quais produziram um livro de poesias, denominado "A leitura é o caminho da sabedoria", onde os escritores e ilustradores foram os próprios alunos. Conclusão: Avalia-se o projeto "EJA: o despertar do encanto pela leitura", como um aprendizado para ambas as partes, os discentes demonstraram um grande interesse e receptividade para o novo, sentiram-se valorizados e respeitados como cidadãos e os estudantes em formação, tiveram contato com a prática, sentindo-se engajados na possibilidade de construir uma nova educação. Portanto, a leitura é capaz de transformar vidas, mentes e valores, pois ela é fonte infi nita de conhecimento e encantos.

PALAVRAS-CHAVE: LEITURA, EJA, DISCENTE, ESCRITA. 


\title{
EQUIPAMENTO DE PROTEÇÃO INDIVIDUAL - EPI NR6
}

\author{
PEDRO HENRIQUE MELO FERREIRA, CRISTIANO MARQUES GOMES DE GODOI, MARCELO DE PAULA \\ SILVA, MARIANA DA SILVA SANTOS, RENATO SANTOS DE GODOI, DANIELA DANTAS
}

INSTITUTO MASTER DE ENSINO PRESIDENTE ANTÔNIO CARLOS - IMEPAC

ferreirapedro_1994@hotmail.com

Apresentação de Pôster

Resumo

Área do Conhecimento: Saúde coletiva e bem-estar

Introdução: 0 presente trabalho tem como tema Discorrer sobre o Equipamento de Proteção Individual (EPI) em uma empresa do ramo de construção civil da cidade de Uberlândia/MG. A análise desta pesquisa busca fundamentar-se em teorias sobre a Gestão de Pessoas, Segurança no Trabalho, bem como análises no próprio canteiro de obras. 0 estudo caracteriza-se como uma pesquisa aplicada, abordando o problema, a falta de conscientização do uso de EPI, de forma qualitativa, com seus objetivos expostos de forma descritiva, e tem por base teórica a pesquisa bibliográfica, sendo também um estudo de caso.

Objetivo: Identificar quais são os principais motivos que levam os trabalhadores da construção civil a deixarem de usar o Equipamentos de Proteção Individual (EPI) durante a execução de suas atividades, bem como analisar os equipamentos de segurança em relação ao trabalhador e as medidas que podem ser adotadas para melhor desempenho do equipamento e trabalhador como um todo.

Metodologia: Trata-se de uma pesquisa qualitativa, exploratória em uma "obra de fundações" e, portanto, tem grau de risco 4. 0 total de funcionários é menor que 250, sendo assim há necessidade de um técnico de segurança, um engenheiro de segurança e ainda um médico do trabalho. Para a apresentação dos resultados obtidos neste estudo de caso, utilizou-se questionário baseado na NR-6.

Resultados: Conforme dados coletados na pesquisa, por meio da aplicação de um questionário a 80 operários que trabalham no canteiro de obras na cidade de Uberlândia/MG, obteve-se um diagnóstico do comportamento das construtoras e/ou empreiteiras de mão de obra e dos trabalhadores em relação ao uso de equipamentos de proteção individual. Observou-se com a pesquisa que $80 \%$ dos entrevistados usam ou já participaram de palestras sobre segurança do trabalho e uso de EPIs fornecidos pelas empresas. De um modo geral, muitos são os fatores que levam os prestadores de serviço de mão de obra da construção civil a negligenciar o uso de equipamentos de proteção individual.

Conclusão: Este trabalho procurou identificar, através do uso de técnicas qualitativas de coleta e tratamento dos dados, as percepções dos trabalhadores da construção civil em relação ao uso do Equipamento de Proteção Individual (EPI) durante a execução dos serviços. Os estudos apontaram diversos problemas na gestão da segurança do trabalho das empresas. Além das falhas na gestão da segurança por parte dessas empresas, destacam-se a mudança constante do espaço ao longo do tempo, alta rotatividade de trabalhadores e a baixa qualificação da mão-de-obra requerida, como obstáculos a serem superados para a melhoria da segurança no ambiente de trabalho.

PALAVRAS-CHAVE: EQUIPAMENTO DE PROTEÇÃO INDIVIDUAL, SEGURANÇA NO TRABALHO, CONSTRUÇÃO CIVIL. 


\title{
ERROS NAS INSERÇÕES DE DADOS E O IMPACTO DO PLANEJAMENTO TRIBUTÁRIO
}

\author{
RENATA LORRANA DE SOUSA MENDONÇA FERREIRA, CHRISLAYNE MARTINS ARAÚJO, ÉRIKA YUMI \\ OHASHI, JÉSSICA SILVA DIAS, KAIQUE SILVA, THAÍS BATISTA MONTES, FABIANO JOSÉ LUCAS \\ SANTOS
}

INSTITUTO MASTER DE ENSINO PRESIDENTE ANTÔNIO CARLOS - IMEPAC

renata_lorrana@hotmail.com

Apresentação de Pôster

Resumo

Área do Conhecimento: Responsabilidade e Negócios

Tendo em vista o desenvolvimento de um trabalho de pesquisa utilizando a Metodologia da Problematização com o Arco de Maguerez, escolhemos como campo de observação da realidade os problemas existentes em uma organização de comércio varejista como erros na inserção de dados que impactam no planejamento tributário.

A realidade foi observada em uma empresa do ramo varejista sediada na cidade de Araguari/MG, a empresa possui 155 funcionários, e seu regime tributário é apurado sobre o Lucro Real.

O objetivo é mostrar as consequências geradas pela inserção de dados errados e/ou a falta do mesmo, e possíveis soluções para evitar que o erro aconteça. Compreendemos que estudar mais profundamente sobre este tema buscando soluções para esse problema contribuirá para evitar uma excessiva carga tributária sobre a empresa.

No campo investigado, notamos que há divergências nos dados inseridos nos sistemas de controle da empresa. Além disso, há uma junção dos patrimônios dos sócios, tanto pessoa física quanto jurídica, o que dificulta na contabilização das despesas, bem como a tributação da mesma. E também os erros de natureza de operação, de produtos adquiridos para insumos com CFOP de revenda.

Porém, o foco da nossa problematização se concentra na mistura de patrimônios da pessoa jurídica com a física que acarreta erros que dificultam o planejamento tributário e financeiro da empresa.

Dessa forma, as observações nos conduziram ao delineamento do seguinte problema de investigação: quais são as maiores desvantagens tributárias quando ocorre o erro na inserção de dados fiscais devido a mistura de patrimônios físicos e jurídicos e o que pode ser feito para solucionar tal problema.

Procuramos identificar os possíveis fatores imediatos associados ao problema em questão. Dessa forma, identificamos os seguintes ponto-chaves: cadastro incompleto e/ou errado de produtos; produtos com natureza de operação divergentes da sua finalidade; tipos de tributação diferentes para o mesmo produto; aquisição de produtos para duas empresas em um único CNPJ; caixa sendo utilizado indevidamente para as despesas dos sócios. Ao considerar possíveis determinantes maiores, elencamos como pontos principais que levam ao erro na inserção de dados: Produtos com natureza de operação divergentes da sua finalidade e Aquisição de produtos para duas empresas em um único CNPJ. Nesta etapa, buscamos uma fundamentação teórica que nos propiciasse uma maior compreensão a respeito dos ponto-chaves levantados e que, consequentemente, pudesse nos conduzir às hipóteses de solução para o problema eleito. Esses aspectos foram objetos de uma revisão da literatura e nos levaram a destacar os seguintes tópicos para teorizar: Nota Fiscal Eletrônica; Contabilidade Tributária; Contabilidade Gerencial; Planejamento Estratégico;Contabilidade de Custos.

PALAVRAS-CHAVE: NOTA FISCAL ELETRÔNICA; CONTABILIDADE TRIBUTÁRIA; CONTABILIDADE GERENCIAL; PLANEJAMENTO ESTRATÉGICO;CONTABILIDADE DE CUSTOS, PLANEJAMENTO TRIBUTÁRIO, ARCO DE MAGUEREZ. 


\title{
ESCASSEZ DOS RECURSOS HÍDRICOS: A BUSCA PELA EDUCAÇÃO AMBIENTAL SUSTENTÁVEL
}

\author{
SARA FRANCIENE DE OLIVEIRA, JAQUELINE PEREIRA ALVARENGA, GEILSON NUNES
}

INSTITUTO MASTER DE ENSINO PRESIDENTE ANTÔNIO CARLOS - IMEPAC

sarakokmah@hotmail.com

Apresentação de Pôster

\section{Resumo}

Área do Conhecimento: Educação para Desenvolvimento Sustentável

Introdução: O presente trabalho terá por objetivo discorrer sobre a sustentabilidade dos recursos hídricos na ordem jurídica Brasileira. Nessa perspectiva, de interesse global, a água é essencial para a perpetuação da vida e o quadro de escassez é um fator que preconiza a necessidade de desenvolver uma Educação Ambiental trajado de seus princípios jurídicos com a sustentabilidade.

Objetivo: Objetiva-se neste trabalho discutir a Educação Ambiental Sustentável como instrumento de intervenção nas esferas e conjunturas do processo educativo, seja no aspecto formal ou não com vistas à promoção de uma consciência crítica e interventiva entre todos os sujeitos da sociedade.

Metodologia: Para alcançar os resultados almejados no presente trabalho, adotar-se-á o método dedutivo de pesquisa, abrangendo a teoria e fatos concretos exemplificativos, para alcançar os objetivos propostos. Resultados: A educação ambiental em todos os níveis de ensino e a conscientização pública para a preservação do meio ambiente deve ser promovida pelo Poder Público o que a torna elemento imprescindível para consolidar a participação social e cidadã suscitando uma consciência crítica e interventiva entre todos os sujeitos da sociedade em face de degradação ambiental. As ações socioeducativas permitem transmutar o liame entre sociedade, ser humano e natureza, isto é, de modo a transformar este cenário, visto que Educação Ambiental Sustentável é mola propulsora e transformadora quando se acopla a uma mutua corresponsabilização entre os indivíduos tornando possível o ensejo de uma nova espécie de desenvolvimento, isto é, o desenvolvimento sustentável. Assim, para que haja mobilização social entre os indivíduos se faz necessário difundir uma cultura de sustentabilidade através da educação ambiental e políticas públicas que garanta o necessário e primordial a condição de vida digna e sustentável. Conclusão: Frente às considerações e reflexões, é possível concluir sinteticamente, que a educação ambiental propicia o desenvolvimento sustentável e consolida a construção da cidadania ambiental e ecológica onde os protagonistas sociais de forma harmonizada, alicerçar a dignidade da pessoa humana com o ambiente e encontrar equilíbrio entre si.

PALAVRAS-CHAVE: DIREITO AMBIENTAL; EDUCAÇÃO AMBIENTAL; SUSTENTABILIDADE. 


\title{
ESTADO NUTRICIONAL, PERFIL BIOQUÍMICO E HÁBITOS ALIMENTARES DE MOTORISTAS DE ÔNIBUS NOTURNOS E DIURNOS
}

\author{
GLAUCYA RAFAELA NASCIMENTO FERNANDES, ANA ROSE NUNES SILVA, EDILAMAR APARECIDA \\ DE MELO, NATHALIA ELIAS BARBOSA, LAURA CRISTINA TIBILETTI BALIEIRO, LUANA THOMAZETTO \\ ROSSATO
}

INSTITUTO MASTER DE ENSINO PRESIDENTE ANTÔNIO CARLOS - IMEPAC

glaucyarafaela@gmail.com

Apresentação de Pôster

Resumo

Área do Conhecimento: Saúde coletiva e bem-estar

Introdução: 0 trabalho em turnos (TT) é fundamental na sociedade moderna, entretanto, essa modalidade laboral pode influenciar negativamente a qualidade nutricional da dieta e o estado nutricional, bem como favorecer o desenvolvimento de doenças crônicas não-transmissíveis incluindo: obesidade, diabetes mellitus, doenças cardiovasculares, síndrome metabólica, câncer. Nesse contexto estão inseridos os motoristas de ônibus, os quais podem apresentar comprometimento da saúde em virtude das condições de trabalho. Objetivo: Avaliar e comparar o estado nutricional, perfil bioquímico e consumo alimentar de motoristas de ônibus noturnos e diurnos. Metodologia: Trata-se de um estudo transversal, realizado em uma empresa de ônibus, em Uberlândia, Minas Gerais. Participaram do estudo 80 motoristas noturnos e 20 motoristas diurnos. Foi utilizado um questionário para avaliar os aspectos sociodemográficos e um questionário de frequência alimentar semiquantitativo, para avaliação dietética. 0 perfil bioquímico foi obtido por meio de dados fornecidos pela empresa, foram avaliados os níveis de glicemia de jejum, colesterol total, colesterol de lipoproteína de alta densidade (HDL-c), colesterol de lipoproteína de baixa densidade (LDL-c), colesterol de lipoproteína de densidade muito baixa (VLDL-c) e triglicerídeos. Para avaliação do estado nutricional, foram aferidos, peso e altura para o cálculo do índice de massa corporal (IMC) e circunferência da cintura. Resultados: Os motoristas noturnos apresentam uma média de idade menor quando comparado aos motoristas diurnos ( 44,0 anos $\pm 8,5$ versus 47,7 anos $\pm 6,1$, respectivamente, $\mathrm{p}=0,037)$. Uma diferença significativa entre os grupos foi observada para a média de peso $(84,6 \mathrm{~kg} \pm 18,9$ motoristas diurnos versus $89,3 \mathrm{~kg} \pm 11,9$ nos motoristas noturnos; $\mathrm{p}=0,007)$ e IMC $\left(27,9 \mathrm{~kg} / \mathrm{m}^{2} \pm 6,1\right.$ para motoristas diurnos e $29,0 \mathrm{~kg} / \mathrm{m}^{2} \pm 3,4$ para motoristas noturnos $\mathrm{p}=0,00$ ), demonstrando que os motoristas noturnos apresentaram maior média de peso e IMC, porém ambos os grupos apresentaram excesso de peso quando avaliados pelo IMC. Não foram encontradas diferenças significativas entre os grupos no perfil bioquímico. Em relação ao consumo alimentar ao analisar o consumo de energia e dos macronutrientes (carboidratos, proteínas e lipídios), observou-se uma diferença significativa entre os grupos apenas para o consumo de lipídios $(70,5 \mathrm{~g}$ [9,0g - 217,] ] trabalhadores noturnos versus 61,0g [28,0g - 140,0g] diurnos, $\mathrm{p}=0,033)$. Conclusão: Conclui-se que os motoristas noturnos apresentaram uma diferença significativa no peso e no IMC e também apresentaram uma maior ingestão de lipídios quando comparados aos motoristas diurnos. Esses resultados demonstram a necessidade de aconselhamento e programas de intervenção no estilo de vida para esses trabalhadores, para que assim tenham ganhos em saúde e qualidade de vida. PALAVRAS-CHAVE: TRABALHADORES EM TURNOS, CONSUMO ALIMENTAR, ESTADO NUTRICIONAL. 


\title{
ESTÁGIO CURRICULAR SUPERVISIONADO NA ATENÇÃO PRIMÁRIA À SAÚDE: VISÃO DOS ACADÊMICOS DE FARMÁCIA
}

\author{
JOÃO PAULO ASSUNÇÃO BORGES, MAGDA MARIA BERNARDES, RITA ALESSANDRA CARDOSO, \\ SUNARA MARIA LOPES, VICTOR GABRIEL DE MORAIS, JOÃO PAULO ASSUNÇÃO BORGES, RITA \\ ALESSANDRA CARDOSO
}

INSTITUTO MASTER DE ENSINO PRESIDENTE ANTÔNIO CARLOS - IMEPAC

enf_joaopaulo@yahoo.com.br

Apresentação de Pôster

Resumo

Área do Conhecimento: Saúde coletiva e bem-estar

Introdução: Atenção Primária à Saúde (APS) representa um conjunto de ações individuais e coletivas que abrange a promoção e proteção da saúde, a prevenção, o diagnóstico, o tratamento, a reabilitação, a redução de danos e a manutenção da saúde, com vistas à melhoria da qualidade de vida dos usuários do Sistema Único de Saúde (SUS). A APS é ordenadora da Rede de Atenção em Saúde, garantindo o acesso, a universalidade, a integralidade e a equidade, sempre pautada na humanização e na participação popular. Metodologia: Trata-se de um relato de experiência do estágio curricular do Curso de Farmácia que aconteceu na Unidade Básica de Saúde da Família (UBSF) Maria Eugênia na cidade de Araguari-MG, onde atuam duas equipes compostas por enfermeiros, médicos, técnicos de enfermagem, agentes comunitários de saúde, assistentes administrativos e serviços gerais. Relato da experiência: Observou-se que o trabalho das equipes prioriza as intervenções de prevenção, promoção e reabilitação dos usuários, de forma integral. Os principais serviços prestados na UBSF são: consultas médicas e de enfermagem, administração de medicamentos, curativos diversos, vacinação, coleta de exame citopatológico do colo uterino, dispensação de medicamentos básicos; assistência ao pré-natal de risco habitual, puericultura, acompanhamento de doenças crônicas não transmissíveis, encaminhamento para especialidades e ações do Núcleo Ampliado de Saúde da Família (NASF). Os atendimentos acontecem na própria unidade e no domicílio dos usuários, sendo notório que o trabalho em equipe é essencial para obter resolutividade. No estágio foram desenvolvidas diversas ações: análise de prontuários; aferição de pressão arterial e glicemia; lançamentos de dados na plataforma do E-SUS; preenchimento de formulários de consultas de puérperas; registro e análise de exames citopatológicos do colo uterino; trocas e validações de pedidos de exames laboratoriais; desenvolvimento do inventário farmacêutico e orientação da farmácia doméstica; requisição e orga nização de medicamentos e insumos; monitoramento do SISPré-natal; acompanhamento de consulta médica e de enfermagem; rotinas de vacinação; visitas domiciliares. Considerações finais: Destacamos que o estágio curricular representa uma importante etapa no processo de formação profissional e tem significativa influência no desenvolvimento de habilidades, competências e atitudes. Esse estágio possibilitou a integração de saberes de diversas disciplinas e o exercício da construção da autonomia e responsabilidade na visão de futuros farmacêuticos atuantes na APS. Além disso, propiciou a experiência acadêmicaprofissional aliada à proximidade com os serviços da APS, o contato direto com os usuários da UBSF e sua equipe e assim, permitiu a vivência da atenção básica e suas interfaces para a construção de uma visão crítica acerca do SUS e o papel do farmacêutico na saúde pública.

PALAVRAS-CHAVE: ATENÇÃO PRIMÁRIA; SAÚDE DA FAMÍLIA; ESTÁGIO (OS); ESTUDANTES DE FARMÁCIA. 


\title{
ESTRATÉGIAS PARA AUXILIAR O TRABALHO VOLUNTÁRIO DO GRUPO SEMENTE ESPERANÇA DE ASSISTÊNCIA À PACIENTES ONCOLÓGICOS
}

\author{
LUCIANA MACHADO DE CARVALHO MEROLA DE SOUSA, CARLOS NAVES DA MOTA, JULIANA \\ BERNADETE BORGES DE CARVALHO, MALVINA EULÁLIA TEIXEIRA, TERESA CRISTINA DA COSTA \\ ALVES, VALÉRIA CRISTINA VIEIRA BARBOSA, ANA LÚCIA COSTA E SILVA
}

INSTITUTO MASTER DE ENSINO PRESIDENTE ANTÔNIO CARLOS - IMEPAC

lucianacarvalhom@uol.com.br

Apresentação de Pôster

Resumo

Área do Conhecimento: Saúde coletiva e bem-estar

Introdução: Trabalho desenvolvido na disciplina de Projeto Integrador, junto ao Grupo Semente Esperança de Araguari-MG, que trabalha há cerca de onze anos apoiando pacientes de Araguari em tratamento de câncer. A partir das observações, identificamos desafios a serem vencidos: aumentar o número de voluntários; trabalhar a questão da aceitação do diagnóstico pelo paciente; necessidade de melhorar a capacitação dos voluntários; maior divulgação do trabalho realizado pela Instituição. Buscamos referencial teórico, respaldados pela Aprendizagem Social e temas como empatia, voluntariado, cuidados paliativos, para que pudéssemos elaborar estratégias que conseguissem sanar ou amenizar os problemas encontrados. Pensamos em estratégias práticas como reorganização do espaço e uma forma de divulgação do trabalho realizado pelo grupo Semente Esperança.

Objetivo: Frente ao exposto, o objetivo do trabalho foi descobrir técnicas e ou melhores práticas para abordagem dos pacientes com câncer, tanto dos que estão em tratamento quanto os que estão sob cuidados paliativos, bem como buscar formas de motivar os visitadores voluntários para participar dos treinamentos e divulgar a instituição filantrópica para maior adesão da comunidade, dentro do "Grupo Semente Esperança". Metodologia: atividade prática com o uso da Metodologia da Problematização com o Arco de Maguerez, considerando suas etapas: observação da realidade, pontos chave, teorização, hipóteses de solução, aplicação a realidade e feedback dos colaboradores. Resultados: Após o estudo, apresentamos alternativas, entre elas: promover oficinas de artesanato/pintura para os pacientes e/ou seus familiares; promover campanha para obtenção de livros a fim de ser montada biblioteca na ONG; promover um levantamento dos amigos íntimos do paciente, a fim de contactá-los e solicitar que esses promovam mais visitas, envio de mensagens ou cartas ao doente; desenvolver um projeto para levar música na visita aos pacientes; promover parceria para que os voluntários do Grupo assistam às palestras de treinamento da ONG Luta pela Vida; promover encontros entre os pacientes para troca de experiências; ministrar aula de ioga para os pacientes; aplicar as Oficinas de Oração e Vida; criar uma sala de informática na ONG para os doentes e, promover treinamento para os familiares do paciente, sobre cuidados, primeiros socorros e prevenções, divulgar o trabalho realizado pela ONG. O grupo autorizou que se fizesse a divulgação da ONG e assim organizamos uma atividade para essa finalidade.Conclusão: Os resultados foram vistos como oportunidades de desenvolvimento e crescimento do grupo e forma de aprendizagem para o grupo pesquisador, pois promover saúde não se restringe à ordem curativa e redução do tempo de tratamento do paciente oncológico. É necessário que o paciente atravesse o tratamento com mais benefícios que prejuízos, diminuindo a dor e o sofrimento.

PALAVRAS-CHAVE: APRENDIZAGEM SOCIAL; VOLUNTARIADO; HABILIDADES SÓCIOEMOCIONAIS; LIMITAÇÕES DO PACIENTE ONCOLÓGICO. 


\title{
ESTUDO DA NR - 13: CALDEIRAS E VASOS DE PRESSÃO EM UMA EMPRESA DE ARAGUARI-MG
}

\author{
CAIO CÉSAR CALDERON DE ALMEIDA, ALUÍZIO ANTÔNIO RIBEIRO, DANIEL LUIZ VIEIRA, GUSTAVO \\ CARDOSO DUARTE, IGOR MENDES MARCIANO, VINICIUS LUIZ MORAIS DA SILVA, DANIELA \\ ALMEIDA DANTAS
}

INSTITUTO MASTER DE ENSINO PRESIDENTE ANTÔNIO CARLOS - IMEPAC

caio.calmeida@yahoo.com

Apresentação de Pôster

Resumo

Área do Conhecimento: Saúde coletiva e bem-estar

Introdução: A Norma Regulamentadora número 13 (NR - 13), que foi criada em 8 de junho de 1978, sofrendo revisões pelas portarias SSMT no 2, de maio de 1984, SSMT no 23, de 27 de dezembro de 1994 e pela portaria SIT no 57 , de junho de 2008. Sua tratativa é referente às Caldeiras e Vasos de Pressão, tendo como objetivo proteger o trabalhador quando em atividade com esses equipamentos e sua aplicação é obrigatória em todas as empresas que tenham esses equipamentos instalados, estabelecendo responsabilidades e condições para a instalação, a segurança de operação de manutenção e inspeção nesses equipamentos. Diante disso, o objetivo deste trabalho foi compreender a NR-13 por meio de uma entrevista informal com funcionários do setor da caldeira, nesta empresa de Araguari - MG, para verificar a importância da aplicação da NR-13 na prática.

Metodologia: Trata-se de um trabalho onde as informações colhidas foram realizadas através de uma entrevista informal com 7 colaboradores do setor da Caldeira que exercem atividades na empresa. Foram realizadas perguntas sem um questionário específico, onde foi possível interrogar os funcionários sobre a importância da NR-13, e se a Caldeira da empresa está dentro do que é preconizado na NR-13.

Relato da experiência: Por meio dos relatos dos colaboradores da empresa foi possível compreender que a empresa possui um tipo de Caldeira Mododrum e Aquatubular, se enquadrando nos requisitos da NR - 13 sendo assim necessário o cumprimento desta Norma Regulamentadora. Para que se considere este equipamento seguro e utilizável, se faz obrigatório possuir um prontuário do equipamento in stalado com informações como pressão máxima de trabalho permitido e admissível compatíveis com o código do projeto. Ainda segundo relatos, para promover a segurança de todos os envolvidos, faz-se necessário possuir manual de operação sempre atualizado e de fácil acesso aos operadores, realizar calibração constante e conservação dos instrumentos de operação, tratamento de água para que se obtenha os parâmetros físico-químicos necessários para operação do equipamento. Quanto aos profissionais atuantes no setor, precisam ter treinamentos e reciclagens sempre atualizadas para segurança na utilização do equipamento.

Considerações finais: A prática correta da NR-13, em caldeiras e vasos de pressão, não se faz somente necessária para o bom funcionamento do equipamento, mas também o seu correto uso eleva a segurança e previne ocorrências de acidentes que, dependendo da dimensão, podem gerar consequências mortais para os trabalhadores e até mesmo para a população que reside próxima as grandes indústrias. Por meio do relato dos funcionários, foi possível compreender a necessidade e importância desta norma regulamentadora e que a empresa participante do estudo, faz corretamente a aplicação da NR-13.

PALAVRAS-CHAVE: CALDEIRA; NORMAS REGULAMENTADORAS; NR - 13; SEGURANÇA; VASOS DE PRESSÃO; 


\title{
ESTUDO E CARACTERIZAÇÃO DA CADEIA DE SUPRIMENTOS DE ARROZ, FEIJÃO E CAFÉ - UMA REVISÃO DE LITERATURA
}

\author{
CAIO CÉSAR CALDERON DE ALMEIDA, NIKE ANDERSON DA SILVA SILVANO, VICTOR LUCIO DA \\ SILVA SILVANO, WALTER RODRIGUES DE ANDRADE
}

INSTITUTO MASTER DE ENSINO PRESIDENTE ANTÔNIO CARLOS - IMEPAC

caio.calmeida@yahoo.com

Comunicação Oral

Resumo

Área do Conhecimento: Responsabilidade e Negócios

Introdução: 0 aumento crescente da demanda de alimentos no mundo figura o Brasil como um dos países líderes de produção de alimento. O SCM (Supply Chain Management) atua como uma importante estratégia organizacional, auxiliando na tomada de decisões e tornando-se um fator-chave para o planejamento das empresas do segmento de grãos. 0 arroz é um dos cereais mais produzidos e consumidos no mundo, tornando-o alimento base para mais da metade da população mundial. 0 café é uma das bebidas mais consumidas no mundo, essa tradicional cultura fez com que o Brasil atingisse o posto de maior produtor e exportador mundial, sendo o segundo maior consumidor do produto. 0 feijão comum (Phaseolus vulgares L.), possui uma posição de grande destaque no cenário agrícola Brasileiro, sendo qualificado como forte produto no mercado interno, além disso, ele dispõe de uma contribuição de proteínas e minerais no cardápio da população, e como consequência contém uma considerável importância socioeconômica.

Objetivo: Frente ao exposto, o objetivo deste trabalho foi a realização de revisão de literatura e análise bibliométrica, para melhor compreender a gestão da cadeia de suprimentos de grãos no Brasil.

Metodologia: Foi realizado uma revisão sistemática de literatura avaliando pesquisas relacionadas ao abastecimento da cadeia de suprimentos de grãos. Para tanto foi realizado análise bibliométrica do conceito de SCM na base de dados "Science Direct". Como forma de fundamentar a pesquisa proposta realizou-se busca na base de dados no dia 27 de agosto de 2018 com o termo SCM em artigos de pesquisa, aplicando os filtros: i) somente no título; ii) nos anos de 2017 e 2018 e; foram encontradas 93 publicações. Para identificar os termos mais citados na base de dados foi realizada análise bibliométrica com o software "Vosviewer 1.6.8".

Resultados A análise foi configurada para: i) mapa baseado em texto; ii) ocorrência dos termos no título, resumo e palavra-chave; iii) contagem binária; iv) no mínimo 5 ocorrências do termo. Os termos mais encontrados foram: i) SCM (35 ocorrências); ii) sustainable SCM (27 ocorrências); iii) green SCM (25 ocorrências) e GSCM (16 ocorrências). Percebe-se que os estudos de SCM estão relacionados, na maior parte das vezes, sobre estudos de sustentabilidade.

Conclusão: 0 agronegócio é um ramo de visível representatividade econômica que envolve todos os segmentos das cadeias produtivas ligadas à agropecuária. 0 Brasil possui um enorme potencial agrícola e há muitos anos figura como um dos mais relevantes produtores rurais do mundo. Nesse sentido o estudo do SCM é relevante no sentido de construir uma cadeia sustentável, o que está em consonância com a teoria.

PALAVRAS-CHAVE: “SUPPLY CHAIN MANAGEMENT”; SUSTENTABILIDADE; AGRONEGÓCIO. 


\title{
ESTUDO SOBRE O USO DE ANTIDEPRESSIVOS EM UMA FARMÁCIA PRIVADA DE DAVINÓPOLIS (GO)
}

\author{
RIBAMAR ÂNTONIO DA SILVA, JOÃO JOSÉ SIMÃO FILHO, MARCELO CARVALHO, NORMA CRISTINA \\ DE SOUSA
}

INSTITUTO MASTER DE ENSINO PRESIDENTE ANTÔNIO CARLOS - IMEPAC

farmaciadavinopolis@hotmail.com

Apresentação de Pôster

Resumo

Área do Conhecimento: Saúde coletiva e bem-estar

\begin{abstract}
Introdução: 0 número de pessoas diagnosticadas com depressão aumentou muito, e segundo a Organização Mundial de Saúde ela será um dos grandes problemas de saúde pública a ser enfrentado nos próximos anos. É perceptível o crescimento de diagnósticos de depressão em nosso cotidiano, e somado a este fato, fica evidente o aumento do uso de psicofármacos, como os antidepressivos, e a indústria farmacêutica acompanha esse crescimento ampliando seu comércio e colocando à disposição dos consumidores uma gama de produtos, distribuídos e identificados por suas classes, como os Inibidores Seletivos de Recaptação de Serotonina (ISRS), Tricíclicos e Inibidor Seletivo de Recaptação de Noradrenalina (ISRN) entre outros, tornando um dos setores mais rentáveis do mundo.

Objetivo: Pesquisar os antidepressivos mais vendidos incluindo as várias classes dos mesmos, a faixa etária e o sexo, se masculino ou feminino, que mais utilizaram estes medicamentos nos últimos dois anos.

Metodologia: Trata-se de um estudo descritivo e exploratório, com abordagem quantitativa o qual foi realizado em uma farmácia privada na cidade de Davinópolis (G0). Os dados foram obtidos segundo análises dos receituários dos pacientes que utilizaram antidepressivos no período de fevereiro de 2016 a dezembro de 2018. Os critérios de inclusão foram pacientes adultos do sexo masculino e feminino, com idade acima de 18 anos e portadores de depressão independente do estágio da doença e da presença ou não de outras patologias. Os critérios de exclusão foram pacientes não portadores de depressão.

Resultados: Observamos que em um total de 1362 pacientes estudados, os grandes usuários de antidepressivos estão representados pelo sexo feminino (71\%), enquanto que o sexo masculino é representado por uma parcela de apenas 29\%, e a faixa etária entre 56 a 65 anos de idade foram os maiores consumidores destes medicamentos. A indústria farmacêutica dispõe de uma grande variedade de psicofármacos no mercado e entre os mais vendidos encontramos a Fluoxetina (21\%) e o menos utilizado foi Imipramida $(0,3 \%)$ e a classe dos ISRS foi a mais utilizada nesse período $(61,2 \%)$, enquanto que os Tricíclicos e ISRN foram de $22,2 \%$ e $16,6 \%$ respectivamente.

Conclusão: Foi possível verificar que a fluoxetina, a qual faz parte dos ISRS foi o antidepressivo mais utilizado, provavelmente por apresentar menos reações adversas em relação aos demais psicofármacos estudados. Não observamos uso expressivo destes medicamentos pelos jovens, mas sim na faixa etária adulta (56 a 65 anos). 0 sexo feminino corresponde ao maior índice de usuários, provavelmente um conjunto de fatores pode estar envolvido nesse resultado como, alterações hormonais constantes, acúmulo de funções, responsabilidades e até mesmo porque as mulheres são mais atentas a saúde e buscam ajuda quando necessário, ao passo que os homens ainda são mais resistentes aos tratamentos.
\end{abstract}

PALAVRAS-CHAVE: DEPRESSÃO; ANTIDEPRESSIVOS; PSICOFÁRMACOS. 


\title{
EVOLUÇÃO DOS CASOS DE SÍFILIS GESTACIONAL NA ÚLTIMA DÉCADA EM ARAGUARI-MG
}

\author{
CAROLINA MARINHO FIRMINO PEIXOTO, NILO SABINO SILVA, LUANA THOMAZETTO ROSSATO
}

INSTITUTO MASTER DE ENSINO PRESIDENTE ANTÔNIO CARLOS - IMEPAC

carolinamarinho100@hotmail.com

Apresentação de Pôster

Resumo

Área do Conhecimento: Saúde coletiva e bem-estar

Introdução: A sífilis é caracterizada por ser uma doença de evolução lenta que, quando não tratada ou inadequadamente tratada, resulta em enfermidade crônica que pode trazer sequelas irreversíveis à saúde. Anualmente, essa enfermidade afeta cerca de um milhão de gestantes no mundo, podendo causar a disseminação hematogênica para o concepto, resultando em alta morbidade e mortes prematuras.

Objetivo: Investigar o número de mulheres diagnosticadas com sífilis gestacional no período de 2009 a 2018, no município de Araguari-MG.

Metodologia: Trata-se de um estudo de caráter quantitativo, descritivo e longitudinal retrospectivo, que teve como foco investigar o número de mulheres registradas com sífilis gestacional, com idade compreendida entre $\geq 10$ e $<60$ anos, no município de Araguari-MG, entre os anos de 2009 a 2018, que foram classificadas de acordo com as seguintes variáveis: zona residencial, idade, raça, escolaridade e fase clínica da doença. Os registros foram obtidos através de uma base de dados do Sistema de Informação de Agravos de Notificação disponível pelo Departamento de Informática do Sistema Único de Saúde, que permite acesso aberto as suas bases de dados pela internet.

Resultados: Foram registrados 138 casos de sífilis gestacional no período de 2009 a 2018 no município de Araguari-MG. A maioria (96,3\%) das gestantes eram moradoras da zona urbana. Foi observado que a maior parte das gestantes $(27,5 \%)$ tinham grau de escolaridade entre $5^{\mathbf{a}}$ a $8^{\mathbf{a}}$ série incompleta e apenas uma gestante apresentava Ensino Superior incompleto. Verificou-se que as gestantes na faixa etária de 20 a 39 anos $(65,2 \%)$ e brancas $(47,1 \%)$ representaram a maioria dos casos registrados. Com relação a classificação clínica, foi registrado maior número de casos na fase primária da doença $(73,1 \%)$. Nos últimos 2 anos, foi observado um aumento exacerbado no número de registros de casos de sífilis gestacional, tendo sido apresentados 32 casos no ano de 2017 e 56 em 2018, comparados com apenas um registro no ano de 2009. Conclusão: Foi observado o aumento significativo de casos de sífilis gestacional registrados nos últimos anos. Desta forma, espera-se que o presente estudo possa contribuir com a conscientização da população araguarina e seus gestores, para que possam se mobilizar e intervir com ações educativas para redução nos números de casos de sífilis.

PALAVRAS-CHAVE: SÍFILIS NA GESTAÇÃO; PRÉ-NATAL; DOENÇAS SEXUALMENTE TRANSMISSÍVEIS. 


\title{
EVOLUÇÃO HISTÓRICA DA LEGISLAÇÃO BRASILEIRA SOBRE PROTEÇÃO AOS ANIMAIS
}

\author{
DAYANE BRAZ MONTES, RODRIGO ROBERT REIS, RODRIGO GUILHERME TOMAZ
}

INSTITUTO MASTER DE ENSINO PRESIDENTE ANTÔNIO CARLOS - IMEPAC

montesdayane@gmail.com

Apresentação de Pôster

Resumo

Área do Conhecimento: Sustentabilidade e Direitos

Introdução: 0 presente trabalho se justifica frente aos avanços dos estudos referentes aos direitos dos animais, com foco na evolução das leis que versam sobre a temática no Brasil. Animais em situação de maus tratos, abandono e/ou exploração por mãos humanas suscitam a necessidade latente de protegê-los do próprio homem - diante do que despontam as leis de proteção animal.

Objetivo: 0 trabalho em questão se propõe a relatar e publicizar a evolução das leis ambientais no Brasil com o intuito de proteger os animais, bem como explicitar quais foram as principais contribuições da legislação pátria para a temática em foco.

Metodologia: A metodologia de pesquisa empregada utilizou-se do método dedutivo, abrangendo teorias, leis e fatos para alcançar resultados.

Resultados: As normas no período colonial visavam apenas lucros para a Portugal. Posteriormente, em 06 de outubro de 1886, São Paulo assomou com os Códigos de Postura, com a principal finalidade de proteger os equinos. Outrossim, o revogado Decreto n 24.645/1934 serve como critério para descrever os maus tratos à fauna. Lado outro, a caça profissional é considerada crime conforme a Lei de proteção à fauna, Lei no 5.197/1967. Em relação a pesca, comedida pelo Decreto-lei no 794/1938, adveio o Código da Pesca, Decreto-lei no 221/1967, que definiu limitações a pesca ilegal. Já a Lei no 7.643/1987 versa sobre a proibição da pesca e ataque às baleias, golfinhos e botos, culminando em pena de reclusão de até 5 anos

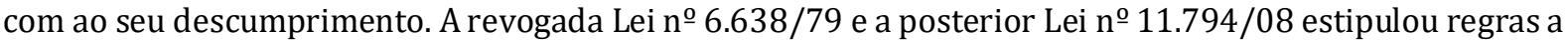
respeito de experiências científicas e estudos com animais vivos. Semelhantemente, a Lei no $7.173 / 1983$ versa sobre a manutenção de zoológicos, bem como a Lei no 7.643/1987 prevê proteção nacional aos cetáceos. Com o intuito de evitar o desparecimento das espécies, a Constituição Cidadã impôs com o art.

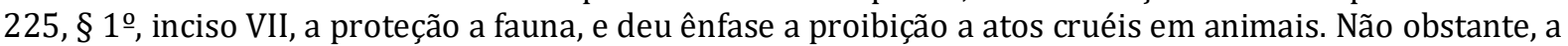
Lei dos Crimes Ambientais, Lei 9.605/98, em seu capítulo IV, seção I, versa sobre os crimes contra a fauna: determina penas para quem pratica crimes contra a fauna.

Conclusão: São latentes os subsídios legais e jurídicos brasileiros acerca da proteção aos animais, com especial atenção ao Decreto 24.645/1934, que define os maus tratos aos animais, e à Lei 9.605/1998, que sanciona penas para os crimes ambientais, dentre eles os cometidos contra a fauna. Porém, ressalva-se que para a concretização da harmonia ambiental, respeitando a relação entre o homem e a natureza, ainda há um longo caminho a ser percorrido, com a aplicação de sanções mais rígidas e principalmente com o amplo conhecimento da necessidade de proteger e respeitar o meio em que nos inserimos.

PALAVRAS-CHAVE: DIREITO AMBIENTAL; DIREITOS DOS ANIMAIS; EVOLUÇÃO LEGISLATIVA. 


\title{
EXERCÍCIO AERÓBIO CONTÍNUO É MAIS EFICAZ PARA PROMOVER HIPOTENSÃO POS ESFORÇO QUE EXERCÍCIO AERÓBIO INTERVALADO.
}

\author{
MARIELY CAROLINE DA SILVA PACHECO, FIRMINO JOAQUIM CELESTINO NETO, HUGO RIBEIRO \\ ZANETTI, ALEXANDRE GONÇALVES
}

INSTITUTO MASTER DE ENSINO PRESIDENTE ANTÔNIO CARLOS - IMEPAC

maripacheco13@hotmail.com

Apresentação de Pôster

Resumo

Área do Conhecimento: Saúde coletiva e bem-estar

Introdução: A hipertensão é uma doença de causa multifatorial e que combinada com outras enfermidades pode ser fatal. Esta patologia vem aumentando a cada dia, devido a fatores como stress, sedentarismo, obesidade, tabagismo. Como estratégias para combater este mal destaca-se o uso de medicamentos e mudança de hábitos de vida, como alimentação saudável e prática de exercício físico. Contudo, ainda permanece pouco esclarecido as diferenças de resposta hipotensivas entre o métodos de exercício aeróbio contínuo e intervalado. Objetivo: 0 objetivo deste estudo foi verificar em quais métodos de treinamento aeróbico, contínuo ou intervalado, é mais eficiente na maximização dos efeitos hipotensores pós-exercício. Método: Para este estudo foram analisados dezesseis voluntários, sendo oito do sexo masculino e oito do sexo feminino com idade média entre 47 (quarenta e sete) e 70 (setenta anos). Foram utilizados indivíduos com frequência de treinamento mínima detrês vezes por semana, com no mínimo seis meses seguidos de treinamento e com pressão arterial controlada. Cada indivíduo foi exposto à avaliação física para coleta de composição corporal,todos foram orientadosa manter o controle medicamentoso dos níveis pressóricos, realizar refeições leves e não praticar exercícios 24 (vinte e quatro) horas antes dos testes. Como cálculo estatístico foi utilizado análise de variância (ANOVA) de uma entrada com medidas repetidas com post hoc de Tukey, com nível de significância quando p<0,05. Resultados: Com relação à FC pós-esforço foi observado diferença significativa entre o momento 0 e os demais momentos $(p<0,05)$ em ambos os métodos. No entanto, não foi observado diferença significativa entre o método contínuo e intervalado ao longo dos 30 minutos de recuperação. Já em relação a pressão arterial média foi observado que os dois métodos de treinamento ocasionaram hipotensão pós esforço durante os 30 minutos de recuperação, comparado ao momento $0(\mathrm{p}<0,001)$. Além disso, evidencia-se que o método contínuo apresentou diferença significativa comparado ao intervalado nos momentos 20, 25 e $30(\mathrm{p}<0,05)$. Conclusão: Através deste estudo pode-se comprovar que os efeitos hipotensores pós-exercício aeróbico veio a ser mais acentuado e sustentado por mais tempo após o treinamento contínuo quando comparado aos efeitos hipotensores pós-exercício aeróbico intervalado.

PALAVRAS-CHAVE: EXERCÍCIO CONTÍNUO, EXERCÍCIO INTERVALADO, HIPOTENSÃO PÓS ESFORÇO. 


\title{
FALHA NA INTEGRAÇÃO DO SISTEMA INTERNO E CONTROLE DOS RECEBÍVEIS DA EMPRESA CALÇADOS JR
}

\author{
GIOVANA RODRIGUES LEMOS, FERNANDA GABRIELA DE DEUS, LOGAN SMAILLY REIS DO \\ NASCIMENTO, MARIA CLARA OLIVEIRA BARBOSA, FABIANO JOSÉ LUCAS DOS SANTOS
}

INSTITUTO MASTER DE ENSINO PRESIDENTE ANTÔNIO CARLOS - IMEPAC

giovana.rodrigueslemos@hotmail.com

Apresentação de Pôster

Resumo

Área do Conhecimento: Responsabilidade e Negócios

0 presente trabalho é resultante da experiência proposta pelo professor e vivenciada no componente curricular Projeto Integrador II, no $1^{\mathrm{o}}$ e $2^{\mathrm{o}}$ período do curso de Ciências Contábeis no Instituto Master de Ensino Presidente Antônio Carlos, do 2º semestre de 2018. 0 mesmo foi desenvolvido segundo a Metodologia do Arco de Maguerez.

Neste projeto são abordados os impactos da tecnologia da informação na contabilidade, uma vez que ao adotar a empresa Calçados JR como objeto de estudo, observou-se que a mesma tinha uma falha na integração do sistema interno e no controle dos recebíveis, visto que a instituição possuía uma ineficiência no processo da conferência e na emissão de boletos bancários, o qual gerava alguns distúrbios, dentre eles o retrabalho das atividades.

Têm-se como objetivo principal relatar a problemática no setor financeiro da empresa Calçados JR onde a emissão e conferência dos boletos ainda eram feitas de forma manual e inábil, como também propor soluções alternativas para tal distúrbio, como base na Metodologia do Arco de Maguerez.

O recurso metódico utilizado foi a pesquisa de campo na Empresa Calçados JR, enriquecida com a pesquisa bibliográfica. Tendo em vista o desenvolvimento de um trabalho de pesquisa utilizando a Metodologia da Problematização com o Arco de Maguerez, proposto pelo professor da disciplina de Projeto Integrador II, escolheu-se como campo de observação da realidade a empresa Calçados JR.

No campo investigado, notamos que os processos para efetuar as baixas dos pagamentos de boletos gastavam muito tempo, pois além de retirar os relatório do banco, tinha que retirar juntamente o relatório do sistema da empresa, e como são inúmeros pagamentos diariamente o fluxo de dados a serem analisados eram grande e repetitivo. E com isso o tempo gasto com essas conferencias poderia ser utilizado em outros pontos do setor que necessitam de apoio e manutenção, porem não são atendidos por falta de tempo.

Sendo assim, por meio da Metodologia do Arco de Maguerez foi possível definir qual o problema principal, definir seus principais fatores e, posteriormente buscar embasamento teórico para propor hipóteses de soluções viáveis e sustentáveis para empresa. Já que ao serem aplicadas na realidade da empresa foram possíveis notar vários resultados, como a diminuição do retrabalho e recursos, eficiência nos setores , o bem estar dos funcionários etc. Além disso, com a automatização dos processos dentro da empresa, foi eliminado grande parte do uso de papel. Pode-se dizer que tais situações asseguram a responsabilidade socioambiental da empresa.

PALAVRAS-CHAVE: AUTOMATIZAÇÃO, CONTROLE, INTEGRAÇÃO, BOLETOS. 


\title{
FATORES DE RISCO ASSOCIADOS À ÚLCERA POR PRESSÃO: DESAFIO NA SAÚDE PÚBLICA DO BRASIL
}

\author{
LAÍS MARTINS BORGES, RODRIGO ALVES GARCIA, MARCOS PAULO DE SOUSA
}

INSTITUTO MASTER DE ENSINO PRESIDENTE ANTÔNIO CARLOS - IMEPAC

lais_martins2@hotmail.com

Apresentação de Pôster

Resumo

Área do Conhecimento: Saúde coletiva e bem-estar

Introdução: A Úlcera Por Pressão (UPP) é uma lesão decorrente de isquemia tecidual evidenciada no perímetro de proeminências ósseas, caracterizada por ser um problema secundário de doenças crônicas que culminam na restrição da mobilidade física ou oriunda da hospitalização. No entanto, é considerada evitável a partir da implantação de medidas preventivas, valorizando a análise dos elementos da evolução dessa lesão pela equipe multiprofissional no âmbito da Atenção Primária à Saúde (APS).

Objetivo: Identificar os fatores de risco relacionados à UPP na APS.

Metodologia: Trata-se de um estudo exploratório e qualitativo com a finalidade de identificar os fatores de risco da UPP, através de estudos relevantes na construção dos conceitos utilizados como base da análise exposta. Foram incluídas bibliografias de fonte primária indexadas no período entre 2012 a 2017 . A exclusão foi feita a partir de trabalhos que foram publicados fora do período mencionado, os que não continham metodologia e os que analisaram somente formas de tratamento da UPP.

Resultados: A UPP é uma complicação recorrente no cenário da APS e possui riscos multifatoriais, extrínsecos e intrínsecos, para o seu surgimento. No primeiro, a pressão é responsável por tal ocorrência, juntamente, com o cisalhamento, a fricção e a umidade. Já os fatores inerentes ao corpo, como a idade, a desnutrição, a pouca mobilidade, o baixo nível de consciência e de sensibilidade, corroboram com o aumento de pressão entorno das proeminências ósseas, propiciando o desenvolvimento da lesão. Ressaltase que a fisiopatologia da UPP envolve, também, a conduta dos colaboradores da equipe multiprofissional, os quais devem estar integrados a fim de proporcionar uma assistência qualificada, uma vez que a lesão pode iniciar nas primeiras vinte e quatro horas após a admissão do paciente e evoluir para um estágio de sepse, se não houver intervenção imediata. No caso de uma infecção, os pacientes poderão apresentar piora clínica, culminando na hospitalização, o que por sua vez desencadeia a elevação dos custos financeiros no tocante à gestão de recursos públicos. Diante ao exposto, existem escalas que auxiliam na avaliação dos riscos para a evolução da lesão por pressão, como a de Braden, que avalia a mucosa, a de Coma de Glasgow, o nível de consciência, e a de Ramsay, a sedação do paciente, propiciando a redução da incidência de UPP. Conclusão: A UPP é uma lesão cutânea frequente na APS, o que torna-se imprescindível a articulação entre a equipe de saúde com o intuito de implementar condutas efetivas na redução epidemiológica deste agr avo, a fim de proporcionar ao paciente melhor qualidade de vida, redução dos riscos de infecções e complicações clínicas, além de resultar na racionalização financeira dos recursos públicos.

PALAVRAS-CHAVE: ÚLCERAS POR PRESSÃO, FATORES DE RISCO, ATENÇÃO PRIMÁRIA À SAÚDE. 


\title{
FATORES QUE INFLUENCIAM A TENACIDADE DO CONCRETO REFORÇADO COM FIBRAS (CRF)
}

\author{
RAPHAEL FONSECA DIAS, ADONIS BARCELOS ROSA, ANTONIO MARCOS ALVES RESENDE, \\ NATHALY REGINA RODRIGUES DE SOUZA, RODRIGO DA SILVA FERNANDES , VINÍCIUS FIRMINO \\ LOPES,
}

INSTITUTO MASTER DE ENSINO PRESIDENTE ANTÔNIO CARLOS - IMEPAC

raphael.dias@imepac.edu.br

Apresentação de Pôster

Resumo

Área do Conhecimento: Responsabilidade, Tecnologia e Ciência

\begin{abstract}
Introdução: 0 concreto é um material frágil, ou seja, rompe-se com pequenas deformações. A adição de fibras de aço ao concreto altera seu comportamento mecânico melhorando a sua capacidade de absorção de energia, ou seja, sua tenacidade. A tenacidade do Concreto reforçado com Fibras (CRF) é a energia absorvida pelo compósito quando carregado, abrangendo a energia absorvida antes e após a fissuração da matriz, quando as fibras passam a atuar de maneira mais efetiva.

Objetivo: Avaliar o comportamento mecânico à tração do concreto reforçado com fibras de aço, por meio da determinação da tenacidade. E investigar a influência da resistência à compressão do concreto e do teor de fibras na tenacidade do concreto reforçado com fibras de aço (CRFA). Deseja-se também, contribuir com a regulamentação e o controle na aplicação do material.

Metodologia: Realizou-se uma pesquisa exploratória sobre os principais fatores que influenciam a tenacidade à flexão do CRFA, e os principais métodos de ensaios normatizados para essa determinação. Posteriormente, realizou-se os ensaios de determinação da tenacidade pelo método da ASTM C1609 e pelo ensaio de Abertura por Encunhamento, na Universidade Federal de Uberlândia. 0 planejamento experimental consistiu em utilizar, para os concretos, dois valores de resistência característica à compressão (20 MPa e $40 \mathrm{MPa}$ ) e três teores de fibra de aço distintos: $30 \mathrm{~kg} / \mathrm{m}^{3}, 40 \mathrm{~kg} / \mathrm{m}^{3}$ e $50 \mathrm{~kg} / \mathrm{m}^{3}$, que correspondem à $0,37 \%, 0,50 \%$ e $0,64 \%$ de volume de fibras, respectivamente.

Resultados: Os resultados dessa pesquisa foram qualitativos e quantitativos. Assim sendo, a adição de fibras de aço promoveu ganhos para a resistência à compressão, resistência à tração e módulo de tenacidade do concreto. 0 ganho mais significativo foi para a resistência à tração por compressão diametral do CRFA. Isso se justifica pela diminuição da propagação de fissuras, uma vez que as fibras servem como pontes de transferência de tensões pelas fissuras e aumentam a ductilidade. Percebe-se que os valores obtidos pelo ensaio de abertura por encunhamento apresenta indicativos de reprodutibilidade e coerência, quando comparado com o teste ASTM C1609 (2012).

Conclusão: A influência do teor de fibras na tenacidade à flexão é maior que a influência da resistência à compressão do concreto. 0 aumento de teor de fibras é favorável, pois uma quantidade maior de fibras interceptará a fissura formada, melhorando a capacidade de absorção de energia pós-fissuração do compósito. 0 uso das fibras de aço é uma interessante alternativa como reforço e para aumento da tenacidade do concreto.

Palavras-chave: Concreto reforçado; fibras de aço; tenacidade; tecnologia.
\end{abstract}

PALAVRAS-CHAVE: CONCRETO REFORÇADO; FIBRAS DE AÇO; TENACIDADE; TECNOLOGIA. 


\title{
FECHEM OS OLHOS, TAPEM OS OUVIDOS: O DIREITO DE EXERCER A CIDADANIA EM SUA PLENITUDE COM RESPONSABILIDADE E COMPROMISSO SOCIAL.
}

\author{
JULIANA DE SOUSA FARIA, ANDREIA REGINA DA SILVA, MARCOS BERNARDES JUNIOR, NAYARA \\ DA SILVA FERNANDES, RAFAELA BORGES CALIXTO, ANA LÚCIA COSTA E SILVA
}

INSTITUTO MASTER DE ENSINO PRESIDENTE ANTÔNIO CARLOS - IMEPAC

julianafaria.pedagoga@gmail.com

Comunicação Oral

Resumo

Área do Conhecimento: Educação e Inclusão

Introdução (Contextualização): Dentro do contexto que nos foi apresentado no decorrer do curso de Pedagogia sobre acessibilidade, escolhemos trabalhar com a deficiência auditiva, pois, em nosso ponto de vista, necessita de revisões e inovações quanto a acessibilidade em nosso município. Nosso projeto teve como objetivo uma proposta de Projeto de Lei à Câmara Municipal de Araguari, para que foss e submetida à votação para criação de uma Central de Intérpretes da Língua Brasileira de Sinais - Libras e GuiasIntérpretes para Surdos cegos, vinculadas a Secretaria Municipal de Educação.

Metodologia: 0 desenvolvimento se deu a partir da investigação das necessidades da comunidade surda da nossa cidade e, por meio de informações obtidas junto a um professor e psicólogo atuante na área de intérpretes de surdos do município de Araguari-MG.

Relato da experiência: Sintetizamos os relatos sobre as dificuldades e barreiras enfrentadas junto à sociedade de ouvintes e em seguida propomos apresentação do projeto de lei em sessão da Câmara Municipal de Araguari, onde todos os vereadores assinaram, havendo também uma repercussão da imprensa local. 0 projeto ainda se encontra na fila para votação e aguardamos ansiosos pela aprovação.

Considerações finais: Como futuros pedagogos e ativos comunicadores, a experiência desse projeto, nos deu a oportunidade de perceber nossa função social, abrindo nosso olhar para a cidade a qual vivemos, Araguari, uma cidade relativamente desenvolvida, onde ainda nos deparamos com certas situações de injustiças físicas, psicológicas e sociais.

Nesse sentido, devemos agir de forma consciente e ativa, colaborando para o processo de inclusão do deficiente no meio social e, consequentemente auxiliando para melhor desenvolvimento em sociedade.

Palavras-chave: acessibilidade; surdos; barreiras; tradutores intérpretes; guias-interpretes; comunicação; inclusão.

Referência

O SURDO é diferente e não ineficiente: DEFICIÊNCIA AUDITIVA. 2015. Denise Serio Consultoria \& Capacitação. Disponível em: <http://deficienciaauditiva.com.br/o-surdo-e-diferente-e-nao-ineficiente/>. Acesso em: 07 abril. 2018.

BRASIL. Fernando Henrique Cardoso. Congresso Nacional. A lei federal $n^{\circ}$ 10.098. 2000. Disponível em: <http://www.planalto.gov.br/ccivil_03/leis/l10098.htm>. Acesso em: 09 abr. 18.

BRASIL. Luiz Inácio Lula da Silva. Casa Civil Subchefia Para Assuntos Jurídicos. DECRETO 5296/04. 2004. Disponível em: http://www.planalto.gov.br/ccivil_03/_ato2004-2006/2004/decreto/d5296.htm>. Acesso em: 31 maio 2018.

PALAVRAS-CHAVE: ACESSIBILIDADE; SURDOS; BARREIRAS; TRADUTORES INTÉRPRETES; GUIAS-INTERPRETES; COMUNICAÇÃO; INCLUSÃO. 


\title{
FORMAS CONSENSUAIS DE RESOLUÇÃO DE CONFLITOS
}

\author{
LILYAN DE FREITAS HENEMANN, EDERSON DE FRANÇA GODOY, DONNER RODRIGUES QUEIROZ
}

INSTITUTO MASTER DE ENSINO PRESIDENTE ANTÔNIO CARLOS - IMEPAC

lilyandefreitas@hotmail.com

Comunicação Oral

Resumo

Área do Conhecimento: Sustentabilidade e Direitos

Introdução: Algumas formas de solução de conflitos tem ganhado grande relevância no âmbito jurídico como forma de acesso à justiça e pacificação social. Assim, trabalhamos os principais meios consensuais de resolução de conflitos utilizados no judiciário como a conciliação, a mediação, a negociação e a arbitragem.

Objetivo: 0 presente estudo tem como objetivo trabalhar o conceito das formas consensuais de conflitos, esclarecendo a prática de tais métodos, bem como as vantagens que cada um deles pode oferecer para a solução da lide e o reestabelecimento das relações humanas.

Metodologia: Para se alcançar o proposto na pesquisa, adotou-se o método dedutivo, a partir de uma revisão bibliográfica com pesquisa em doutrinas, legislação e demais documentos pertin entes ao tema.

Resultados: Ao se perceber a sobrecarga do poder judiciário em relação a grande demanda de lides que poderiam ser resolvidas de forma mais célere, ou que mesmo resolvidas acabam por voltar ao judiciário, o Conselho Nacional de Justiça, juntamente ao poder judiciário, iniciou a implantação de políticas voltadas para a solução de conflitos, com o objetivo de alcançar a maior celeridade na resolução das demandas de forma pacífica. A conciliação possui peculiaridades mais rápidas e objetivas, visando um acordo sobre uma lide extremamente pontual, autorizando uma atuação mais contundente da figura do conciliador, de forma imparcial mas com a liberdade de propor formas de alcançar um acordo. A mediação vem com o objetivo de trabalhar em processos onde as partes tiveram um relacionamento anterior, de longa duração, com o propósito de que os mesmos possam restabelecer laços perdidos, construindo assim um acordo ou uma possibilidade de acordo. A teoria da negociação é baseada em princípios voltados para a persuasão, buscando resultados mais satisfatórios para os reais interesses das partes, diferente da negociação posicional, que os negociadores se tratam como oponentes com o objetivo de um ganhar e o outro perder. Quanto a arbitragem, esta é definida como um processo eminente privado, pois nestes casos as partes buscam auxílio de um terceiro ou mais pessoas, imparciais ao conflito e estes após análise de documentos, ouvir testemunhas bem como os argumentos de advogados, prolatam uma sentença arbitral, colocando fim ao conflito.

Conclusão: Portanto, conclui-se que os métodos de solução de conflitos não são utilizados apenas para solução da lide em si mas também visam soluções para as relações humanas conflituosas que ficam ocultas e levam a parte a ingressar com um processo.

PALAVRAS-CHAVE: ACESSO À JUTIÇA; CONFLITOS; PACIFICAÇÃO. 


\title{
GERENCIAMENTO DE PEQUENOS PROJETOS A PARTIR DO GUIA PMBOK ${ }^{\circledR}$
}

\author{
LILIANE MENEZES MARTINS, DANILO FARIA DE MOURA
}

FACULDADE PITÁGORAS DE UBERLÂNDIA

liliane_martins12@hotmail.com

Comunicação Oral

\section{Resumo}

Área do Conhecimento: Responsabilidade e Negócios

\begin{abstract}
Introdução: As empresas que aplicam uma metodologia de gerenciamento de projetos apresentam melhorias no tempo, redução nos custos, uma otimização dos recursos humanos e maior taxa de sucesso no desenvolvimento de novos produtos e soluções. A metodologia completa de Gestão de Projetos, para alguns ambientes é complicada de se aplicar, devido ao fato de conter muitas fases e ser extremamente detalhada, o que pode ocasionar um atraso e uma dificuldade a mais no gerenciamento e execução de um determinado projeto. Sendo assim, é necessário escolher a metodologia correta de acordo com as características pertencentes ao mesmo.

Objetivo: 0 artigo teve como objetivo apontar uma metodologia simples, além das melhores práticas usadas na integra, instruídas pelo PMBOK, para o gerenciamento de pequenos projetos.

Metodologia: 0 artigo é composto por um apontamento bibliográfico fundamentado no Guia PMBOK 5a edição e em artigos e livros nacionais e internacionais. 0 apontamento bibliográfico apresenta teorias sobre novos modelos de gestão de pequenos projetos e através das mesmas, foi feito um apontamento de quais teorias podem ser usadas na prática de um ambiente de pequenos projetos.

Resultados: 0 artigo apresentou em seu referencial teórico as dificuldades e impedimentos de pequenos projetos executarem na integra todos os processos e as melhores práticas sugeridas pelo PMBOK para que o mesmo tenha sucesso em sua gestão. Em âmbito geral, as fases e etapas propostas pelo PMBOK, são de cunho burocráticas e extensas, o que pode prejudicar o andamento do projeto e uma maior dificuldade para quem faz o controle de sua gestão. Usar o ciclo PDCA é uma alternativa para tal feito, pois é através de suas etapas, é possível planejar, executar e verificar onde existem os erros cometidos durante esse mesmo processo de execução, permitindo assim uma qualidade maior no produto entregue. 0 que vale ressalta, é por justamente se tratar de projetos, não se deve abandonar completamente todos os princípios do PMBOK, pois o mesmo ensina as melhores práticas a serem usadas, mas o que é proposto é que não se estenda muito a partes burocráticas e trabalhosas que poderiam atrasar o andamento do projeto.

Conclusão: Juntamente com os princípios do PMBOK, deve-se aplicar o PDCA que proporciona ao projeto uma melhoria continua. 0 projeto deve ser executado após o planejamento, e realizado uma verificação durante toda a execução, e se houver algo que não esteja de acordo com o planejado, é feito um novo plano, começando o ciclo do início. Foi proposta uma metodologia de gerenciamento de projetos com foco em pequenos projetos, que devesse ser, descomplicada e útil para as necessidades do mercado e que traga para o projeto uma maior possibilidade de sucesso. Com o gerenciamento de projetos as empresas esperam obter uma maior taxa de sucesso em seus projetos.
\end{abstract}

PALAVRAS-CHAVE: PEQUENOS PROJETOS; GESTÃO DE PROJETOS; PDCA. 


\title{
GESTÃO DA CADEIA DE SUPRIMENTOS DOS EQUIPAMENTOS DE PROTEÇÃO INDIVIDUAL (EPIS) DA REDE PÚBLICA DE SAÚDE DO MUNICÍPIO DE ARAGUARI-MG
}

\author{
ISABELLA ALVES REZENDE, DANIELA MARIN MACHADO SILVEIRA, FERNANDA DE CARVALHO \\ PEREIRA, JULIA CARVALHO COSTA, THAÍS RIBEIRO OLIVEIRA SANTOS DE MARCELLO, YNARA \\ CAROLINE DE ABREU FURQUIM, CÉSAR ANTÔNIO DE OLIVEIRA
}

INSTITUTO MASTER DE ENSINO PRESIDENTE ANTÔNIO CARLOS - IMEPAC

isabellaalvessr@gmail.com

Comunicação Oral

Resumo

Área do Conhecimento: Gestão de recursos econômicos (naturais)

INTRODUÇÃO: A gestão da cadeia de suprimentos consiste-se em atividades para movimentar o produto do fornecedor para o consumidor. Na saúde, o objetivo do setor de suprimentos é a manutenção da continuidade e qualidade dos materiais, medicamentos e Equipamentos de Proteção Individual (EPIs).

OBJETIVO: Compreender, analisar, comparar e propor intervenções na gestão da cadeia de suprimentos de EPIs na Secretaria Municipal de Saúde (SMS) e nas Unidades Básicas de Saúde da Família (UBSF) do município de Araguari -MG.

METODOLOGIA: Estudo qualitativo, transversal e observacional, da gestão da cadeia de suprimentos de EPIs em Araguari-MG, por meio de análise de arquivos e documentos, entrevistas semiestruturadas com gestores e funcionários da SMS e da UBSF de maior demanda do município. Os achados foram cruzados para verificar a correspondência entre as informações da SMS e da UBSF.

RESULTADOS: Verificou-se que os recursos para as compras de EPIs se baseiam na política tripartite e têm recursos provenientes da assistência farmacêutica.

Segundo a SMS, a compra de EPIs no município é feita pelo diretor da farmácia municipal, diretor financeiro e de compras da SMS. A solicitação de produtos para SMS é individualizada para cada UBSF e a distribuição de EPIs é de acordo com a necessidade da unidade segundo o registro de uso de materiais no período anterior.

Ficaram claros três pontos de discordância primordiais entre as informações da SMS e da UBSF. 0 primeiro ponto diz respeito à maneira como são feitas as solicitações de EPIs. A UBSF informou que essa é feita por meio de uma ficha padrão. Entretanto, a SMS repassou que tal solicitação é realizada por meio de um programa chamado "Sistema Sonner".

O segundo ponto de discordância diz respeito à validade dos EPIs. A SMS afirma que não há perda de EPIs em decorrência da ultrapassagem do prazo de validade. Entretanto, na UBSF constatou-se que há sim perda de produtos por atingirem o prazo de vencimento.

0 terceiro ponto de discordância refere-se ao local de estocagem dos EPIs. A SMS informou que só há estocagem nas dependências da farmácia popular. Porém, na UBSF constatou-se que há a prática de estocagem na unidade, onde inclusive tem-se uma sala reservada para o depósito de materiais, que incluem EPIs.

CONCLUSÃO: Os administradores públicos da cidade regularizam e otimizam o gerenciamento da cadeia de EPIs municipal. Essa cadeia consegue atingir seu objetivo de suprir a demanda, entretanto, possui potencial para melhor custo-benefício.

Foi constatado falta de EPIs e vencimento de material lacrado. Para abolir as lacunas destacadas na pesquisa, a conduta sugerida é reforçar a comunicação entre setor de solicitação, compra e estoque.

PALAVRAS-CHAVE: EQUIPAMENTO DE PROTEÇÃO INDIVIDUAL; CADEIA DE SUPRIMENTOS; GESTÃO. 


\title{
GRUPOS E ATIVIDADES COLETIVAS DE EDUCAÇÃO EM SAÚDE NA ATENÇÃO PRIMÁRIA À SAÚDE
}

\author{
JANAÍNA MARIA DA SILVA, ELISANGELA DE CÁSSIA RODRIGUES , GABRIELA PEIXOTO CARVALHO \\ , GEOVANNA INGRID RODRIGUES, JOÃO PAULO ASSUNÇÃO BORGES
}

INSTITUTO MASTER DE ENSINO PRESIDENTE ANTÔNIO CARLOS - IMEPAC

janainamariasilva1999@gmail.com

Apresentação de Pôster

Resumo

Área do Conhecimento: Saúde coletiva e bem-estar

Introdução: A Educação em Saúde é o processo de ensino-aprendizagem que visa à mudança no estilo de vida, de hábitos, práticas e atitudes, bem como a socialização de conhecimentos, por meio da utilização de métodos pedagógicos participativos e problematizadores. A Educação em Saúde consiste em uma prática social, com importante impacto no compartilhamento de informações adequadas às necessidades de um grupo, estando relacionada com a promoção da saúde e a prevenção de agravos e doenças. Pode ser desenvolvida por meio de grupos no âmbito da Atenção Primária à Saúde (APS), os quais incluem: Grupos de Gestantes e de Puericultura; Hipertensos e Diabéticos (Hiperdia); Cessação do Tabagismo; Programa Saúde na Escola, entre outros. Objetivo: Objetivou-se identificar na literatura científica as evidências mais recentes acerca da importância da Educação em Saúde na APS. Métodos: 0 presente estudo trata-se de uma revisão de literatura, exploratória e descritiva, com base em 16 artigos científicos, publicados entre 2009 a 2018, obtidos por meio de busca avançada na base de dados Biblioteca Virtual de Saúde, utilizando os descritores em Ciências da Saúde: atenção primária, promoção, prevenção, educação em saúde e enfermagem. Os artigos obtidos foram extensamente analisados e decompostos em informações primárias relativas ao tema central. Resultados: Identificou-se que a Educação em Saúde permite a conscientização crítica dos indivíduos e a transformação da realidade destes, pois representa uma excelente alternativa para levar as pessoas a adotarem mudanças de hábitos de vida, desencadeando mudanças de comportamento que podem prevenir ou controlar doenças e suas complicações, proporcionando uma melhor qualidade de vida, diminuindo a ocorrência de internações, que muitas vezes podem ser prevenidas por meio de orientações adequadas. As atividades de Educação em Saúde devem se estabelecer como espaços de diálogos para a construção de saberes conjuntos entre profissionais e usuários. Logo, a educação deve proporcionar o questionamento, a escuta, o diálogo, e a reflexão para assim poder encontrar alternativas de resolver problemas associados à manutenção da saúde e prevenção das doenças. Conclusão: A compreensão de Educação em Saúde transcende a simples oferta de orientações. Ela considera a participação dos sujeitos e coletivos, valorizando também o conhecimento da população com o propósito de desenvolver uma construção coletiva e um aprendizado mútuo. Além disso, os indivíduos são beneficiados a partir da estabilização de sua condição de saúde-doença, promovendo melhor qualidade de vida e reduzindo riscos e vulnerabilidades de desenvolver comorbidades associadas.

PALAVRAS-CHAVE: EDUCAÇÃO EM SAÚDE; ATENÇÃO PRIMÁRIA À SAÚDE; PROMOÇÃO DA SAÚDE; PREVENÇÃO DE DOENÇAS. 


\title{
HORTAS VERTICAIS URBANAS: UMA REALIDADE PARA TODAS AS FAMÍLIAS EM QUAISQUER ESPAÇOS
}

\author{
ANNA CLARA DE OLIVEIRA MARTINS, ROSANA DE CÁSSIA OLIVEIRA
}

COLÉGIO NACIONAL DE UBERLÂNDIA

annaclara.martins@outlook.com

Apresentação de Pôster

Resumo

Área do Conhecimento: Saúde coletiva e bem-estar

Introdução: O consumo regular de frutas e verduras é de vital importância para a saúde humana. Considerando o índice cultural da população brasileira e as constantes campanhas de promoção à saúde na sociedade, nota-se crescente demanda por alimentos livres de insumos agrícolas. Isso levou à expansão de meios alternativos de cultivo de hortaliças, uma vez que produtos orgânicos são marcados por preço elevado e oferta escassa. Nesse sentido, objetivou-se implantar uma unidade alternativa de cultivo de hortaliças (folhas verdes), por meio de cultivo vertical em tubos de PVC, livres de agrotóxicos, que suprisse o consumo mensal de folhas verdes de uma família com consumo regular de pelo menos dois tipos de folhas, por refeição principal (almoço e jantar).

Metodologia: 0 projeto foi executado em área urbana, com a construção de um suporte de ferro de demolição capaz de abarcar 13 canos de PVC (sete de 150 e seis de $100 \mathrm{~mm}$ de diâmetro, todos com 1,45m de comprimento), em quatro níveis. Em cada cano foi feita uma abertura horizontal de $15 \mathrm{~cm}(150 \mathrm{~mm})$ e $10 \mathrm{~cm}(100 \mathrm{~mm})$ de largura, três furos de drenagem na região oposta à abertura e suas extremidades fechadas com tampões de PVC. Dentro de cada cano foram adicionados pedaços de carvão vegetal para facilitar a drenagem. Em seguida, uma mistura de terra com esterco de gado (3:1) foi colocada, e após, mudas ou sementes de hortaliças de ciclo rápido (alface, espinafre japonês, rúcula e almeirão) foram plantadas. Adotou-se um espaço entre plantios de 15 dias, de modo que, a partir da primeira colheita (45 dias), sempre houvesse folhas em ponto de consumo. Foram feitas duas regas diárias (manhã e tarde) e o controle de pragas feito de forma manual ou por aspersão de calda de alho com pimenta (três dentes de alho e duas pimentas malaguetas batidos em 1 litro de água e coados). A área total ocupada pelo suporte de hortaliças é de $95 \times 150 \times 165 \mathrm{~cm}$, com sombrite $30 \%$ localizado $40 \mathrm{~cm}$ acima do último nível.

Relato de Experiência: 0 projeto foi planejado e executado em família, com o auxílio de um serralheiro para a construção da estrutura metálica e os cortes nos canos. Os insumos necessários (terra, esterco, mudas e sementes) foram adquiridos em loja de materiais agropecuários. 0 processo de preparação e plantio foi feito em família nos finais de semana, e as regas diárias em sistema de rodízio.

Considerações Finais: A possibilidade de produzir hortaliças de forma alternativa é algo que desperta atenção nos agricultores familiares e moradores de áreas urbanas que desejam produzir o próprio alimento. Dessa forma, o desenvolvimento de hortas em espaços reduzidos como corredores, sacadas e quintais resulta na produção de alimentos livres de agrotóxicos, na possibilidade de agregar materiais alternativos e/ou recicláveis e mostra a sua capacidade para a resolução de diversos desafios atuais enfrentados pelo planeta.

PALAVRAS-CHAVE: AGRICULTURA URBANA FAMILIAR; PRODUTOS ORGÂNICOS; HORTAS VERTICAIS. 


\title{
HUMANIZAÇÃO E CUIDADO EM SAÚDE EM PACIENTES COM CÂNCER: UM ESTUDO DE CASO DE UMA ONG.
}

\author{
FERNANDO DE ANDRADE PINHEIRO, BRATHENER PAULO MOURA ARAÚJO, EMANNUEL NOVAES \\ DE CARVALHO, JOSÉ AUGUSTO COELHO NETO, KÉSIA SILVA MOREIRA, LUÍS FERNANDO SOARES \\ GOMES, PEDRO HENRIQUE BORGES DE OLIVEIRA, HERBERT CRISTIAN DE SOUZA
}

INSTITUTO MASTER DE ENSINO PRESIDENTE ANTÔNIO CARLOS - IMEPAC

fernando.andrade12@gmail.com

Comunicação Oral

Resumo

Área do Conhecimento: Saúde coletiva e bem-estar

Introdução: A humanização requer um processo reflexivo acerca dos valores e princípios que norteiam a prática profissional, além de tratamento e cuidado digno, solidário e acolhedor ao seu principal objetivo, o doente/ ser fragilizado. Um diagnóstico de câncer é sempre um choque e uma preocupação para quem o recebe, e por isso, a humanização vai ao encontro na melhoria da qualidade de vida de pacientes oncológicos.

Objetivos: Analisar o impacto da humanização em pacientes com câncer assistidos por uma ONG no município de Araguari (MG).

Metodologia: Trata-se de um estudo qualitativo, observacional do tipo estudo de caso realizado em uma em uma ONG que assiste pacientes oncológicos em Araguari (MG). A realização da pesquisa se deu por meio da coleta de dados realizada em duas visitas à ONG, e em outra visita à casa de um paciente atendido pela ONG, as quais foram realizadas entre os meses de março e abril de 2018. A coleta foi feita de maneira distinta em cada cenário. No âmbito da ONG, utilizou-se de uma entrevista semiestruturada, a partir de um questionário com perguntas suporte sobre o funcionamento geral, recursos e humanização. No segundo cenário apenas observou-se como é a visita dos representantes da ONG a um paciente assistido pela mesma, o que possibilitou uma maior compreensão de como é dado o suporte da organização para com sua populaçãoalvo. A entrevista foi registrada por meio de anotações realizadas, seguindo princípios éticos e após preenchimento do Termo de Consentimento Livre e Esclarecido (TCLE).

Resultados: A ONG tem 10 anos de funcionamento e sua proposta de trabalho está alicerçada na partida do Hospital do Câncer de Uberlândia, a qual atende 347 pacientes. 0 atendimento realizado pela ONG é exclusivamente aos pacientes SUS, sendo que os recursos financeiros são oriundos do município e de doações.

Nos casos de cuidados paliativos, a ONG conta com uma psicóloga específica para realizar esse trabalho, favorecendo uma assistência humanizada que abraça não apenas o paciente, como igualmente a sua família na prestação de cuidados, promovendo diminuição do medo e angústia que cerca o momento difícil pelo qual estão passando. Ademais o serviço prestado pela ONG não ocasiona mudanças nas condutas médicas preestabelecidas.

Existe ainda a presença de voluntários e de uma assistente social trabalham essencialmente a parte humanística, colaborando para a abrangência e complementação holística do tratamento médico prestado pelo Hospital do Câncer, colaborando para melhoria da qualidade de vida dos pacientes, uma vez que promove amparo e empatia para com as necessidades deles.

Conclusão: Assim, percebe-se que a ONG se encaixa fielmente à ideia de humanização, colocando em prática ações primordiais para melhor enfrentamento do câncer, proporcionando motivação e qualidade de vida aos pacientes, sendo um serviço essencial e gratificante.

PALAVRAS-CHAVE: HUMANIZAÇÃO, VOLUNTÁRIO, SERVIÇO SOCIAL. 


\title{
IMPACTO DO CONTROLE DE ESTOQUE NO PLANEJAMENTO TRIBUTÁRIO E FINANCEIRO
}

\author{
MAX LEANDRO DA CONCEIÇÃO SALGADO, EMÍLIA CAROLINA DE RESENDE SACOMAN, NATHÁLIA \\ VIEIRA COUTINHO, PEDRO AUGUSTO CARDOSO CARNEIRO, RAPHAELA ALEIXO BARBOSA, \\ FABIANO JOSE LUCAS DOS SANTOS
}

INSTITUTO MASTER DE ENSINO PRESIDENTE ANTÔNIO CARLOS - IMEPAC

max_leando@hotmail.com

Apresentação de Pôster

Resumo

Área do Conhecimento: Responsabilidade e Negócios

\begin{abstract}
Introdução
Tendo em vista o desenvolvimento de um trabalho de pesquisa utilizando a Metodologia da Problematização com o Arco de Maguerez, escolheu-se como campo de observação da realidade o controle de estoque na empresa Construtora Lar Doce Lar, pois verificou-se que se não há controle, não conseguese controlar as despesas, receitas e custo das mercadorias, sendo assim não consegue-se tributar o verdadeiro lucro obtido, ocasionando um lucro defasado.

Tal escolha se deve a importância que os estoques tem nas empresas, pois funcionam como mediadores da movimentação dos negócios.

Objetivo:

Observância correta da legislação tributária e apropriação correta dos custos dos estoques.

Metodologia

No campo investigado nota-se que a empresa abordada neste trabalho adota um regime tributário, o Lucro Presumido, além disso conta com mais ou menos 192 funcionários, uma média de faturamento mensal, referente ao ano de 2018 foi de $\mathrm{R} \$ 4.058 .003$, 66. Sendo assim, os estoques merecem atenção especial para que se evitem reveses financeiros e se possa buscar um diferencial competitivo no mercado

Observa-se também que a empresa tem uma certa dificuldade em manter um controle de estoque eficaz ao ponto de evitar desvios e registrar as perdas ocorridas durante a transição das mesmas.

Dessa forma, as observações foi conduzida ao delineamento do seguinte problema de investigação: 0 Impacto do controle de estoque no Planejamento tributário e Financeiro.

Conclusão:

Compreende-se que estudar mais profundamente sobre este tema, busca possíveis soluções para esse problema, uma noção mais aprofundada sobre planejamento estratégico e tributário, proporcionando abordagens que levará a pensar de forma profissional, ou seja, deixara de pensar como alunos e passará a ver e pensar como contadores, levando a uma possível solução real deste problema. Portanto a falta de cumprimento das normas tributarias e contábeis sujeita a pesadas multas aplicadas pela receita Federal do Brasil. Enfim, a aplicação desse trabalho, em um problema real, como foi dito, o pensamento, o questionamento vai ser lapidado, para que possa solucionar tal adversidade, mas também vai surgir outros, tanto na carreira profissional, quanto na vida pessoal, sendo assim este trabalho foi de grande importância, para adquirir um conhecimento a parte.

Sob o ponto de vista da empresa contribui para um planejamento tributário onde se controla as operações da mesma e a identificação de cenário mais benéficos sociais econômicos na gestão de continuidade sustentável da empresa.
\end{abstract}

PALAVRAS-CHAVE: ARCO DE MAGUEREZ; CONTROLE DE ESTOQUE; PLANEJAMENTO FINANCEIRO E TRIBUTÁRIO. 


\title{
IMPACTOS DA FISIOTERAPIA EM PACIENTE INSTITUCIONALIZADO COM DIAGNÓSTICO DE DEMÊNCIA E DEGENERAÇÃO CEREBELAR ALCÓOLICA: UM RELATO DE CASO.
}

\author{
GUSTAVO VILELA ALVES, JOÃO VICTOR SILVEIRA MACHADO DE CAMPOS, MARA RÚBIA FRANCO \\ TEIXEIRA
}

INSTITUTO MASTER DE ENSINO PRESIDENTE ANTÔNIO CARLOS - IMEPAC

gustavovilelaalves@hotmail.com

Comunicação Oral

Resumo

Área do Conhecimento: Saúde coletiva e bem-estar

\begin{abstract}
Introdução:
A Organização Mundial da Saúde (OMS) classifica o alcoolismo como uma doença crônica. Além disso, evidências científicas robustas já demonstraram que o consumo crônico de álcool pode ocasionar uma série de alterações fisiológicas e anatômicas a nível do Sistema Nervoso Central, principalmente no cerebelo, órgão este responsável pela manutenção do equilíbrio, pelo controle do tônus muscular, dos movimentos voluntários, da aprendizagem motora, dentre outras funções. Para um eficiente equilíbrio postural estático e dinâmico, que permita o deslocamento corporal com segurança, é necessário que haja uma troca rápida e efetiva de informações entre os sistemas aferentes (exterocepção e propriocepção), eferentes (neurônios motores) e sistema nervoso central. Dessa forma, restaurar e ou melhorar o estado de deambulação do paciente deve ser, sempre, uma preocupação nos protocolos de reabilitação. Neste contexto, um adequado tratamento fisioterapêutico deve contemplar exercícios de treino de equilíbrio em diferentes posições, treino de coordenação motora, treino de força e resistência com vistas a estimular e facilitar os ajustes neuromusculares exigidos durante a marcha, o que promove melhora da mobilidade funcional e minimiza o risco de quedas.
\end{abstract}

Objetivo:

Analisar o impacto da fisioterapia na redução do risco de quedas em um paciente institucionalizado portador de repercussões motoras em membros inferiores decorrentes do consumo crônico de álcool.

Materiais e métodos:

Paciente J.A.J., homem, 59 anos, residente em instituição de longa permanência no município de Araguari - MG. Apresenta sinais e sintomas neurológicos: déficit de equilíbrio, marcha anormal, alteração do tônus (mais pronunciada nos membros inferiores), confusão mental e disartria.

0 teste Timed Up and Go (TUG) foi utilizado como ferramenta para avaliação do risco de quedas e acompanhamento de sua evolução motora e marcha em resposta à fisioterapia. Para tanto, foi realizada uma análise retrospectiva e comparativa entre um teste aplicado antes do início do tratamento fisioterapêutico, em 06 de Setembro de 2017, e outro aplicado em 02 de Abril de 2019.

Resultados:

O primeiro teste TUG, aplicado em 06 de setembro de 2017, foi completado pelo paciente em 1'47". Já o segundo teste TUG, aplicado em 02 de abril de 2019, após aproximadamente 19 meses de fisioterapia motora e respiratória, foi finalizado pelo paciente em $54 "$ ".

Conclusão:

Os resultados encontrados em ambos os testes TUG classificam o paciente com alto risco para quedas. Contudo, percebe-se uma diminuição importante de mais de $50 \%$ no tempo consumido pelo paciente para realização do teste após intervenção fisioterapêutica.

PALAVRAS-CHAVE: ALCOOLISMO; MARCHA; QUEDAS; FISIOTERAPIA; TESTE TUG; 


\title{
IMPORTUNAÇÃO SEXUAL
}

\author{
LUCAS MANTUAN ZANCANELLA, GYOVANNA GOMES ALMEIDA, VITOR FREITAS CIUFFA, GEILSON \\ NUNES
}

INSTITUTO MASTER DE ENSINO PRESIDENTE ANTÔNIO CARLOS - IMEPAC

lucasmantuan1@hotmail.com

Apresentação de Pôster

Resumo

Área do Conhecimento: Sustentabilidade e Direitos

Introdução: A presente pesquisa analisará de forma sucinta a proteção da dignidade sexual da pessoa, com enfoque na importunação sexual, bem como as inovações legislativas que buscam sempre reprimir atos ilícitos e aumentar a proteção ao ser humano como um todo. Neste sentido, a pessoa que pratica ato libidinoso contra alguém e sem a sua anuência com a intenção de satisfazer a própria lascívia e a de terceiro, estará praticando o crime de importunação sexual. Considerando o trauma vivido pelas vítimas destes crimes e o grande número de casos de importunação sexual em transportes públicos, restará demonstrado a importância da Lei $\mathrm{n}^{\mathbf{0}}$ 13.718/18 na tentativa de proteger a dignidade sexual da pessoa com intuito de coibir as ocorrências de importunação sexual.

Objetivo: Ante ao exposto, o objetivo deste trabalho é demonstrar a importância da inovação legislativa na tentativa de coibir o crime de importunação sexual, na busca da proteção e consagração da dignidade da pessoa humana.

Metodologia: Trata-se de uma pesquisa que utilizou o método dedutivo, buscando demonstrar a efetiva inovação legislativa como meio de inibir o fato delituoso caracterizado como importunação sexual, decorrente do aumento expressivo do número de casos ocorridos principalmente em transportes públicos. Resultados: 0 crescente número de casos envolvendo o crime de importunação sexual em transportes públicos, lugares movimentados, bem como a grande comoção midiática e da população, fizeram com que o legislador atuasse de forma mais rígida, entendendo por bem incluir um novo tipo penal, qual seja, a importunação sexual. Desta forma, a pratica de conduta ilícita que caracteriza o crime de importunação sexual terá pena de reclusão, de 1 (um) a 5 (cinco) anos. Anterior a Lei no 13.718/18, muitas vezes o fato era considerado como mera contravenção penal deixando as pessoas que sofriam tal abuso impossibilitadas de agir contra o agressor e, por isso, com a nova tipificação, visou-se tutelar a liberdade sexual das pessoas, bem como a dignidade sexual.

Conclusão: Desta forma, entende-se que agiu corretamente o legislador ao criar o novo tipo penal, já que anteriormente a conduta era considerada, em muitos casos, apenas como contravenção penal, não punindo o agressor de maneira devida. Logo, eliminou-se a lacuna ora existente e efetivou uma maior segurança jurídica aos casos. Portanto, o legislador entendeu que a forma para coibir a prática de novos crimes de importunação sexual foi através de uma pena mais rígida.

PALAVRAS-CHAVE: DIGNIDADE SEXUAL DA PESSOA; CONTRAVENÇÃO PENAL; CRIME DE IMPORTUNAÇÃO SEXUAL. 


\title{
INCESTO E SUAS IMPLICAÇÕES PENAIS ACERCA DA CRIMINALIZAÇÃO DA CONDUTA.
}

\author{
CAMILO RAMOS DE OLIVEIRA, GEILSON NUNES
}

INSTITUTO MASTER DE ENSINO PRESIDENTE ANTÔNIO CARLOS - IMEPAC

camilorramos@hotmail.com

Apresentação de Pôster

Resumo

Área do Conhecimento: Sustentabilidade e Direitos

O exposto artigo buscará retratar o incesto no Brasil e no mundo, incesto (manter relações sexuais com parentes consanguíneos), aonde busquei na legislação brasileira, dados reais de casos de incesto no Brasil e no mundo, dados de como é tipificado o incesto como crime ou fato atípico.

O objetivo a ser alcançado e tentar diminuir a incidência de casos de incesto no país, criando políticas criminais adequadas, com áreas jurídicas específicas em crimes de incesto, contudo, trazendo segurança para quem sofre abusos. A finalidade do referido resumo seria a tentativa de evitar a unificação da raça humana, através do cruzamento genético nascerem crianças defeituosas, na medicina prova essa possibilidades.

MÉTODO

Em busca de resultados acerca da pesquisa, para efetivar o resumo foi utilizado métodos de pesquisas particulares em torno de dados reais, para a obtenção de resultados na presente pesquisa, foi adotado o método dedutivo, a partir de argumentos gerais como forma a alcançar os resultados propostos na problemática em tela, por consequência a conclusão da pesquisa.

RESULTADOS ALCANÇADOS

Foi possível verificar que o incesto vem junto com história da civilização da humanidade com Cleópatra. Apenas 10 a 15\% dos casos de incestos são denunciados, segundo Dias (2016, n.p.) dados provam que $20 \%$ das meninas e 5 a 10\% dos meninos são abusados sexualmente, o que leva a concluir, o menor número de casos envolvendo meninos decorre do estigma da homossexualidade, que sempre acompanha a revelação, em $90 \%$ das denúncias o autor do abuso é membro da família 69,6\% dos casos é o pai biológico em 29,8\% o padrasto em $0,6 \%$ o pai adotivo. Não há registro de abuso por pais homossexuais. Se esses casos fossem com o consentimento seria possível formalizar essa união incestuosa? Não no Brasil! por expressa vedação conforme Art. 1.521 CC, Não podem casar parentes consanguíneos, para evitar nascimento de crianças defeituosas. Na Alemanha na Itália, punem o incesto com penas privativas de liberdade. No Brasil, por mais estranho que se possa parecer, não e crime! Não existe em nosso ordenamento jurídico um crime em específico? A resposta. Por não ser crime, dificulta a punição, quem pratica sexo com ascendente e descendente sendo maior de 14 anos e com consentimento não e crime, podendo ser praticar normalmente. CONCLUSÃO

Sendo assim, nos leva a extrema relevância do referido tema, o que demonstra a necessidade de leis específicas para criminalizar a conduta. Seria a solução? Assim fica a indagação, Existem incidências para criminalizar? Para tipificar a conduta incestuosa como crime. Coibir quem pratica? criando leis com penas de prisão resolveria o problema? Talvez não. Essa pergunta não teremos respostas, mas uma tentativa, seria a criação de locais específicos de apoio para conscientizar, educando de forma efetiva, que de certa forma essas pessoas sofrem com sérios problemas de saúde física e mental.

PALAVRAS-CHAVE: CRIMINALIZAÇÃO. DIREITO CIVIL. DIREITO PENAL. INCESTO. RELAÇÕES PARENTAIS. 


\title{
INDENIZAÇÃO POR TEMPO ÚTIL PERDIDO DO CONSUMIDOR
}

\author{
SIMONE APARECIDA RIBEIRO DE OLIVEIRA, NICIONE MARIA SILVA, LEONARDO HENRIQUE DE \\ OLIVEIRA
}

INSTITUTO MASTER DE ENSINO PRESIDENTE ANTÔNIO CARLOS - IMEPAC

simonecra@hotmail.com

Apresentação de Pôster

Resumo

Área do Conhecimento: Sustentabilidade e Direitos

A importância do tempo útil investido nas atividades cotidianas, as reclamações consumeristas os direitos fundamentais e a resposta do poder judiciário ao direito do consumidor, desperta o interesse em saber em que medida tem sido efetivo a proteção aos direitos fundamentais do consumidor? Objetivando estudar a lesão ao tempo perdido, a resposta e o fundamento jurídico nas reclamações consumeristas, através do método dedutivo, pesquisa bibliográfica e análise jurisprudencial será abordado princípios constitucionais e infraconstitucionais do direito do consumidor a vulnerabilidade, proteção as vítimas e por último o reconhecimento a indenização por dano temporal. Atualmente a liberdade e qualidade de vida proporcionados advindas do consumo, tornando disponível o tempo e as competências de produção, permitem o emprego do tempo em outras atividades de livre escolha e preferência consistindo em poder libertador. No entanto a perca de tempo na busca pela resolução de problemas causados pelo fornecedor é um desrespeito ao direito ao tempo livre, uma infração aos direitos a dignidade da pessoa humana e como infração legal deve sofrer a pena de indenização pecuniária ao consumidor. 0 dano pelo tempo perdido do consumidor, passa ser uma nova modalidade de dano. Porém há temor de que a multiplicac ão de novas figuras de dano venha a ter como únicos limites a criatividade do intérprete e a flexibilidade da jurisprude`ncia. 0 direito ao tempo livre, objeto de discussões recentes, mostra interesse merecedor de tutela à luz da dignidade da pessoa humana. A dignidade humana não se limita, nem poderia, como cláusula geral que é, aos interesses existenciais, inclui aspectos diversos da pessoa que "ve^m se enriquecendo, articulando e diferenciando sempre mais. 0 Código de Defesa do Consumidor, reconhece a vulnerabilidade deste, visa atender as necessidades dos consumidores, o respeito à dignidade, saúde e segurança, a proteção dos interesses econômicos, melhoria da qualidade de vida inclusive no aspecto de ganho de tempo São várias as normas constitucionais que tratam dos direitos do consumidor. Dada a vulnerabilidade deste na relação de consumo, reconheceu-se a necessidade de intervenção estatal, proteção e defesa do consumidor. O tempo é limitado, inacumulável e irrecuperável, portanto bem econômico primordial e valioso disponível na existência. É representado pela duração da vida e havendo dano e prejuízo deve ser indenizado. Uma visão generalista do judiciário enseja a indústria do mero aborrecimento, o distanciamento da proteção legitima do consumidor sob argumento de violação de pouca monta que não considera a via crucis enfrentada. Conclui-se, não se pode admitir a indiferença aos danos pela usurpação do tempo que pode ser evitada ou atenuada, pondo fim a cultura de lucratividade, preconceituosa e asfixiante dos princípios da lei.

PALAVRAS-CHAVE: CONSUMIDOR; TEMPO ÚTIL; INDENIZAÇÃO. 


\title{
INDICADORES HOSPITALARES DE GESTÃO: LOGÍSTICA HOSPITALAR
}

\author{
ANA CARLA DE MENEZES, FERNANDA JREGE ARANTES, LEANDRO HENRIQUE SALES, NATASKA \\ BATISTA POSSAS, NATHÁLIA NUNES BESSA SOUSA, ROSÂNIA EMÍLIA RIBEIRO CUNHA
}

INSTITUTO MASTER DE ENSINO PRESIDENTE ANTÔNIO CARLOS - IMEPAC

anacarlademenezes@hotmail.com

Comunicação Oral

Resumo

Área do Conhecimento: Responsabilidade e Negócios

Introdução: Os indicadores são utilizados para mensurar o desempenho de atividades produtivas e abordam a perspectiva financeira, do cliente e do processo, fornecendo subsídios importantes para a administração. Dentre os indicadores de gestão, a logística hospitalar é um dos maiores desafios encontrados pelos gestores dos hospitais quanto ao atendimento das necessidades organizacionais de forma rápida, correta e eficiente. Esta logística atende requisitos financeiros e operacionais para que possa abranger toda a cadeia de suprimentos, levando a resultados globais e não setoriais. 0 planejamento dos processos logísticos auxilia na utilização dos recursos dos hospitais, reduzindo custos. A gestão dos hospitais é particular, pois se preocupa com os custos e prioriza a saúde. Objetivo: Analisar o fluxo de serviço de logística hospitalar do Hospital São Sebastião de Araguari-MG. Metodologia: Estudo transversal, descritivo, de caráter qualitativo realizado por meio de entrevista ao setor de gestão hospitalar do Hospital São Sebastião de Araguari, instituição exclusivamente privada, escolhida devido à disponibilidade e ao interesse do gestor em compartilhar o funcionamento do seu departamento. A coleta de dados ocorreu por meio de entrevista semiestruturada com o administrador do hospital, marcada com antecedência por telefone. A pesquisa de campo, que foi visita ao hospital, foi realizada no mês de junho de 2018 pelos autores e gravada, com autorização do entrevistado. A entrevista teve enfoque nos processos logísticos do setor (compras, estoques e equipamentos) e nas inter-relações com os demais departamentos do hospital. Resultados: 0 processo de compra é realizado por meio de cotação de preços de acordo com a necessidade por determinado período de tempo baseado na experiência e previsibilidade da demanda. Sendo que todos os fornecedores são cadastrados no hospital, como exige a Vigilância Sanitária. 0 estoque de insumos é automatizado e o lote econômico é feito quando há mais de um fornecedor ou quando há previsão de alteração do valor de mercado de determinado insumo. A compra de emergência é realizada em situações especiais, como medicação de alto custo e quando há necessidade de adquirir um equipamento é realizada cotação de mercado e negociações. A inter-relação entre os setores é feita por meio de reuniões periódicas, sendo que funcionam de forma centralizada, passando por autorização do setor administrativo. Atualmente, a administração não considera importante destinar recursos para o marketing. Conclusão: 0 sistema é informatizado, composto por 61 funcionários, tendo a inserção do farmacêutico junto à administração, responsáveis pelas compras. O hospital atenta nos equipamentos, diagnósticos e tratamentos e realiza manutenções preventivas e corretivas. A diretoria administrativa e clínica buscam analisar os custos e os benefícios relacionando a necessidade do uso.

PALAVRAS-CHAVE: GESTÃO; INDICADORES; HOSPITALAR; LOGÍSTICA, ECONOMIA. 


\title{
INFLUÊNCIA DA DENSIDADE NO CONTROLE DE QUALIDADE DE ENCAPSULADOS
}

\author{
KAROLAYNE DOS SANTOS BORGES, CARLA SILVA PEIXOTO, ERICA SILVEIRA BRITO, ERIKA MARIA \\ MENDES, JESSICA MENDES, SAMUEL JUSTINO BARBOSA DA CONCEIÇÃO, ALINE FERNANDES \\ HIPÓLITO
}

INSTITUTO MASTER DE ENSINO PRESIDENTE ANTÔNIO CARLOS - IMEPAC

karolayneprodutosnaturais@gmail.com

Apresentação de Pôster

Resumo

Área do Conhecimento: Responsabilidade, Tecnologia e Ciência

\begin{abstract}
Introdução: A partir da resolução de diretoria colegiada - RDC noํ. 49, de 23 de novembro de 2010, foi aprovada a Farmacopeia Brasileira 5a edição e definiu-se no seu segundo artigo que os insumos farmacêuticos, os medicamentos e outros produtos sujeitos à vigilância sanitária devem atender às normas e especificações estabelecidas na Farmacopeia Brasileira. As farmácias magistrais e indústrias de suplementos alimentares utilizam técnicas e normas de encapsulamentos de produtos em formas de pós devendo cumprir as legislações pertinentes. Desta forma, perceber-se a importância de garantir a qualidade em todas as etapas do processo de manipulação para a obtenção de um produto final que não represente riscos à saúde dos consumidores e que atenda os padrões de qualidade.

Objetivo: 0 objetivo do trabalho foi avaliar as várias etapas do processo de encapsulação, observando a influência da densidade dos insumos utilizados na cadeia produtiva e avaliar as dificuldades de atender as legislações específicas e qualidade do produto final de alimentos funcionais manipulados em indústria de suplementos situada na cidade de Uberlândia - MG.

Metodologia: No estudo utilizou-se 20 cápsulas de cada produto, escolhidas aleatoriamente da produção final, antes do envasamento, totalizando em 140 amostras. Para avaliar o processo mediu-se a densidade das substâncias (matérias-primas), o peso médio (PM) e o coeficiente de variação (CV) das cápsulas prontas dos seguintes produtos: Guaraná, Cogumelo, Creatina, Chá-verde, Quitosana, Psyllium e Colágeno. As cápsulas utilizadas na encapsulação de todas as substâncias analisadas foram a $0(0,68 \mathrm{ml})$, a qual segundo a Farmacopeia Brasileira é desejável no mínimo 0,5 g de excipientes e princípio ativo, com o CV coeficiente aceitável de 7,5\%.

Resultados: Mediu-se a densidade das matérias-primas e o peso médio (PM) das cápsulas prontas e obtevese os coeficientes de variação, o que permitiu a otimização do processo e determinou uma faixa de variação aceitável da densidade entre 0,4 a $0,6 \mathrm{~g} / \mathrm{mL}$, a qual será disponibilizada aos fornecedores para melhorar a eficiência no controle de qualidade do produto final. Além disso, percebe-se que o uso de matéria-prima com alta densidade promoveu a encapsulação de uma maior quantidade de produto, enquanto insumos com densidades baixas apresentaram encapsulação de produto abaixo do mínimo de $0,5 \mathrm{~g}$.

Conclusão: Portanto, a realização do estudo detalhado a respeito da densidade se mostrou útil e de grande aplicabilidade, comprovando que a maioria das preparações com as respectivas matérias-primas utilizadas no processo se apresentaram satisfatórias e passaram nos testes de qualidade. A influência da densidade no processo produtivo de encapsulados é um dos pontos fundamentais, pois implica diretamente na qualidade do produto final e no cumprimento das normas sanitárias.
\end{abstract}

PALAVRAS-CHAVE: ENCAPSULADOS; DENSIDADE; CONTROLE DE QUALIDADE. 


\title{
INTERCEPTAÇÃO TELEFÔNICA E ADMISSIBILIDADE COMO MEIO DE PROVA
}

\author{
ALINE ALVES RIBEIRO, JANNAYNA CRISTINA ROCHA DE OLIVEIRA,
}

INSTITUTO MASTER DE ENSINO PRESIDENTE ANTÔNIO CARLOS - IMEPAC

ainealvesribeiro@gmail.com

Apresentação de Pôster

Resumo

Área do Conhecimento: Sustentabilidade e Direitos

Introdução: O presente artigo tem como objetivo o estudo da interceptação telefônica e a possibilidade da admissibilidade como meio de prova no Direito Processual Penal Brasileiro. Esclarece a escolha do presente assunto diante das diversas discussões acerca das interceptações telefônicas, já que está relacionado com um direito fundamental de privacidade elencado na Constituição Federal. Atualmente, é bem corriqueiro o procedimento das investigações com a utilização desse meio, além de ser requerido pelo Delegado de polícia e também pelo Promotor de Justiça, os quais vem obtendo excelentes resultados.

Objetivo: 0 objetivo da presente pesquisa é demonstrar que as provas obtidas através de interceptação telefônica não são provas ilícitas, tendo em vista que contribui de forma favorável para o desenvolvimento das investigações do crime. Entretanto para ser apontado como meio de prova legal é necessário respeitar os princípios constitucionais, sem deixar de atentar para a eficácia do resultado da investigação.

Metodologia: Como método de pesquisa optou-se pelo dedutivo, partindo-se de uma regra geral para esse caso metodologia utiliza-se uma pesquisa essencialmente bibliografia.

Resultados: A interceptação telefônica é quando uma terceira pessoa que não esteja envolvida no ato fica incumbida de escutar a gravação sem conhecimento dos interlocutores, contudo, este tipo de prova só será válido em investigação criminal ou instrução processual penal. Vale ressaltar a observância de tais requisitos como vestígios de autoria ou participação em infração penal; a indispensabilidade de tal medida. Nesse sentido ainda é importante frisar que é fundamental a autorização judicial sendo necessária a verificação do fumus boni Iuri e o periculum in mora. Consequentemente, para a interceptação ser admitida como prova é essencial observar se há justa causa em utilizar esse meio de prova, bem como se não está sendo violada a intimidade da pessoa envolvida.

Conclusão: A interceptação telefônica é de extrema importância quando não há outro meio de prova, já que traz informações relevantes e de grande fundamento para alcançar um resultado eficaz. Tendo em vista, que com o avanço tecnológico surge o aprimoramento de técnicas para o criminoso que vem para burla o ordenamento jurídico se fazendo assim necessário a utilização da interceptação telefônica como meio de prova para amenizar os grupos criminosos de eventual impunidade. Salienta que as provas obtidas através de interceptação telefônica não são prova ilícitas posto que contribui de forma favorável para o desenvolvimento das investigações do crime. Consequentemente, o intuito das interceptações telefônicas é o alcance da prova voltada, ou seja, superar a presunção de inocência.

PALAVRAS-CHAVE: INTERCEPTAÇÃO TELEFÔNICA; LEGALIDADE; MEIO DE PROVA. 


\title{
INTERFACE ENSINO E EXTENSÃO NA ATENÇÃO À SAÚDE DA MULHER: RELATO DE EXPERIÊNCIA DO PROJETO OUTUBRO ROSA
}

\author{
LINCOLN RODRIGUES FERNANDES JUNIOR, JHONATAN PEREIRA CASTRO, JOÃO PAULO \\ ASSUNÇÃO BORGES, KARLA CRISTINA WALTER / DANIELLE FERNANDES ALVES
}

INSTITUTO MASTER DE ENSINO PRESIDENTE ANTÔNIO CARLOS - IMEPAC

lincoln_fernandesjr@yahoo.com.br

Apresentação de Pôster

Resumo

Área do Conhecimento: Saúde coletiva e bem-estar

Introdução: A campanha Outubro Rosa é realizada mundialmente por meio de ações afirmativas relacionadas à prevenção e diagnóstico precoce do câncer de mama e do colo do útero. Ações de promoção da saúde da mulher e prevenção do câncer são fundamentais para reduzir a incidência e prevalência destes agravos, bem como suas consequências na população feminina. Eventos técnicos, debates, apresentações acerca do tema, produção de materiais informativos sobre hábitos saudáveis, fatores protetores e detecção precoce do câncer exemplificam as principais atividades desenvolvidas por profissionais de saúde com destaque para o enfermeiro. Objetivos: relatar a experiência dos docentes e acadêmicos dos Cursos de Enfermagem, Medicina e Nutrição de uma instituição de ensino privada, com ênfase na descrição e reflexão da vivência do Projeto de Extensão Outubro Rosa em um município do Triângulo Mineiro. Metodologia: Relato de Experiência produzido a partir da observação participante do desenvolvimento das ações estratégicas planejadas e realizadas no mês de outubro de 2018 direcionadas à Saúde da Mulher em empresas privadas e unidades de saúde da Atenção Básica do município. Relato de Experiência: A vivência ocorreu com aproximadamente 300 mulheres trabalhadoras da cidade de Araguari-MG, no mês de outubro de 2018. Todas as funcionárias eram convidadas anteriormente para participar do projeto. As atividades foram planejadas e executadas por alunos do curso de enfermagem, nutrição e medicina. A ação foi dividida em três etapas: a primeira foi educação em saúde, executada pelos alunos do curso de enfermagem e medicina, destacando conceitos, causas e consequência do câncer de mama e do colo de útero, como: os fatores de risco; a importância da prevenção primária, que inclui cuidados com o estilo de vida, como alimentação saudável, exercício físico, comportamento preventivo e controle do estresse; a prevenção secundária, que abrange os exames de rotina para detecção precoce da doença, autoexame das mamas e mamografia; além de orientar sobre os locais onde são ofertados os serviços de exames para a saúde da mulher. Em seguida, na segunda etapa do projeto, os alunos do curso de nutrição convidaram todas as mulheres para realizar uma avaliação nutricional e orientação de dicas para uma alimentação de qualidade, por meio de um folheto educativo intitulado "Os Dez Passos para a Alimentação Saudável". Na terceira e última etapa, foram agendados exames preventivos para as mulheres que tiveram interesse e que não tinham realizado no último ano. Todos os exames preventivos foram realizados em uma Unidade Básica de Saúde que aceitou a participar da ação. Considerações finais: A realização deste projeto foi de grande valor para a formação acadêmica dos pesquisadores, visto que apresentou experiencias favoráveis ao crescimento profissional desses estudantes no âmbito de ações multiprofissionais voltadas a saúde da mulher.

PALAVRAS-CHAVE: CÂNCER DE MAMA; CÂNCER DE COLO DO ÚTERO; SAÚDE DA MULHER; PROMOÇÃO DA SAÚDE. 


\title{
JUSTIÇA RESTAURATIVA NO BRASIL
}

\author{
NATALIANE GONÇALVES MIRANDA DO NASCIMENTO, GIOVANNA SILVA GABRIEL, GEILSON \\ NUNES
}

INSTITUTO MASTER DE ENSINO PRESIDENTE ANTÔNIO CARLOS - IMEPAC

natalianedonascimento@hotmail.com

Apresentação de Pôster

Resumo

Área do Conhecimento: Sustentabilidade e Direitos

INTRODUÇÃO:A Justiça Restaurativa trata-se da resolução de conflito entre a vítima e o agressor, por meio de um mediador, de uma forma totalmente diversa da imposta pelo Estado, surgindo para redefinir a missão da justiça penal e, consequentemente, elaborando um novo paradigma de justiça criminal, tendo por vez, reparar o mal ocasionado pela prática de atos ilícitos. É completamente voluntário, de forma absoluta e caráter informal, sendo o encontro, indispensável, pois é necessária a relação das partes para que solucione o caso concreto. Não têm a pretensão de deixar o ofensor impune, mas que ele não passe a ter caráter de pena, tornando-o um processo de restauração. É usada para suprir a ineficiência e algumas das falhas do sistema punitivo tradicional.

PROBLEMA DE PESQUISA: As partes de um processo restaurativo não podem ter como o principal objetivo a reparação pecuniária, e sim a responsabilização do infrator. Pois assim haverá a resolução dos traumas e perdas causados pelo crime. Traria a reparação para a vítima, e do outro lado o transgressor, após receber a sua medida de justiça seria reintegrado. A justiça restaurativa é eficaz na pacificação e restauração dos conflitos na sociedade?

OBJETIVO: 0 objetivo a ser alcançado, refere-se à tentativa de demonstrar que a Justiça Restaurativa é o método mais benéfico para resolver os conflitos na sociedade, pois há uma participação maior das partes, há responsabilização pelos danos causados, e emponderamento. A justiça restaurativa tira o foco do delito, e transfere-o para a solução decorrente deste delito. Prezando pela autonomia, a dignidade da pessoa humana, razoabilidade, e proporcionalidade.

MÉTODO: Para a obtenção dos resultados almejados na presente pesquisa será adotado o método de pesquisa bibliográfica, com o objetivo de reunir as informações e dados que servirão de base para alcançar os resultados propostos na problemática da pesquisa.

RESULTADOS ALCANÇADOS:Entende-se que na justiça restaurativa as partes envolvidas no conflito, especialmente ofensor e ofendidas, constroem sua própria sentença, e, consequentemente, as formas de reparação e responsabilização ficam nas mãos dos participantes. Sica ressalta que se instaurou na realidade atual o "esgotamento do modelo repressivo de gestão crime". A fim de solucionar os problemas decorrentes da ineficácia do sistema de justiça criminal, inúmeras tentativas foram realizadas no decorrer no processo histórico, sendo a mais recente, a adoção de medidas alternativas ao encarceramento, especificamente o monitoramento eletrônico. Todavia, nunca se prendeu tanto no Brasil. Os números só aumentam o que indica que o estabelecimento de penas alternativas não causou grandes impactos no sistema criminal. PALAVRAS-CHAVE: CONFLITOS JUSTIÇA RESTAURAÇÃO. 


\title{
LEAN HEALTHCARE COMO ESTRATÉGIA DE MELHORIA NA PRESTAÇÃO DE SERVIÇOS NA ÁREA DE SAÚDE: UMA REVISÃO DA LITERATURA
}

\author{
CAROLINA DA SILVA VOGADO, CAMILA DOS ANJOS, DANIELA CAETANO DA SILVA COSTA, \\ OTONIEL GONÇALVES DE ALMEIDA, RAYRA RANYÊ DA SILVA RAMOS, WALTER ANDRADE
}

INSTITUTO MASTER DE ENSINO PRESIDENTE ANTÔNIO CARLOS - IMEPAC

carolina.dasilvavogado@yahoo.com.br

Comunicação Oral

Resumo

Área do Conhecimento: Saúde coletiva e bem-estar

\begin{abstract}
Introdução: Em matéria publicada na revista exame, em setembro de 2017, o Ministro da Saúde, Ricardo Barros, em palestra no Exame Fórum Saúde afirmou: "Não falta dinheiro para a saúde. Falta gestão. Enquanto recursos não forem bem aplicados, o país não terá uma boa saúde". Nesse contexto surge um questionamento sobre a possibilidade de metodologias como o LH (Lean Healthcare) ser utilizada como estratégia organizacional de melhoria na eficiência da prestação de serviços na área de saúde, pois centrase na eliminação de desperdícios e em melhoria contínua com alto nível de envolvimento dos funcionários. Surge-se aí o interesse pela temática, onde se propõe estudar o LH com o objetivo de buscar melhorias no sistema de saúde.

Objetivo: Frente ao exposto, o objetivo deste trabalho foi a realização de revisão de literatura e análise bibliométrica, para melhor compreender a utilização do Lean no segmento de saúde, caracterizado como LH. Têm-se como hipótese que a aplicação do LH promoverá a sustentabilidade dos Sistemas de Saúde, sejam públicos ou privados.

Metodologia: Foi realizado uma revisão sistemática de literatura avaliando pesquisas relacionadas à utilização do Lean no segmento de saúde. Para tanto foi realizado análise bibliométrica do conceito de LH na base de dados "Science Direct".

Resultados: Como forma de fundamentar a pesquisa proposta realizou-se busca na base de dados no dia 09 de maio de 2019 com o termo LH em artigos de pesquisa, somente no título da publicação. Foram encontradas 17 publicações entre os anos de 2010 e 2017, dos quais 4 foram aplicados no Brasil, 4 nos Estados Unidos, 3 na Espanha, 2 no Reino Unido, 2 na Suíça, 1 em Portugal e 1 na Romênia. Percebeu-se que estão associados ao LH os conceitos de Melhoria Contínua e Lean Thinking, demonstrando que o Lean está atrelado aos conceitos do STP (Sistema Toyota de Produção). Outra percepção de grande relevância na pesquisa é referente ao local de aplicação do LH, que em grande parte das publicações são em hospitais e clínicas. Não foram encontradas publicações em Sistemas de Saúde.

Conclusão: Percebe-se a grande relevância do LH para melhoria da eficiência na prestação dos serviços de saúde, com foco na Jornada do Paciente. Também é possível concluir que a aplicação no LH normalmente está limitada a aplicações pontuais e não em Sistemas de Saúde, como o Sistema Único de Saúde (SUS) por exemplo. Espera-se que com o aumento da aplicação do LH o mesmo evolua para além de aplicações pontuais e passe a transformar a prestação de serviços de saúde em um país, estado ou município, de forma sistêmica.
\end{abstract}

PALAVRAS-CHAVE: LEAN HEALTHCARE; SISTEMA DE SAÚDE; EFICIÊNCIA. 


\section{LEI MARIA DA PENHA LEI N. 11.340}

\section{NATHALIA GOMES CRUZ, GIOVANNA DUARTE MENDONÇA}

INSTITUTO MASTER DE ENSINO PRESIDENTE ANTÔNIO CARLOS - IMEPAC

nathaliagocruz@gmail.com

Apresentação de Pôster

Resumo

Área do Conhecimento: Sustentabilidade e Direitos

\section{INTRODUÇÃO}

O propósito deste estudo é explorar a legislação que garante a proteção das mulheres contra qualquer tipo de violência doméstica, física, psicológica, patrimonial ou moral, a lei no 11.340, de 7 de agosto de 2006, popularmente conhecida como Lei Maria da Penha, mostrando as medidas preventivas quem tem a finalidade de prevenir, punir e erradicar a violência contra a Mulher.

PROBLEMA DE PESQUISA

A falta de conhecimentos de algumas mulheres que sobrevivem mediante ameaças do gênero masculino agravam a situação, em que são abusadas e por medo, muitas não busca sua proteção na Lei Maria da Pena e sofre com os abusos e muitas perdem a vida. A lei existe, é um direito da mulher que sentir ameaçada, buscar esta proteção na justiça. O que falta ainda na sociedade além da Lei Maria Pena, para proporcionar aos agressores a não praticar estas tais violências?

OBJETIVOS

O objetivo deste estudo é mostrar que hoje as mulheres tem uma lei que as ampara, que ofereça proteção, acompanhamentos psicológicos e dar a elas o direito a recorrer o socorro dos abusos que sofrem e a prevenir que o pior aconteça. Qualquer mulher que se sentir ameaçada tem amparo da lei e devem denunciar os abusos sofridos.

MÉTODOS

A conclusão deste estudo contou com uma pesquisa significativa com método dedutivo a partir de argumentos de revisão em bibliografia de determinados autores e artigos que contribuíram para a construção deste estudo.

RESULTADOS ALCANÇADOS

Em 7 de agosto de 2006 foi sancionada a Lei Maria da Penha lei n. ${ }^{0} 11.340$ que protege a mulher da violência doméstica, familiar e de transtorno psicológicos devido o ato de abuso.

No dia 22 de setembro de 2006 a lei entrou em vigor tendo como primeiro caso de um homem que tentou estrangular sua mulher ocorrida em Rio de Janeiro. A origem do nome da lei é em homenagem a Maria da Penha Maia, que foi agredida pelo marido durante seis anos até se tornar paraplégica, depois de sofrer atentado com arma de fogo, em 1983. 0 marido de Maria da Penha ainda tentou matá-la por meio de afogamento e eletrocussão e só foi punido depois de 19 anos de julgamento, ficando apenas dois anos em regime fechado.

Esta violência de gênero contra a mulher vem a ser compreendida como problema de saúde pública pela Organização Mundial da Saúde (OMS). A questão do gênero vem gerando muito polemica devido à lei determinar conduta de ação ou omissão deve ser baseada no gênero em que leva a questionar uma conduta baseada no gênero? E tem como resposta que violência se baseia no gênero em um sujeito ativo contra o sujeito passivo, que indica uma concepção de dominação, de poder, em que o sujeito ativo se mostra tão poderoso, tão superior que exige submissão do outro, chegando a ser considerado o dono do corpo e da mente do sujeito passivo fazendo que a dominação seja completa da vitima.

PALAVRAS-CHAVE: VIOLÊNCIA, LEI, MARIA DA PENHA. 


\title{
LEISHMANIOSE VISCERAL CANINA NO MUNICÍPIO DE UBERLÂNDIA-MG
}

\author{
GABRIELY LOPES FRANCO, ANNA JULIA ZANFORLIN PEREIRA, JEAN ROBERT SOARES, MARCUS \\ VINÍCIUS MIKELAITIS, PABLO ANDREW BARBOSA COSTA, VITÓRIA REGINA TOMAZ E ZICA, \\ BRENDA CARLA LUQUETTI
}

INSTITUTO MASTER DE ENSINO PRESIDENTE ANTÔNIO CARLOS - IMEPAC

gabriely.Ifranco@hotmail.com

Apresentação de Pôster

Resumo

Área do Conhecimento: Saúde coletiva e bem-estar

Introdução: 0 Brasil enfrenta uma expansão de LVC (Leishmaniose Visceral Canina) em cidades não endêmicas. 0 principal vetor da doença causada por Leishmania infaatum é o flebotomíneo Lutzomyia longipalpis e o cão é o principal reservatório no ambiente doméstico e peri doméstico. É uma doença que deve ser notificada e pelo seu caráter zoonótico, crônico e sistêmico pode levar animais e seres humanos infectados a óbito. Os cães infectados podem permanecer por um longo período servindo como fonte de infecção para o vetor.

Metodologia: Relatar um caso de Leishmaniose em um cão errante residente nas ruas de Uberlândia - MG. Relato da Experiência: Um cão errante da cidade de Uberlândia - MG, no bairro Jaraguá, com sinais clínicos suspeitos de LVC, foi acolhido por um proprietário de uma clínica veterinária. 0 animal, uma fêmea de Poodle de pelagem branca pesava $3 \mathrm{~kg}$ e apresentava sinais de LVC, como apatia, emagrecimento, lesões oculares e cutâneas, convulsões, alterações neurológicas, onicogrifose, dificuldade de locomoção, poliúria, vômitos e diarreia. Embora clássicos, os sintomas poderiam ser confundidos com outras doenças, razão pela qual, diferentes amostras biológicas foram coletas para exames sorológicos. Com isso foram realizados hemograma, bioquímica, testes sorológicos (ELISA e RIFI), teste para toxoplasmose, neospora e cinomose. Os resultados dos exames de hemograma e bioquímica constataram alterações nos monócitos, demonstrando anemia, porém não suficiente para diagnosticar leishmaniose. 0 exame deu positivo para a doença em ELISA e RIFI e negativo para as outras. Entre os métodos utilizados para prevenção à doença é muito importante o uso continuo da coleira repelente, além de vacinas já disponíveis registradas pelo MAPA. O diagnóstico é dificultado, pela variedade de outros sintomas comuns, sendo realizados teste de ELISA e RIFI para contestar a doença. A eliminação do animal positivo, assintomático ou não, é o ponto mais controverso da relação animal-tutor, que influencia a atuação do veterinário, que se depara com a questão legal sobre a notificação e a eutanásia. Recentemente o Ministério da Saúde liberou o fármaco Milteforan ${ }^{\circledR}$ como tratamento da leishmaniose em cães, que promove melhora clínica, redução da carga parasitária, recuperação imunológica e redução ou bloqueio da transmissão da doença por ter efeito leishmanicida. Sua administração deve ser feita durante 28 dias ininterruptos, por via oral, associado com Alopurinol e outros imunomoduladores. 0 animal sempre irá precisar de acompanhamento veterinário.

Considerações finais: Devido ao diagnóstico positivo proveniente do teste ELISA pode-se afirmar que há confirmação de LVC na região.

PALAVRAS-CHAVE: CÃO, LEISMANIA, PROTOZOÁRIO; ZOONOSE; 


\title{
LESÃO POR PRESSÃO: A IMPORTÂNCIA DO PROTOCOLO PARA MINIMIZAR DANOS.
}

\author{
MARIANA INGRID MESSIAS GONÇALVES, MARIA PAULA YAMAGUTI, MARIA VITÓRIA DE PAIVA \\ NOVAES, MARIANE RESENDE DAVID , MATHEUS ARAUJO, RODRIGO GARCIA E MARCOS PAULO DE \\ SOUSA
}

INSTITUTO MASTER DE ENSINO PRESIDENTE ANTÔNIO CARLOS - IMEPAC

marianaingridmg@hotmail.com

Apresentação de Pôster

Resumo

Área do Conhecimento: Saúde coletiva e bem-estar

\begin{abstract}
Introdução: O Ministério da Saúde propõe a efetivação de Protocolos na Atenção Primária à Saúde (APS). Todavia, é notória a negligência de alguns profissionais de saúde, sendo a ineficiência na comunicação entre a equipe e o não cumprimento das diretrizes ministeriais fatores que culminam no surgimento das lesões por pressão (LPP). 0 contato com esse processo promoveu reflexões que motivaram esse projeto, cujo objetivo é ressaltar a necessidade da aplicabilidade dos protocolos da APS em pacientes com restrição na movimentação locomotora. Nesse viés, destaca-se a importância do princípio da beneficência que se encontra intimamente atrelado ao cuidado integral e a minimização de danos, sendo sua relevância um norteador das ações médicas e da equipe multiprofissional.

Metodologia: 0 projeto foi desenvolvido por um grupo de acadêmicos do curso de graduação em medicina do $3^{\circ}$ período do IMEPAC. No mês de abril de 2019, por dois dias, o referido grupo realizou visitas domiciliares (VD) a um paciente com LPP em estágio III e IV, em distintas localizações anatômicas, com a realização de técnicas de debridamento mecânico e curativos.

Relato da Experiência: No primeiro dia, a VD teve como intuito a realização da anamnese e do exame físico do paciente que se encontrava acamado com LPP, visto que, após a hospitalização por um período de dois meses, com complicações hemodinâmicas oriundas de infartos, a equipe multiprofissional da atenção secundária à saúde não efetivou a assistência vinculada às medidas preventivas de LPP. Foi identificado a presença de lesão na região occipital, necrose de liquefação na região sacral e necrose de coagulação no calcâneo esquerdo. Realizou-se debridamento físico, que consiste na remoção de tecido desvitalizado, sendo aplicado a pomada colagenase com cloranfenicol para o debridamento químico. Ademais, utilizou-se a sulfadiazina de prata à $1 \%$ como agente cicatrizante e antimicrobiano no tecido de granulação para estimular a angiogênese e formação de colágeno. Por fim, foi construído o projeto terapêutico singular objetivando a integração entre ensino-serviço, com a interface na avaliação do estado nutricional visto que o paciente com LPP se encontrava em estado catabólico. No segundo dia, o avanço da cicatrização era notório, não sendo necessário a realização de debridamento manual, nem tampouco químico. Após a inspeção e discussão do caso clínico, foi realizado curativo com aplicação da pomada sulfadiazina de prata à $1 \%$.

Considerações Finais: Por meio da experiência vivenciada, foi possível internalizar a importância da efetivação do Protocolo de Prevenção de LPP a fim de otimizar o custo financeiro, a redução no tempo da hospitalização e, sobremaneira, o risco de infecção em pacientes que evoluem com LPP, garantindo o princípio da beneficência no cuidado.
\end{abstract}

PALAVRAS-CHAVE: LESÃO POR PRESSÃO, PROTOCOLO DE PREVENÇÃO DE LPP, ATENÇÃO PRIMÁRIA À SAÚDE, INTEGRAÇÃO ENSINO-SERVIÇO. 


\title{
LEVANTAMENTO DE CISTICERCOSE BOVINA EM UM MATADOURO FRIGORIFICO NO MUNICÍPIO DE ARAGUARI-MG NO PERÍODO DE 01/01/2018 A 31/01/2018
}

\author{
JEFTÉ BERNARDES, CINTHIA SANTANA JUNQUEIRA, MARCELO BARBOSA CARDOSO, MARCELO \\ PEREIRA DA SILVA, DANIELLE VITORINO MORAES E SILVIO ANDRE PEREIRA MUNDIM
}

INSTITUTO MASTER DE ENSINO PRESIDENTE ANTÔNIO CARLOS - IMEPAC

jeftebernardes@hotmail.com

Apresentação de Pôster

\section{Resumo}

Área do Conhecimento: Saúde coletiva e bem-estar

\begin{abstract}
Introdução: A cisticercose bovina é causada por Cysticercus bovis. 0 ciclo da zoonose consiste na ingestão de água ou pastagens contaminadas por ovos de Taenia saginata pelos bovinos destinados ao abate, que apresentaram em sua musculatura a forma larval da Tenia saginata, que resulta na teníase humana na sua forma adulta.

Segundo o Ministério da Agricultura, Pecuária e Abastecimento, Secretaria de Defesa Agropecuária e o Departamento de Inspeção de Produtos de Origem Animal, a inspeção e fiscalização da carne bovina é de responsabilidade do médico veterinário, assim como todo produto de origem animal. Essa medida tem como objetivo reduzir a comercialização e o consumo de carne contaminada por cisticercos, tem ainda o papel de orientar os pecuaristas sobre formas de aproveitamento da carcaça.

Objetivo: 0 presente trabalho teve por finalidade quantificar os casos de cisticercos encontrados em um frigorífico da cidade de Araguari.

A cisticercose bovina é uma zoonose na qual há presença de larvas parasitárias de tênia saginata, o consumo de carnes infectadas pela cisticercose leva a um quadro de parasitose conhecida como teníase.

A quantificação dos casos de cisticercose é uma ferramenta essencial para avaliar as condições sanitário/ambientais a que os rebanhos são submetidos.

Metodologia: Os dados foram coletados através de um relatório emitido pelo frigorífico, onde consta os dados discriminados por municípios, origem do animal, tipo de alteração e data do abate.

Desconsideramos alterações como pneumonia, contaminação, contusão e tuberculose, focando apenas as alterações por cisticercos dentre o período de 01/01/2018 a 31/12/2018.

Foram quantificados os casos de cisticercose viva e calcificadas e discriminadas em relação ao tipo e ao total.

Resultados: Foram encontradas um total de 795 carcaças com contaminação por cisticerco, sendo: 636 carcaças com cisticercos vivos que apresentam lesões císticas, parede translúcida ou levemente opaca, com líquido claro e um ponto esbranquiçado no interior, denominado escólex, e 159 carcaças com cisticercos calcificados ou mineralizados que não possui capacidade infecciosa.

Conclusão: Concluímos que a atuação do médico veterinário é fundamental para o controle e a prevenção do complexo teníase-cisticercose, uma vez que esse profissional atua como promotor da sanidade animal, inspeção de carnes, e principalmente na educação sanitária.

Concluímos também que apesar das informações sobre saúde e higiene serem amplamente divulgadas, ainda são necessárias medidas para aprimorar a prática de tais preceitos.
\end{abstract}

PALAVRAS-CHAVE: CISTICERCOSE, SAÚDE PÚBLICA, ARAGUARI, EDUCAÇÃO. 


\title{
LUDICICLAGEM: A REUTILIZAÇÃO DE MATERIAIS RECICLÁVEIS EM ESPAÇOS OCIOSOS DA EDUCAÇÃO INFANTIL
}

\author{
MARIA HELENA BELO DE ARAUJO, JÉSSICA PINHEIRO DE SOUZA, MARIA EDUARDA SANTOS DA \\ SILVA, MARIA TERESA DE BEAUMONT
}

INSTITUTO MASTER DE ENSINO PRESIDENTE ANTÔNIO CARLOS - IMEPAC

mariahelenabelo771@gmail.com

Apresentação de Pôster

Resumo

Área do Conhecimento: Educação para Desenvolvimento Sustentável

Introdução: É importante conversar com as crianças sobre a sustentabilidade e a relevância de usar os materiais recicláveis, que são descartados no meio ambiente e a eles não é dado o valor que merecem, pois podem se tornar objetos úteis, desde que se tenha um novo olhar sobre seu aproveitamento. Por isso, se deve trabalhar com as crianças, para que elas se tornem adultos conscientes de que ao reutilizar esses materiais, conseguirão entender a importância de se manter o meio ambiente limpo. A comunidade e os pais também devem estar inseridos na escola, participar junto com as crianças, para ver o que elas estão fazendo, pois não se trata apenas de "juntar um monte de lixo", mas mostrar à comunidade e aos pais que esses materiais têm outros tipos de utilidades. A intervenção teve como objetivo a confecção de dois brinquedos com o uso de materiais reutilizáveis como papelão e garrafa pet para ocupar um espaço ocioso na sala de aula.

Metodologia: 0 projeto foi desenvolvido com três turmas de crianças de quatro anos de uma escola municipal de Araguari (MG), e constou da elaboração de brinquedos com materiais recicláveis, realizada em um dia, no mês de setembro de 2018.

Relato da experiência: Foi feita uma pré-montagem dos brinquedos em um corredor do lado de fora da sala de aula. Após a hora do sono, entramos e refizemos a pré-montagem dos brinquedos em uma das salas de aula, onde houve uma pequena conversa informativa e de fácil compreensão devido à idade das crianças. Perguntamos se poderíamos reutilizar alguns materiais, dando exemplos. As crianças responderam sem dificuldades. Começamos a montagem, juntamente com as crianças um dos brinquedos, o treminhão por ser o mais fácil de montar e, logo em seguida chamamos as crianças para pintar o mesmo. Depois demos continuidade a outro brinquedo que era uma cozinha gigante. Depois de tudo pronto, observamos como as crianças brincaram com os brinquedos feitos de materiais reciclados.

Considerações finais: Podemos destacar a iniciativa de utilizar materiais reutilizáveis como caixas de papelão e garrafas pet para confecção de brinquedos que podem e devem ser usados para ocupar espaços ociosos nas salas de aula. Iniciativas como esta podem colaborar com o aumento do interesse das crianças pela sustentabilidade, pelas brincadeiras e pela interação uma vez que os espaços, hoje considerados o terceiro educador tornam se muito mais lúdicos e convidativos. Devemos considerar, ainda, que professores e gestores de creches e escolas públicas ou privadas devem apoiar iniciativas de valorização dos materiais recicláveis visto serem estes recursos valiosos que muito pode somar nas aulas e projetos. 


\title{
MANUFATURA ADITIVA
}

\section{ALEXANDRE LUCAS DIAS COSTA, ELTON PACHORA COSTA FERREIRA, JEFERSON FERNANDES RIBEIRO, LEONARDO MARTINS RIBEIRO, FÁBIO GARCIA TEMÍSTOCLES FERREIRA}

\author{
INSTITUTO MASTER DE ENSINO PRESIDENTE ANTÔNIO CARLOS - IMEPAC
}

alexandrelucasdiascosta@yahoo.com.br

Comunicação Oral

Resumo

Área do Conhecimento: Responsabilidade, Tecnologia e Ciência

Introdução: Manufatura Aditiva (Additive Manufacturing - AM) é um processo de fabricação por adição de material em camadas sucessivas que possibilita a adição de material para união de peças ou sua recuperação. Por ser uma tecnologia relativamente nova, estão em escassez na literatura características mais precisas que definam o desempenho e a aplicabilidade do processo produtivo, principalmente no que diz respeito às propriedades do material impresso.

Objetivo: De forma geral o objetivo deste trabalho é demonstrar, através de dados e conceitos, os benefícios da utilização da manufatura aditiva, como método inovador de fabricação. Também se pretende ter uma visão mais clara do processo por meio do estudo dos parâmetros de impressão e suas relações com a qualidade do objeto de impressão.

Metodologia: Modelagem por Deposição de Material Fundido (FDM, Fused Deposition Modeling): Nesse método, filamentos de material aquecido são extrudados a partir de um orifício que se move num plano XY. O filamento aquecido e maleável é depositado conforme a geometria desejada. A plataforma é mantida sob uma temperatura inferior à do material, de forma que este endurece e cura rapidamente, e logo após, a plataforma se abaixa ligeiramente e a matriz de extrusão deposita uma segunda camada sobre a primeira. As peças produzidas pela impressora de manufatura aditiva são ensaiadas em suas propriedades mecânicas para o levantamento de sua resistência ao carregamento mecânico quando da aplicação em uma estrutura ou como peça sujeita a um esforço. Os valores encontrados são postos em paralelo com os dados disponíveis na literatura a fim de evidenciar a diferença de resistência mecânica provocada pelo método da deposição de material fundido (FDM).

Resultados: Para demonstrar a capacidade de resistência que os objetos produzidos por AM têm, realizouse um ensaio de tração com 10 corpos de prova impressos pelo método FDM, onde obteve-se uma tensão de ruptura média de 42,244 MPa. 0 valor nominal de tensão de ruptura para esse objeto é de $55 \mathrm{MPa}$ (segundo a literatura), sendo que o objeto impresso apresentou uma tensão média inferior, uma vez que o preenchimento não é total já que é realizado por filamentos.

Conclusão: Conclui-se que a Manufatura Aditiva é capaz de produzir peças com resistência eficiente próxima da de um processo produtivo convencional, o que aliada a sua versatilidade tem a capacidade de aperfeiçoar os processos produtivos de um modo geral. É uma tecnologia extremamente prática e flexível, devido o fato de que os objetos produzidos por ela são consolidados através de um ambiente totalmente amigável ao usuário.

PALAVRAS-CHAVE: MANUFATURA ADITIVA; IMPRESSÃO EM 3D; DEPOSIÇÃO DE MATERIAL FUNDIDO, ENSAIO DE TRAÇÃO. 


\title{
MÃOS QUE FALAM: UM OLHAR AOS CONSUMIDORES DEFICIENTES AUDITIVOS
}

\author{
MARIA EDUARDA SANTOS DA SILVA, JÉSSICA PINHEIRO DE SOUZA, MARIA HELENA BELO DE \\ ARAUJO, MARIA TERESA DE BEAUMONT
}

INSTITUTO MASTER DE ENSINO PRESIDENTE ANTÔNIO CARLOS - IMEPAC

mariaduds06@outlook.com

Apresentação de Pôster

Resumo

Área do Conhecimento: Educação e Inclusão

Introdução: Atualmente muito se tem discutido sobre a inclusão de deficientes auditivos. A sociedade está mais sensível aos problemas colocados por ela própria aos deficientes e tem buscado soluções para uma melhor qualidade de vida dessas pessoas, tanto pessoal quanto profissionalmente. Ao surdo, entre outros, é assegurado por lei o direito de ser atendido na forma natural de expressão, ou seja, em Língua Brasileira de Sinais (LIBRAS), em diversos serviços públicos. Foi a partir daí que todas as áreas da educação tiveram que se capacitar para atender essa demanda e hoje já encontramos a necessidade de intérpretes de LIBRAS em todos os segmentos da sociedade. Muitos dos consumidores surdos não têm compreensão da língua portuguesa, e mesmo que tenham é muito difícil compreender, pois eles fazem associação das palavras da língua portuguesa com os sinais da LIBRAS. Todos na sociedade são consumidores, pois sempre estão precisando ou querendo algo. E no intuito de chegar mais perto desses consumidores foram criadas as propagandas, que são elaboradas a partir do comportamento de cada um, sempre em busca de saber a cultura, o estilo de vida e o que influencia um comprador. Há diferentes tipos de consumidores, sendo necessário que o profissional de Marketing conheça todos eles. Entre esses consumidores há os consumidores surdos. Frente aos problemas expostos, a intervenção teve como objetivo a conscientização e qualificação de vendedores e colaboradores do comércio visando um atendimento adequado aos clientes deficientes auditivos.

Metodologia: A partir das observações realizadas e dos problemas identificado, foi promovido um minicurso, oferecido para trabalhadores do comercio de introdução a Libras, tendo como ênfase a importância desta língua. Durante o minicurso foi distribuído material de apoio, contendo apostila e um folder explicativo sobre a importância da aprendizagem da LIBRAS, com o apoio da Câmara de Dirigentes Lojista (CDL), que forneceu o local para o minicurso e fez a divulgação no comércio, e da professora mestre Laurice da Silveira, docente de Libras, no IMEPAC, ministrante do minicurso.

Relato da experiência: Houve a presença de 38 participantes que permaneceram por duas horas e meia no auditório da CDL. Foi trabalhado o alfabeto em datilologia, cumprimentos e temas relacionados a venda e comércio de roupas, medicamentos, papelaria e eletrônicos. Foi enfatizada a importância da LIBRAS em todo o convívio social.

Considerações finais: foi-se percebido o entusiasmo dos participantes, recebemos vários feedbacks onde vários relataram que repassarão o conhecimento adquirido. É uma semente de inclusão e responsabilidade que foi plantada. Muito ainda há que se aprender sobre a cultura da pessoa surda, sua escrita, sua identidade e sua forma de aprender. A partir da valorização da LIBRAS é possível pensar-se em uma metodologia própria para o surdo.

PALAVRAS-CHAVE: DEFICIENTES AUDITIVOS; INCLUSÃO; MERCADO; LIBRAS. 


\title{
MATERIAIS NÃO ESTRUTURADOS NA APRENDIZAGEM INFANTIL.O BRINCAR NA CONSTRUÇÃO DO SUJEITO.
}

\author{
LUANA DE ASSIS SILVA, ROSANGELA LEITE AGUILAR CARDOSO, VALÉRIA ALVES DA SILVA / ANA \\ LÚCIA COSTA E SILVA
}

INSTITUTO MASTER DE ENSINO PRESIDENTE ANTÔNIO CARLOS - IMEPAC

luanaassis159@hotmail.com

Comunicação Oral

Resumo

Área do Conhecimento: Educação para Desenvolvimento Sustentável

Introdução: Desde o nascimento, a criança precisa de espaços que ofereçam liberdade a seus movimentos, segurança e que possibilitem sua socialização. Nesse sentido, o espaço físico escolar torna-se um elemento importante a ser observado. A organização desse lugar deve ser pensada, criada e organizada de acordo com a faixa etária de cada criança propondo desafios cognitivos e motores. A partir da disciplina Projeto Integrador, cuja temática abordava "Espaços de Aprendizagem na Educação Infantil", desenvolvemos um trabalho de pesquisa utilizando a Metodologia da Problematização com o Arco de Maguerez.

Objetivo: 0 objetivo do projeto foi reorganizar o parquinho interditado de uma escola, da rede municipal de Araguari, Minas Gerais, reaproveitando pneus e inserindo as cores; bem como desenvolver uma oficina com os alunos que exigisse a criação do próprio brinquedo, utilizando os materiais não estruturados.

Metodologia: Por meio de observações, identificamos o uso de recursos pré-estabelecidos, comprometimento da recreação das crianças pela interdição do parquinho, devido à falta de recursos para a manutenção dos brinquedos e pouca utilização do espaço externo pelos alunos, comprometendo a ludicidade. Dessa forma, as observações nos conduziram ao delineamento do seguinte problema de investigação: Como adequar o espaço da escola para estimular a criatividade, produção e motivação das crianças por meio das brincadeiras, utilizando materiais não estruturados?

Resultados: Para a realização, recebemos a doação de vinte e dois pneus, que foram pintados com tinta esmalte, nas cores azul, vermelho, verde e amarelo. Para dar mais vida ao espaço, pintamos todos os brinquedos que constituíam o parque e criamos, com a ajuda de um marceneiro, dois acentos de pneus personalizados, sendo uma girafa e uma zebra. E, por fim, doamos alguns brinquedos confeccionados com materiais não estruturados para a escola. A mudança foi surpreendente. Um lugar que estava interditado, sem possibilidade de utilização, agora muito colorido e chamativo. A inauguração foi inesquecível, pois as crianças entraram no parque com muito entusiasmo, que emocionou tanto a nós, executores do projeto, como aos professores da escola.

Diante dos resultados obtidos e das considerações sobre como adequar o espaço da escola para estimular a criatividade, produção e motivação das crianças por meio das brincadeiras, utilizando materiais não estruturados, entendemos que o ambiente é um fator relevante no projeto pedagógico, que necessita, portanto, ser cuidado para que os envolvidos sintam-se efetivamente partícipes de seus ambientes. Conclusão: Através do projeto realizado, percebemos na prática que o espaço na Educação Infantil também se torna um educador, pois auxilia no desenvolvimento da criança. Este, porém deve ser intencionado pelo professor, para que experiências de aprendizagem aconteçam.

PALAVRAS-CHAVE: ESPAÇOS; EDUCAÇÃO INFANTIL; BRINCAR; APRENDIZAGEM. 


\title{
MATERIAIS NÃO ESTRUTURADOS: PRA QUE TE QUERO?
}

\author{
LAURA NASCIMENTO ESPÍNDULA, VIVIANE NOBRE DE ANDRADE ASSUNÇÃO, ANA LÚCIA COSTA E \\ SILVA; VALÉRIA ALVES DA SILVA
}

INSTITUTO MASTER DE ENSINO PRESIDENTE ANTÔNIO CARLOS - IMEPAC

laauraespindula@gmail.com

Comunicação Oral

Resumo

Área do Conhecimento: Agenda 2030 e os Objetivos de Desenvolvimento Sustentável

Introdução: A Educação Infantil é uma etapa da educação básica, onde deve ser permitido as crianças a possibilidade da interação e relação com os seus pares, professores, comunidade escolar e espaço. Cujo este, tem um papel essencial para o desenvolvimento e aprendizagem do aluno, pois é nele que a criança encontra possibilidades em desenvolver suas capacidades motoras, cognitivas e afetivas através do lúdico, com liberdade para a criação como protagonista, agindo com autonomia e cooperativismo. A disposição desse espaço escolar dever ser feito e pensado na criança, sendo acolhedor, de bom conforto físico, composto de cores, sons, luzes, odores, palavras e gostos. A oferta de atividades e materiais para que as crianças possam exercer suas habilidades criadoras e exploratórias, devem instigar suas curiosidades, reflexões, pesquisas e experiências. Considerando que é comum encontrar no ambiente escolar, recursos e brinquedos convencionais, prontos para serem manuseados, os materiais não estruturados, diferentemente, possibilitam uma ressignificação de suas ações e pensamentos na construção daquilo que é percebido e sentido pelo educando, considerando seus conhecimentos prévios.

Diante disso, o objetivo do Projeto Integrador, foi de proporcionar experiências e descobertas, usando a imaginação, a fantasia, o cooperativismo, contribuindo para a formação e desenvolvimento integral da criança.

Metodologia: 0 projeto foi desenvolvido numa escola da rede municipal de Araguari (MG), com crianças de 4 e 5 anos, em dois dias no espaço da Brinquedoteca e sob a mediação dos integrantes do grupo. Sendo utilizados materiais como: caixas de papelão, retalhos de tecidos, cartelas de ovos, rolinhos de papel higiênico e de guardanapo, tampinhas de garrafas pet, cones plásticos de linha, plástico bolha, tubos de papelão, entre outros.

Resultado: Foi possível observar que este trabalho propiciou às crianças, a interação entre elas o brincar no espaço da educação infantil e o envolvimento delas com os materiais sugeridos, a exploração dos mesmos, de instigar a imaginação, a criação, a troca entre os pares, a coordenação motora e percepção do ambiente, que refletem no crescimento e no bom resultado do desenvolvimento das habilidades e competências dos educandos.

Conclusão: Constituindo assim, uma proposta participativa e transformadora, no que se refere a criança como protagonista da sua aprendizagem e das suas vivências. 


\title{
MÉDIA DA PRODUÇÃO LEITEIRA DA CIDADE DE ARAGUARI E REGIÃO, NO PERÍODO DE 01/01/2019 A 31/01/2019
}

\author{
JEFTÉ BERNARDES, ISABELA ARAÚJO DOS ANJOS, JOÃO BATISTA MONTEIRO SOBRINHO, \\ LAYANNE CRISTINA RIBEIRO, VITOR ALVES PIASSA, DANIELLE VITORINO MORAES E SILVIO ANDRE \\ PEREIRA MUNDIM
}

INSTITUTO MASTER DE ENSINO PRESIDENTE ANTÔNIO CARLOS - IMEPAC

jeftebernardes@hotmail.com

Apresentação de Pôster

Resumo

Área do Conhecimento: Responsabilidade, Tecnologia e Ciência

\begin{abstract}
Introdução: Tendo em vista a importância social do leite para a região, para a saúde da população e para a movimentação do capital financeiro no agronegócio e visando elevar a grande contribuição para o produto interno bruto (PIB) do país, a quantificação mostra-se uma ferramenta essencial para dimensionar a produção láctea de Araguari.

Foram analisadas oito regiões do município citado, com a finalidade de calcular e demonstrar a média da produção leiteira tal qual o destino que se dá ao mesmo. 0 leite dessas regiões é entregue ao laticínio Minas Castro, situado na cidade de Araguari-MG, e tem como principal derivado, a produção do queijo tipo muçarela.

Objetivo: 0 presente trabalho teve por finalidade avaliar a média leitera da cidade de Araguari, dado que mostra-se fundamental para cálculos futuros e para a avaliação do progresso desta área nesta cidade.

Metodologia: 0 presente trabalho foi realizado entre o período de 01/01/2019 a 31/01/2019, foram analisadas 135 propriedades, todas fornecendo leite para o laticínio Minas Castro Ltda-me.

Foram apresentados os dados em forma de gráficos, os nomes das propriedades foram mantidos em sigilo a pedido dos produtores e do laticínio.

A média diária foi feita a partir da divisão do leite coletado e os dias referentes ao período de coleta, os resultados serão apresentadas em forma de tabela, divididas por regiões.
\end{abstract}

Resultados: As cento e 135 propriedades produziram no período de 01/01/2019 a 31/01/2019 um total de 18.760 litros de leite.

A região com maior média apresentada foi a do Varjão, com média de 193,35 litros diários, e apresentando a menor média temos a região da Patrona, com média de 91,25 litros diários.

A média da cidade de Araguari-MG foi de 137,94 litros, dando a posição de 79o em um ranking de 852 municípios produtores de leite em Minas Gerais, e no ranking nacional se encontra em 289 ․

Podemos observar que a produção leiteira de Araguari gera 200 empregos diretos no laticínio Minas Castro, e gera cerca de outros 200 empregos de forma indireta, evidenciando a importância desta cadeia produtiva.

Conclusão: Concluímos que a cidade de Araguari-MG tem média leiteira de 137,94 litros de leite por dia. As regiões da cidade que mais produziram leite foram Bom Jardim, Contenda e Piracaíba, consecutivamente. Em contrapartida, as regiões que menos produziram leite foram Patrona, Amanhece e Bocaina consecutivamente.

A média da cidade de Araguari-MG foi de 137,94 litros, dando a posição de 79o em um ranking de 852 municípios produtores de leite em Minas Gerais, e no ranking nacional se encontra em 289 ‥

PALAVRAS-CHAVE: LEITE, ARAGUARI, MEDIA LEITEIRA DIÁRIA, PRODUÇÃO. 


\title{
MEDIDA DA AMPLITUDE ATIVA DE DORSIFLEXÃO DE TORNOZELO EM JOGADORES DE BASE DO MANCHA ESPORTE CLUBE NO PERÍODO PRÉ-TEMPORADA
}

\author{
RAFAEL DA SILVA JORGE, IGOR ALVES GOMES OLIVEIRA, ISAÍAS JOSÉ FERNANDES, HUGO RIBEIRO \\ ZANETTI, DANIELLE FERNANDES ALVES
}

INSTITUTO MASTER DE ENSINO PRESIDENTE ANTÔNIO CARLOS - IMEPAC

rafaeljorge01@gmail.com

Apresentação de Pôster

Resumo

Área do Conhecimento: Saúde coletiva e bem-estar

Introdução: 0 futebol atualmente é um dos esportes mais praticados no mundo, por ser um esporte de contato que exige bastante do físico como um todo, especialmente os membros inferiores pelas mudanças bruscas de velocidade e direção que o esporte permite, por isso se tem a necessidade de avaliar a amplitude ativa de dorsiflexão de tornozelo dos jogadores visto que a entorse de tornozelo é uma lesão com elevada incidência e que, em alguns casos de tratamento inadequado ou insuficiente, leva ao aparecimento de um quadro de queixas residuais que se prolonga no tempo e limita de forma significativa o desempenho desportivo dos atletas. 0 movimento de dorsiflexão do tornozelo é necessário para o desempenho funcional e também em esportes onde há um contato físico maior. Objetivo: Avaliar a amplitude ativa de dorsiflexão de tornozelo em jogadores de base do Mancha Esporte Clube de Araguari-MG. Metodologia: Trata-se de uma pesquisa transversal, descritiva e quantitativa onde foram avaliados atletas das categorias pré-mirim (10 e 11 anos), mirim (12 e 13 anos), infantil (14 e 15 anos) e juvenil (16 e 17 anos) de base do Mancha Esporte Clube da cidade de Araguari/MG no período de pré-temporada e afim de avaliar a amplitude de tornozelo foi utilizado o teste de Weight-Bearing Lunge que avalia a dorsiflexão em cadeia cinética fechada (CCF). Neste teste, o atleta ficou de frente para uma parede com cerca de $10 \mathrm{~cm}$ de distância entre os pés e a parede e, logo após o comando do avaliador, o atleta flexionou o joelho à frente até tocar na parede (mantendo o calcanhar no chão). Caso o atleta não conseguisse tocar o joelho na parede sem o calcanhar sair do solo, o mesmo realizou uma nova tentativa com o pé mais próximo da parede. Por se tratar de um estudo descritivo, os valores estão expressos em média \pm desvio-padrão e separados por categorias. Resultados: Na categoria pré-mirim foi encontrado uma amplitude de tornozelo (ADT) de $8,75 \pm 3,38 \mathrm{~cm}$. Na categoria mirim o ADT foi de $8,21 \pm 1,81 \mathrm{~cm}$. A categoria infantil a ADT foi de $10 \pm 2,9 \mathrm{~cm}$. E na categoria juvenil o resultado foi de $11 \pm 5,35 \mathrm{~cm}$. Conclusão: Por ser um esporte que exige bastante da mobilidade de tornozelo, podemos verificar que a categoria pré-mirim e mirim, os jogadores possuem uma amplitude ativa de dorsiflexao de tornozelo considerara fraca $(<9 \mathrm{~cm})$ o que pode ser melhorado através de treinamentos específicos durante a temporada, e que os jogadores das categorias infantil e juvenil, pode-se consideram que possuem uma boa mobilidade de tornozelo $(>9 \mathrm{~cm})$.

PALAVRAS-CHAVE: FUTEBOL, AMPLITUDE DE MOVIMENTO, TORNOZELO. 


\title{
MORINGA OLEÍFERA: POTENCIAL ANTIOXIDANTE DOS EXTRATOS DA PLANTA OBTIDOS A PARTIR AMOSTRAS COLHIDAS EM ÁREA URBANA SOB CONSTANTE POLUIÇÃO, ESTRESSE HÍDRICO E DE NUTRIENTES.
}

\author{
PLíNIO NASCIMENTO FREITAS, CARLOS ALBERTO DE OLIVEIRA, DANILO SABINO DE SOUZA, \\ IZABELA RODRIGUES, MIRIAN RIBEIRO MOREIRA CARRIJO
}

INSTITUTO MASTER DE ENSINO PRESIDENTE ANTÔNIO CARLOS - IMEPAC

plinioslipknot@gmail.com

Apresentação de Pôster

Resumo

Área do Conhecimento: Saúde coletiva e bem-estar

\begin{abstract}
Introdução: Além de influenciar negativamente na saúde das pessoas, a poluição é capaz de prejudicar também a fauna e flora. Metais pesados como chumbo e manganês, presentes nas partículas emitidas pelos veículos, contaminam o solo e recobrem as folhas, alterando o metabolismo das plantas. Os estudos com as plantas medicinais permitiram um desenvolvimento rápido na química farmacêutica devido as descobertas de muitas substâncias ativas que foram introduzidas como medicamentos. A Moringa Oleífera é considerada como uma potência nutricional. As folhas são altamente nutritivas, sendo uma fonte significativa de betacaroteno, vitamina C, proteína, ferro e potássio. Os extratos de folhas de M. O., exibem atividade antioxidante in vitro e in vivo devido a presença de altas concentrações de ácidos fenólicos e flavonoides. Esses compostos com suas respectivas estruturas e concentrações, têm sido alvo de intensas investigações. Vários métodos são utilizados para avaliar esta atividade antioxidante, um dos mais usados é do radical 2,2-difenil-1-picril-hidrazila (DPPH) que consiste em avaliar a atividade sequestradora do DPPH.

Objetivo: $\mathrm{O}$ objetivo do trabalho foi investigar e comparar os efeitos dos extratos etanoicos das partes da M. O. na capacidade de ação antioxidante in vitro pelo sequestro do DPPH, usando como flavonoide padrão a quercetina.

Metodologia: Os materiais vegetais utilizados na preparação dos extratos foram: folhas, hastes e flores de M. O., coletados em maio de 2017 as 19:00 horas na área urbana da cidade de Araguari-MG. A preparação dos extratos etanoicos foi realizada como descrito pela farmacopeia brasileira para plantas fitoterápicas. A atividade antioxidante foi avaliada pela redução do DPPH $(0,1 \mathrm{mmol} / \mathrm{L})$, monitorada pela alteração da absorbância a $510 \mathrm{~nm}$ em um espectrofotômetro FEMTO. Realizou-se curvas de concentração contra efeito dos extratos para o ensaio de DPPH. A leitura foi monitorada por 40 minutos e posteriormente a porcentagem de DPPH reduzido foi calculada. 0 diluente utilizado foi o tampão acetato 0,1 mol/L pH 5,5 e o etanol P.A. Os dados obtidos foram analisados estatisticamente (média, erro padrão da média) no software Microsoft Office Excel@.

Resultados: Os extratos das partes da M. O. não apresentaram os resultados esperados, sendo que em sua maior concentração analisada, o flavonoide quercetina foi capaz de reduzir em $90 \%$ radical DPPH, enquanto o extrato das hastes, o mais eficaz, reduziu aproximadamente em apenas $63 \%$.

Conclusão: 0 presente trabalho mostrou que o extrato das partes da M. O. presente na área urbana, possui respostas totalmente diferenciadas em relação a literatura científica, muito provavelmente devido a constante exposição a poluição, estresse hídrico e alta temperatura.

PALAVRAS-CHAVE: MORINGA OLEÍFERA; ANTIOXIDANTES; DPPH; QUERCETINA; POLUIÇÃO; RADICAIS LIVRES; ESTRESSE HÍDRICO; EXTRATO ETANOICO; FLAVONOIDES; ÁCIDOS FENÓLICOS;
\end{abstract}




\title{
NR6 - EQUIPAMENTO DE PROTEÇÃO INDIVIDUAL
}

\author{
MATHEUS JERONYMO, DIONATAN PEREIRA DE OLIVEIRA MELO, IGOR FARIA DOS SANTOS, JOĀO \\ VICTOR DA SILVA GIMENES, PEDRO HENRIQUE DE OLIVEIRA BARBOSA, WASHINGTON JOSÉ DA \\ COSTA, DANIELA ALMEIDA DANTAS
}

INSTITUTO MASTER DE ENSINO PRESIDENTE ANTÔNIO CARLOS - IMEPAC

mjeronymorv@hotmail.com

Apresentação de Pôster

Resumo

Área do Conhecimento: Saúde coletiva e bem-estar

Conhecimento e percepção sobre o uso de equipamento de proteção individual NR 06 (EPI)

Introdução: Para todo e qualquer trabalho, seja ele insalubre ou não, faz-se necessário a utilização de EPI Equipamento de Proteção Individual adequado para que se mantenha a integridade e saúde física e mental do profissional que atua em determinada área. Esta Norma Regulamentadora 06, traz exatamente a aplicação de cada tipo de Equipamento para Proteção Individual, seguindo os padrões exigíveis de mercado e autorizados através de um CA - Certificado de Aprovação pelo Órgão Nacional Competente, e se tratando de Equipamentos para Proteção advindos do Mercado Exterior, os mesmos devem passar por avaliações de uso e aplicações, e depois disto feito, poderão ou não dependendo de seu uso, qualidade e resistência, receber sua aprovação CA em âmbito nacional. 0 presente artigo visa demonstrar a utilização adequada de Equipamentos de Proteção Individual referente as diversas aplicações no cenário das grandes empresas e indústrias da cidade de Araguari - Minas Gerais, especificamente voltado à empresa no ramo de processamento de grãos, onde os referidos equipamentos devem ser utilizados e padronizados antes de se dar início aos trabalhos diários, sendo que e além de tudo o empregador deve disponibilizar cursos e estágios para a utilização correta e adequada em cada situação e serviço aplicado, e para isso discorreremos mais à frente sobre as obrigações do empregador, bem como as do empregado. Iremos apresentar algumas situações onde o trabalhador deverá zelar pelos seus direitos ao uso de EPIs adequados para a execução de seu trabalho, além de apresentar os deveres do trabalhador, onde o mesmo deve entender a necessidade da utilização e os riscos inerentes à profissão, bem como o tipo de serviço a ser prestado. Contudo de maneira geral, trabalhador e empregador devem conhecer suas responsabilidades perante não somente à Norma, mas também a vida de quem presta serviço em determinada área de atuação na indústria, quaisquer que seja a sua natureza. 0 objetivo deste trabalho é a conscientização da importância da utilização dos EPI's, quanto a correta forma e conservação do mesmo, para que o colaborador não venha sofrer nenhum dano a integridade física e a saúde. Metodologia: 0 projeto foi desenvolvido baseando-se nas premissas do Ministério do Trabalho, neste caso a NR6, com coleta de dados informais relatado por um colaborador, que atua na manutenção de uma determinada empresa do ramo,haja visto o risco eminente do trabalho realizado pelo mesmo e a preocupação da empresa em manter a integridade física dos colaboradores.Conclusão:A realização desde trabalho foi de grande valia para formação acadêmica e profissional, haja visto que,vari os colegas ainda não estão inseridos no mercado de trabalho, o que lhe proporcionou uma visão favorável, com relação ao risco inseridos em tarefas que possam desenvolver ao longo de suas carreiras.

PALAVRAS-CHAVE: RISCOS, SAÚDE, COLABORADOR. 


\title{
O ACESSO DA PESSOA PORTADORA DE DEFICIÊNCIA AUDITIVA À JUSTIÇA COMO PRECEITO DE DIGNIDADE DA PESSOA HUMANA
}

\author{
GIOVANNA DE MENEZES BERNARDO, FRANTISKA MIKAELE SANTOS SILVEIRA, DONNER \\ RODRIGUEZ QUEIROZ
}

INSTITUTO MASTER DE ENSINO PRESIDENTE ANTÔNIO CARLOS - IMEPAC

giomenber@hotmail.com

Apresentação de Pôster

Resumo

Área do Conhecimento: Sustentabilidade e Direitos

Introdução: 0 presente analisará o acesso à justiça às pessoas com deficiência auditiva, considerando, para tanto, seus deveres, direitos e garantias fundamentais como a cidadania e a inclusão social, no que tange a efetividade da justiça.

Problema de Pesquisa: Em que medida o Poder Judiciário, na promoção de mecanismos de inclusão social e construção de cidadania, garante a efetividade destes em relação a proteção de direitos e garantias fundamentais, elencadas na CF/88 e na norma infraconstitucional para as pessoas com deficiên cia auditiva? Objetivo: Busca-se demonstrar a importância da capacitação dos membros que atuam no Poder Judiciário para a garantia da efetividade das garantias fundamentais à luz do princípio da dignidade da pessoa humana sob o acesso à justiça do deficiente auditivo.

Método: Para alcançar os resultados desejados, utiliza-se do método dedutivo, com qual se inicia uma pesquisa da análise do complexo até se atingir pontos mais simples de pesquisa.

Resultados: Considera-se pessoa com deficiência aquela que tem impedimento de longo prazo de natureza física, mental e intelectual ou sensorial, o qual, em interação com uma ou mais barreiras, pode obstruir sua participação plena e efetiva na sociedade em igualdade de condições com as demais pessoas. Na Constituição Federal, o art. 5ำ em seu caput afirma "Todos são iguais perante a lei, sem distinção de qualquer natureza..."; E de acordo com o art. 5ำ XXXV, cita que a lei não excluirá da apreciação do Poder Judiciário lesão ou ameaça de direito. Trata-se de máxima com o escopo de deixar claro a todos, a impossibilidade de qualquer pessoa de impedir o acesso à justiça por qualquer jurisdicionado. Importante salientar que o acesso à justiça não deve ser vislumbrado como mero acesso ao judiciário, mas ao conhecimento de cada procedimento processual, o que se passa em cada ato praticado por qualquer membro do judiciário, e uma atuação mais "humana" e "menos técnica" do operador do Direito.

Conclusão: Dessa forma, nota-se, que o Estado deve efetivamente promover o aperfeiçoamento dos agentes públicos para o exercício da cidadania, democracia e inclusão social da pessoa com deficiência auditiva. Os operadores do Direito devem estar prontos a atender a todos conforme suas necessidades e individualidades, aprender a língua de sinais - Libras, seria algo interessante para uma sociedade buscar a solução de conflitos de maneira equitativa e qualitativa. Finalmente, demostrando a importância da língua/discurso para a solução de conflitos principalmente dentro da esfera jurídica. 


\title{
O ASSÉDIO SEXUAL NO CONTEXTO ACADÊMICO: UM DEBATE NECESSÁRIO
}

\author{
GABRIELA MARRA SOARES, AMANDA COELHO BORGES, LILIANE VELOSO DE ALMEIDA, RAFAEL \\ FERREIRA, ANNY MARIE PEREIRA DOS SANTOS, PAULO ROBERTO DE OLIVEIRA SANTOS
}

INSTITUTO MASTER DE ENSINO PRESIDENTE ANTÔNIO CARLOS - IMEPAC

gabriela_soares4@outlook.com

Comunicação Oral

Resumo

Área do Conhecimento: Sustentabilidade e Direitos

Introdução: O termo assédio surge de latim obsidere, que significa opor-se, atacar, sitiar; já o assédio sexual pode ser definido como práticas de investimento sexual e/ou corporal e/ou afetivo implícito e/ou explícito que envolve um não consentimento por parte do outro, com o objetivo de ferir a honra, e a personalidade do assediado. Vale ressaltar que, esse tipo de assédio na maioria de sua ocorrência, acontece com mulheres, mas não descartam a possibilidade de ocorrer com um homem.

Objetivo: 0 presente resumo trata-se de um estudo exploratório que tem como objetivo geral investigar o tema assédio sexual, buscando entender os comportamentos negativos que o caracterizam dentro do ambiente acadêmico, bem como identificar o nível de consciência e informação que os envolvidos possuem sobre o tema.

Metodologia: No intuito de se alcançar os objetivos acima descritos; foi utilizado o método empírico-jurídico e como metodologia foi empregada a aplicação de um questionário contendo questões fechadas sobre assédio sexual e uma questão aberta para relato de vivências no mencionado contexto.

Resultados: Foi claramente perceptível que dos alunos participantes 45,3\% apresentam dúvidas sobre o assunto, dentre os quais $40,5 \%$ acreditam que o assédio sexual se configura apenas como um ato sexual praticado contra a vontade da pessoa, ou seja, sem ser verbal, entre as outras formas, 4,8\% acreditam que seja apenas a partir da resistência do ato sexual, 11,9\% não sabem caracterizar os assédios, e os 42,9\% tem conhecimento sobre o assunto.

Acrescenta-se que - como o foco do trabalho reside em pesquisar a incidência do assédio sexual no âmbito acadêmico - o questionário acima mencionado foi aplicado aos estudantes de uma Instituição de Ensino Superior (IES) e analisou como tal acontecimento pode tornar o ambiente hostil e por consequência causar transtornos aos alunos.

Ainda de forma incipiente, por conta do estágio inicial da pesquisa, percebeu-se, com a pesquisa, que o tema assédio sexual, apesar de pouco debatido, está presente no cotidiano acadêmico e decorre da vontade de um indivíduo em subjugar outro, usando ou não de sua posição hierárquica.

Conclusão: Neste contexto, com base nos dados aferidos, defende-se: um amplo debate sobre os comportamentos negativos que caracterizam assédio sexual dentro do ambiente acadêmico como forma de esclarecimento e educação, bem como, inclusão nos regimentos internos de eventuais sanções aplicáveis nos casos identificados como assédio sexual.

PALAVRAS-CHAVE: ASSÉDIO SEXUAL; COMPORTAMENTOS NEGATIVOS; REGIMENTO INTERNO; 


\title{
O ATRASO DO FECHAMENTO CONTÁBIL DA EMPRESA MACEDO S/A PARA COM O ESCRITÓRIO DE CONTABILIDADE
}

\author{
DIEGO COSTA NUNES, VICTOR MONTES REIS, FABIANO JOSE LUCAS DOS SANTOS
}

INSTITUTO MASTER DE ENSINO PRESIDENTE ANTÔNIO CARLOS - IMEPAC

diego7045@gmail.com

Apresentação de Pôster

Resumo

Área do Conhecimento: Responsabilidade e Negócios

O presente trabalho é resultante da experiência proposta pelo professor Fabiano José Lucas dos Santos e vivenciada no componente curricular da disciplina Projeto Integrador I no curso de Ciências Contábeis, no 1ำ período, do $1^{\text {o }}$ semestre de 2018, vez que o mesmo foi desenvolvido por meio da Metodologia da Problematização com o Arco de Maguerez.Foi escolhida a empresa Macedo S/A como alvo da pesquisa de campo, onde observamos as atividades realizadas na realidade da empresa, em parceria com o escritório contábil, para solucionarmos os possíveis problemas ocorridos na área contábil.

Para nos auxiliar na solução do problema utilizamos de metodologia do Arco de Maquerez, no qual observamos a realidade, encontramos os pontos chaves, aplicamos a teorização pertinente ao problema, e elaboramos a hipótese de solução para aplicarmos à realidade da empresa.Tendo em vista o desenvolvimento de um trabalho de pesquisa utilizando a Metodologia da Problematização com o Arco de Maguerez, escolhemos como campo de observação da realidade a empresa Macedo S/A. Tal escolha se deve ao ambiente que iremos estudar, pois há um fácil acesso aos dados da empresa.

No campo investigado, notamos que há uma falha no sistema de lançamento de dados contábeis na empresa. Além disso, notamos a falta de integração do sistema no departamento contábil da empresa Macedo S/A com o escritório de contabilidade. E também uma mão de obra desqualificada ao realizar os lançamentos de dados com eficácia.

Dessa forma, as observações nos conduziram ao delineamento do seguinte problema de investigação: 0 atraso do fechamento contábil da empresa Macedo S/A para com o escritório de contabilidade.

Compreendemos que estudar mais profundamente sobre este tema buscando possíveis soluções para esse problema, contribuirá para o fechamento dentro do exercício contábil. Sob o ponto de vista empresarial de uma melhor gestão dentro da empresa de forma sustentável e do escritório. E, finalmente, para nossa formação como futuros profissionais na área contábil procuraremos nos atentar a cumprir o prazo determinado de fechamento e lançamentos de dados.

Nossa proposta é encontrar um problema, dentro da área contábil de uma empresa real conhecida por algum integrante do grupo.

Como futuros contadores queremos estudar a rotina dentro da área contábil da empresa, para aprendermos a lidar com as situações referentes à atuação do contador.

Criamos a empresa Macedo S/A, representando hipoteticamente uma organização real observa

PALAVRAS-CHAVE: FALTA DE DOCUMENTAÇÃO; SISTEMA INEFICAZ; FALTA DE CONHECIMENTO; FALTA DE PLANEJAMENTO; NÃO CUMPRIMENTO DO PRAZO DETERMINADO; 


\title{
O DESASTRE AMBIENTAL DE BRUMADINHO E SUAS CONSEQUÊNCIAS JURÍDICAS NO MEIO AMBIENTE LABORAL.
}

\author{
WALTER LUIZ DECAT MANHÃES DA COSTA, AUGUSTO CESAR SCUISSATTO RAMOS, IURY ALVES \\ PEDROSA, JOÃO VICTOR TUFI ABRANTES, VICTOR HUGO PEREIRA PAIVA, VINICYOS EMANNUEL \\ FONSECA OLIVEIRA, VINÍCIUS DE PAULA REZENDE
}

ESAMC UBERLÂNDIA

waltermanhaes19@yahoo.com.br

Comunicação Oral

Resumo

Área do Conhecimento: Sustentabilidade e Direitos

Introdução: Em janeiro de 2019, o rompimento da barragem de resíduos de uma grande mineradora, no município de Brumadinho/MG, ocasionou imensos prejuízos de ordem humanitária, ambiental, econômica e social. 0 colapso da Barragem 1 da Mina Feijão evidenciou inúmeros fatores que favorecem a negligência das mineradoras no exercício de suas atividades, dentre eles, a legislação incoerente e a precária fiscalização. Consequentemente, essa negligência afeta os trabalhadores da própria empresa, vez que, os mesmos se põem em situações de risco cotidianamente. Assim, na óptica do Meio Ambiente laboral, o empregador deve seguir rigorosamente as normas relativas aos seus serviços, devendo impedir que seu operário, o qual se encontra em posição de hipossuficiência, venha a sofrer riscos à sua segurança e integridade física em seu espaço de trabalho, a luz da Constituição Federal e da Consolidação das Leis Trabalhistas.

Objetivo: A elaboração de meios que atenuem o risco das atividades das mineradoras no país se faz urgentemente necessária, de modo que, a segurança dos trabalhadores não venha a interferir na viabilidade econômica e social da empresa, bem como na exploração da respectiva atividade econômica, devido à sua importante participação pecuniária no Estado brasileiro. Sendo assim, o intuito do presente trabalho é criar uma maneira de preservar a segurança desses operários e continuar sendo possível a operação das mineradoras respeitando a preservação ambiental.

Metodologia: Trata-se de uma análise dos processos judiciais dos indivíduos atingidos pelo desastre ambiental de Brumadinho, já instaurados, e em andamento, e das consequências jurídicas originadas pela tragédia nos ramos do direito ambiental, trabalhista, cível, constitucional, administrativo e penal. Adotando como forma de inovação o método de 'compliance' para que empresas mineradoras não deem continuidade em suas tarefas sem que de fato sigam as orientações legais e assecuratórias.

Resultados: Do ponto de vista legal a ocorrência do dano é nítida, porém, as raízes desse dano são profundas, tendo em vista que, afetam tanto direta quanto indiretamente um conjunto extenso de pessoas. Dessa forma, tem-se a dificuldade em quantificar o dano ocasionado, sobretudo levando em consideração a inviável tarefa de se calcular o valor de uma vida. No intuito de amenizar essas dificuldades e pensando na gravidade das circunstâncias a presente proposta traz o 'compliance' como meca nismo hábil para esse serviço.

Conclusão: 0 'compliance' em funcionalidade como uma ferramenta de se evitar o dano através de orientações profissionais preventivas, acarretando sanções para o seu descumprimento e, em último caso, como meio que possibilita a maior precisão na abrangência dos danos causados, pois, a partir de sua execução se torna possível acompanhar o que levou a causa do dano. Proporcionando segurança laboral e desenvolvimento econômico.

PALAVRAS-CHAVE: DESASTRE AMBIENTAL; MEIO AMBIENTE LABORAL; COMPLIANCE; ANÁLISE JURÍDICA. 


\title{
O INSTITUTO DA COLABORAÇÃO PREMIADA E SEU CARÁTER PROBATÓRIO
}

\author{
RENATA BERNARDES SILVA, TALITA ALVES ALMEIDA, GEILSON NUNES
}

INSTITUTO MASTER DE ENSINO PRESIDENTE ANTÔNIO CARLOS - IMEPAC

renatabernardespessoal@outlook.com

Apresentação de Pôster

Resumo

Área do Conhecimento: Sustentabilidade e Direitos

Introdução: 0 presente artigo estudou acerca da colaboração premiada que é um instituto que beneficia quem participou de determinado crime, caso ele colabora com o Estado, entregando os demais comparsas. Desta feita, percorreu-se acerca do procedimento para se valorar uma prova no processo penal, a sua admissibilidade, bem como o seu caráter probatório para fundamentar uma sentença penal condenatória. Objetivo: Frente ao exposto, o artigo teve como objetivo estudar o caráter probatório da colaboração premiada e se tal instituto, por si só, pode fundamentar uma sentença penal condenatória. Nesse sentido, como melhor forma de ilustrar a pesquisa, percorremos a sua conceituação, bem como os procedimentos para se valorar uma prova no âmbito penal, partindo de uma visão doutrinária.

Metodologia: Para a obtenção dos resultados almejados no presente artigo, optou-se por uma pesquisa bibliográfica, sendo o método de abordagem o dedutivo, de forma a alcançar os resultados propostos envolvendo o debate entre a valoração das provas no processo penal e sua estreita relação com o instituto da colaboração premiada.

Resultados: É sabido que a colaboração premiada é um instituto que beneficia quem colaborar com a investigação criminal, de modo que entregue os demais comparsas de determinado crime. Desta feita, vale entender que a colaboração premiada, é considerada como um meio de prova frágil, uma vez que, apesar do depoimento do mesmo colaborar com o Estado, advém de uma pessoa que cometeu o crime, pelo que, pode, com o intuito de beneficiar-se, entregar alguém que não participou do delito. Posto isso, as informações prestadas pelo colaborador não tem caráter probatório para fundamentar uma sentença sem que venha acompanhada de outros meios de provas que estejam em sintonia com as declarações do colaborador, tendo em vista que o colaborador não traz junto de suas declarações uma confiança da veracidade dos fatos, pois, participou de uma conduta delituosa. Assim, nota-se que tal instituto, por si só, não tem capacidade de fundamentar uma sentença condenatória, devendo vir acompanhada de outras provas que corroborem com as colaborações trazidas pelo delator, uma vez que, apesar de ser um meio de obter uma prova elencado na Legislação Brasileira, têm um potencial menor na convicção do magistrado, pois o colaborador também praticou o fato delituoso.

Conclusão: Diante do exposto, foi possível concluir que a colaboração premiada, apesar de ser considerada um meio de prova, não tem poder para fundamentar, por si só, uma sentença penal condenatória, sendo que, deverá está acompanhada de outros meios de prova que corroborem as suas alegações, para contribuir com o convencimento do magistrado, uma vez que os fatos estão sendo narrados por uma pessoa que praticou a conduta delituosa.

PALAVRAS-CHAVE: COLABORAÇÃO PREMIADA; PROVAS; VALOR PROBATÓRIO. 


\title{
O INSTITUTO DO FEMINICÍDIO SOB A ÓTICA DOS TRANSEXUAIS
}

\author{
JESSICA AGUIAR RONDI, MARIANA DE LIMA KEHDY, GEILSON NUNES
}

INSTITUTO MASTER DE ENSINO PRESIDENTE ANTÔNIO CARLOS - IMEPAC

jessy_vladescu@hotmail.com

Apresentação de Pôster

Resumo

Área do Conhecimento: Sustentabilidade e Direitos

Introdução: O presente estudo tratará da possibilidade de aplicação do instituto do feminicídio, o qual visa a proteção das mulheres, aos casos de vítimas transexuais, os quais são também vítimas de violência recorrentes.

Problema de pesquisa: Considerando o instituto do feminicídio estar inserido em nosso ordenamento jurídico o problema desta pesquisa é analisar: Qual a possibilidade de aplicação da proteção do feminicídio aos casos de vítimas de violência transexuais?

Objetivo: 0 presente trabalho objetiva por demonstrar a possível aplicação do crime de Feminicídio para as vítimas de violência transexuais, apresentando as posições favoráveis e contrárias a aplicação de tal instituto.

Metodologia: No presente trabalho será adotado o método dialético, pois objetivamos caracterizar o dialogo entre as fontes.

Resultados Alcançados: 0 art. 121, VI do C.P. estabelece o crime de feminicídio, sendo esse matar uma vítima mulher em razão de sua condição de ser mulher. 02 § do artigo trata das condições que caracterizam o gênero feminino da vítima, especificando ser aplicado aos crimes de violência doméstica e familiar ou quando o crime fosse cometido em razão de menosprezo ou discriminação à condição de mulher.

A questão da aplicação do dispositivo do feminicídio para os transexuais seria de sua qualificadora da definição de mulher, podendo esta ser aplicável apenas as mulheres nascidas do sexo feminino ou também aos transexuais os quais nasceram em um gênero com o qual não se identificam, promovendo alterações seu gênero original. Podem ser aplicados três critérios de analise, o psicológico, onde a vítima é psicologicamente uma mulher, o critério biológico, onde a vítima já nasce biologicamente mulher e o critério jurídico onde a condição de mulher fica estabelecida após a decisão judicial, tornando-se assim fisicamente, psicologicamente e juridicamente mulheres. As demais aplicações aos indivíduos que não cumpram estes requisitos ficam impossibilitadas, uma vez que o legislador na lei 13.104/15 fora taxativo ao estabelecer a condição de mulher.

Conclusão: Como observamos, existem variadas interpretações acerca da temática, uma vertente entende ser cabível a aplicação do Feminicídio para as vítimas transexuais que possuam sua definição de gênero alterados em seu nome e registro civil por conta de reconhecimento judicial. Enquanto em outra corrente se a mulher transexual não for reconhecida juridicamente e formalmente, não poderá ocorrer a aplicação, em virtude da realização da analogia in malan partem, se devendo sempre lembrar da incidência dos variados outros princípios e ordenamentos já anteriormente previstos em nosso ordenamento jurídico pátrio, configurando assim a proteção as mulheres até os limites de aplicação e respeito aos dispositivos legais brasileiros.

PALAVRAS-CHAVE: FEMINICÍDIO; CRIME; TRANSSEXUAIS. 


\title{
O PAPEL DO ESTÁGIO NA EDUCAÇÃO INFANTIL PARA A FORMAÇÃO DOCENTE: UMA EXPERIÊNCIA EM CURSO.
}

\author{
OSÉIAS CARNEIRO AMORIM, ANA LÚCIA COSTA E SILVA E VALERIA ALVES DA SILVA
}

INSTITUTO MASTER DE ENSINO PRESIDENTE ANTÔNIO CARLOS - IMEPAC

oseiaspedagogo03@gmail.com

Apresentação de Pôster

Resumo

Área do Conhecimento: Educação e Inclusão

Introdução: Experienciar a prática pedagógica durante o curso de graduação é extremamente importante para que tenhamos oportunidade de conhecer, pelo menos um pouco, como podemos articular as teorias trabalhadas e dialogadas em sala de aula com o espaço além-muro. Nesse sentido, este trabalho apresenta o relato de uma experiência de estágio supervisionado em Educação Infantil, observando a rotina desse ciclo educacional.Objetivo: explorar a rotina das crianças, conhecendo um pouco mais acerca dos espaços e materiais utilizados no contexto educacional, investigando ainda, sobre a formação e prática do profissional que atua na Educação Infantil.Metodologia: As observações foram realizadas em um Centro Municipal de Educação Infantil- CMEI, do município de Araguari/MG, com duas turmas de Educação Infantil: Maternal I e Maternal II, por meio de acompanhamento diário com as turmas. Para o desempenho dessas observações foi levado em consideração relatos dos professores e o contato com os alunos acerca da rotina real izada dentro do CMEI.Relato da experiência: Na primeira visita fui apresentado aos alunos, os quais me acolheram de forma calorosa assim como os demais profissionais que atuam no CMEI. De acordo com as possibilidades, pude passar algumas manhãs com os alunos, ora no Maternal I ora no Maternal II. Os alunos ficaram curiosos à respeito da minha presença e, por vezes, até eufóricos. Conforme a rotina ia acontecendo, as educadoras me explicavam o porquê das atividades. Foi uma notável experiência para conhecer, na realidade, como se dá para a criança o espaço educacional no qual ela está inserida, considerando a atuação do educador (a). Pude acompanhar a hora do café da manhã, momento no qual houve um contato de todas as turmas e também quando retornavam para a sala e realizavam diversas atividades, como brincar, usar peças de encaixe, massinhas. No que diz respeito à parte interna da sala de aula, verifiquei que é um ambiente acolhedor, com brinquedos, ilustrações do alfabeto e ilustrações numéricas. A educadora separa alguns minutos dentro da rotina para ensiná-los o alfabeto e os números. Notei que os espaços e materiais influenciam consideravelmente no processo educacional. Considerações finais: 0 estágio realizado, por meio de observações, atendeu minhas expectativas no que diz respeito à colaborar no desenvolvimento de conhecimentos, habilidades e atitudes relativas à profissão docente, considerando o contato direto com a realidade educacional. Assim, pude ter a oportunidade de aprendizagem que me permitirá refletir tanto acerca da minha formação quanto da minha atuação futuramente.

PALAVRAS-CHAVE: OBSERVAÇÃO; FORMAÇÃO; ROTINA; ESPAÇOS; MATERIAIS. 


\title{
O PERFIL DO FARMACÊUTICO NA SAÚDE ESTÉTICA
}

\author{
MARIANA CÂNDIDA FERREIRA TELES, SIMONE DE FÁTIMA OLIVEIRA PRIMO, MARIANA PACÍFICO \\ GARVIL
}

INSTITUTO MASTER DE ENSINO PRESIDENTE ANTÔNIO CARLOS - IMEPAC

ferreira-06@hotmail.com

Apresentação de Pôster

Resumo

Área do Conhecimento: Saúde coletiva e bem-estar

Introdução: A procura pela beleza e jovialidade impulsionaram o crescimento do mercado da estética. Procedimentos e técnicas inovadoras surgem neste aspecto possibilitando a inserção de profissionais habilitados na saúde estética. Sendo assim, é permitido ao farmacêutico, legalmente habilitado, se responsabilizar pelos estabelecimentos que utilizam técnicas de natureza estética e recursos terapêuticos, enfatizando a saúde como benefício primordial do indivíduo.

Objetivo: Conhecer o perfil do farmacêutico esteta e suas atribuições na saúde estética.

Metodologia: Trata-se de uma pesquisa qualiquantitativa, transversal e exploratória. Tal levantamento teve como alvo os farmacêuticos que atuam na área da saúde estética, sem delimitação de estado e faixa etária. Foi realizado através de questionário on-line desenvolvido pela plataforma do Google Forms®, entre o período de dezembro de 2018 a março de 2019. O questionário constou de perguntas qualitativas como as dificuldades de aceitação no mercado de trabalho, a atuação do profissional, os procedimentos estéticos aplicados, entre outras.

Resultados: Observou-se que as questões com os maiores níveis de dificuldades foram referentes à aceitação do profissional esteta farmacêutico em relação aos médicos da área de saúde estética. 0 estudo mostrou que a maior parte dos participantes são do sexo feminino $(86,8 \%)$, com a faixa etária predominante entre 25 a 35 anos $(46,4 \%)$. No que se refere ao conhecimento dos procedimentos e recursos estéticos, a maioria $(74,8 \%)$ afirma possuir especialização na área estética e/ou cursos livres. Dentre os participantes a maioria $(35,5 \%)$ considera a área da estética rentável com remuneração entre $R \$ 1.000$ a $\mathrm{R} \$ 3.000$. Em relação aos farmacêuticos estetas, a maioria dos profissionais $(55,9 \%)$ predominam na região sudeste, com destaque para o estado de São Paulo. Entre os procedimentos mais realizados, se destacou o microagulhamento, representando $80,4 \%$, seguido de intradermoterapia $80,3 \%$.

Conclusão: De acordo com os resultados obtidos, a grande maioria dos profissionais farmacêuticos estetas possuem especialização em saúde estética, são seguros e atentos em relação aos conhecimentos e cuidados ao realizar cada procedimento estético. Ademais, percebe-se que o mercado de saúde estética está em evolução para os profissionais farmacêuticos, abrindo novas perspectivas de atuação profissional

PALAVRAS-CHAVE: SAÚDE ESTÉTICA. FARMACÊUTICO. PERFIL PROFISSIONAL. 


\title{
O PERFIL DOS DEPENDENTES QUÍMICOS E A IMPORTÂNCIA DA IMPLEMENTAÇÃO DA ASSISTÊNCIA FARMACÊUTICA EM UMA CASA DE AUXÍLIO EM ARAGUARI- MG.
}

\author{
MARYAH FELICIO DE JESUS, RHAMOM SAMUEL DE SOUZA SILVA, MIRIAN RIBEIRO MOREIRA \\ CARRIJO, SABRINA GONÇALVES RESENDE
}

INSTITUTO MASTER DE ENSINO PRESIDENTE ANTÔNIO CARLOS - IMEPAC

feliciomaryah@yahoo.com.br

Apresentação de Pôster

Resumo

Área do Conhecimento: Saúde coletiva e bem-estar

\begin{abstract}
Introdução: O uso abusivo de substâncias químicas vem progredindo de maneira considerável e preocupante nas últimas décadas. Esta dependência compromete a saúde, a dinâmica familiar e a vida social dos usuários. Alguns dos fatores que motivam o uso de drogas estão associados ao prazer, curiosidade, influência e ansiedade. Os dependentes químicos necessitam de uma atenção imediata, e requerem cuidados de profissionais qualificados na área de saúde para garantir uma reabilitação eficaz.

Objetivo: Analisar o perfil dos dependentes químicos e avaliar a importância da implementação de um serviço de assistência farmacêutica durante processo de reabilitação dos dependentes químicos em uma casa de auxilio em Araguari-MG.

Metodologia: Trata-se de um estudo observacional, descritivo, realizado no período de fevereiro a março de 2019, em uma casa de recuperação de dependentes químicos em Araguari -MG. A amostra é composta por 29 indivíduos do sexo masculino, cadastrados e em atendimento na casa de recuperação. Para a coleta dos dados, um questionário foi elaborado contendo perguntas fechadas e abertas e contou também com a avaliação dos registros cadastrais da instituição. De todos os pacientes foi obtido o Termo de Consentimento Livre e Esclarecido.

Resultados: Verificou-se que, dentre os 29 entrevistados estão entre indivíduos com 18 e 30 anos. Em relação a idade em que foi iniciado o consumo de drogas e álcool, observou-se uma variação entre 8 e 28 anos. Sobre o apoio familiar nesse processo de reabilitação, 52\% responderam que contam com ajuda da família durante essa internação. Motivos como curiosidade, más influências, problemas familiares foram citados como causas para o início do consumo de drogas, destacando que 55,2\% já viveram na rua por serem dependentes da droga. Maconha e álcool foram amplamente citadas, observando-se o uso das mesmas como droga de início, dando entrada para outros tipos de substâncias. Dos entrevistados, 38\% são diagnosticados como portadores de doenças crônicas, os demais relataram não possuir nenhum problema perceptível nesse sentido, embora não realizem exames periódicos. Os medicamentos disponibilizados aos internos ficam sob responsabilidade de internos reabilitados, chamados de cuidadores, que não possuem conhecimento técnico para administrar esses fármacos. A totalidade dos entrevistados disseram que seria de grande valia a assistência de um farmacêutico no local, pois teriam cuidados especiais, sobre as medicações administradas, cuidados básicos com a saúde, dentre outros benefícios citados.

Com os resultados obtidos, evidencia-se que existe uma necessidade da assistência farmacêutica para auxiliar na recuperação dos internos. É possível definir a partir deste fato, um plano de ação, voltado para esta prática no local, que inclui sanar dúvidas dos internos, auxiliar na administração dos fármacos visando o uso racional de medicamentos.

PALAVRAS-CHAVE: DEPENDÊNCIA QUÍMICA; DROGAS; ASSISTÊNCIA; FARMACÊUTICO; REABILITAÇÃO.
\end{abstract}




\title{
O PRINCÍPIO DO CONTRADITÓRIO E DA AMPLA DEFESA NO INQUÉRITO POLICIAL
}

\author{
WENDELL DA SILVA ROSA, ÂNGELO NATANIEL MARZULO, GEILSON NUNES
}

INSTITUTO MASTER DE ENSINO PRESIDENTE ANTÔNIO CARLOS - IMEPAC

wendell.rock@hotmail.com

Apresentação de Pôster

Resumo

Área do Conhecimento: Sustentabilidade e Direitos

INTRODUÇÃO: A pesquisa versará sobre a presença do princípio do contraditório e da ampla defesa no inquérito policial, sendo que este procedimento administrativo não contempla tais princípios por se trata de uma fase pré-processual.

OBJETIVO: 0 objetivo deste trabalho será demonstrar a importância do princípio do contraditório e da ampla defesa no inquérito policial, resguardando os direitos e garantias do suspeito, assim, buscando a verdade real dos fatos referente investigados e por conseguinte, uma conclusão do que se consignou na pesquisa.

MÉTODO: Utiliza-se o método dedutivo, a partir de argumentos legais, comprovando a necessidade do contraditório e da ampla defesa no inquérito policial. Como metodologia, adotará a pesquisa bibliográficas com base na lei, a doutrina e a jurisprudência.

RESULTADOS: Sobre o tema, percebe-se que a ausência do princípio do contraditório e da ampla defesa no procedimento administrativo, traz a sensação de injustiça no que tange garantia dos direitos de proteção do investigado e a paridade de armas na peça investigativa, ainda que se trata de uma fase pré-processual, onde não há acusação. 0 inquérito é inquisitivo, porque é presidido por uma só pessoa (autoridade policial), que tem por objetivo a apuração da autoria e materialidade da infração penal, de caráter informativo que muito das vezes é o único elemento de base para instauração da ação penal. Motivo de não contemplar o princípio do contraditório e da ampla defesa, pois se não há acusação, não se fala em defesa. Todavia, o princípio do contraditório é garantido de forma indireta no procedimento investigatório, pois que, considerando a Lei 13.245/16, aliado à Súmula 14 do STF, permite o acesso do advogado na investigação preliminar, seja de natureza criminal ou administrativa. Também, assegura o princípio da ampla defesa, ou seja, o direito de defesa técnica (advogado conhecedor da lei) do investigado.

CONCLUSÃO: Diante o exposto, conclui-se que ser necessário e importante o princípio do contraditório e ampla defesa no inquérito policial, para que não haja injustiça na elucidação dos elementos de provas colhidos no curso da investigação, de modo a garantir os direitos defesa do investigado, protegendo a verdade real dos fatos e a paridade de armas entre o Estado e acusado.

PALAVRAS-CHAVE: INQUÉRITO POLICIAL; PRINCÍPIO DO CONTRADITÓRIO; PRINCÍPIO DA AMPLA DEFESA. 


\title{
O SISTEMA PRISIONAL E A RESSOCIALIZAÇÃO DO PRESO
}

\author{
WELLINGTON LOPES DE SOUZA, MURILO LOPES VIEIRA, GEILSON NUNES
}

INSTITUTO MASTER DE ENSINO PRESIDENTE ANTÔNIO CARLOS - IMEPAC

wellingtonlopes.desouza@hotmail.com

Apresentação de Pôster

\section{Resumo}

Área do Conhecimento: Sustentabilidade e Direitos

Introdução: 0 presente artigo buscou tratar acerca do desvio social criminalizado que se encontra em intervenção estatal uma das maiores abordagens que resulta em debates no sistema jurídico brasileiro é acerca do sistema carcerário, tendo em vista, às condições precárias e ineficientes presentes na prática. Diante disso, há uma importância específica a ser tratada e questionada com coerência, a ressocialização do detento, a partir de uma postura inclusiva e humana.

Objetivo: Frente ao exposto, o objetivo deste trabalho foi analisar a retomada do preso à sociedade de forma que o seu convívio social seja respeitado.

Metodologia: Para a obtenção dos resultados pretendidos no âmbito do sistema prisional e a ressocialização do apenado, trata-se de uma pesquisa qualitativa, exploratória, a qual se usou o método dedutivo, fazendo aplicação através de pesquisa bibliográfica, dessa maneira expondo os objetivos propostos na problemática apresentada, e por fim, trazendo uma conclusão passível de compreensão geral.

Resultados: Foi possível observar que cabe ao Estado promover a assistência do preso, orientando-o ao retorno e à convivência perante a sociedade, incluindo o apoio para reingressá-lo à vida em liberdade. Quanto a relação da ressocialização e o sistema carcerário, pude perceber que a realidade do sistema impede que o agente se reestruture como um cidadão íntegro em meio à sociedade, tendo em vista que, apesar de o Estado fornecer alguns meios de se ressocializar, a precariedade dos presídios, a falta de preparo dos profissionais e a falta de efetividade da aplicação das normas previstas em leis, são suficientes para desestruturar todo método utilizado. Ademais, verifiquei que na Lei de Execução Penal contém normas que tem de fato o intuito de ressocializar o preso, por outro lado, não é respeitada como deveria, sendo que é a partir daí que começa a grande falha no sistema carcerário, dificultando o retorno do preso à sociedade. Conclusão: Com base nos resultados alcançados, verificamos que existe um grande aumento de reinciden tes no sistema prisional, sendo que tal aumento vai além da responsabilidade da Lei de execução penal ou da precariedade dos presídios, uma vez que deve-se levar em conta a maneira em que são operados os conceitos estabelecidos, que acabam por dificultar a efetiva e eficaz ressocialização do apenado

PALAVRAS-CHAVE: PRESO; RESSOCIALIZAÇÃO; SISTEMA PRISIONAL. 


\title{
O TERMO DE AJUSTAMENTO DE CONDUTA COMO INSTRUMENTO DE GESTÃO E MANEJO ADEQUADO AO MEIO AMBIENTE EQUILIBRADO.
}

\author{
MARCELO DE LIMA VASCONCELOS, ANA LAURA LANDA IGNÁCIO, PROF. MESTRE GEILSON NUNES
}

INSTITUTO MASTER DE ENSINO PRESIDENTE ANTÔNIO CARLOS - IMEPAC

marcelobiolong@hotmail.com

Apresentação de Pôster

Resumo

Área do Conhecimento: Sustentabilidade e Direitos

Introdução: 0 presente trabalho tratou de estudar a praticabilidade dos recursos provenientes do Termo de Ajuste de Conduta (TAC) como instrumento de gestão e manejo a um ambiente mais equilibrado como solução de conflitos sem entrar no mérito judicial, ou seja, pela via extrajudicial.

Objetivo: A pesquisa teve como objetivo geral estudar sobre o Termo de Ajustamento de Conduta (TAC) como um meio mais eficaz e eficiente de minimizar os efeitos dos danos ambientais provocados por empresas ao meio ambiente de forma geral.

Metodologia: Adotou-se o método dedutivo, a partir de argumentos gerais para particulares, utilizando-se da pesquisa teórica, por estudo de doutrinas e demais documentos pertinentes ao tema.

Resultados: 0 meio ambiente equilibrado é um desafio para o presente e futuras gerações que correm o risco de não possuir um ambiente saudável e ter seus recursos naturais comprometidos pelos abusos cometidos no passado e assim, ter a manutenção e perpetuação de suas espécies ameaçadas. Até pouco tempo era muito vigente para alguns ainda que os recursos naturais fossem infinitos, ou seja, poderiam gastar e usar a vontade dos recursos naturais que a natureza nos proporcionou sem se preocupar com o futuro e com as seguintes gerações, o que logo, tais ideias foram sendo descartadas devido ao aumento dos meios de informações e principalmente da educação ambiental que proporcionou uma visão mais real dos riscos que poderiam e podem acontecer caso não mudasse a maneira de conviver com o meio ambiente, respeitando seu tempo de renovação. Não obstante, a evolução é um problema para o meio ambiente equilibrado e saudável, mas a conscientização em não poluir ou mitigar ao máximo os impactos ambientais produzidos pelos poluentes é de suma importância para o desenvolvimento de um ambiente equilibrado e que respeite as leis e normas que regem o direito fundamental. Assim, devido a tantas reincidências nos danos ambientais que a importância do tema originou uma legislação ambiental que fosse mais célere e sem entrar na via judicial, criando assim o Termo de Ajustamento de Conduta com a finalidade de dar maior rapidez à resolução das questões ambientais com o intuito de precaver práticas que degradem o meio ambiente.

Conclusão: Com base nos resultados alcançados, concluímos que o Termo de Ajustamento de Con duta (TAC) é um procedimento extrajudicial inovador, tendo seu uso mais recorrente na solução de controvérsias ao meio ambiente equilibrado, minimizando ou de preferência acabando com o problema causado de forma rápida, fazendo valer a satisfação da sociedade e de uma maneira punir o poluidor.

PALAVRAS-CHAVE: GESTÃO E MANEJO; MEIO AMBIENTE EQUILIBRADO; TERMO DE AJUSTE DE CONDUTA. 


\title{
O TRABALHO DE GESTANTES E LACTANTES EM AMBIENTE INSALUBRE PELA ÓTICA CONSTITUCIONAL
}

\author{
BEATRIZ VANÇO FIRMINO, LETÍCIA DE OLIVEIRA, RODRIGO GUILHERME TOMAZ
}

INSTITUTO MASTER DE ENSINO PRESIDENTE ANTÔNIO CARLOS - IMEPAC

biavanco@hotmail.com

Apresentação de Pôster

Resumo

Área do Conhecimento: Sustentabilidade e Direitos

INTRODUÇÃO: Este resumo tem por finalidade explanar sobre o tema do trabalho em ambiente insalubre pelas gestantes e lactantes, o que a Reforma Trabalhista trouxe de inovações sobre esse aspecto e quais as consequências para as trabalhadoras que foram e serão amparadas por essa legislação. Nesse entendimento, aludiremos ainda sobre as implicações da aplicação da nova legislação quanto ao que influencia no labor e na vida da empregada.

OBJETIVO: Quanto ao objetivo, vale ressaltar que se almeja demonstrar que apesar de a Reforma Trabalhista trazer várias alterações e sanar algumas dúvidas que existiam acerca do tema da atividade em ambiente insalubre pelas gestantes e lactantes, ainda assim é preciso que haja mais adaptações para que se atendam vários dos princípios constitucionais.

MÉTODO: Para o esclarecimento do tema abordado, será utilizado o método dedutivo com finalidade ainda de obter os resultados de forma eficaz.

RESULTADOS: 0 artigo 394-A da CLT dispõe que a empregada gestante será afastada sem a necessidade de atestado médico, quando a insalubridade atingir grau máximo. Se o grau de insalubridade for médio ou mínimo, a mulher somente será afastada, caso apresente atestado de seu médico de confiança, com a recomendação de seu afastamento. No caso das lactantes, independente do grau de insalubridade, serão afastadas no período da amamentação mediante atestado médico. Insta salientar, que no caso da gestante que trabalha em grau máximo de insalubridade, é concedido a ela o adicional de insalubridade de forma imediata. Já no caso das que trabalham em grau médio ou mínimo, será concedido o adicional mediante apresentação de atestado médico. 0 trabalho em local insalubre além de trazer sérios problemas para a saúde da mulher, também traz problemas ao desenvolvimento do nascituro. Vale dizer que, as mulheres que não conseguirem atestado médico estão sujeitas ao risco de seu feto desenvolver alguma deficiência. Ademais, a deficiência pode impedir que a mulher volte ao mercado de trabalho caso ela opte por cuidar do seu filho. Apesar de o objetivo principal da mudança ser o de proporcionar às mulheres um posto de trabalho mais formal, acabou retirando das mesmas oportunidades de emprego, haja vista que, as empresas podem optar por não contratarem mulheres pensando nas consequências que possam surgir quando elas estiverem neste estado. E, no fim, as mais prejudicadas são as próprias mulheres, pois, as que não pretendem ter filhos ou aquelas que já são mães, acabam perdendo espaço no mercado de trabalho. Analisando a pretensão do legislador reformista, o qual teve o entendimento de que esta modificação é um progresso ao direito da mulher, uma forma de diminuir as desigualdades, é notório o retrocesso, uma vez que a mudança atinge os princípios constitucionais como o direito à vida e a saúde, dando mais imp ortância ao direito ao trabalho, do que a proteção da vida.

PALAVRAS-CHAVE: GESTANTE; LACTANTE; TRABALHO INSALUBRE. 


\title{
O TRATAMENTO SUCESSÓRIO PARA O COMPANHEIRO(A) FRENTE A INCONSTITUCIONALIDADE DO ARTIGO 1790 DO CÓDIGO CIVIL
}

\author{
KEILA PULICEL CHAHIN MEDEIROS, CLEUBER FRANCISCO MEDEIROS, RODRIGO GUILHERME \\ TOMAZ
}

INSTITUTO MASTER DE ENSINO PRESIDENTE ANTÔNIO CARLOS - IMEPAC

keilap@cjselecta.com.br

Apresentação de Pôster

Resumo

Área do Conhecimento: Sustentabilidade e Direitos

Introdução: 0 direito das sucessões regula através do conjunto de normas a transferência do patrimônio de alguém, devido a causa mortis, ao herdeiro, em virtude de lei ou disposição de vontade. Tinha-se por consideração ao conceito tradicional de família aquela formada a partir do casamento, contudo, diante das constantes mudanças e necessidades sociais ainda que na Carta Magna prevêa união estável entre o homem e a mulher (casal heterossexual), estendeu-se as pessoas de mesmo sexo (casal homossexual).

Problema de Pesquisa: 0 problema desta pesquisa é perquiri sobre os efeitos da declaração do STF pela inconstitucionalidade do art. 1790 do Código Civil, sendo assim, é devido o tratamento igualitário entre os institutos?

Objetivo: Refere-se ao questionamento de demonstrar que a Constituição Federal de 1988 por ser considerada cidadã, reconheceu como entidade familiar a união estável e amparou os companheiros em suas relações de afeto ao status de Família.

Método: será adotado na presente pesquisa o método dedutivo, a partir de argumentos particulares para o geral de diferentes pontos de vista.

Resultados: A luz do Código Civil de 2002, houve uma previsão que "desequiparou” para fins de sucessão, ou seja, para o casamento um tratamento sucessório para o(a) cônjuge e para a união estável outro tipo de tratamento para o companheiro(a) do falecido prevendo uma proteção bem menor do que aquela que é conferida ao cônjuge. Havia divergência sobre o assunto, os Tribunais Estaduais do Rio de Janeiro e São Paulo tinham interpretações divergentes em sede de arguição de inconstitucionalidade. Ao tempo que o TJSP e TJMG reconheciam a recepção constitucional art. 1.790 do CC/2002, o TJRJ o tinha por inconstitucional, tamanha foi a controvérsia que chegou a Corte Especial. Assim, há que estender-se o conceito de família quer seja pelo casamento, vínculos de filiação e pôr fim a união estável. As leis ordinárias (Lei no 8.971/94 e Lei 9.278/96) equiparavam os regimes jurídicos sucessórios do casamento e da união estável, acabou regredindo o tratamento do tema e "desequiparou" com o Código Civil de 2002 para fins de sucessão, ou seja, o companheiro tinha uma proteção menor do que aquela que é conferida ao cônjuge, causando retrocesso e hierarquização entre as famílias, ferindo a Constituição que dispensa tratamento igualitário para todas as famílias.

Conclusão: Em recente julgado o STF proferiu tese de entendimento que o companheiro é herdeiro legitimo por isso goza dos mesmos direitos do cônjuge aplicando-se o artigo 1829 do CC na sucessão hereditária causa mortis. A equidade entre os institutos de formação familiar foi alcançada, a jurisprudência na sua maioria já aplicava esse entendimento aos casos apresentados nos tribunais, sob o entendimento da aplicação dos princípios constitucionais da dignidade da pessoa humana, isonomia e livre escolha de regime de casamento.

PALAVRAS-CHAVE: DIREITO DAS SUCESSÕES, FAMÍLIA, TRATAMENTO IGUALITÁRIO. 


\title{
O USO DA INTELIGÊNCIA EMOCIONAL ASSOCIADO DIRETAMENTE A LIDERANÇA NA GESTÃO DE PROJETOS
}

\author{
JULIANA ABADIA GALVÃO VIEIRA, DANILO FARIA DE MOURA
}

FACULDADE PITÁGORAS

julianagalvao9@hotmail.com

Comunicação Oral

Resumo

Área do Conhecimento: Responsabilidade e Negócios

Introdução: Devido a lei de livre mercado, dentro da ampla concorrência entre as organizações, sobrevive a que mais se empenha em usar estratégias diferenciadas de gestão, que possa engajar seus colaboradores para que os mesmos cumpram as suas atividades e entreguem o que se é esperado pelo cliente. Apostar em um formato de liderança que possa melhor compreender as necessidades de um líder e de seus liderados, se torna algo cada vez mais presente em ambientes corporativos. Através dessa percepção, é notório que a Inteligência Emocional, que pode ser definida como a capacidade de compreensão das próprias emoções e as de outras pessoas, pode contribuir para que a empresa obtenha mais sucesso em seus projetos desempenhados.

Objetivo: 0 artigo teve como objetivo apontar a importância da Inteligência Emocional associada diretamente a liderança na Gestão de Projetos, demonstrando que a mesma pode ser de suma importância como uma ferramenta de gestão de pessoas.

Metodologia: 0 artigo foi desenvolvido através de uma revisão bibliográfica composta por livros, artigos nacionais e internacionais, que abordam conceitos que definem inteligência emocional e liderança, quais os desafios de um líder de projetos e teorias que associam a importância do uso da inteligência emocional dentro de um contexto de um ambiente de projetos.

Resultados: A revisão bibliográfica aponta que existem campos dentro da literatura que podem ser levados para o ambiente prático de execução de projetos, onde as teorias apontam carências na gestão de pessoas, devido ao fato de ser um ambiente em que a liderança, em sua maioria das vezes, não se atenta com o bem estar e as necessidades dos seus colaboradores, quanto deveriam. As teorias apontadas pela revisão bibliográfica também identificaram que, investir em capital intelectual dentro de uma organização, é fazer com que o seu colaborador se sinta cada vez mais satisfeito em executar suas funções propostas e entregar as mesmas com qualidade.

Conclusão: As organizações e os sistemas de gerenciamento de projetos se encontram em constante evolução, visto que as técnicas usadas em décadas anteriores, atualmente já estão em caráter obsoleto. Liderar pessoas com personalidades, anseios e objetivos diferentes, se torna cada vez mais um desafio de quem está à frente de uma equipe. Conhecer e identificar as emoções de sua equipe promoverá uma comunicação mais fluida, pois o líder saberá como agir perante as suas necessidades e como essa decisão não influenciará no seu resultado que deve ser entregue no final do projeto. 0 projeto que não possui um bom líder tende diretamente ao seu insucesso, visto que esse mesmo líder precisa de uma equipe comprometida para que as tarefas possam ser realizadas. Ter um líder apático a frente de um determinado grupo, implicará certos desconfortos no ambiente de trabalho, o que pode gerar insatisfação dos colaboradores e a sua produção consequentemente pode cair de patamar.

PALAVRAS-CHAVE: INTELIGÊNCIA EMOCIONAL, LIDERANÇA, GESTÃO DE PROJETOS. 


\title{
O USO DE "METODOLOGIAS ATIVAS DE APRENDIZAGEM BASEADA EM PROJETOS" NO COMPONENTE CURRICULAR: ENGENHARIA DE SOFTWARE
}

\author{
LEANDRA MENDES DO VALE, CRISTIANE DIVINA LEMES HAMAWAKI,
}

INSTITUTO MASTER DE ENSINO PRESIDENTE ANTÔNIO CARLOS - IMEPAC

leandramvale@gmail.com

Comunicação Oral

Resumo

Área do Conhecimento: Agenda 2030 e os Objetivos de Desenvolvimento Sustentável

Introdução: A Engenharia de Software é um componente curricular de cunho teórico com aplicação prática Portanto, é necessário encontrar metodologias que levem o aluno a conhecer os conceitos e aplicá-los. Em 2018, os docentes escolheram usar a metodologia ativa de aprendizagem baseada em projetos conforme Bender, William N. Essa metodologia permite o envolvimento com tarefas e desafios que levam ao desenvolvimento de projeto ou produto integrando diferentes conhecimentos. Além de estimular o desenvolvimento de competências, como trabalho em equipe, protagonismo e pensamento crítico.

Objetivo: Trabalhar conceitos teóricos aliados à prática profissional através de metodologias ativas de aprendizagem baseada em projetos tendo como foco os processos de desenvolvimento de softwares.

Metodologia: A experiência foi realizada com 18 alunos do 1o período do curso superior de tecnologia em análise e desenvolvimento de sistemas. Destes 100\% eram do sexo masculino, sendo 50\% entre 18 e 22 anos, $21,4 \%$ entre 23 e 27 e 28,6\% superior a 28 anos. As atividades propostas foram divididas em três fases, grupos de cinco alunos, sendo necessário quatro aulas de cinquenta minutos para a realização. Em cada fase foram criados cenários fictícios nos quais os grupos deveriam representar e executar tarefas conforme roteiro proposto pelo docente. Após a realização da atividade, o docente aplicou aos alunos um questionário de satisfação sobre a mesma.

Relato da experiência: Como produto final cada grupo deveria entregar um meio de transporte futurístico. Na primeira fase cada grupo se comportou como empresários interessados em buscar uma solução. Já na segunda fase, cada grupo sorteou um projeto da fase anterior para desenvolver. Assim sendo, elencaram os requisitos de hardware e software, escolheram um processo de desenvolvimento e apresentaram o orçamento ao grupo de empresários. Depois de acordado o desenvolvimento, o grupo deu início ao desenvolvimento usando objetos e materiais recicláveis. Na última fase, os desenvolvedores apresentaram o seu protótipo aos empresários para que estes validassem.

Considerações finais: 0 questionário de satisfação nos mostrou que o objetivo da atividade proposta levou a uma experiência exitosa e prática, pois $50 \%$ dos alunos consideraram que esta contribuiu para a melhor compreensão dos conceitos e 77,8\% conseguiram identificar a importância de processos bem definidos. Dentre as habilidades desenvolvidas ficou evidenciada as cognitivas: interpretação $(72,2 \%)$, análise $(66,75 \%)$, argumentação (50\%), pensamento crítico $(44,4 \%)$ e tomada de decisões $(33,3 \%)$. Dentre as interpessoais: trabalho em equipe (83,3\%), cooperação (50\%), resolução de conflitos $(38,9 \%)$ e empatia $(27,8 \%)$. Das habilidades intrapessoais: produtividade $(61,1 \%)$, responsabilidade, flexibilidade e aprendizado contínuo (50\%) e iniciativa (38,9\%).

PALAVRAS-CHAVE: METODOLOGIA ATIVA; ENGENHARIA DE SOFTWARE; APRENDIZAGEM BASEADA EM PROJETOS. 


\title{
OCORRÊNCIA DE RAIVA EM HERBÍVOROS DO MUNICÍPIO DE ARAGUARI-MG, NOS PERÍODOS DE 2015 A 2019
}

\author{
JEHSSE FERREIRA PACHECO, GABRIELA FERREIRA SANTOS, GETÚLIO LUIZ RABELO NETO , LIANDRA \\ LAÍS LUNA MELO, YASMIM EDUARDO CRUVINEL, DANIELLE VITORINO MORAES
}

INSTITUTO MASTER DE ENSINO PRESIDENTE ANTÔNIO CARLOS - IMEPAC

jehsse@yahoo.com

Apresentação de Pôster

Resumo

Área do Conhecimento: Saúde coletiva e bem-estar

Introdução: A raiva consiste em uma doença viral, de evolução aguda, altamente contagiosa que ocorre mundialmente, visto que apresenta prevalência em todo território nacional, sendo endêmica em diversas regiões do Brasil, e considerada uma das doenças de maior importância tanto socioeconômica como para a saúde pública, pois acomete múltiplas espécies de mamíferos, apresenta altas taxas de letalidade, e pode ocorrer no ambiente urbano, rural, aéreo e selvagem, tendo em cada local um animal reservatório, que contribui para a circulação do vírus nestes ambientes.

Objetivo: O presente estudo tem como objetivo realizar um levantamento dos casos positivos para raiva nos herbívoros (bovinos e equinos) registrados no município de Araguari-MG, entre os períodos de 2015 a 2019, e comparar com o número de casos registrados no Estado de Minas Gerais nos anos anteriores a 2015, tendo como finalidade determinar a ausência ou circulação do vírus na região, e ressaltar a importância da implantação ou aprimoramento das medidas de vigilância epidemiológica que visam controlar ou prevenir a ocorrência da doença.

Metodologia: Foi realizado um levantamento dos casos positivos de raiva em bovinos e equinos que ocorreram e foram registrados no município de Araguari -MG, durante o período de 2015 a 2019 . Os registros foram obtidos por meio de fichas de notificação enviadas ao Instituto Mineiro de Agropecuária IMA.

Resultados: Segundo o IMA, durante os períodos de 2015 a 2019, foram registrados oito casos de raiva em bovinos e equinos, pertencentes a cinco propriedades rurais localizadas no município de Araguari-MG no ano de 2018, devido à falta de vacinação dos animais. Em todos os casos, o IMA foi notificado, e a doença foi confirmada através da coleta de fragmentos (amostra) da região do cerebelo dos animais afetados, sendo a maioria das amostragens feitas por um médico veterinário do IMA, com posterior realização do exame laboratorial de imunofluorescência direta no Laboratório de Saúde Animal (LSA) do IMA.

Conclusão: Foi possível concluir que houve a circulação do vírus no município de Araguari, e no Estado de Minas Gerais entre os períodos de 2015 a 2019, devido à existência de registros dos casos positivos. Estes resultados sugerem a necessidade de um melhoramento na eficiência das medidas de controle e prevenção da doença no ambiente rural do município, bem como há a necessidade da realização de mais estudos recentes em relação a ocorrência da doença nos ambientes urbano, silvestres e aéreo, para reduzir o número de animais infectados e assim controlar a disseminação da doença, visto que a presença de bovinos e equinos infectados bem como de morcegos hematófagos (reservatórios), contribuem para a circulação do vírus no ambiente e disseminação da doença, que pode infectar diversos animais, bem como os seres humanos.

PALAVRAS-CHAVE: RAIVA. HERBÍVOROS. CIRCULAÇÃO DO VÍRUS. CONTROLE E PREVENÇÃO DA DOENÇA. 


\section{OMISSÃO LEGISLATIVA PREVIDENCIÁRIA EM RELAÇÃO AOS TRANSEXUAIS E A QUEBRA DO PARADIGMA DA DIGNIDADE DA PESSOA HUMANA.}

TAUANE APARECIDA SOARES MARÇAL, SÉRGIO RODRIGUES,

INSTITUTO MASTER DE ENSINO PRESIDENTE ANTÔNIO CARLOS - IMEPAC

tauanesoaresmarcal@hotmail.com

Apresentação de Pôster

Resumo

Área do Conhecimento: Sustentabilidade e Direitos

Introdução: 0 presente estudo tratará das situações jurídicas previdenciárias de pessoas que mudaram de gênero, em razão da alteração de sexo. Nota-se oportuna a pesquisa, o fim se busca entender a forma como a relação previdenciária destas pessoas se amolda a legislação em vigor.

Problemática: Diante a situação social específica apresentada, busca-se, em síntese, abarcar o seguinte: de que maneira a legislação previdenciária em vigor no sistema brasileiro poderá garantir os direitos de pessoas que alteraram o sexo e, consequentemente o gênero?

Objetivo: Quanto ao objetivo a ser alcançado, refere-se a questionamentos de uma abordagem em nosso ordenamento jurídico sobre a ótica do Direito Previdenciário e seus benefícios, com enfoque nos direitos e deveres dos transexuais, tendo como prisma a dignidade da pessoa humana e os direitos fundamentais.

Método: Para a presente pesquisa será usado o método dedutivo, a partir de argumentos gerais para argumentos particulares, com intuito de buscar um resultado para a problemática proposta.

Resultados: Em 2018 o Supremo Tribunal Federal, por unanimidade pacificou que os transexuais poderão alterar o seu nome e gênero no registro civil sem ter realizado os procedimentos da cirurgia da transgenitalização ou decisão judicial, com respeito ao princípio dignidade da pessoa humana que consta na Constituição Federal.

Baseado no princípio da isonomia, tido como o da igualdade, e diante da ausência de normas, há de fixar como forma adequada os princípios como métodos e requisitos para a aposentadoria dos transexuais, diante da omissão legislativa que por seu turno não regulamenta o tempo de contribuição e idade do transexual, deixando-os, assim sem amparo legal.

A dignidade da pessoa humana é constitucional, no qual os transexuai s estão inseridos, e por isso, deverá ter todas as garantias e direitos inerentes a qualquer pessoa.

Atualmente torna-se imprescindível que o Poder Legislativo regulamente os direitos previdenciários dos transexuais, pois com essa omissão legislativa o Estado está dispensando tratamento preconceituoso e discriminatório com referidas pessoas uma vez que estará ferindo preceitos constantes na Carta Magna, sujeitando aos destinatários benefícios por entendimentos jurisprudenciais e não por diploma legal.

PALAVRAS-CHAVE: GÊNERO; SEGURIDADE SOCIAL; TRANSEXUALIDADE. 


\title{
OS GÊNEROS MULTIMODAIS NO DESENVOLVIMENTO DOS ALUNOS NAS SÉRIES INICIAIS
}

\author{
VALÉRIA ALVES DA SILVA ROSA, LEDA FREIRE SOARES, MATHEUS TAYLOR SOUZA BORGES, \\ ROSANGELA LEITE AGUILAR CARDOSO,
}

INSTITUTO MASTER DE ENSINO PRESIDENTE ANTÔNIO CARLOS - IMEPAC

alvesvaleria169@gmail.com

Comunicação Oral

Resumo

Área do Conhecimento: Agenda 2030 e os Objetivos de Desenvolvimento Sustentável

Introdução: Este trabalho apresenta os resultados de uma pesquisa desenvolvida junto a um grupo de professores de escolas públicas da cidade de Araguari sobre o uso de gêneros textuais nas séries iniciais do Ensino Fundamental. Para trabalhar com gêneros nas aulas, deve-se ter atenção às razões de sua escolha, às características e às funções do tipo selecionado. Os Parâmetros Curriculares nacionais evidenciam a necessidade der um trabalho pautado no uso de gêneros textuais a fim de garantir uma aprendizagem contextualizada. Foi proposto ao grupo de professores um questionário para termos uma visão de como estariam sendo aplicados os gêneros textuais em sala de aula.

Objetivo: Frente ao exposto, o objetivo deste trabalho foi o de compreender se os professores priorizam em seus planejamentos de aula o trabalho efetivo com os gêneros textuais e quais as dificuldades encontradas em seu desenvolvimento em sala de aula.

Metodologia: Trata-se de uma pesquisa qualitativa, usando o questionário para o levantamento das informações. Participaram da pesquisa 46 professores que atuam na rede pública, nas séries iniciais do Ensino Fundamental. O levantamento dos dados aconteceu nos meses de fevereiro e março. A pesquisa investigou o nível de conhecimento dos professores a respeito do uso dos gêneros textuais e sua aplicação na prática da sala de aula.

Resultados: Foi possível observar que as questões com os maiores níveis de dificuldade foram referentes ao uso dos gêneros multimodais no ensino, cerca de $85 \%$ dos envolvidos na pesquisa desconheciam esse gênero e, portanto, não o utilizavam em suas aulas. Quanto às questões referentes ao conhecimento e uso dos gêneros em sala, 70\% responderam que conhecem e utilizam os gêneros textuais em suas aulas. Em relação a entender qual o objetivo de trabalhar com gêneros textuais, 15\% responderam que seu objetivo era o aprofundamento para compreender a função social, $36 \%$ responderam que o objetivo era conhecer os gêneros, $41 \%$ evidenciou que o objetivo do trabalho com gêneros é para se fazer análise textual e $30 \%$ utiliza o gênero textual para desenvolver o hábito de leitura nos alunos.

Conclusão: Conclui-se que, apesar da diversidade de investigações que existem sobre gêneros, na esfera científica, precisa-se desenvolver formações continuadas que contemplem o trabalho com os gêneros textuais, de forma mais específica, com os professores que trabalham no ensino fundamental, possibilitando discussões teórico-metodológicas sobre os gêneros, pois acredita-se que por intermédio deste conhecimento o ensino da língua materna desenvolverá as competências linguísticas, textuais e discursivas dos alunos.

PALAVRAS-CHAVE: GÊNEROS TEXTUAIS, FORMAÇÃO DOCENTE, FORMAÇÃO CONTINUADA. 


\title{
OS MEIOS ALTERNATIVOS DE RESOLUÇÃO DE CONFLITOS: A CHAVE PARA A ATUAL MOROSIDADE DO JUDICIÁRIO.
}

\author{
THAYS CRISTIANE BRUNO DA SILVA
}

INSTITUTO MASTER DE ENSINO PRESIDENTE ANTÔNIO CARLOS - IMEPAC

thayscristianebruno@gmail.com

Apresentação de Pôster

Resumo

Área do Conhecimento: Sustentabilidade e Direitos

A crescente busca pela prestação jurisdicional, ocasionada pela cultura do litígio, potencializa a eclosão da morosidade no sistema. Assim, é imprescindível a busca pelos meios alternativos que possam garantir um adequado acesso à justiça.

No que trata do acesso à justiça, nota-se que a apreciação jurisdicional não é proporcionada de forma justa e igualitária, indagando-se, como os meios alternativos de resolução de conflitos podem garantir o devido acesso à justiça?

O presente trabalho busca demonstrar que os meios alternativos de resolução de conflitos são a solução atual adequada para proporcionar as partes um resultado útil e efetivo na solução do litígio. A metodologia adotada na presente será foi o método dedutivo, com base em argumentos globais para argumentos particulares.

Acerca dos resultados alcançados, o princípio da Inafastabilidade do Controle Jurisdicional, art. $5^{\circ}, \mathrm{XXXV}$ $\mathrm{CF} / 88$, estabelece que todos possuem o direito de obter do Poder Judiciário a tutela jurisdicional adequada. Todavia, referido direito constitucional não está sendo efetivado de forma justa e igualitária. Uma vez que a sobrecarga judiciária afeta em sua prestação. Assim sendo, foram feitas reformas no Código de Processo Civil que buscam desafogar o judiciário por meio de soluções alternativas de conflitos, tais como; a mediação, a conciliação e a arbitragem. Cappelletti $(1988$, p. 86) assevera que, tais soluções possuem um papel altamente útil para variadas demandas, bem como para as partes, quando consideramos restaurar relacionamentos, ao contrário de somente julgar as partes vencedoras ou vencidas. As soluções consensuais retratará a face amistosa da Justiça Brasileira, que não está destinada a resolver o direito, mas sim, possibilitar ao jurisdicionado, de forma eficiente, ao invés de oferecer todo o momento, a sentença, a qual raramente promove a pacificação do conflito. Portanto, enfatiza Cappelletti (1988, p. 87) embora, os meios alternativos de resolução de conflitos se destine, a reduzir o congestionamento do judiciário, devemos certificarmo-nos de que logrem verdadeiros êxitos, não sendo apenas meios para resolver os problemas do Judiciário, os quais poderiam ter outras soluções. Portanto, é notável que o emprego dos meios alternativos seja medida de rigor para que se diminua a demanda da máquina judiciária, tornando-a mais eficiente e eficaz. Uma vez que, há notáveis argumentações e provas para considerarmos que o emprego de tais meios detém a capacidade de dizimar o número de novas demandas no judiciário, bem como trazer benefícios na restauração das relações sociais.

REFERÊNCIAS

BRASIL. Constituição da República Federativa do Brasil de 1988. Disponível em: <http://www.planalto.gov.br/ccivil_03/constituicao/constituicaocompilado.htm>. Acessado em 7 de março de 2019.

CAPPELLETTI, Mauro. Acesso à Justiça. Porto Alegre: Fabris, 1988.

PALAVRAS-CHAVE: MEIOS ALTERNATIVOS DE RESOLUÇÃO DE CONFLITOS; SOLUÇÃO; MOROSIDADE JUDICIÁRIA. 


\title{
OUVIR, FALAR, LER E ESCREVER: O CAMINHO CERTO PARA A APRENDIZAGEM.
}

\author{
LEANDRA MENDES DO VALE, PATRÍCIA ROSA DO VALE,
}

INSTITUTO MASTER DE ENSINO PRESIDENTE ANTÔNIO CARLOS - IMEPAC

leandramvale@gmail.com

Comunicação Oral

Resumo

Área do Conhecimento: Agenda 2030 e os Objetivos de Desenvolvimento Sustentável

Introdução (Contextualização): O ser humano no seu processo de desenvolvimento estabelece relações e interage com o meio a partir das experiências vividas. 0 ensino da Língua Portuguesa sempre foi um desafio entre educadores. A escrita, enquanto produção de texto, não se constitui em um ato de solidão, nem de intimidade exclusiva entre o produtor e o texto. A produção textual é um processo dialógico que deve estar contido na escola, mas também, vai além de sua jurisdição. A prática da escrita também possui uma realidade, uma prática social e sua utilização dentro desta realidade. Para tanto, o professor de ve buscar situações que coloquem o aluno em contato com essas questões e procurar solucioná-las. Buscar experiências na realidade do educando, procurando levá-los a trabalhar no campo de suas idéias concomitantemente ao trabalho no campo das palavras.

Objetivo: Orientar professores do ensino fundamental acerca da importância de fazer com que a criança construa e desenvolva habilidades que possibilitem a participação e o convívio social e, que as levem à capacidade de compreender e produzir textos.

Metodologia: A experiência foi realizada na turma do 4 o ano em uma escola estadual no município de Araguari/MG. Contou com 4 etapas de desenvolvimento baseando-se nas avaliações diagnósticas aplicadas em sala de aula, pois detectou-se que a dificuldade de interpretar e de produzir textos estava evidente na maioria dos alunos impedindo e dificultando seu avanço. Depois de concluídas as etapas foi realizada uma apresentação das atividades aos professores e posteriormente oficinas para que eles pudessem aplicar as mesmas atividades com seus alunos.

Relato da experiência: A 1a etapa teve como propósito desenvolver o hábito da leitura através do projeto Maleta Viajante (escolhe um livro na biblioteca, leva para casa, relata em sala), pois os mesmos não possuíam livros de literatura infantil em casa. A 2 ${ }^{\underline{a}}$ etapa contemplou a produção textos através do uso de sequências de imagens, onde a criança pudesse absorver informações precisas para a produção textual. A $3^{\text {a }}$ etapa contou com os gêneros textuais. Nesta etapa, o aluno pode conhecer, apreciar e compreender diversos tipos de textos que circulam dentro e fora do ambiente escolar, ampliando a possibilidade de um amplo repertório em leituras. Foi proposto para cada aluno que este trouxesse para a sala de aula um gênero textual que seria trabalhado em sala. A 4 a etapa foi a de se produzir textos coletivos. Os alunos teriam a oportunidade de expor suas ideias, analisando, melhorando e colaborando.

Considerações finais: As atividades foram realizadas com êxito, e os resultados foram satisfatórios, pois com as propostas apresentadas e com as atividades permanentes, os alunos se demonstraram mais participativos, interessados confiantes e motivados, levando-os a adquirir um repertório amplo que possibilitou condições melhores para a compreensão e produção de textos. PALAVRAS-CHAVE: LEITURA; PRODUÇÃO DE TEXTO; APRENDIZAGEM. 


\title{
PEDAGOGITALIZANDO: APROXIMANDO O EDUCADOR DA GERAÇÃO DIGITAL E DO USO DE NOVAS TECNOLOGIAS
}

\author{
FLÁVIA CRISTINA NAVES DOS SANTOS MELO, EDNAMAR MARTINS DE FREITAS, JÉSSICA DE \\ OLIVEIRA GONÇALVES, LORENA SALES DUARTE, MARIA CAROLINA DO NASCIMENTO, MARIA \\ TERESA DE BEAUMONT
}

INSTITUTO MASTER DE ENSINO PRESIDENTE ANTÔNIO CARLOS - IMEPAC

flavia.naves.melo@gmail.com

Apresentação de Pôster

Resumo

Área do Conhecimento: Educação e Inclusão

Introdução: Para que haja aprendizado é preciso dinamismo. E com a nova geração que está sempre atualizada, devemos explorar ao máximo as ferramentas oferecidas pela tecnologia. A tecnologia pode trazer melhorias na aprendizagem, tornando as aulas mais dinâmicas e criativas, mas nem todo educador é referência na orientação sobre recursos digitais. Portanto, não somente os alunos, mas também os professores podem ser beneficiados com a devida formação. 0 uso do celular em sala de aula pode estar presente de forma consciente e orientada para ensinar e aprender novas linguagens. A utilização de equipamentos disponíveis e o uso da Internet são opções para prender a atenção dos alunos, inovando com a utilização de vídeos aulas, data show, imagens, jogos, fugindo do tradicionalismo. A escola necessita acompanhar o ritmo da tecnologia na sociedade: como um grupo no Whatsapp, por exemplo, entre alunos e professores que pode facilitar a interação e comunicação e beneficiar a troca de informações. Mas as aulas contemporâneas não necessitam apenas de aparelhos tecnológicos, é preciso professores que tenham facilidade em se adaptar aos recursos e um espaço adequado para que ocorra uma aula produtiva. A alfabetização digital para alunos e educadores irá favorecer o uso produtivo do celular e outras tecnologias, aproveitados como um recurso de ensino e não como um empecilho ou uma distração.

Objetivo: Auxiliar professores no uso de novas tecnologias, aproximando a geração analógica da digital. Aprimorar a qualidade da educação proporcionando novos caminhos na aprendizagem, descobrindo novas estratégias para o aperfeiçoamento e crescimento individual e social. Tornar as aulas mais atraentes, dinâmica e motivadoras. Aumentar a integração dos professores e alunos incentivando a autoconfiança e autonomia. Envolver os alunos em recursos tecnológicos atuais e auxiliar na aprendizagem de conteúdo das disciplinas de forma prática.

Metodologia: A metodologia utilizada para realização desse projeto é acessível, pois utilizaremos uma rede social para informar textos, vídeos, artigos, entre outros elementos sobre o uso das tecnologias na Educação, além de compartilhar algumas experiências sobre o tema em questão. Os professores poderão reconhecer se estão facilitando a aprendizagem e saber que o conhecimento sobre a utilização de ferramentas tecnológicas abre um leque de oportunidades no ensino.

Resultados: Por ora, possuímos informações básicas sobre as experiências de professores em relação à sua inserção no mundo da tecnologia, como: o nível de ensino no qual trabalham e se utilizam ou não a tecnologia no seu cotidiano.

Conclusão: A partir de um questionário virtual realizado concluímos que os professores, apesar de estarem inseridos na tecnologia, possuíam ou possuem dificuldade em alguns quesitos, seja de inseri-la na educação a favor do ensino ou de utilizá-la para aprimorar a aprendizagem dos alunos.

PALAVRAS-CHAVE: MÍDIAS SOCIAIS; TECNOLOGIA NA EDUCAÇÃO; INCLUSÃO DIGITAL; CAPACITAÇÃO. 


\title{
PERCEPÇÃO DOS ACADÊMICOS DA ÁREA DE SAÚDE SOBRE A ATUAÇÃO DO MÉDICO VETERINÁRIO NA SAÚDE PÚBLICA
}

\author{
JESSICA FREITAS DA SILVA, ALEX FERNANDES SILVA, BRUNO HUMBERTO CRUVINEL DE MIRANDA, \\ DANIELA CRISTINA VAZ DA SILVA, FLAVIA MIRANDA DE OLIVEIRA ROCHA, DANIELLE VITORINO \\ MORAES
}

INSTITUTO MASTER DE ENSINO PRESIDENTE ANTÔNIO CARLOS - IMEPAC

freitasjessica04@gmail.com

Apresentação de Pôster

Resumo

Área do Conhecimento: Saúde coletiva e bem-estar

Introdução: É perceptível a abrangência do curso de Medicina Veterinária, sendo ampliado para uma abordagem de orientação para a saúde pública, em seu aspecto fisiológico e preventivo, especialmente para promover a qualidade de vida da população a partir da comprovação dos efeitos que a prevenção reflete no bem-estar humano. Além da clínica veterinária em si, o médico veterinário atua também em ações de vigilância sanitária, em políticas de educação sanitária, como responsável técnico em estabelecimentos que produzem produtos de origem animal, entre outras áreas.

Portanto, torna-se cada vez mais necessária a consolidação das posições conquistadas pelo Médico Veterinário nos avanços da Saúde Pública em toda sua abrangência.

Objetivo: O objetivo desse trabalho foi demonstrar o conhecimento que outros profissionais que lidam com saúde humana têm da atuação do Médico Veterinário na área da saúde pública.

Metodologia: Neste trabalho foi feito um levantamento de caráter qualitativo e descritivo, utilizando-se de um questionário presencial e individual sobre a importância da atuação do Médico Veterinário na saúde pública. Foram entrevistados um total de 195 alunos do IMEPAC, sendo 74 graduandos do curso de Educação Física, com 35 alunos do primeiro ano, 15 alunos do segundo e terceiro ano e 24 alunos do quarto ano, 32 graduandos do curso de Enfermagem, com 16 alunos do primeiro ano, 11 alunos do terceiro ano, 5 alunos do quinto ano e 89 graduandos do curso de Medicina, com 29 alunos do segundo ano, 30 alunos do terceiro ano e 30 alunos do quarto ano.

Resultado: Através da análise dos resultados, pôde-se concluir que 76\% dos 195 graduandos que responderam ao questionário acreditam que o aluno de Medicina Veterinária escolhe o curso por ter afinidade com animais e não pela ampla área de atuação que a profissão oferece, 54 \% sabem que alimentos de origem animal precisam ser fiscalizados por um Médico Veterinário, $71 \%$ acreditam que o Médico Veterinário possui atuação na Saúde Pública, mas apenas 15\% reconhecem que o Médico Veterinário possui atuação efetiva na participação dos Núcleos de Apoio a Saúde da Família (NASF). Apenas 34\% tem conhecimento de que Saúde Única é a união entre a saúde humana, a saúde animal e a saúde ambiental e 87\% concordam que a Medicina Veterinária também é um dos pilares da saúde pública.

Conclusão: Os resultados evidenciaram que os alunos entrevistados estão cientes da importância do Médico Veterinário para a saúde pública, afirmando assim sua importância, mas a grande maioria dos acadêmicos ainda tem a concepção de que o aluno de Medicina Veterinária escolhe o curso apenas pela afinidade por animais e também desconhecem alguns conceitos e como se dá sua atuação nessa área.

Pôde-se concluir que a inserção curricular dos conteúdos da área de saúde pública é insuficiente, pois a maioria dos acadêmicos não conseguem correlacionar a atuação do Médico Veterinário com as áreas da saúde pública.

PALAVRAS-CHAVE: SAÚDE PÚBLICA, MEDICINA VETERINÁRIA, ATUAÇÃO, ZOONOSE. 


\title{
PERCEPÇÃO DOS ACADÊMICOS DE MEDICINA A RESPEITO DOS MEDICAMENTOS GENÉRICOS
}

\author{
ISABELA MENDES CORREIA, CAROLINE SOARES MENDONÇA ALVES, EURIDES BATISTA FARIA \\ NETTO, INGO YOSHI MATSUBARA GARCIA, JULIANA OLIVEIRA, LARISSA MIRANDA ROCHA, \\ HERBERT CRISTIAN DE SOUZA
}

INSTITUTO MASTER DE ENSINO PRESIDENTE ANTÔNIO CARLOS - IMEPAC

isamcorreia0405@gmail.com

Comunicação Oral

Resumo

Área do Conhecimento: Saúde coletiva e bem-estar

IIntrodução: Os medicamentos genéricos surgiram no Brasil a partir da Lei n. 9.787, em 10 de fevereiro de 1999, alterando a Lei n. 6.360 e instituindo a Política de Medicamentos Genéricos. Dessa forma, considerando a magnitude do mercado farmacêutico, desde sua implantação o comércio desses medicamentos cresceu muito no país. 0 mercado brasileiro de genéricos tem crescido a uma taxa superior ao mercado farmacêutico total. Contudo, mesmo diante essa realidade econômica, existe por parte da população (inclusive da área médica) certa insegurança com relação à utilização de medicamentos genéricos.

Objetivo: Avaliar o conhecimento dos acadêmicos do curso de medicina de uma faculdade na cidade de Araguari (MG) acerca dos medicamentos genéricos.

Metodologia:Trata-se de um estudo quantitativo de corte transversal, com aplicação de questionários em uma Instituição de Ensino Superior (IES), na cidade de Araguari-MG. Participaram da pesquisa 229 alunos do Curso de Medicina da IES de estudo, correspondendo 40,6\% do universo total de alunos do $1^{\text {o }}$ ao $8^{\text {o }}$ período do Curso, com nível de confiança de 95\%. A coleta de dados ocorreu entre os meses de outubro e novembro de 2018 por meio de um questionário desenvolvido pelos autores, o qual abordava relativas aos conhecimentos e crenças dos alunos de Medicina acerca dos medicamentos genéricos. Os dados obtidos nos questionários foram compilados em tabelas no software MS Excel@, sendo posteriormente analisados.

Resultados: A amostra foi composta com significativa predominância de mulheres (73,33\%). Quanto à faixa etária, quase metade dos entrevistados (44,9\%) possuem entre 21 a 23 anos. Com relação às respostas ao questionário constatou-se que 74,2\% sabiam corretamente o conceito de "medicamentos genéricos". Na questão sobre a eficácia desses medicamentos, verificou-se que $85,5 \%$ consideram a sua eficácia igual ao medicamento de referência e, ao comparar valores,96,9\% responderam que o medicamento genérico tem o preço menor que o de referência. Além disso, no que tange à classificação do estudante sobre seu autoconhecimento sobre a temática, verificou-se que 39,3\% e 30,13\% o classificam como médio e pouco, respectivamente.

Conclusões:Com base nos achados deste estudo, ainda que a maior parte dos alunos da IES soube avaliar corretamente conceitos acerca de medicamentos genéricos, percebe-se que ainda há uma parcela significativa que desconhece ou discorda deste conceito, evidenciando a importância de ações de educação sobre este assunto.

PALAVRAS-CHAVE: PERCEPÇÃO; ESTUDANTES DE MEDICINA; MEDICAMENTO GENÉRICO. 


\title{
PERFIL ANTROPOMÉTRICO DE JOGADORES DE CATEGORIAS DE BASE DO MANCHA ESPORTE CLUBE NO PERÍODO PRÉ- TEMPORADA
}

\author{
RAFAEL DA SILVA JORGE, IGOR ALVES GOMES OLIVEIRA, ISAÍAS JOSÉ FERNANDES, HUGO RIBEIRO \\ ZANETTI, DANIELLE FERNANDES ALVES
}

INSTITUTO MASTER DE ENSINO PRESIDENTE ANTÔNIO CARLOS - IMEPAC

rafaeljorge01@gmail.com

Apresentação de Pôster

Resumo

Área do Conhecimento: Saúde coletiva e bem-estar

\begin{abstract}
Introdução: 0 futebol é considerado o esporte mais popular em todo o mundo, sendo praticado praticamente por todos as regiões e devido à sua duração, pode ser considerado um esporte de endurance, portanto a avaliação e a determinação das características antropométricas (estatura, massa corporal e composição corporal) se faz essencial para o sucesso de uma equipe não só durante um jogo, mas durante todo o ano, visto que tais informações podem ser usadas pelo treinador para se obter maior sucesso nas partidas durante toda a temporada. Objetivo: Avaliar o perfil antropométrico de jogadores de futebol das categoria de base da escola Manchester Esporte Clube da cidade de Araguari/MG no ano de 2019. Metodologia: Trata-se de uma pesquisa transversal, descritiva e quantitativa onde foram avaliados atletas das categorias pré-mirim (10 e 11 anos), mirim (12 e 13 anos), infantil (14 e 15 anos) e juvenil (16 e 17 anos) de base do Mancha Esporte Clube da cidade de Araguari/MG no período de pré-temporada. Foram avaliados o índice de massa corporal (IMC) calculado com a fórmula [IMC = massa corporal/estatura2], além dos perímetros de pescoço (PP) - determinada pela circunferência que passa pela proeminência laríngea, tórax (PT) - determinada pela circunferência que passa pela linha dos mamilos, quadril (PQ) determinada pela maior circunferência que passa pelos glúteos, cintura (PC)- determinada pela circunferência que passa pela última costela, e abdômen (PA) - circunferência que passa pela cicatriz umbilical. As mensurações foram realizadas com auxílio de uma fita antropométrica e antes de realização do treino. Por se tratar de um estudo descritivo, os valores estão expressos em média \pm desvio -padrão e separados por categorias. Resultados: Na categoria pré-mirim foi encontrado IMC de 19,2 $\pm 3,3 \mathrm{~kg} / \mathrm{m} 2$, PP de $30,6 \pm 2,3 \mathrm{~cm}$, PT de $72,9 \pm 8,5 \mathrm{~cm}, \mathrm{PQ}$ de $79,8 \pm 10,5 \mathrm{~cm}$, PC de $68,4 \pm 10,3 \mathrm{~cm}$ e PA de $68,9 \pm 7,3 \mathrm{~cm}$. Na categoria mirim o IMC foi 19,4 $\pm 2,8 \mathrm{~kg} / \mathrm{m} 2$, PP de $31,2 \pm 2,1 \mathrm{~cm}$, PT de 73,8 $\pm 7,4 \mathrm{~cm}, \mathrm{PQ}$ de $83,6 \pm 7,4 \mathrm{~cm}, \mathrm{PC}$ de $72,3 \pm 8,2 \mathrm{~cm}$ e PA de $72,8 \pm 9,4 \mathrm{~cm}$. Na categoria infantil o IMC foi de $20 \pm 2,8 \mathrm{~kg} / \mathrm{m} 2$, PP de $33,4 \pm 2,3 \mathrm{~cm}$, PT de $77,8 \pm 10,5 \mathrm{~cm}, \mathrm{PQ}$ de $87,2 \pm 7,2 \mathrm{~cm}$, PC de $74,9 \pm 8,2 \mathrm{~cm}$ e PA de $75,5 \pm 7,8 \mathrm{~cm}$. Na categoria juvenil o IMC foi de $22,1 \pm 2,2 \mathrm{~kg} / \mathrm{m} 2$, PP de $36 \pm 1,6 \mathrm{~cm}$, PT de $85,5 \pm 3,7 \mathrm{~cm}$, PQ de $94,1 \pm 3,9 \mathrm{~cm}$, PC de 77,4 $\pm 5,9 \mathrm{~cm}$ e PA de $79,9 \pm 4,8 \mathrm{~cm}$. Conclusão: 0 futebol é um esporte de alto gasto calórico, e a importância de se mensurar as medidas antropométricas são de suma importância para uma melhor performance. Dessa forma, as medidas antropométricas em jogadores de futebol das categorias de bases devem ser analisadas constantemente afim de verificar a evolução do atleta bem como do desempenho esportivo.
\end{abstract}

PALAVRAS-CHAVE: FUTEBOL, ANTROPOMETRIA, ATLETAS. 


\title{
PERFIL DE MULHERES COM PREDISPOSIÇÃO AO CÂNCER DE COLO DO ÚTERO E CÂNCER DE MAMA.
}

\author{
CICERA SAIANE AMARAL SOUZA, FABIANA SILVA OLIVEIRA, JULLY GONÇALVES BERNARDES, \\ LINDALVA BATISTA MARTINS, MIRALVA OLIVEIRA AGUIAR, ISMELINDA MARIA DINIZ MENDES
}

INSTITUTO MASTER DE ENSINO PRESIDENTE ANTÔNIO CARLOS - IMEPAC

amaralsaiane@gmail.com

Apresentação de Pôster

Resumo

Área do Conhecimento: Saúde coletiva e bem-estar

Introdução: Diante do cotidiano da mulher trabalhadora atualmente e da importância do cuidado com a saúde, idealizou-se a realização desta pesquisa com ênfase no Câncer de Mama e do Colo do Útero. Ambas as doenças, quando detectadas precocemente, tem elevadas chances de cura. 0 rastreamento é o melhor método para obter uma detecção precoce, porem há muitos relatos na literatura da dificuldade ao acesso à saúde, dentre eles dificuldade de acesso a uma unidade básica e/ou falta de acolhimento na unidade; o que sucede a baixos índices no rastreamento.

Objetivo: Conhecer a situação da saúde e perfil das trabalhadoras de uma instituição de ensino superior, e seus conhecimentos sobre o autocuidado, objetivou-se identificar as maiores falhas por elas relatadas; e orientá-las com ações de educação em saúde a partir dos resultados da pesquisa.

Metodologia: Pesquisa realizada por meio de entrevista individual, com aplicação de questionário com questões de múltipla escolha, formulado pelos próprios pesquisadores. 0 público-alvo foi caracterizado por colaboradoras de uma instituição de ensino superior privada, que trabalham no período noturno na cidade de Araguari-MG. Foi utilizada estatística descritiva para apresentação dos dados.

Resultado: Foram respondidos 21 questionários por mulheres que trabalham no período noturno desta instituição; dentro dos resultados encontrados, detectamos pontos positivos e negativos, sendo citados os mais frequentes: Alto índice de predisposição ao Câncer de Mama e Uterino e outros, devido a incidência de casos em familiares conforme foi relatado pelos entrevistados com uma porcentagem total de 68\%; devido ao alto índice de conhecimento sobre realizar o autoexame, foi detectado que apenas 18\% das entrevistas realiza o autoexame da mama periodicamente; sobre informações ginecológicos, 55\% apresentava corrimentos com aspecto esbranquiçado associado ao prurido. Encontrou-se também entre as entrevistadas que $64 \%$ sabem realizar o autoexame de mama tendo o conhecimento da técnica através de um profissional da saúde. Além de $82 \%$ realizar o exame Papanicolaou regularmente. Com tudo $82 \%$ possuem grau de escolaridade em Nível superior.

Conclusão: Apesar da maioria das mulheres desse estudo saberem fazer o procedimento preventivo para o câncer de mama, poucas o realizam. Torna-se necessário maior ênfase em ações educativas que visam a prevenção de doenças e a promoção da saúde. Foi muito importante para o nosso conhecimento, o aprofundamento deste tema, visto que permitiu nos novas descobertas sobre a realidade no ambiente de trabalho das mulheres participantes da pesquisa.

PALAVRAS-CHAVE: SAÚDE DA MULHER. CÂNCER DE MAMA. CÂNCER DO COLO DO ÚTERO. SAÚDE DO TRABALHADOR. 


\title{
PERFIL DE SAÚDE DO TRABALHADOR RURAL NO MUNICÍPIO DE ARAGUARI - MG: ABORDAGEM PRELIMINAR
}

\author{
BRUNA APARECIDA DE OLIVEIRA, LETÍCIA APARECIDA DE PAIVA NAVES MARTINS, ROSANA DE \\ CÁSSIA OLIVEIRA
}

INSTITUTO MASTER DE ENSINO PRESIDENTE ANTÔNIO CARLOS - IMEPAC

brunaoliveiraaparecida20@gmail.com

Comunicação Oral

Resumo

Área do Conhecimento: Saúde coletiva e bem-estar

Introdução: A agricultura passou por significativas mudanças ao longo da história e tornou-se uma atividade moderna de produção comercial com foco na exportação e geração de divisas. 0 excesso de trabalho advindo da alta produtividade e as condições de vida a que os trabalhadores agrícolas estão submetidos os tem tornado vulneráveis a diversas doenças ocupacionais, em especial as intoxicações causadas por agrotóxicos. Objetivo: Conhecer o perfil sociodemográfico e condições de saúde do trabalhador rural da agricultura do município de Araguari-MG.

Metodologia: 0 estudo é de caráter quali-quantitativo de corte transversal e constou de coleta de dados de trabalhadores rurais do município de Araguari que compareceram em uma loja de materiais agropecuários em área urbana, onde rotineiramente adquirem produtos para o trabalho. A obtenção de dados ocorreu por meio de questionário semi-estruturado com questões objetivas e discursivas acerca do perfil sóciodemográfico e de saúde, e ainda, por coleta de informações sobre o peso, altura e pressão arterial, de fevereiro e março de 2019.

Resultados: Dos 34 trabalhadores rurais, 100\% foram do sexo masculino e com média de idade de 55,2 anos. 73,6\% informaram renda de um a cinco salários mínimos, 76,4\% com o ensino fundamental incompleto ou completo e $82 \%$ sem carteira assinada. $71 \%$ não utilizam protetor solar e $36 \%$ informaram ser fumantes ou ex-fumantes. $38 \%$ e $35 \%$ buscam o atendimento médico na Unidade de Pronto Atendimento (UPA) e em clínicas particulares, respectivamente. 59\% faz uso regular de medicação, send o, $75 \%$ para pressão arterial, $15 \%$ para colesterol, $15 \%$ para o coração e $10 \%$ para diabetes, com trabalhadores apresentando até quatro tipos de doenças simultâneas. Quanto ao uso de defensivos agrícolas, 85\% relataram manuseá-los, sendo que apenas 55,9\% utilizam equipamentos de proteção individual (EPIs). Para aqueles que não utilizam os EPIs, 73,4\% informam o incômodo e/ou calor, bem como a falta de costume como motivos para o não uso. Por fim, ao avaliar os parâmetros biológicos, 79\% dos trabalhadores se encontravam com a pressão arterial (PA) acima do desejável, com valores entre os níveis limítrofes e hipertensão no estágio 3, e 53\% com o Índice de Massa Corporal (IMC) entre a classe de sobrepeso e obesidade classe I.

Conclusão: Diante dos dados, considerando o índice socioeconômico e grau de instrução, as dificuldades de deslocamento do campo até a cidade para o acompanhamento de saúde e a sobrecarga de trabalho percebese que os trabalhadores rurais negligenciam os riscos do seu ambiente de trabalho e a própria condição de saúde. Nesse sentido, com vistas a proporcionar uma vida saudável a essa população, reforça-se a importância da implantação e manutenção de políticas preventivas em saúde no Sistema Único de Saúde (SUS), bem como nas esferas reguladoras do mundo do trabalho.

PALAVRAS-CHAVE: PERFIL SOCIODEMOGRÁFICO; SAÚDE; TRABALHADOR RURAL. 


\title{
PERFIL DEMOGRÁFICO E EPIDEMIOLÓGICO DE GESTANTES EM ATENDIMENTO PRÉ-NATAL EM UMA UNIDADE BÁSICA DE SAÚDE DA FAMÍLIA
}

\author{
JOÃo PAULO ASSUNÇÃO BORGES, LEILIANE A. V. DELFINO, LUANA T. ROSSATO, RAÍSSA M. SILVA, \\ JOÃO PAULO ASSUNÇÃO BORGES
}

INSTITUTO MASTER DE ENSINO PRESIDENTE ANTÔNIO CARLOS - IMEPAC

enf_joaopaulo@yahoo.com.br

Apresentação de Pôster

Resumo

Área do Conhecimento: Saúde coletiva e bem-estar

Introdução: A implantação da Estratégia Saúde da Família (ESF) vem melhorando os indicadores epidemiológicos em todas as regiões brasileiras, bem como em Araguari, Minas Gerais (MG). 0 acompanhamento pré-natal é uma das ações desenvolvidas no âmbito da ESF, que possibilita identificar as situações de risco e vulnerabilidade das gestantes, promovendo uma gestação saudável e com desfecho favorável para a mãe e o bebê, contribuindo para a redução da morbimortalidade materno e infantil. Objetivo: Conhecer o perfil demográfico e epidemiológico das gestantes cadastradas e acompanhadas em uma Unidade Básica de Saúde da Família (UBSF). Metodologia: Trata-se de um estudo transversal, descritivo com abordagem quantitativa. Para coleta dos dados foram utilizadas fichas de cadastramento do Sistema de Pré-Natal (SISPRENATAL), pertencentes aos arquivos de uma UBSF do município de Araguari, MG, com a autorização do enfermeiro responsável pela unidade. A análise consistiu de listagem de frequência e medidas de tendência. Resultados: Foram incluídas 11 gestantes acompanhadas na UBSF. A maioria das gestantes apresentou nível de escolaridade equivalente ao ensino médio completo $(60 \%, \mathrm{n}=$ 7). Quanto ao estado civil ou tipo de união, 46\% $(n=5)$ relataram conviver com o companheiro e não ter filhos $(46 \%, n=5)$. Com relação aos dados da gestação atual, 55\% (n=6) delas planejaram a gravidez, 27\% $(n=3)$ não planejaram e 18\% $(n=2)$ não declararam. A maioria realizou a primeira consulta do pré-natal no primeiro trimestre, com idade gestacional entre 6-10 semanas (73\%, n=8). Dentre as gestantes, $18 \%(n=2)$ possuem antecedentes clínicos, prévios à gestação atual, sendo eles Transtorno Mental e Diabetes, enquanto $73 \%(n=9)$ não possuem e $9 \%(n=1)$ não declarou. No que diz respeito ao histórico obstétrico, $36 \%(n=4)$ são multíparas e destas, 75\% (n=3) afirmaram ter realizado parto normal em outras gestações. Conclusão: Observou-se que, de modo geral, as gestantes acompanhadas iniciaram o pré-natal no primeiro trimestre da gestação e não apresentam fatores de risco, podendo resultar em mais saúde e bem-estar para a mãe e para o bebê. Entretanto, a maioria das mulheres relataram não apresentar uma gestação planejada, o que pode representar falhas no planejamento familiar. Assim, espera-se que este estudo contribua com a ESF, de modo a possibilitar a elaboração de planos de acompanhamento com incentivo ao planejamento familiar.

PALAVRAS-CHAVE: ATENÇÃO PRIMÁRIA À SAÚDE; CUIDADO PRÉ-NATAL; GESTAÇÃO. 


\title{
PERFIL DOS FATORES CAUSAIS DE PARALISIA CEREBRAL EM PACIENTES DE INSTITUIÇÃO DE APOIO ÀS PESSOAS COM DEFICIÊNCIA NO MUNICÍPIO DE ARAGUARI-MG
}

\author{
VITOR RODRIGUES COSTA DA SILVA, JOÃO PEDRO SILVA ARAÚJO, ROSANA DE CÁSSIA OLIVEIRA \\ E MIRIAN RIBEIRO MOREIRA CARRIJO
}

INSTITUTO MASTER DE ENSINO PRESIDENTE ANTÔNIO CARLOS - IMEPAC

vitorrodriguescostasilva@hotmail.com

Apresentação de Pôster

Resumo

Área do Conhecimento: Saúde coletiva e bem-estar

\begin{abstract}
Introdução: Paralisia cerebral (PC) é a encefalopatia crônica não progressiva da infância mais conhecida. É uma lesão estática que afeta o sistema nervoso central em fase de maturação resultando em comprometimento neuro-psico-motor, postural e do tônus muscular que influencia sobremaneira o desempenho funcional. Cerca de $30 \%$ dos casos de PC acontecem por causas pré-natais, $60 \%$ dos casos por causas perinatais e $10 \%$ dos casos por causas pós-natais.
\end{abstract}

Objetivo: Avaliar os fatores causais de paralisia cerebral em pacientes de instituição de apoio às pessoas com deficiência no munícipio de Araguari-MG.

Metodologia: 0 projeto constou de um estudo de coorte retrospectivo de prontuários de pacientes com PC da Associação de Pais e Amigos dos Excepcionais (APAE) de Araguari-MG, no mês de abril de 2019. Dados sobre causas genéticas ou ambientais predisponentes à PC foram levantados, com foco na hipóxia/anóxia perinatal. 0 estudo obteve a autorização da instituição mantenedora dos prontuários e seguiu os critérios éticos de confidencialidade dos dados.

Resultados: Dos 30 prontuários informados como sendo de pacientes PC, apenas 16 foram incluídos no presente estudo por apresentarem pelo menos duas evidências claras (causas e/ou sintomas clínicos) que remetessem à Paralisia Cerebral. Dessa forma, a amostra restringiu-se à análise de apenas 16 prontuários. A faixa etária da população analisada está entre 7 e 33 anos, sendo 56,3\% do sexo masculino e 43,7\% do sexo feminino. Quanto aos agentes predisponentes de PC, em 18,8\% prontuários foram encontradas evidências de causas genéticas, em $43,7 \%$ dos prontuários foi observada pelo menos uma causa exclusivamente ambiental (fatores evitáveis) e, em 37,5\%, embora o paciente apresentasse um laudo médico de PC ou apenas um quadro clínico compatível, não foi possível identificar o agente causal. Dos fatores ambientais identificados, a hipóxia/anóxia sofrida no parto foi responsável por 58,3\%, drogas na gestação com $25 \%$ e traumas gestacionais $16,7 \%$. Dentre os prontuários com causas identificadas $(\mathrm{N}=10)$, em $50 \%$ foi possível observar mais de um evento predisponente à PC (genético mais ambiental ou dois fatores ambientais simultâneos).

Conclusão: 0 comprometimento do sistema nervoso central nos pacientes com PC decorre de fatores endógenos e exógenos (ambientais), caracterizando uma constelação etiológica e levando a um consenso de multifatorialidade. Contudo, mesmo considerando essa variabilidade de fatores predisponentes, constata-se que a asfixia sofrida pelo recém-nascido foi o evento causal de PC mais significativo na amostra estudada. Nesse sentido, o acompanhamento eficaz das gestantes durante todo o pré-natal e no momento do parto poderia contribuir para redução dos casos de PC, no município.

PALAVRAS-CHAVE: PARALISIA CEREBRAL; AGENTES CAUSAIS, ANÓXIA/HIPÓXIA PERINATAL. 


\title{
PERFIL DOS POTENCIAIS USUÁRIOS DE UM CONSULTÓRIO FARMACÊUTICO: ANÁLISE DA POPULAÇÃO NA CIDADE DE CATALÃO - GOIÁS
}

\author{
MIRELLE TORQUATO SILVA, FLAVIANE ALVES DA SILVA, KARLA CRISTINA WALTER
}

INSTITUTO MASTER DE ENSINO PRESIDENTE ANTÔNIO CARLOS - IMEPAC

mirelle-torquato@hotmail.com

Apresentação de Pôster

Resumo

Área do Conhecimento: Saúde coletiva e bem-estar

Introdução: A implantação de um consultório farmacêutico é um momento histórico para a profissão, trazendo à tona nesse sentido seu papel para toda a população, não mais sendo um simples indicador de medicamentos, mas também um profissional que auxilia na expectativa de tratamento. Trata-se de um acompanhamento farmacoterapêutico no qual, o farmacêutico durante a consulta deve buscar estabelecer um vínculo de confiança com o paciente, e assim se responsabilizando pela sua condição de saúde e pelo tratamento utilizado.

Objetivo: Diante desse cenário, o presente estudo tem por objetivo analisar o perfil dos potenciais usuários de um consultório farmacêutico, visando acompanhamento farmacoterapêutico, garantindo assim uma melhor atenção farmacêutica e promoção à saúde.

Metodologia: Refere-se a um estudo observacional e descritivo, utilizando procedimentos técnicos de obtenção de dados por meio de um questionário elaborado pelas pesquisadoras. Realizado em uma drogaria, no município de Catalão (GO), adotada devido ao grande fluxo de pessoas. Incluídos neste estudo todos os pacientes, de ambos os sexos, que frequentaram o local no período da coleta de dados e se propuseram a participar e assinar o TCLE (Termo de Consentimento Livre e Esclarecido). E excluídos pacientes menores de 18 anos. Foram efetuadas 145 entrevistas entre os meses de março e abril de 2019. Resultados: A maioria dos entrevistados, 81,38\%, relataram não ter conhecimento sobre consultório farmacêutico. Mas, caso fosse implantado, 93,79\% frequentariam, e 75,86\% estariam dispostos a pagar por este atendimento. Essa aceitação acontece na maioria dos doentes crônicos (96,49\%), e em pacientes que fazem uso rotineiro de medicamentos, porém sem doença crônica, o índice também é alto, com 93,54\% dos casos. Entre as pessoas que não usam medicamentos, 91,22\% tiveram predileção por acompanhamentos farmacoterapêuticos citados, em meio aos mais desejados destacam-se hipertensão e perda de peso com índices iguais (36,03\%). As faixas etárias com 100\% de interesse estão entre 78-87 e 88-97 anos. Dentre os perfis que não se sentem atraídos pelos serviços de um consultório farmacêutico, observamos que, a maior parte $(33,33 \%)$ estão entre a faixa etária de 28 a 37 anos, são do sexo feminino e nível de ensino superior. Seguidos por, com $22,22 \%$, sexo masculino e nível de ensino médio.

Conclusão: Diante dos perfis analisados, apesar da falta de conhecimento da população sobre o que seria um consultório farmacêutico e dos serviços que ele pode oferecer, verifica-se que, caso fosse implantado haveria interesse e confiança por parte da maioria dos usuários. Sob a óptica da adesão, evidenciou-se que, haveria busca aos acompanhamentos farmacoterapêuticos oferecidos, e isso promoveria a fidelização de clientes.

PALAVRAS-CHAVE: ACOMPANHAMENTO FARMACOTERAPÊUTICO; ATENÇÃO FARMACÊUTICA; PROMOÇÃO À SAÚDE. 


\title{
PLANEJAMENTO JURÍDICO E EMPRESARIAL
}

\author{
NÁTALI FERREIRA DE ANDRADE, KAIO HABNNER DE OLIVEIRA AVELINO, WOILLE AGUIAR \\ BARBOSA
}

INSTITUTO MASTER DE ENSINO PRESIDENTE ANTÔNIO CARLOS - IMEPAC

andradenatali490@gmail.com

Apresentação de Pôster

Resumo

Área do Conhecimento: Sustentabilidade e Direitos

O referido estudo se analisará a importância do planejamento jurídico e empresarial dentro do contexto da Teoria Geral de Direito Empresarial, visando analisar o conhecimento de leis normais e regras que regem o âmbito empreendedor.

Dentre os aspectos mais notados nas empresas com planejamento jurídico, está o problema da fragilidade financeira, processos trabalhistas e conflitos por prestação de serviços. De qual maneira o planejamento jurídico e empresarial pode melhorar a negociação, organização, sucesso, transparência, caráter, empreendedorismo e a empresa em si?

O objetivo a ser alcançado visa a capacidade superior da empresa em aproveitar, organizar e trabalhar da forma mais estrutural possível, determinando seus parâmetros, e suas fragilidades, que provavelmente serão encontradas ao longo do negócio empresarial. 0 planejamento jurídico e empresarial, consiste em uma importante tarefa de gestão e administração, que está relacionada com a preparação, organização e estruturação de um determinado objetivo. Aárea do comércio é um dos principais alvos sem planejamentos jurídicos, atuando em grande parte nos comércios de alimentação. A questão mais abrangente se trata da organização das finanças a serem pagas e gastas na empresa, tendo em vista que não há garantias que o dinheiro gasto com a compra dos alimentos será recuperação com a venda do produto oferecido pela empresa, pois existem diversas situações que podem vir a levar a empresa à falência.

Dados mostram que mais da metade das micro e pequenas empresas quebram por falta de um planejamento jurídico e empresarial, tornando a atividade inviável em decorrência de uma demanda judicial ou uma autuação administrativa com aplicação de multa pecuniária de determinadas entidades por violação de diversas normas consumeristas, trabalhistas, tributárias dentre diversas outras.

Uma demanda judicial trará a instabilidade porque a empresa terá que arcar com altos custos de honorários advocatícios, cumulado como a ausência de eficácia na defesa jurídica principalmente pelo motivo de o advogado novo contratado não saber os detalhes internos e de funcionamento da empresa, trazendo uma queda significativa de estratégia de defesa a ser utilizada. Cumulado com esse fator, junta-se o aspecto emocional, uma vez que o microempresário em vez focar sua atenção na atividade exercida, terá que despender muito tempo.

O planejamento empresarial juntamente com o jurídico é a fusão de sucesso e organização do empreendedor, que busca incansavelmente o lucro.

PALAVRAS-CHAVE: EMPREENDEDORISMO; ASSESSORIA; DIREITO EMPRESARIAL; COMERCIO; LUCROS; PLANEJAMENTO; JURÍDICO; FINANCEIRO; TRABALHO. 


\title{
PLANEJAMENTO TRIBUTÁRIO E FINANCEIRO/ FALTA DE CONTROLE DE ENTRADAS E SAÍDAS FISCAIS / FINANCEIRAS E O SEU IMPACTO NO PLANEJAMENTO TRIBUTÁRIO
}

\author{
VIVIANE SENA DUTRA, FABIANO JOSÉ LUCAS DOS SANTOS
}

INSTITUTO MASTER DE ENSINO PRESIDENTE ANTÔNIO CARLOS - IMEPAC

vivianesena.dutra@hotmail.com

Apresentação de Pôster

\section{Resumo}

Área do Conhecimento: Responsabilidade e Negócios

Tendo em vista o desenvolvimento de um trabalho de pesquisa utilizando a Metodologia da Problematização com o Arco de Maguerez, voltado para o tema Planejamento Tributário e Financeiro escolhemos como campo de observação da realidade a empresa Restaurante Temperinho - Araguari /MG, tal escolha se deve pela facilidade de acesso as informações visto que a proprietária é integrante deste grupo.A princípio se estabeleceu uma observação geral de todo o quadro financeiro e fiscal da empresa, a fim de se encontrar um ponto de partida para se obter uma problemática e buscar até onde suas ramificações se encontram inseridas.Após uma análise mais aprofundada foi possível começar a delimitar os gargalos que gerariam a problemática a ser trabalhada ao longo desse trabalho. De imediato foi possível perceber que não há nenhuma forma efetiva de controle financeiro,Ainda no mesmo segmento pode se notar que o controle das receitas é impreciso,Outro ponto latente é a carência de uma gestão fiscal visto que nem todas as mercadorias adquiridas possuem Nota Fiscal, da mesma maneira que as vendas nem sempre são realizadas juntamente com a emissão das NF. Dessa forma, as observações nos conduziram ao delineamento do seguinte problema de investigação: Falta de controle de entradas e saídas fiscais / financeiras e o impacto no planejamento tributário. Ou seja, para a elaboração de um Planejamento Tributário e Financeiro adequado e efetivo não se tem os dados vitais para sua concepção. Sendo assim compreendemos que estudar de maneira mais profunda e analítica sobre este tema e buscar também possíveis soluções para a problemática retratada, contribuirá para o entendimento da importância do planejamento tributário, qual a sua necessidade para o dia a dia empresarial e porque é vital para a sobrevivência da empresa.

Sob o ponto de vista social, irá auxiliar micro empresários, muitas vezes sem acesso a um serviço completo de contabilidade e consultoria, na compreensão, elaboração e execução do planejamento tributário, favorecendo assim na lucratividade da empresa. E ainda possui relevância sustentável já que o presente trabalho busca durante todo o seu processo os seguintes objetivos: obter diferencial competitivo, aumentar a riqueza patrimonial, desenvolver uma cultura de empreendedorismo, buscar adotar uma cultura de práticas sustentáveis; esse último se torna um diferencial para a empresa no mercado de trabalho já que muitos dos consumidores ou a população em geral tem buscado empresas que possuam práticas sustentáveis tendo em vista o cenário global. E pode se dizer que as práticas sustentáveis podem ajudar o grupo a chegar nos objetivos pretendidos para este projeto.

Possibilitando ainda que o grupo possa começar a ter uma nova visão e concepção sobre uma das diversas áreas de atuação da Contabilidade, e talvez se identificar com tal e fazer dela sua área de atuação após sua formação. E possui alta relevância acadêmica.

PALAVRAS-CHAVE: CONTROLADORIA, PLANEJAMENTO FINANCEIRO , PLANEJAMENTO TRIBUTÁRIO, CONTABILIDADE GERENCIAL. 


\title{
PLATAFORMAS VIRTUAIS COMO MEIO DE PACIFICAÇÃO SOCIAL NO ÂMBITO PRÉ-PROCESSUAL NAS RELAÇÕES DE CONSUMO
}

\author{
MATHEUS FIGUEIREDO OLIVEIRA, VANESSA ZERI SESTARI, DONNER RODRIGUES QUEIROZ
}

INSTITUTO MASTER DE ENSINO PRESIDENTE ANTÔNIO CARLOS - IMEPAC

killstyen@hotmail.com

Apresentação de Pôster

Resumo

Área do Conhecimento: Sustentabilidade e Direitos

\begin{abstract}
Introdução: 0 presente estudo trata da evolução dos meios alternativos/integrativos para se alcançar a solução dos conflitos sociais de menor complexidade nas relações de consumo. Dentre as vias de solução de conflitos possíveis serão abordados tópicos pertinentes a internet e as respectivas plataformas virtuais. Objetivo: Demonstrar a possível existência de um meio alternativo/integrativo e que, efetivamente, promova, dentre os princípios processuais constitucionais, dos quais, destaca-se, a duração razoável do processo, a fim de solucionar conflitos sociais vinculados a relações de consumo, bem como demonstrar os impactos e resultados gerados a partir de tal inovação. Dessa forma, buscar-se-á promover a verdadeira cultura da paz na resolução de conflitos sociais.

Metodologia: Adota-se o método dedutivo para desenvolvimento da presente, considerando argumentos gerais que abordam o instituto da autocomposição no ordenamento jurídico brasileiro, até se chegar aos argumentos particulares que se referem às plataformas virtuais, a fim de atingir preceitos positivos relativos à adequada resolução dos conflitos vinculados a relações de consumo.

Resultados: A autocomposição de caráter consumerista possui previsão legal nos artigos $6^{\circ} ; 8^{\circ} ; 139, \mathrm{~V} ; 165$; $166, \S 3^{\circ} ; 334, \S 7^{\circ}$ e $\S 11$, todos do Código de Processo Civil, os quais visam, em suma, aproximar as partes por meio do diálogo e respeito mútuo, objetivando, assim, uma resolução adequada do confl ito. 0 avanço significativo da Rede Mundial de Computadores, também denominada de internet, na conjuntura social, política e econômica da sociedade, como um novo meio de relacionamento entre as pessoas, o que, portanto, em razão da própria evolução da sociedade, deverá se encontrar na pauta da resolução dos conflitos dos indivíduos. A existência do próprio Direito, justifica-se pela sua aplicabilidade às pessoas, tendo em vista se tratar de uma ciência humana. Sendo assim, a própria evolução social impõe novas concepções à ciência jurídica, haja vista que as plataformas virtuais se revelam como verdadeiros instrumentos de pacificação social, sobretudo nas relações consumeiristas, necessitando, no entanto, de se extrair, em essência, das grandes corporações, a cultura do litígio, de forma a se tornar factível a efetivação desses mecanismos.

Conclusão: Em suma, considerando a relevância do referido meio alternativo para se resolver questões controvertidas, é perceptível o potencial que as plataformas virtuais possuem na efetivação de direitos vinculados a relações de consumo, bem como a tentativa de se estabelecer uma nova forma de resolução de conflitos nas relações consumeiristas, ou seja, uma ascensão da efetivação do direito amparado na própria dignidade do indivíduo, pois, trata-se de instrumento integrativo que busca, dentre outras perspectivas, sobretudo, a respectiva sustentabilidade econômica e social.
\end{abstract}

PALAVRAS-CHAVE: RELAÇÃO CONSUMEIRISTA; CONFLITO SOCIAL; SOLUÇÃO; PLATAFORMAS VIRTUAIS. 


\title{
POLUIÇĀO ATMOSFÉRICA E DOENÇAS RESPIRATÓRIAS: UMA BREVE REVISĀO
}

\author{
MARIA PAULA RUBACK BRINGEL CHAVES, CLÁUDIO AFONSO CAETANO PEREIRA PEIXOTO, \\ MARCOS PAULO LEAL FERREIRA, NATHALIA ANTUNES SILVA, VERÔNICA LEITE MORAIS, DR. \\ ALEXANDRE GONÇALVES
}

INSTITUTO MASTER DE ENSINO PRESIDENTE ANTÔNIO CARLOS - IMEPAC

mpaularuback@gmail.com

Apresentação de Pôster

Resumo

Área do Conhecimento: Saúde coletiva e bem-estar

Introdução: A poluição do ar, ao longo dos anos, tem afetado a saúde da população de inúmeras formas. Análises e pesquisas apontam como principal prejuízo à saúde as doenças respiratórias, podendo ou não estar associadas a doenças cardiovasculares, tanto no âmbito nacional quanto mundial. Dentre as principais fontes emissoras de poluentes, os automóveis e as indústrias ganham destaque principalmente na realidade nacional, sendo fundamental para tal descontrole ambiental. Além destes, outros fatores também são potenciais agravantes do problema, como a sazonalidade, os materiais particulados (MP) e a queima da cana-de-açúcar.

Objetivo: Analisar, através de uma revisão de literatura, a relação da poluição ambiental com a incidência de doenças respiratórias na população.

Metodologia: Foi realizado uma revisão de literatura na base de dados Scielo buscando analisar a correlação entre a poluição atmosférica e doenças respiratórias. Foram encontrados 107 artigos utilizando os descritores "Doenças respiratórias" e "Poluição", sem realizar a delimitação de data. A partir desse resultado, foi delimitado um período de publicação entre 2015 e 2019, resultando em 17 documentos. Desses, foram excluídos os artigos que apareceram diversas vezes. Finalmente, a busca resultou em 11 artigos.

Resultados: Demonstrou-se que a ocorrência de doenças respiratórias ocorre majoritariamente e fortemente em grupos considerados vulneráveis que incluem crianças menores de cinco anos, idosos e portadores de doenças respiratórias pré-existentes. Ademais, constatou-se que para ocorrer um efeito deletério à saúde por meio da poluição -seja por queima prévia de cana de açúcar ou emissão de poluentes pelos automóveis- é necessário elementos como um material particulado. Vale ressaltar que a Organização Mundial da Saúde estabelece níveis máximos de tolerâncias de MP, entretanto as doenças aparecem mesmo quando sua concentração atmosférica situa-se abaixo desses níveis. Além disso, a sazonalidade é um outro fator que facilita o desenvolvimento não só de doenças respiratórias, como também cardiovasculares.

Conclusão: A relação entre poluição atmosférica e a incidência de doenças respiratórias foram nitidamente observados a partir dos estudos. Os poluentes dos automóveis e das indústrias e os materiais particulad os têm grande relevância no aumento dessa relação. Associado a esses fatores a sazonalidade torna-se fator agravante de doenças. Portanto, a poluição do ar está relacionada, não somente a problemas na saúde humana, como também na perda de qualidade de vida, tendo em vista o exacerbado aumento de internações e mortalidade, principalmente, em regiões metropolitanas. Sendo necessário, por fim, estabelecer políticas para conter esse impacto na saúde da população brasileira.

PALAVRAS-CHAVE: DOENÇAS RESPIRATÓRIAS; POLUIÇÃO; 


\title{
PREVALÊNCIA DA AUTOMEDICAÇÃO E AUTOSSUPLEMENTAÇÃO DE ESTUDANTES DA ÁREA DA SAÚDE EM UM CENTRO UNIVERSITÁRIO EM ARAGUARI-MG
}

\author{
DIOVANA LUCIANO DOS SANTOS, TÁSSIO AUGUSTO DA SILVA FRANCISCO, MARIA CLÁUDIA \\ CÂNDIDA RODRIGUES, LUANA THOMAZETTO ROSSATO
}

INSTITUTO MASTER DE ENSINO PRESIDENTE ANTÔNIO CARLOS - IMEPAC

diovanaluciano@hotmail.com

Apresentação de Pôster

Resumo

Área do Conhecimento: Saúde coletiva e bem-estar

Introdução: A automedicação e a autossuplementação apresentam aspectos relevantes dentro do contexto de saúde, sendo que as razões que motivam as pessoas a realizarem essas práticas são muitas, desde alívio de sintomas até a intensa oferta do mercado farmacêutico com investimentos em publicidade. As consequências de caráter positivo são provenientes da aplicação responsável das mesmas, contudo, quando praticadas de modo inadequado, geram riscos como reações adversas, atraso no diagnóstico, até consequências mais graves, como intoxicações e eventuais óbitos, destacando-se assim a problematização no âmbito de saúde vigente por consequência dessas ações.

Objetivo: Verificar a prevalência e as características das práticas de automedicação e autossuplementação em acadêmicos de uma Instituição de Ensino Superior de Araguari - MG.

Metodologia: Trata-se de um estudo observacional e descritivo, de corte transversal com aplicação prática em campo, do tipo quantitativo. Os dados foram coletados por meio de um questionário semiestruturado, de caráter anônimo e de autopreenchimento, aplicado em 311 discentes acima de 18 anos, que aceitaram participar da pesquisa após a assinatura do Termo de Consentimento Livre e Esclarecido. Os alunos foram provenientes dos cursos de farmácia, enfermagem, psicologia, nutrição e educação física.

Resultados: Constatou-se que a maioria dos participantes era do sexo feminino $(72,3 \%, \mathrm{n}=225)$ e a média de idade foi de 24,15 \pm 7,99 anos. A prevalência da automedicação e autossuplementação foi de $80,7 \%$ $(n=251)$, com padrão semelhante entre os cursos e no decorrer dos períodos ( $p>0,05)$. Os principais fatores que motivaram os alunos a usarem medicamentos e suplementos sem prescrição foram: facilidade de acesso $(57,2 \%, n=178)$; orientação provinda de fontes de informação informal, como indicação de terceiros $(53,3 \%, n=166)$; pesquisas na internet $(35,3 \%, n=110)$ e reutilização de receitas antigas $(32,7 \%, n=102)$. As principais justificativas para a realização de tais práticas foram o alívio da dor $(76,8 \%, \mathrm{n}=239)$, a prevenção de doenças $(25,0 \%, n=78)$ e por finalidade estética $(17,6 \%, n=55)$. Os medicamentos de uso mais prevalente foram os analgésicos $(85,2 \%, n=265)$, antitérmicos $(55,3 \%, n=172)$, anti-inflamatórios $(54,9 \%$, $\mathrm{n}=171)$ e, dentre as classes de suplementos, a prevalência foi dos suplementos vitamínicos $(28,9 \%, n=90)$, proteicos $(19,9 \%, n=62)$ e esportivos $(20,2 \%, n=63)$, sendo que dentro do grupo deste último, os mais consumidos foram whey protein $(31,5 \%, n=98)$, creatina $(19,9 \%, n=62)$ e multivitamínicos $(18,0 \%, n=56)$. Conclusão: Os dados obtidos mostram a necessidade de educar os universitários quanto a realização das práticas de automedicação e autossuplementação responsáveis, enfatizando seus possíveis riscos, visando garantir a formação de profissionais capacitados a esclarecer à população quanto ao uso racional de medicamentos e suplementos.

PALAVRAS-CHAVE: AUTOMEDICAÇÃO; AUTOSSUPLEMENTAÇÃO; ACADÊMICOS DA ÁREA SAÚDE. 


\title{
PREVALÊNCIA DA SÍNDROME DE BURNOUT EM UMA UNIDADE BÁSICA DE SAÚDE DA FAMÍLIA NO MUNICÍPIO DE ARAGUARI - MG.
}

\author{
ALESSANDRA JACÓ YAMAMOTO, BÁRBARA MOURA MEDEIROS, BÁRBARA OLIVEIRA RODRIGUES \\ DO NASCIMENTO, CAMILA RIBEIRO TIBILETTI, KAROLLYNE FRANCISCO PRADO, ANICÉSIA CECÍLIA \\ GOTARDI LUDOVINO
}

INSTITUTO MASTER DE ENSINO PRESIDENTE ANTÔNIO CARLOS - IMEPAC

leleyamamoto@hotmail.com

Apresentação de Pôster

Resumo

Área do Conhecimento: Saúde coletiva e bem-estar

Introdução e Objetivos: A Síndrome de Burnout (SB) foi descrita pela primeira vez como staff burnout por Freudenberger, em 1974. No entanto, o conceito mais utilizado atualmente é o de Maslach e Goldberg, que define como um conjunto de sintomas caracterizados por exaustão emocional, despersonalização e reduzida realização profissional em decorrência de uma má adaptação do indivíduo a um trabalho prolongado, altamente estressante e com grande carga tensional. Diante disso, o presente trabalho teve como objetivo identificar a ocorrência da Síndrome de Burnout nos profissionais de saúde em uma Unidade Básica de Saúde da Família em Araguari-MG. Materiais e Métodos: Trata-se de um estudo de corte Transversal, com abordagem quantitativa de pesquisa exploratória com levantamento de dados por meio da aplicação da Escala de Estresse no Trabalho (EET). A amostra foi composta por 25 profissionais da equipe de saúde de uma UBSF de Araguari-MG, sendo 23 mulheres e 2 homens. Todos os participantes assinaram o Termo de Consentimento Livre e Esclarecido, de acordo com a Resolução no 466/2012, da Comissão Nacional de Saúde. Após a coleta, foi realizada uma análise descritiva dos dados através da tabulação simples das variáveis do estudo, com auxílio da ferramenta Microsoft Excel. Resultados e Discussão: Após a aplicação da EET 17 participantes apresentaram score acima de 2,5 demonstrando que possuem estresse nas atividades exercidas, correspondendo a 68\% da amostra e, 8 participantes (32\%) não demonstraram indicativos de estresse. Os dados deste trabalho demostram uma prevalência elevada da SB nos profissionais da saúde, já Silva et al. (2015) encontraram uma prevalência baixa (6,7\% a 10,8\%) em seu estudo, porém, apontaram que 54,1\% apresentou um risco elevado e moderado para desenvolver essa síndrome, demonstrando uma alta probabilidade de ocorrência da SB e a necessidade da implantação de medidas preventivas. Considerações Finais: Diante disso, destacamos que o mais importante é a prevenção, e para isso são necessárias algumas medidas, como: proporcionar condições de trabalho atrativas e gratificantes; implementar programas de socialização visando melhorar o clima organizacional; investir no aperfeiçoamento profissional e na educação permanente; garantir papel ativo e participação nas decisões laborais, dar suporte social às equipes. Diante disso, ao final do trabalho a administração da UBSF recebeu os resultados e orientações para reduzir o estresse dos funcionários.

PALAVRAS-CHAVE: PROFISSIONAIS DE SAÚDE, SÍNDROME DE BURNOUT, UNIDADE BÁSICA DE SAÚDE. 


\title{
PREVALÊNCIA DE ANSIEDADE DURANTE A RELIZAÇÃO DE AVALIAÇÕES ACADÊMICAS EM ESTUDANTES DO CURSO DE MEDICINA EM UM CENTRO UNIVERSITÁRIO DE ARAGUARI-MG
}

\author{
DAYME FREITAS GUIMARÃES, MARIA CLAUDIA CANDIDA RODRIGUES
}

INSTITUTO MASTER DE ENSINO PRESIDENTE ANTÔNIO CARLOS - IMEPAC

dayme@hotmail.com

Apresentação de Pôster

Resumo

Área do Conhecimento: Saúde coletiva e bem-estar

\begin{abstract}
Introdução: 0 estudante de medicina, ao ingressar na Faculdade, acaba mudando de forma bastante radical o seu estilo de vida, com perdas na sua vida pessoal, nas suas relações sociais e no seu lazer, com o intuito de adaptar-se ao novo contexto de ensino-aprendizagem da vida universitária. A formação médica é um período sabidamente difícil, com elevados níveis de estresse e ansiedade provocados, dentre outros fatores, pelas avaliações educacionais. Tal fato impacta negativamente o desempenho acadêmico, o cuidado com $o$ paciente e a qualidade de vida do estudante.
\end{abstract}

Objetivo: Frente ao exposto, o objetivo deste trabalho foi avaliar o grau de ansiedade dos estudantes de medicina, no período que antecede a realização de avaliações educacionais teóricas e práticas.

Metodologia: Trata-se de um estudo transversal referente a uma população constituída de estudantes matriculados no curso médico de uma faculdade localizada em Araguari-MG. Os dados foram coletados utilizando-se o Inventário de Ansiedade Traço-Estado (IDATE), instrumento validado de autopreenchimento aplicado aos estudantes maiores de 18 anos que aceitaram participar da pesquisa após a assinatura do Termo de Consentimento Livre e Esclarecido (TCLE). Para comparação dos dados, o instrumento foi aplicado na primeira semana de aulas do segundo semestre do ano de 2018 e imediatamente antes de uma prova prática do último ciclo do mesmo semestre.

Resultados: Os questionários foram aplicados para 52 alunos no início do semestre e para 62 alunos antes da prova. 0 somatório do IDATE variou entre 31 e 74, com média de 49,49. Houve diferença significativa entre o somatório do IDATE no início do semestre e antes da prova. No início do semestre, o somatório do IDATE variou entre 32 e 65 , com média de 46,38. Sendo que para os homens, o somatório variou entre 35 e 65 , com média de 44,80. Já para as mulheres, o somatório variou entre 32 e 63 , com média de 46,78. No momento antes da prova, o somatório do IDATE variou entre 31 e 74, com média de 52,10. Sendo que para os homens, o somatório variou entre 31 e 74, com média de 48,53. Já para as mulheres, o somatório variou entre 32 e 73, com média de 53,44. Mostrou-se um aumento de 5,72 na média do início do semestre para o momento antes da prova. Nos dois momentos da pesquisa as mulheres mostraram escore maior que os homens. A pesquisa mostra que a média dos alunos estudados estão acima da média populacional, que é de 40 , sendo que escore maior que 42 tende a ansiedade e menor que 38 tende a depressão.

Conclusão: As diferenças de gênero quanto à ansiedade-traço coincidem com o que se verifica na literatura, a qual indica que as mulheres apresentam maior ansiedade do que os homens, o que sugere a pertinência da presente pesquisa. Assim, conhecer como a ansiedade se expressa em relação a diferentes variáveis é importante para que se criem estratégias de intervenção eficazes.

PALAVRAS-CHAVE: DEPRESSÃO; ANSIEDADE; ESTUDANTES DE MEDICINA; 


\title{
PREVALÊNCIA DE DIABETES EM IDOSOS RESIDENTES EM INSTITUIÇÕES DE LONGA PERMANÊNCIA LOCALIZADAS EM ARAGUARI-MG
}

\author{
ALESSANDRA JACÓ YAMAMOTO, ALEXANDRE VIDICA MARINHO, BÁRBARA MOURA MEDEIROS, \\ MELISSA MARIENE DOS REIS
}

INSTITUTO MASTER DE ENSINO PRESIDENTE ANTÔNIO CARLOS - IMEPAC

leleyamamoto@hotmail.com

Apresentação de Pôster

Resumo

Área do Conhecimento: Saúde coletiva e bem-estar

Introdução: Entre as doenças crônicas não transmissíveis, o diabetes mellitus se destaca como importante causa de morbidade e mortalidade, especialmente entre os idosos. Aos 75 anos, aproximadamente $20 \%$ da população já sofre da doença, de acordo com a literatura. 0 acelerado ritmo do processo de envelhecimento da população, a maior tendência ao sedentarismo e a inadequados hábitos alimentares, além de outras mudanças sócio comportamentais, contribuem para os crescentes níveis de incidência e prevalência do diabetes, bem como de mortalidade pela doença. A prevalência do diabetes vem crescendo mundialmente, configurando-se atualmente como uma epidemia resultante, em grande parte, do envelhecimento da população. As hospitalizações atribuíveis ao diabetes mellitus representam 9\% dos gastos hospitalares do Sistema Único da Saúde.

Objetivo: Frente ao exposto, o objetivo deste estudo foi determinar a prevalência de diabetes em dois asilos localizados na cidade de Araguari-MG, e correlacionar a presença da doença com o sexo do paciente.

Metodologia: Estudo transversal que incluiu 111 idosos (60 anos ou mais), institucionalizados, residentes nos asilos Cristo Rei e São Vicente de Paula, na cidade de Araguari, MG, no ano de 2015. Os dados deste estudo foram colhidos através da análise dos prontuários disponíveis nas instituições referentes ao quadro de saúde de cada paciente, e posteriormente comparados à literatura disponível sobre o assunto. Todos os prontuários disponíveis foram utilizados na pesquisa. 0 teste do qui-quadrado foi utilizado ao final do trabalho, para verificar possível correlação entre sexo e prevalência de diabetes.

Resultados: A média de idade dos idosos que participaram deste estudo foi de 72,1 anos, sendo que 63 (56\%) eram mulheres, e 48 (43\%) homens. A prevalência de diabetes foi de 21 casos (18\%). Dentre os casos da doença encontrados, 6 (30\%) ocorreram em homens e 15 (71\%) em mulheres. 0 teste do quiquadrado indicou que não há correlação entre sexo e prevalência de diabetes nos idosos do estudo em questão.

Conclusão: 0 aumento do contingente de idosos e a maior vulnerabilidade desta população em apresentar doenças crônicas impõem a necessidade de rediscutir a atenção à saúde, visando implementar ações promocionais e, sobretudo, a orientação de idosos e seus cuidadores, na perspectiva da manutenção da autonomia e independência, assim como reforçar o conteúdo de geriatria e gerontologia nas instituições de ensino.

PALAVRAS-CHAVE: DIABETES; IDOSOS; ENVELHECIMENTO. 


\title{
PRISÃO EM SEGUNDA INSTÂNCIA EM OPOSIÇÃO À PRESUNÇÃO DE INOCÊNCIA
}

\author{
MICHELE SANTOS OLIVEIRA CURCINO, MARIA LUIZA APARECIDA DA CUNHA, RODRIGO \\ GUILHERME TOMAZ
}

INSTITUTO MASTER DE ENSINO PRESIDENTE ANTÔNIO CARLOS - IMEPAC

michelesantoli@yahoo.com.br

Apresentação de Pôster

Resumo

Área do Conhecimento: Sustentabilidade e Direitos

INTRODUÇÃO: 0 presente resumo visa debater o tema prisão em segunda instância em oposição à presunção de inocência. Correntes contrárias e a favor da prisão antes do trânsito em julgado de sentença penal condenatória divergem em argumentos válidos que serão expostos no referido resumo.

OBJETIVO: Temos a demonstração de argumentos e fundamentações para a legalidade ou não de prisão a partir da condenação em segunda instância. Duas fortes correntes têm sido debatidas em torno do referido tema e, contudo, causando uma sensação de insegurança jurídica. É certo que o Direito deve acompanhar as constantes evoluções sociais, mas para que a sociedade possa ter o sentimento de segurança jurídica, o texto da Carta Magna que rege nosso ordenamento não deve ser interpretado de forma a ferir as garantias de direitos individuais que são cláusula pétrea tamanha sua importância.

METODOLOGIA: Para a realização deste resumo que se apresenta utilizou-se o método dialético pelo confronto de idéias onde essas contradições se transcendem dando origem a novas contradições que passam a requerer solução.

RESULTADOS: A doutrina que se posiciona com entendimento favorável à prisão em segunda instância se baseia na tese de que esta não fere a Constituição. A Carta Magna diz em seu art. 5丷, LVII: "ninguém será considerado culpado até o trânsito em julgado da sentença penal condenatória", portanto, o texto constitucional não fala sobre prisão ou mesmo cumprimento de pena, fala somente da culpa. Se o entendimento dos legisladores constituintes fosse impedir a prisão antes do trânsito em julgado, a CF que tanto se faz uso do vocábulo prisão não teria grafado o inciso LVII com palavra "culpado" que logicamente tem significado diferente de preso. Em posicionamentos contrários a este tema, inúmeros juristas se baseiam também no texto da CF, no princípio da presunção de inocência cravado no próprio inciso LVII do art. 5ํo que diz a tão multi-interpretada frase "ninguém será considerado culpado até o trânsito em julgado da sentença penal condenatório". Tal princípio garante todos os meios de defesa cabíveis ao acusado e todas as possibilidades de recurso até que venha a sentença definitiva, assim que ninguém seja declarado culpado até que a sentença transite em julgado.

CONCLUSÃO: Concluímos que o posicionamento contrário à prisão após o julgamento em segunda instância está de acordo com a Carta Magna brasileira e respeita os direitos humanos não só em âmbito nacional como internacional. Em respeito à interpretação correta do texto constitucional o indivíduo presume-se inocente até que todos os seus recursos de defesa tenham se esgotado e, portanto, não há que se falar em cumprimento antecipado de pena, salvo nos casos concretos em que se faz necessária a prisão em caráter preventivo-cautelar.

PALAVRAS-CHAVE: PRISÃO EM SEGUNDA INSTÂNCIA; LEGALIDADE; PRESUNÇÃO DE INOCÊNCIA. 


\title{
PROBLEMAS NAS DOCUMENTAÇÕES CONTÁBEIS
}

\author{
VITORIA STEFFANI MACENA FERNANDES DE SOUZA, ANA MARIA DE FREITAS, CARLOS EDUARDO, \\ CINDY MORREIRA, LORRAYNE FERREIRA, WELLIGTON EDER, FABIANO JOSE LUCAS
}

INSTITUTO MASTER DE ENSINO PRESIDENTE ANTÔNIO CARLOS - IMEPAC

steffanysouza483@gmail.com

Apresentação de Pôster

Resumo

Área do Conhecimento: Responsabilidade e Negócios

Levando em consideração o trabalho de pesquisa utilizando a metodologia da problematização do arco de Maguerez, que e baseada na resolução de problemas tratados em grande grupo, não voltada para o "saber", mas para o "saber fazer", partindo da observação das necessidades do real para uma discussão tendo em consideração, não os conhecimentos, mas a experiência de cada um, para se chegar à criação da solução do problema naquela realidade observada. Fomos atraídos pelo campo de visão da realidade referente à empresa "MINERAÇÃO MINAS LTDA". Tal escolha foi motivada pela facilidade ao acesso que um dos integrantes do grupo possui, por trabalhar no departamento fiscal da empresa.

Após termos autorização para realização do trabalho e estipulado o tempo do projeto, foram feitas pesquisas, investigações, levantamentos e observações para recolhimento das informações necessárias. Antecipadamente, arquitetamos um roteiro com o objetivo de visualizar como os administradores, funcionários, sócios, e os tributos estão se comportando na empresa.

No campo investigado, notamos que há uma grande falta de fluxo organizacional na empresa o que está provocando problemas nas documentações contábeis que impacta diretamente no de controle de estoque e no controle dos custos. Percebemos também que há uma confusão patrimonial dos sócios e a entidade. Em vista das observações obtidas fomos conduzidos ao delineamento do seguinte problema de investigação: a falta de documentações contábil para o planejamento estratégico da empresa "MINERAÇÃO MINAS LTDA".

Abrangemos que o aprofundamento do estudo com o intuito de buscar possíveis soluções para o problema em questão, contribuirá para um melhor funcionamento das atividades e uma melhor aplicação das táticas de mercado. Isto irá colaborar para que empresas de grandes, médias e pequeno porte, percebam que o planejamento deve ser elaborado tendo em vista o objetivo almejado levando em consideração o prazo, a amplitude, o risco as atividades e a flexibilidade, além de como diminuir os tributos de forma legal ao máximo. Assim, temos que isso desencadeará empresas mais informadas e profissionais mais bem qualificados no mercado de trabalho promovendo melhoras quantitativas no mercado econômico e sustentabilidade para os mesmos. E, finalmente para nossa formação levando conosco a experiência de trabalhar com este determinado assunto.

$\mathrm{Na}$ realização do projeto, buscamos identificar os possíveis fatores imediatos pertinentes ao problema em questão.

PALAVRAS-CHAVE: DOCUMENTAÇÃO CONTÁBIL; PLANEJAMENTO ESTRATÉGICO; TRIBUTOS. 


\title{
PRODUÇÃO DE BIOGÁS A PARTIR DE BAGAÇO DE CANA-DE- AÇÚCAR APÓS PRÉ-TRATAMENTO COM ÁCIDO CÍTRICO DILUIDO
}

\author{
MICHELLE GARCIA GOMES, DANIEL PASQUINI
}

UNIVERSIDADE FEDERAL DE UBERLÂNDIA

michelle19gg@gmail.com

Comunicação Oral

Resumo

Área do Conhecimento: Responsabilidade, Tecnologia e Ciência

Introdução: Resíduos lignocelulósicos podem ser usados como biomassa para geração de energia, tal como biogás, que serve como uma alternativa viável às fontes de energia tradicionais, fornecendo formas energéticas limpas e sustentáveis. Porém, um pré-tratamento (PT) deve ser aplicado ao resíduo para solubilização dos açúcares e/ou para remoção da lignina. A celulose em decorrência da sua estrutura não pode ser facilmente hidrolisada, sendo necessária a ação de meios ácidos, ou até mesmo o uso de enzimas específicas. Celulose e hemiceluloses, quando sofrem hidrólises, produzem exclusivamente açúcares fermentescíveis que podem ser usados para produção anaeróbia de biogás.

Objetivo: O objetivo deste trabalho foi avaliar o potencial do PT do bagaço de cana-de-açúcar (BC) comácido cítrico diluído, sob pressão atmosférica e avaliar a possibilidade de aplicação do BC pré-tratado para produção de biogás.

Metodologia: Neste trabalho, avaliou-se o PT (pré-hidrólise com ácido cítrico diluído) do resíduo do BC, em sistema de refluxo (pressão atmosférica e temperatura fixa), utilizando-se o planejamento experimental com variáveis operacionais como tempo $(\mathrm{t}$, min) e concentração de ácido cítrico (C, \%). 0 tempo de reação variou-se de 17,57 a 102,43 min e a concentração da solução de ácido cítrico foi de 0,35 a 11,65\% (m/m). Foram feitas as caracterizações dos teores de celulose, de hemiceluloses e de lignina. Em complemento, microscopia eletrônica de varredura (MEV) foi utilizada para examinar as mudanças na superfície de BC pré-tratado. Utilizou-se da fração liquida, após o PT, para alimentar reatores anaeróbios para produção de biogás.

Resultados: os PT físico-químicos mostram que as variáveis em estudo não tiveram relação diretamente em relação ao teor de lignina, celulose e hemiceluloses. Na literatura traz a importância do emprego de diferentes temperaturas para eficiência do PT. No entanto, a estrutura, comprovada pelo MEV, foi alterada, melhorando a acessibilidade da celulose. A amostra (variáveis de 6,0\% e 102,43 min) mostrou o menor teor de lignina $(22,6 \%)$ e descamações das fibras (após o PT), sendo utilizada para a produção de biogás, atingindo-se alto potencial de 55,14 NmL (média máxima).

Conclusão: É importante buscar tecnologias para melhor reaproveitar o BC como resíduo ou fonte de energia, com baixo custo, já que é um subproduto das usinas de açúcar e álcool, gerado em grande quantidade no Brasil. Além disso, o ácido cítrico utilizado é um dos produtos de fermentação mais produzidos no mundo e possui características como baixa toxicidade, ser facilmente biodegradável e baixos preços. Contudo, o estudo possibilitou a verificação da ação de um ácido, desde o PT do BC até a produção de biogás, para um processo econômico (em virtude do consumo de energia e de insumos), bem como da produtividade global do processo e ambientalmente viável. PALAVRAS-CHAVE: BAGAÇO-DE-AÇÚCAR; PRÉ-TRATAMENTO, ÁCIDO CÍTRICO, BIOGÁS. 


\title{
PRODUÇÃO DE PISO DE CONCRETO COM ADIÇÃO DE BORRACHA
}

\author{
MARCIO CAIXETA TEIXEIRA, NAIARA MARTINS FARIAS, THATIANE NOGUEIRA ROSA,
}

INSTITUTO MASTER DE ENSINO PRESIDENTE ANTÔNIO CARLOS - IMEPAC

eng.caixeta@icloud.com

Apresentação de Pôster

Resumo

Área do Conhecimento: Responsabilidade, Tecnologia e Ciência

Introdução: A minimização dos impactos ambientais tem colocado o mundo a se preocupar com a destinação final e reutilização ambientalmente corretas, adequadas e seguras de varias matérias-primas. Assim, as pesquisas envolvendo o reaproveitamento da borracha intensificaram-se e com essa constatação procurou-se nesse trabalho, uma alternativa para a construção civil que fosse viável econômica e tecnicamente e conseqüentemente implementada em curto espaço de tempo.

Objetivo: O objetivo deste trabalho foi desenvolver um traço de concreto com adição de borracha de pneus em tiras, e apontar possíveis usos.

Metodologia: Trata-se de uma pesquisa com finalidade de estudo de traço de concreto com substituição do agregado miúdo por borracha de pneus em tiras. Utilizou-se concreto de Cimento Portland com um traço denominado padrão, empírico, de onde foram dosados três traços de concreto, em três proporções em relação ao agregado miúdo, 50\%, 25\% e 12,5\%. Optou-se pela substituição do agregado miúdo por borracha de pneus em tiras como forma de dar destino aos resíduos oriundos dos pneus. Realizou-se os ensaios de abatimento de tronco de cone segundo a NBR NM 67:1998, e o ensaio a compressão de corpos cilíndricos aos 7, 14 e 28 dias de cura, conforme NBR 5738:2015 e NBR 5739:2018. Os materiais utilizados foram Cimento Portland CPII E 32, areia lavada média, brita no 1, água, Borracha em tiras, livre de pedaços grandes que eventualmente encontram-se no material. Adotamos o traço: $25 \mathrm{~kg}$ Cimento, 35kg agregado miúdo, $50 \mathrm{~kg}$ agregado graúdo, $101 \mathrm{~kg}$ de água.

Resultados: À medida que se adiciona borracha a trabalhabilidade diminui, portanto, há uma relação direta entre o volume de borracha, a quantidade de água e a trabalhabilidade. Em relação à resistência à compressão percebe-se uma queda considerável na medida em que se acrescenta borracha por apresentar menor resistência à compressão que a areia. Com a busca da trabalhabilidade sem a utilização de aditivos, altera-se a relação água/cimento e também uma reduz-se a resistência à compressão. Ao se retirar o corpo de prova da prensa, notou-se que, mesmo rompido, o corpo de prova tendeu a retornar à posição original sem resistência a compressão, porém ainda com todo o volume preso entre si.

Conclusão: Após os ensaios realizados, percebe-se que há uma diminuição considerável da resistência ao se substituir areia por outro material com menor resistência e com alto grau de deformação. Porém, o fato do corpo de prova não ter se desfeito após o rompimento, leva a supor uma característica de absorção de impacto. É necessário diminuir a extração de produtos minerais e de alguma forma utilizar o resíduo derivado de produtos de forma a diminuir os impactos ambientais, e pelos resultados apresentados fica a proposta de utilizá-lo em obras sem finalidade estrutural.

PALAVRAS-CHAVE: ECOLÓGICO, PNEU, RESÍDUOS. 


\title{
PROJETO INTEGRADOR: “ESPORTE E DEFICIÊNCIA INFANTO- JUVENIL: UMA ABORDAGEM INTERVENCIONAL DA DANÇA E LAZER"
}

\author{
DENER BELKLIN DA SILVA ALVES, GLAUCIA CRISTINA CARVALHO GOMES, HUGO RIBEIRO ZANETTI, \\ JAQUELINE PONTES BATISTA
}

INSTITUTO MASTER DE ENSINO PRESIDENTE ANTÔNIO CARLOS - IMEPAC

alunoaluno06@gmail.com

Comunicação Oral

Resumo

Área do Conhecimento: Educação e Inclusão

Introdução: Associação de Pais e Amigos dos Excepcionais (APAE) é uma instituição de ensino especial destinado a crianças, adolescente e adultos com deficiência intelectual ou física. Para profissionais da área da saúde é de suma importância saber lidar com diferentes deficiências e níveis, utilizando nossos conhecimentos. Objetivo: desenvolver e integrar os alunos da APAE com atividades lúdicas e esportivas como futebol e atividades de lazer como dança, buscando melhoras no desenvolvimento social e motor dessas crianças e adolescentes através da música e observar o estímulo mútuo da interação entre os alunos para análise das limitações dentro de cada deficiência. Metodologia: 0 processo de fundamentação teórica e vivência que antecederam a intervenção como modo preparatório para execução do evento ocorreu nas aulas de Projeto Integrador IV. A intervenção foi executada com uma turma de 50 crianças, adolescentes e adultos com deficiência, no centro de ensino especial APAE, no município de Araguari (MG) no período noturno. 0 evento foi realizado pelos alunos do $3^{\circ}$ e $4^{\circ}$ período do curso de Educação Física do Instituto Máster De Ensino Presidente Antônio Carlos (IMEPAC - Araguari). Tivemos o consentimento dos responsáveis pela APAE por se tratar de um grupo considerado vulnerável. Começamos as atividades motoras com jogos e brincadeiras preparatórias para a brincadeira "queimada", minicampeonato de futsal e oficina de habilidades motoras finas. Foi ofertado um lanche aos participantes do evento e logo após observado a interação social do grupo em análise com um grande baile. Relato da experiência: Ao analisar e vivenciar as dificuldades de pessoas com deficiências físicas e intelectuais notou-se a importância da acessibilidade e como nossa sociedade está distante da equidade no meio social. Tivemos todo suporte acadêmico para realizar atividades com grupo de deficientes intelectuais e alguns com limitações físicas como em casos de paralisia cerebral. Compreendemos os riscos e cuidados para trabalhar com este grupo e vimos a necessidade de uma equipe multiprofissional para atuar com qualidade em busca de benefícios a estes indivíduos. E o profissional de Educação Física tem um papel fundamental neste contexto para desenvolver os princípios da saúde que se dá pela autonomia e interação social positiva que a atividade física proporciona. Considerações finais: No decorrer da disciplina projeto integrador vimos que saúde não consiste apenas na ausência de doença, e que desfrutar do melhor estado de saúde que é possível atingir, constitui um dos direitos fundamentais de todo ser humano, sendo ele uma pessoa com deficiência ou não. 0 esporte promove a inclusão da pessoa com deficiência na sociedade, o deficiente se torna mais independente para a realização de suas atividades diárias e melhora sua a autoconfiança e a autoestima, ficando mais otimistas e seguros para alcançarem seus objetivos.

PALAVRAS-CHAVE: ATIVIDADE FÍSICA; ESPORTE; DEFICIÊNCIA; SAÚDE. 


\title{
PROJETO VOLUNTARIO: EDUCAÇÃO, SAÚDE E LAZER
}

\author{
GABRIELA DE FREITAS SILVA, HEVELYN ALVES SANTOS, JOSIANE ALVES FERREIRA, KELLEN \\ GONÇALVES DE ALMEIDA, MILENA ALMEIDA MARTINS, THAYS MANUELLA DE LIMA E SILVA,
}

INSTITUTO MASTER DE ENSINO PRESIDENTE ANTÔNIO CARLOS - IMEPAC

byby_freitas@hotmail.com

Apresentação de Pôster

Resumo

Área do Conhecimento: Educação e Inclusão

Introdução: A ONU define o voluntário como: "voluntário é o jovem ou o adulto que, devido a seu interesse pessoal e ao seu espírito cívico, dedica parte do seu tempo, sem remuneração alguma, a diversas formas de atividades, organizadas ou não, de bem-estar social, ou outros campos...”. Essa temática veio de acordo com o tema proposto na disciplina de projeto integrador, do curso de Enfermagem, a partir deste princípio, foi desenvolvido um projeto voluntário em uma escola que teve como objetivo auxiliar os estudantes do ensino fundamental 1 no desenvolvimento escolar, proporcionando atividades educativas para a amplificação do conhecimento das crianças em relação a educação e a saúde.

Metodologia: 0 projeto foi realizado duas vezes por semana, durante um período de dois meses, com crianças do $1^{\circ}$ ao $5^{\circ}$ ano, foram realizadas atividades como cinema, oficina de leitura, pintura, teatro, monitoria de matemática, conscientização sobre hábitos higiênicos e alimentares, entre outros. Ao final o projeto realizamos um evento de finalização e retorno do resultado das atividades propostas.

Relatos de experiência: A primeira atividade foi Oficina de leitura e gramatica, pedimos para que os alunos em um pedaço de papel escrevessem um pouco sobre sua vida afim de ser reconhecido por outro colega ao ler o papel. Foi proposto na segunda atividade um cinema educativo, usamos o filme 'Divertidamente' para poder conversar com eles sobre os nossos pensamentos e atitudes em relação aos nossos sentimentos internos. Nossa terceira atividade foi uma Monitoria de matemática, fizemos algumas listas de exercícios e entregamos para eles resolverem. Falamos sobre higienização corporal, as crianças entendem bem sobre o assunto só não colocam muito em pratica o que sabem. A quinta atividade abordamos o assunto sobre alimentação saudável e higienização dos alimentos, conversamos um pouco sobre o tema e depois realizamos uma brincadeira com eles onde envolvia musica e conhecimento sobre o assunto, essa atividade foi a que mais observamos a interação dos alunos um com o outro e também o interesse em participar das atividades. A última atividade foi uma gincana de matemática, desenhamos uma 'amarelinha' no chão onde continha algumas equações desenhadas, as crianças jogavam o dado e o número que caia era a quantidade de vezes que deveriam pular, onde paravam. Nosso ultimo dia na escola, o fechamento do projeto, buscamos levar um momento de descontração para os alunos, conseguimos levar pula-pula, algodão doce, pipocas, suco e lembrancinhas para eles.

Considerações finais: Foi de grande importância a realização desse projeto para nós estudantes de enfermagem, pois foi possível observar as necessidades das pessoas fora do âmbito hospitalar que e o que vivenciamos dia a dia. Também conseguimos levar um pouco do nosso conhecimento para aquelas crianças.

PALAVRAS-CHAVE: VOLUNTARIADO, CRIANÇAS, PROJETO, DESENVOLVIMENTO. 


\title{
PROMOVENDO SAÚDE NA EDUCAÇÃO
}

\author{
LARISSE MARQUES DA SILVA, BIANCA PEREIRA ARAÚJO, PEDRO GUILHERME BRAGA DE ALMEIDA, \\ KARLA CRISTINA WALTER
}

INSTITUTO MASTER DE ENSINO PRESIDENTE ANTÔNIO CARLOS - IMEPAC

larisse.mds9@gmail.com

Apresentação de Pôster

Resumo

Área do Conhecimento: Saúde coletiva e bem-estar

Introdução: Existem diversos problemas na sociedade que afetam a saúde escolar pública; desde a falta de conhecimento individual e da comunidade, até uma educação em saúde eficiente dentro das unidades escolares. 0 voluntariado representa uma das formas para solucionar esta situação, por intermédio da abordagem educativa, com a realização práticas educativas em saúde. A educação em saúde torna favorável a construção de espaço na veiculação de novos conhecimentos e práticas relacionadas. Todos os modelos de educação em saúde evidenciam a mudança de hábito, atitudes, e comportamentos em grupos individuais e no coletivo, e tal mudança está dentro da aquisição de novos conhecimentos e adoção de atitudes favoráveis à saúde.

Objetivo: Nessa perspectiva, o trabalho tem o intuito de utilizar ambiente educativo para promoção e prevenção em saúde; proporcionar atividades que enfatizem a importância da saúde infantil.

Metodologia: O projeto foi desenvolvido em uma Escola Municipal na cidade de Araguari-MG, nos meses de Outubro a Dezembro de 2018, com duas visitas semanais, de acordo com a necessidade da comunidade escolar observada pela direção da escola.

Relato da experiência: No primeiro encontro, os acadêmicos e os alunos compartilharam saberes e dúvidas sobre higiene corporal e lavagem das mãos, onde se questionou a importância destes, mudanças de atitudes e condutas que tragam hábitos saudáveis. Durante as outras visitas, foram abordados tópicos nutricionais, com ênfase na alimentação adequada; sendo verificados em seguida, a estatura, o peso e o Índice de Massa Corporal (IMC) das crianças. Posteriormente abordaram-se temas como primeiros socorros; aspectos emocionais na infância; bullying; respeito e paciência. A etapa final foi consolidada com a participação de pais e responsáveis das crianças, através de brincadeiras lúdicas e gincanas, sintetizando o que foi aprendido durante o projeto.

Considerações finais: 0 voluntariado no âmbito escolar, com enfoque na educação em práticas de saúde, mostra-se eficaz, proporcionando conhecimento aos escolares. Estes se tornam propagadores da informação, contribuindo para uma sociedade participante de ações que visem a redução de patologias e aumento da qualidade de vida. Foi possível perceber que a educação aliada à saúde, forn ece elementos imprescindíveis para capacitar o cidadão para uma vida saudável. 


\title{
PROSTITUIÇÃO, DIGNIDADE DA PESSOA HUMANA E DIREITOS TRABALHISTAS
}

\author{
JESSICA CRISTINA SANTOS DE PAULA, MARTA REGINA RODRIGUES FERNANDES, GEILSON NUNES
}

INSTITUTO MASTER DE ENSINO PRESIDENTE ANTÔNIO CARLOS - IMEPAC

jessica_cristina5@hotmail.com

Apresentação de Pôster

Resumo

Área do Conhecimento: Sustentabilidade e Direitos

Introdução: A presente pesquisa relatará as relações entre os movimentos organizados por prostitutas sobre questões de gênero e sexualidade, em busca da liberdade sexual e do fim da brutalidade sofrida por elas. Objetiva demonstrar a relação entre a prostituição e os direitos trabalhistas que norteiam essa profissão, quando se trata de proteção da dignidade humana.

Objetivo: 0 objetivo desta pesquisa foi investigar os movimentos realizados pelas prostitutas em busca de direitos fundamentais, bem como analisar a prostituição como uma relação de trabalho, frente ao princípio constitucional da dignidade da pessoa humana.

Método: Para atingir os resultados na presente pesquisa será empregado o método dedutivo, a começar de argumentos gerais em direção a específicos, consagrando assim, os resultados expostos na presente problemática. Como metodologia utilizada, optou-se pela pesquisa histórica e doutrinária, bem como pela legislação pertinente.

Resultados: Foi possível observar que antigamente as prostitutas eram destacadas como Deusas da fertilidade e dispunham de maior autonomia política e social que as outras mulheres, consideradas objetos do homem. Com a conversão do Império Romano para o Cristianismo, a prostituição passou a ser ilícita, hostilizada e brutalmente penalizada. Diante disso, as meretrizes começaram a criar movimentos em busca do reconhecimento de direitos e garantias mínimas fundamentais. Em 1994, nasceu os primeiros direitos trabalhistas, reconhecendo a prostituição como uma atividade lícita, visando afastar as agressões e assegurando a liberdade e autonomia destas mulheres.

As prostitutas exercem suas atividades de forma pessoal, subordinada, não eventual e mediante remuneração de seus clientes ou de casas de prostituição, cumprindo todos os requisitos para caracterizar uma relação de emprego, conforme o artigo $3^{\circ}$ a Consolidação das Leis Trabalhistas. Nota-se que a única diferença entre a prostituição e as demais profissões, é a discriminação social, que as impedem de lograr vários direitos trabalhistas fundamentais, como benefícios previdenciários, férias e outros. Desse modo, a perspectiva das organizações nacionais é enfatizar os direitos trabalhistas e sociais, de forma justa, respeitando a autonomia, a liberdade, e a dignidade humana.

Conclusão: Embora não exista nenhuma regulamentação institucional, a prostituição é considerada uma atividade lícita, desde que seja autônoma. Devendo, apenas ser proibido a prostituição infantil ou de vulnerável, bem como os comportamentos que incentive a prática desta. Além disso, por ser uma atividade historicamente estigmatizada, não é reconhecida como uma profissão, apesar de constitui trabalho de fato, devendo ter direitos sociais reconhecidos, tendo em vista os Princípios Constitucionais da dignidade humana, da igualdade perante a lei e do direito mínimo existencial. PALAVRAS-CHAVE: DIREITO; DIGNIDADE DA PESSOA HUMANA; PROSTITUIÇÃO; TRABALHO. 


\title{
RASTREIO DE HIPERTENSOS EM CIDADE DO NORTE DE MINAS GERAIS: RESPONSABILIDADE SOCIAL DO ATENDIMENTO VOLUNTÁRIO
}

\author{
THAÍS RIBEIRO OLIVEIRA SANTOS DE MARCELLO, EMANNUEL NOVAES DE CARVALHO, NATHALIA \\ NUNES BESSA SOUSA, ALEX MIRANDA RODRIGUES
}

INSTITUTO MASTER DE ENSINO PRESIDENTE ANTÔNIO CARLOS - IMEPAC

thaisoliveiramarcello@gmail.com

Comunicação Oral

Resumo

Área do Conhecimento: Saúde coletiva e bem-estar

INTRODUÇÃO:0 voluntariado é definido em lei como atividade não remunerada prestada por pessoa física a entidade pública de qualquer natureza, que tenha objetivos educacionais, científicos ou de assistência social. Logo, a magnitude de tal ação torna essencial a ampliação da concepção das atividades voluntariarias, principalmente daquelas relativas a promoção de saúde. Tendo em vista a relevância da Hipertensão Arterial Sistêmica (HAS) e a ênfase colocada sobre o "status socioeconômico" dessa patologia (derivada de sua utilidade nos estudos epidemiológicos como índice das diferenças entre indivíduos expostos às experiências ambientais e de vida) o trabalho voluntário apresenta-se como ferramenta magna para a triagem dessa patologia em comunidades carentes.

OBJETIVOS: apresentar resultados estatísticos de ação voluntária de triagem de hipertensos em comunidade do Norte de Minas Gerais.

MÉTODOS: Estudo classificado como transversal e descritivo. Possui cunho quantitativo, analítico, observacional e de levantamento. As informações utilizadas neste trabalho foram fornecidas formalmente pelos responsáveis técnicos pela coleta de dados, de maneira a respeitar os princípios éticos de sigilo. A população deste estudo é constituída por todos os indivíduos que tiveram sua Pressão Arterial (PA) aferida em ação de um projeto voluntário, na cidade de São João da Lagoa-MG que é localizada no norte do estado e possui 4656 habitantes. A aferição da PA foi realizada por um único profissional devidamente capacitado e por aparelho calibrado e certificado pelo Inmetro. Posteriormente, foram calculadas as medidas centrais e de variabilidade, e frequências absolutas e relativas.

RESULTADOS: Dentre as 63 pessoas participantes do estudo, 40 eram mulheres e 23 eram homens. As idades variaram entre 32 e 75 anos. Dessa população, 44,44\% apresentaram valores de PA iguais ou superiores aos recomendados pelo Ministério da Saúde, no Caderno 37 de 2014, sendo 85,72\% do sexo feminino e $14,28 \%$ do sexo masculino. Desses, 35,71\% apresentaram PA considerada limítrofe, 25\% tiveram PA compatível com HAS estágio 1 e 39,29\% com HAS estágio 2.

CONCLUSÃO: A triagem foi de suma importância para averiguar a situação epidemiológica da comunidade estudada. Tal trabalho voluntário mostrou-se relevante a medida que possibilitará que a parcela da população que apresentou valores limítrofes de PA $(35,71 \%)$ receba orientações e que, aqueles que tiveram PA compatível com algum estágio de HAS (64,29\%), sejam acompanhados para que o diagnóstico final de tal patologia possa ser realizado precocemente, de maneira a se evitar complicações.

PALAVRAS-CHAVE: TRABALHO VOLUNTÁRIO; TRIAGEM; HIPERTENSÃO. 


\title{
REFORMA DA PREVIDÊNCIA: UM DILEMA POLÍTICO, SOCIAL OU ECONÔMICO?
}

\author{
LAURA APARECIDA DA CUNHA PEIXOTO, ANTÔNIO AUGUSTO BRANDÃO DE SOUSA, RODRIGO \\ GUILHERME TOMAZ
}

INSTITUTO MASTER DE ENSINO PRESIDENTE ANTÔNIO CARLOS - IMEPAC

laaurapeixoto@hotmail.com

Apresentação de Pôster

Resumo

Área do Conhecimento: Sustentabilidade e Direitos

\begin{abstract}
Introdução: A Previdência é um direito social garantido pela Carta Magna a todos os trabalhadores brasileiros, organizada sob a forma de regime geral, por meio de contribuições mensais em cima de seu salário. 0 objetivo de tal instituto é prover renda na ausência de sua remuneração em caso de uma eventualidade, de forma a custear seu sustento em razão da dignidade da pessoa humana. Em razão das constantes mudanças no comportamento e estilo de vida da sociedade contemporânea, o governo editou uma Proposta de Emenda à Constituição (PEC 06/2019) relacionada à previdência social.

Objetivo: Elucidar as razões não somente sociais, mas também econômicas e de Direito acerca da proposta, tendo em vista tratar-se de uma Emenda à Constituição.

Metodologia: Quanto ao método utilizado, optou-se pelo dedutivo, partindo de uma premissa geral para uma específica. Como metodologia adotou-se uma pesquisa bibliográfica embasada na Constituição Federal, na Proposta de Emenda Constitucional 06/2019, na Lei 8.213 de 24 de julho de 1991 e na doutrina.

Resultados alcançados: A referida PEC, visa equacionar de maneira igualitária esta crise da previdência, a fim de viabilizar a gestão dos cofres públicos do país sem utilizar-se de recursos destinados a outras áreas, tais como saúde, segurança e educação. A contrassenso popular, faz-se necessário a Reforma Previdenciária, tendo em vista, pesquisa da ONU que aponta para uma crescente melhora no Índice de Desenvolvimento Humano (IDH) no Brasil. Embasando tal fato, o Instituto Brasileiro de Geografia e Estatística (IBGE), aponta a constante queda nos índices de mortalidade infantil e o paulatino envelhecimento da população, o que impacta diretamente o custeio da previdência, obrigando o Estado a tomar medidas a fim de viabilizar financeiramente a estrutura previdenciária brasileira. Neste sentido, a dívida dos contribuintes previdenciários para os cofres da União é altamente preocupante para a economia do país, vez que, apenas $42 \%$ deste déficit possui chances de ser recuperado. Aliado a este fator tem-se a elevada despesa pública que, unicamente com o setor previdenciário, perfaz o montante de 13,6 \% do Produto Interno Bruto (PIB), o que acarreta o déficit agregado de $\mathrm{R} \$ 944$ bilhões, nos termos da justificativa de número 38 da PEC $06 / 2019$.

Conclusão: Trata-se de uma emenda à Constituição com efeito erga omnes, visando a equidade, ou seja, abarcará a todos sem distinção política ou partidária. Portanto, as principais dificuldades do entendimento da população acerca da nova proposta estão nas questões políticas, vez que a viabilidade socio-econômica restou comprovada no presente trabalho por meio de pesquisas que comprovam o envelhecimento populacional, a diminuição na taxa de natalidade e o alto déficit previdenciário.
\end{abstract}

PALAVRAS-CHAVE: CONSTITUIÇÃO FEDERAL; EQUIDADE; ECONOMIA; REFORMA DA PREVIDÊNCIA. 


\title{
REGULAMENTAÇÃO DA PROSTITUIÇÃO: UMA QUESTÃO DE DIGNIDADE
}

\author{
BÁRBARA ANDRESSA FERREIRA PRADO, RODRIGO GUILHERME TOMAZ
}

INSTITUTO MASTER DE ENSINO PRESIDENTE ANTÔNIO CARLOS - IMEPAC

barbaraandressa21@gmail.com

Apresentação de Pôster

Resumo

Área do Conhecimento: Sustentabilidade e Direitos

Introdução: A regulamentação da prostituição como profissão aborda assuntos diretamente ligados a questões sociais, morais, religiosas, porém, o fator mais impactante olvidado quando o assunto é debatido se relaciona aos direitos constitucionais "garantidos" a todos pela Constituição Federal de 1988, com exceção de certas classes de pessoas, dentre elas, as que tiram da prática da prostituição o seu sustento, seja por falta de opções ou por livre e espontânea vontade.

Objetivo: Frente ao exposto, o objetivo deste trabalho será demostrar a falta de reconhecimento do princípio fundamental da dignidade da pessoa humana em relação a essa classe de trabalhadores, tendo em vista a marginalização sofrida por estes.

Metodologia: Trata-se de uma pesquisa de campo, aplicada, exploratória, qualitativa de âmbito nacional, que buscará o comportamento da sociedade brasileira frente à possibilidade de regularização da prostituição no país. Tal levantamento pretenderá ter como população alvo moradores da cidade de Araguari, bem como os próprios trabalhadores dessa classe. Até o presente momento, a pesquisa se encontra no estágio de coleta de dados e informações para desenvolvimento e posterior confecção de Trabalho de Conclusão de Curso.

Resultados: Até o momento, foi possível observar que a CF/88 preceitua em seu art.6o o trabalho e a segurança como direitos sociais do cidadão, porém, ao analisar o tema em questão é de fácil percepção afirmar que o cidadão que tira da prostituição o seu sustento não possui condições de usufruir de tais direitos por conta da marginalização sofrida por conta da profissão, bem como a falta de sua regulamentação. Quanto à questão social, apesar da prática da prostituição ser vista como ato imoral perante a sociedade, houve marco importante para a classe no ano de 2002 com o reconhecimento pelo Ministério do Trabalho da prostituição como ocupação profissional (CBO 5198-05), permitindo, então, que as profissionais do sexo possam se registrar como trabalhadoras autônomas e contribuir com a previdência, garantindo a possibilidade de uma aposentadoria futura.

Conclusão: Seguindo esta linha de raciocínio e considerando que a CF de 1988 têm como fundamento a dignidade da pessoa humana, a regulamentação da prostituição proporcionaria a inclusão desses profissionais na sociedade como cidadãos de direito. Além disso, devido ao fato de a sociedade estar em constante evolução, uma vez que houvesse a regulamentação, os costumes e valores morais evoluiriam também e a pessoa que antes tirava da prostituição o seu sustento poderá ser admitida em outro trabalho sem qualquer discriminação da sociedade e sem nenhuma vergonha do seu passado, possibilitando, portanto, o desenvolvimento inclusivo que a sociedade necessita.

PALAVRAS-CHAVE: REGULAMENTAÇÃO DA PROSTITUIÇÃO; DIREITOS SOCIAIS; DIGNIDADE DA PESSOA HUMANA 


\title{
RELATO DE CASO - BEM ESTAR E ESTRESSE NO MANEJO NA FAZENDA TRONCOS - GRUPIARA - MG
}

\author{
EDUARDO NIELSEN FERNANDES, JERRI DONIZETE HONORATO DA SILVA, JOÃO VICTOR DA SILVA, \\ DANIELLE VITORINO MORAES
}

INSTITUTO MASTER DE ENSINO PRESIDENTE ANTÔNIO CARLOS - IMEPAC

eduardo_nielsen@hotmail.com

Apresentação de Pôster

Resumo

Área do Conhecimento: Responsabilidade, Tecnologia e Ciência

Introdução (Contextualização): A produtividade leiteira na nossa região apresenta grandes desafios. 0 gado que apresenta melhor produtividade é o gado Holandês, em contra partida a essa alta produção, apresenta baixa resistência à alta temperatura, pois a raça é de origem europeia, onde se predomina baixa temperatura, diante disso se optou pelo cruzamento do holandês com o GIR leiteiro, onde deu origem a girolando que é uma raça com maior resistência e com relativa produtividade, e bem adaptada ao clima tropical. 0 presente trabalho teve como objetivo relatar a experiencia de adequação do manejo e melhora do bem estar animal, ocorrida na propriedade TRONCOS localizada no município de Grupiara MG.

Metodologia: Foram utilizados alguns fármacos, ex (ocitocina) com intenção de amenizar a queda na produção leiteira, evitar que o leite fique represado no ubere e diminuir prejuízos econômicos.

Os animais eram (5/8) cinco oitavos girolando, com boa produção leiteira. Na parte reprodutiva utilizavase monta natural com um total de 25 vacas e 1 boi.

0 curral recebeu benfeitorias, foi trocado o piso e recebeu cobertura. Na parte externa foi retirada a lama e colocado piso ante derrapante. A sala de ordenha recebeu piso de alvenaria, o que facilitou a limpeza, gerando bem-estar aos animais.

Relato da experiência: Ouve uma grande mudança na rotina da propriedade, a mudança mais radical foi a troca do ordenhador, de inicio os animais estranharam e ficaram estressados, o que resultou na queda da produção. Os animais não entravam na sala de ordenha e a produção leiteira caiu de 300 litros diários para 70 litros diários.

Após as adequações e com o passar do tempo, os animais se acostumaram e voltaram a sua produção normal, começaram a ter resultados positivos, partindo de 70 litros dia para 350 litros, com a mesma alimentação, somente com mudanças de manejo e estrutura na propriedade.

Considerações finais: Concluímos que o modo de tratamento durante o manejo de ordenha tem impacto enorme na eficiência da produção, considerando este fato de grande relevância. Principalmente os responsáveis pelo rebanho desenvolvam e estimulem práticas de bem estar aos animais, recomenda-se que cada funcionário seja treinado para manusear de forma calma e sem agressão, para que os animais não associe os funcionários a dor e medo, desde as fazes de criação das bezerras até as vacas em lactação.

PALAVRAS-CHAVE: BOVINO DE LEITE, ORDENHA, ESTRESSE TÉRMICO, TEMPERATURA, MANEJO. 


\title{
RELATO DE CASO CLÍNICO: GIARDIA SPP. EM UM CANÍDEO DA RAÇA GOLDEN RETRIEVER NA REGIÃO DE CAMPINAS/SP
}

\author{
ALEXSANDRA VIEIRA SILVA CADIMA, GABRIEL AUGUSTO PACHECO LEMOS, GISLAINE NONINO \\ ROSA, NATHÁLIA ANDRADE MOTA, STEFHANY DA SILVA COELHO, TALITA DE CÁSSIA ALVES, \\ BRENDA CARLA LUQUETTI
}

INSTITUTO MASTER DE ENSINO PRESIDENTE ANTÔNIO CARLOS - IMEPAC

alexsandra.cadima@gmail.com

Apresentação de Pôster

Resumo

Área do Conhecimento: Saúde coletiva e bem-estar

Introdução: A Giardia sp. é um protozoário de ciclo de vida simples, presente em regiões tropicais e temperadas. Todos os mamíferos são suscetíveis à infecção,porém os animais jovens são os mais propensos a contraírem a doença.

Metodologia: Foram utilizadas observações e documentações a respeito de um atendimento de caso de giardíase ocorrido na cidade de Campinas/SP, em um cão de raça Golden Retriever durante quatro meses. Relato da Experiência: Em uma clínica veterinária, localizada em Campinas/SP, foi realizado o atendimento em uma cadela da raça Golden Retriever, com cinco meses de idade. 0 animal apresentou defecação anormal com evidência de fezes diarreicas, volumosas, com consistência líquida, fétida e com gases. Em maio de 2018, foi realizado o hemograma, que não apresentou anormalidade, e o exame parasitológico fecal, demonstrando a presença de cistos de Giardia spp. Prescreveu-se febantel, pamoato de pirantel, praziquantel e metronidazol, sendo que após o término do tratamento os sintomas ressurgiram. Em junho, realizou-se o exame coproparasitológico, obtendo resultado positivo para Giardia spp. Indicou-se o uso de nitazoxanida e ranitidina, mas o animal apresentou sintomas adversos, sendo assim suspendida a medicação. No dia 14 de junho foi feito o exame parasitológico e posterior prescrição de metronidazol e sulfadimetoxina - ormetoprim, e recomendou-se a higienização do ambiente. Em julho, foi realizado o exame parasitológico, obtendo resultado positivo para Giardia spp. Recomendou-se o uso de metronidazol e fenbendazol sendo aplicada primeira dose da vacina GiardiaVax®. Em agosto, intensificou-se o uso de metronidazol e fenbendazol e aplicou-se a segunda dose da vacina. Verificou-se após dois meses do tratamento que a cadela deixou de apresentar manifestação clínica de giardíase, houve ganho de peso com estabelecimento normal de massa corporal e com comportamento ativo, sem uso de medicação. Portanto, para a resolução deste caso, foi realizada a prescrição de vários fármacos distintos até se obter o resultado desejado. Uma das possibilidades que solucionaram o quadro de parasitose foi a prescrição de metronidazol e fenbendazol associado à vacinação que foi de grande importância na cura. Em relação à possível resistência desse protozoário neste animal, sugere-se que o contágio pode ter ocorrido antes do animal ter sido adquirido, pois segundo o tutor, o cão já apresentava sintomatologia e sabe-se que muitos canis realizam-se tratamentos preventivos, fazendo assim o uso indiscriminado de fármacos giardicidas e em posologias incorretas.

Considerações finais: No que diz respeito à especificidade do presente caso, o que garante aspecto incomum a parasitose acometida pelo canídeo é a duração prolongada da doença, pois durante o período de quatro meses houve a adoção de cinco diferentes métodos de tratamento até obter-se a cura definitiva.

PALAVRAS-CHAVE: PROTOZOÁRIO; ZOONOSE; TRATAMENTO; GIARDIA. 


\title{
RELATO DE CASO: TROMBOCITOPENIA CAUSADA POR ANCYLOSTOMA CANINUM EM CÃO SRD NA REGIÃO DE CAMPINAS-SP
}

\author{
BÁRBARA MARIA GONÇALVES GAMA, ALLAN VICTOR LIMA MARQUES, GISLAINE NONINO ROSA, \\ NÂMELA CARVALHO SILVA, STÉFANY ALVES MORAES RADE, TAYNARA MANOUKIAN TELES, \\ BRENDA CARLA LUQUETTI
}

INSTITUTO MASTER DE ENSINO PRESIDENTE ANTÔNIO CARLOS - IMEPAC

barbara312011@hotmail.com

Apresentação de Pôster

Resumo

Área do Conhecimento: Saúde coletiva e bem-estar

Introdução: 0 Ancylostoma caninum é um nematóide causador da Ancilostomose e inflamação cutânea humana. Este parasita é próprio de felídeos e canídeos domésticos ou silvestres, mas pode acometer acidentalmente o homem. O objetivo desse trabalho foi relatar um caso de Ancilostomose com trombocitopenia ocorrido em uma clínica veterinária em cão SRD.

Metodologia: Foram utilizadas documentações e observações clínicas de um atendimento de um cão em uma clínica veterinária na região de Campinas-SP.

Relato da experiência: Um cão macho, de seis anos, foi atendido em uma clínica onde foi requisitado o hemograma e a pesquisa de endoparasitas (positiva para Ancylostoma caninum). 0 animal foi vermifugado e após três meses notou-se aumento do peso, mas persistência de prurido cutâneo generalizado. 0 hemograma foi de 35\% com trombocitopenia (140.000 plaquetas). Após um mês a anemia se acentuou e foi realizada ultrassonografia onde se observou congestão hepática, esplênica e também exame de reação de cadeia da polimerase (PCR) para Babesia/Erlichia sendo receitado Doxiciclina. Após 10 dias, o cão apresentava fraqueza nos membros posteriores, tremores, sensibilidade epigástrica, taquipnéia, melena e vômito. Com o hemograma refeito, foi observado piora do quadro. Foi prescrita suplementação de nutrientes, vermífugo e Dexametasona, já que havia suspeita de uma doença imunoimediada, onde foi observada boa resposta. A anemia hemolítica tem sua forma autoimune, que ocorre quando o sistema imunológico identifica erroneamente seus próprios glóbulos vermelhos como corpos estranhos, desenvolvendo anticorpos que atacam as hemácias, destruindo-as prematuramente. A anemia pode ter sido provocada por duas causas, devido ao fato de que os parasitas são hematófagos ou poderia também ter sido originada como uma doença secundária, já que houve a desregulação do sistema imune após a infecção pelo parasito. Após mais um mês, o hemograma apresentou discreta melhoria, embora com trombocitopenia e melhora da sensibilidade epigástrica e dos tremores. Após 13 dias, foi realizado o exame parasitológico de fezes e observado que os parasitas ainda estavam presentes e o vermífugo foi administrado pela quarta vez. Passado mais um retorno foi efetuado outro hemograma e o animal obteve grande melhora após qua tro meses de tratamento. 0 cão foi considerado livre do parasita assim que o exame coproparasitológico resultou negativo. A anemia foi curada, as manifestações clínicas remissionadas e o animal recebeu alta clínica, com indicação de repetição do vermífugo.

Considerações finais: Por se tratar de um endoparasita de hábito hematófago, provavelmente o paciente apresentou uma resposta secundária à infecção. Sugere-se que o cão possa ter desenvolvido uma anemia de caráter autoimune, o que poderia estar correlacionado com a elevada infecção pelo parasito. Implica-se que isso tenha causado a anemia hemolítica no animal.

PALAVRAS-CHAVE: ANCILOSTOMÍASE, ANEMIA HEMOLÍTICA; INFECÇÃO PARASITÁRIA. 


\title{
RELATO DE EXPERIÊNCIA SOBRE PROJETO VOLUNTÁRIO VOLTADO PARA ORIENTAÇÃO DE GESTANTES
}

\author{
MARIA LUIZA OLIVEIRA, ALLANA TONINI FERNANDES , ANA CLARA GOMES RIBEIRO, ANA RAQUEL \\ FERREIRA BORGES, FELIPE DE OLIVEIRA VITORINO, MARCELLA PINHEIRO BRANDÃO, MELISSA \\ MARIANE REIS
}

INSTITUTO MASTER DE ENSINO PRESIDENTE ANTÔNIO CARLOS - IMEPAC

marialuizaoliveira213@gmail.com

Apresentação de Pôster

Resumo

Área do Conhecimento: Saúde coletiva e bem-estar

\begin{abstract}
Introdução (Contextualização): Sabe-se que a gestação é um momento de mudanças anatômicas, fisiológicas e psicológicas para a mulher; e a maternidade, muitas vezes, transforma suas prioridades e preocupações. Nessa perspectiva, o projeto voluntário “Gestoação" realizado desde agosto de 2018 desenvolve atividades de educação em saúde com enfoque na atenção primária da saúde da mulher, no que tange os cuidados durante a gestação, parto, puerpério, além de cuidados com o bebê. Há um esforço no incentivo ao aleitamento exclusivo.

O objetivo consiste em conscientizar os discentes sobre a importância da humanização na orientação e na sensibilização do público-alvo. Bem como, prover a acessibilidade à informação e assistência da mulher no ciclo gravídico puerperal.
\end{abstract}

Metodologia: 0 projeto voluntário contou com a participação de 27 acadêmicos de medicina do $1^{\circ}$ ao $8^{\circ}$ período selecionados através de uma avaliação cognitiva escrita. No $1^{\circ}$ semestre do projeto ocorreu um ciclo de seminário coordenado por profissionais da área da saúde totalizando 28 reuniões. Para o segundo semestre, a aplicação dos conhecimentos adquiridos foi efetuada por meio da promoção de um curso de gestantes. Dessa forma, foram convidadas, em visita domiciliar, 40 gestantes adscritas na UBSF firmada a parceria mediante a Secretaria Municipal de Saúde de Araguari-MG. Destas, 10 compareceram no $1^{\circ}$ encontro.

Relato da experiência: Ao longo de um ano os acadêmicos de medicina foram capacitados para por profissionais da área da saúde abordando temas dentro da Ginecologia e Obstetrícia, com o objetivo de prepará-los para disseminar o conhecimento entre as participantes do curso de gestante. No fim deste período, houve a organização e realização do curso que foi divido em três encontros, sendo que, até o presente momento, 1 encontro foi concluído. A fim de incentivar a adesão e facilitar a comunicação entre público alvo e os organizadores, foi criado um grupo em uma rede social. No dia do evento, houve um momento de recepção e identificação de cada gestante, bem como a aferição da pressão arterial e avaliação do índice glicêmico. Além disso, os membros do projeto conduziram uma roda de conversa que abordou temas como "Pré natal: o que é, importância, quais exames são realizados e o porquê?" e "Aleitamento materno: importância e principais orientações". Nessa etapa, as mulheres retiraram dúvidas e relataram experiências da gestação atual e anteriores. Posteriormente, o coffee break foi servido. Ao final, as gestantes foram presenteadas com itens diversos relacionados à maternidade como fraldas, jogo de toalha, kit de xampu e condicionador infantis.

Considerações finais: A realização deste projeto foi de grande valor para as gestantes, devido à oferta de informação e promoção da atenção à saúde da mulher no ciclo gravídico puerperal. Já os pesquisadores vivenciaram experiências favoráveis ao crescimento profissional e a humanização.

PALAVRAS-CHAVE: GESTAÇÃO; HUMANIZAÇÃO; AÇÃO EM SAÚDE; PROJETO VOLUNTÁRIO; ORIENTAÇÃO. 


\title{
RESPONSABILIDADE EMPRESARIAL E SOCIAL SOBRE A LEI DE COTAS PARA PESSOAS COM DEFICIÊNCIA NO MERCADO DE TRABALHO
}

\author{
REGIANE FAUSTA RESENDE BUZINHANI, LEONARDO LOPES MAGALHÃES, GEILSON NUNES
}

INSTITUTO MASTER DE ENSINO PRESIDENTE ANTÔNIO CARLOS - IMEPAC

regianeresende2014@gmail.com

Apresentação de Pôster

Resumo

Área do Conhecimento: Responsabilidade e Negócios

INTRODUÇÃO: 0 presente trabalho tratará do processo de inclusão de portadores de necessidades especiais no mercado de trabalho, com vistas à Lei n.. 8.213/91, empresas com 100, ou mais colaboradores, tornam-se obrigadas a contratar portadores de deficiências físicas. Constata-se uma grande falha na inclusão dos deficientes no mercado de trabalho, de modo que, esse será o real motivo para uma reflexão conjunta, na qual, empresas e sociedade analisem a melhor forma de gestão de inclusão.

PROBLEMA DE PESQUISA: Quando da ponderação do tema a que se propõe analisar, faz-se mister esclarecer qual a importância da inclusão social aos portadores de deficiência frente ao preconceito sofrido em sociedade e, sobretudo, identificar quais as características podem ser constatadas no ambiente empresarial como estratégias de defesa, a fim de protelar ou até mesmo deixar de contratar estes profissionais. Porque as empresas não se adaptam aos sistema de inclusão, que se interagem com a vida dos deficientes, se eles fazem parte da sociedade trabalhadora deste país?

OBJETIVO :Objetivo deste trabalho é trazer essa pequena minoria para mundo organizacional, porque é uma classe pode atender um determinado setor da empresa, pelo fato de ser deficiente não prejudica em nada, melhor dizendo, só tem agregar o bom funcionamento corporativo da empresa. As práticas adotadas para inclusão de pessoas com deficiências físicas no Brasil, onde a inclusão na maioria das vezes é deixada somente na legislação, a baixa adesão dos processos de inclusão, como o órgão fiscalizador atua para que as garantias fundamentais sejam respeitadas e, como os deficientes se sentem ao serem excluídos e vistos de maneira diferente.

MÉTOD0:0 trabalho desenvolveu-se por uma metodologia de referencial bibliográfico, buscando em artigos e livros auxilio para a pesquisa e almejando harmonizar a relação entre deficiente e empresas, como forma de esclarecimento real sobre a igualdade, adotando o método dedutivo, de forma a alcançar os resultados propostos na problemática.

RESULTADOS ALCANÇADOS: Na Lei no 8.213/91, em seu art. 93, dispõe quanto a empresa que constitui mais de 100 empregados ser obrigada a preencher de $2 \%$ a $5 \%$ dos cargos com profissionais portadores de deficiência, na própria Constituição da República Federativa do Brasil/88, garante esse direito, em seu art. $3^{\circ}$, inciso IV, os objetivos fundamentais que visam a promoção do bem de todos, sem quaisquer discriminações.Contudo esse trabalho, a falta de possibilidades de inclusão social aos deficientes na vida laboral como para qualquer outra pessoa. Mesmo com suas limitações, se faz necessária a realização de mudanças em nossa cultura, extinguindo-se a discriminação e em contrapartida, a realização de programas no meio empresarial que visem oportunizar a classe, tornando o deficiente socializado e com trabalho digno.

PALAVRAS-CHAVE: DEFICIÊNCIA EMPRESA. INCLUSÃO. MERCADO. 


\title{
RESPONSABILIDADE SOCIAL COM O ATENDIMENTO PEDIÁTRICO: CONHECIMENTO DE ACADÊMICOS DE MEDICINA SOBRE HUMANIZAÇÃO E COMUNICAÇÃO
}

\author{
NATHÁLIA NUNES BESSA SOUSA, EMANNUEL NOVAES DE CARVALHO, THAÍS RIBEIRO OLIVEIRA \\ SANTOS DE MARCELLO, CLÁUDIA REGINA ALVES DAUD
}

INSTITUTO MASTER DE ENSINO PRESIDENTE ANTÔNIO CARLOS - IMEPAC

nathalia_bbessa@hotmail.com

Comunicação Oral

Resumo

Área do Conhecimento: Saúde coletiva e bem-estar

INTRODUÇÃO: A constituição de um atendimento calcado em princípios como a integralidade da assistência, a equidade e a participação social do usuário demanda a revisão das práticas cotidianas, focadas em humanização e comunicação, de modo a valorizar a dignidade do profissional e do usuário. Logo, percebe-se que o médico, como membro da equipe multidisciplinar, a qual exerce cargo líder, é responsável pela escuta ativa entre seus liderados, de forma humanizada. E, o direito à saúde se garante com direito à comunicação. Uma comunicação que também se transforma, pluridimensional, contemplando múltiplas vozes. OBJETIVOS: fornecer dados acerca do conhecimento dos acadêmicos de Medicina sobre Humanização e Comunicação na área pediátrica e traçar perfil de conhecimento adquirido a cada período do curso. MÉTODOS: Trata-se de um estudo transversal, descritivo, de cunho quantitativo, classificado como analítico, observacional e de levantamento, por meio de aplicação de questionário. Esse tem como fator avaliativo o conhecimento teórico de acadêmicos de Medicina sobre Humanização e Comunicação em Pediatria. A população deste estudo é composta por todos os acadêmicos de Medicina, matriculados no Instituto Master de Ensino Presidente Antônio Carlos (IMEPAC) que demonstraram interesse em participar de um projeto de humanização pediátrica. Para a coleta dos dados foi utilizado um questionário confeccionado por um fórum de médicos especialistas pela Sociedade Brasileira de Pediatria. Trata-se de um questionário fechado, contendo 5 perguntas sobre o tema. Para análise dos dados foram comparadas as respostas dos acadêmicos com o gabarito elaborado pelos especialistas. Foram calculadas medidas centrais e de variabilidade, e frequências absolutas e relativas. RESULTADOS: Dentre as pessoas 38 pessoas que responderam as questões, 50\% delas eram do ciclo básico e 50\% do ciclo clínico. Sendo 89,5\% do sexo feminino. Dentre essas questões, 8 pessoas acertaram todas elas, sendo 3 pessoas do ciclo básico e 5 pessoas do ciclo clínico. Entretanto, $5 \%$ dos acadêmicos, sendo eles do ciclo clínico, erraram todas as questões. Das questões aplicadas, a questão que teve maior número de erro (50\%), abordava um comparativo da Humanização de hoje com a Humanização do século passado. A respeito da questão com maior número de acertos, que abordou conceitos como empatia, compaixão, humanização e comunicação, apenas 6 pessoas erraram (4 pessoas do ciclo clínico e 2 pessoas do ciclo básico. CONCLUSÃo: Por mais que a Humanização e Comunicação sejam temas bastante trabalhado ao logo do curso de Medicina, faz-se necessário maior ênfase e abordagens mais assertivas, visto que o índice de acertos de todas as questões foi baixo. PALAVRAS-CHAVE: CONHECIMENTO; PEDIATRIA; COMUNICAÇÃO; HUMANIZAÇÃO. 


\title{
REUSO: VOCÊ DEFENDE ESSA IDEIA?
}

\author{
VIVIANE NOBRE DE ANDRADE ASSUNCAO, LAURA NASCIMENTO ESPINDULA, ANA LUCIA COSTA E \\ SILVA
}

INSTITUTO MASTER DE ENSINO PRESIDENTE ANTÔNIO CARLOS - IMEPAC

vivianenobreaa@gmail.com

Apresentação de Pôster

Resumo

Área do Conhecimento: Educação para Desenvolvimento Sustentável

Introdução: É comum ouvirmos ações que envolvem a Sustentabilidade, impactando no desenvolvimento da economia, cultura, ambiente e tecnologia e; por meio da Educação, podemos estimular a reflexão e as mudanças atitudinais, sociais e políticas. Diante da observação do quadro atual de nossos consumos, especialmente no que diz respeito aos recursos naturais, surge a preocupação com água, que é um recurso extremante necessário para a manutenção da vida e que não é ilimitado. Faz-se necessário, então, viabilizar medidas de conservação das fontes existentes que podem um dia escassear, devido às mudanças climáticas do planeta bem como o uso desenfreado desse bem tão importante para a humanidade e para todo o ecossistema. Pensando nisso, surgiu a proposta de analisar a legislação ambiental existente no munícipio de Araguari-MG, que utiliza como meio de abastecimento de água, a fonte de aquíferos - formação geológica subterrânea que funciona como reservatório de água, alimentado pelas chuvas que se infiltra pelo solo. Como a recarga desta fonte, ocorre somente por meio natural, cabe a preocupação em reduzir o consumo da mesma, já que as precipitações pluviais estão cada vez menores. Com o entendimento de que medidas de incentivo por parte da administração pública podem contribuir para a finalidade da reeducação ambiental, bem como estimular o uso consciente do recurso hídrico, o reuso da água das chuvas, este trabalho teve como objetivo apresentar uma proposta de projeto de lei que defenda de incentivo ao uso de cisternas para auxiliar no planejamento urbano, evitando problemas como enchentes devido a impermeabilização do solo, o que seria de extrema relevância para o município e ambiente como um todo. Metodologia: a partir da disciplina Projeto Integrador, o grupo convidou um engenheiro para uma roda de conversa com alunos da Pedagogia do Imepac, para esclarecer e enfatizar a relevância da instalação de cisternas para a economia de água e como ação principal elaborou uma proposta de Projeto de Lei, onde o munícipio promulga uma Lei de incentivo ao uso de cisternas, propiciando um reaproveitamento dessa água para uso não potável em casas, estabelecimentos comerciais e instituições públicas. Relato de experiência: Estas medidas trouxeram o estudo de teóricos que salientavam o benefício para o meio ambiente do uso de cisternas, destacando cidades que passaram a utilizar este recurso como forma de resolver parte dos problemas urbanos decorrentes da água da chuva que encharcavam as ruas, por ter solos impermeáveis, bem como a economia financeira gerada pelo uso das cisternas e reaproveitamento da água pluvial para outros fins. Considerações finais: Este trabalho contribuiu para a formação pessoal e acadêmica, favorecendo o crescimento profissional, uma vez que propõe o uso de iniciativa pública para o bem coletivo, além do valor social que enaltece a participação da sociedade no desenvolvimento urbano e ambiental.

PALAVRAS-CHAVE: SUSTENTABILIDADE; CONSERVAÇÃO HÍDRICA; ECONOMIA; REUSO. 


\title{
SAÚDE DA MULHER: AVALIAÇÃO DO PERFIL DAS MULHERES QUE PARTICIPARAM DE UMA AÇÃO SOCIAL REALIZADA NO CONTEXTO DO OUTUBRO ROSA NA CIDADE DE ARAGUARI - MG.
}

\author{
JHONATAN PEREIRA CASTRO, CICERA SAIANE AMARAL SOUZA, LEILIANE APARECIDA VIEIRA \\ DELFINO , LINCOLN RODRIGUES FERNANDES JÚNIOR, KARLA CRISTINA WALTER; DANIELLE \\ FERNANDES ALVES
}

INSTITUTO MASTER DE ENSINO PRESIDENTE ANTÔNIO CARLOS - IMEPAC

jhonatancastro1996@gmail.com

Comunicação Oral

Resumo

Área do Conhecimento: Saúde coletiva e bem-estar

\begin{abstract}
Introdução: A saúde da mulher , evidenciado no Outubro Rosa foi criado no início da década de 1990 com o Movimento internacional de conscientização para o controle do câncer de mama. A data é celebrada anualmente, com o objetivo de compartilhar informações e promover a conscientização sobre a doença; proporcionar maior acesso aos serviços de diagnóstico e de tratamento e contribuir para a redução da mortalidade.

Objetivo: avaliar o perfil da saúde das mulheres em uma ação social no contexto da campanha Outubro Rosa na cidade de Araguari - MG em 2018
\end{abstract}

Metodologia: trata-se de um estudo transversal descritivo, realizado com mulheres que participaram de uma ação social no contexto do Outubro Rosa na cidade de Araguari - MG. Tivemos o intuito de avaliar o perfil de saúde dessas mulheres, sendo aplicado um questionário semiestruturado vislumbrando os seguintes dados: Idade, escolaridade, IMC, se é tabagista e/ou etilista, se já realizou o exame clínico das mamas, se já realizou mamografia e quando foi a última e se já realizou exame colpocitopatológico.

Resultado: foram avaliadas 115 mulheres, sendo 20 com idade menor que 30 anos, 11 entre 10 e 35 anos, 14 entre 35 e 40 anos, 19 entre 40 e 50 anos, 39 maiores que 50 anos e 13 não responderam ao questionário. Quanto a escolaridade, apenas 1 era analfabeta, 20 possuíam o ensino fundamental incompleto e 9 o completaram, 23 terminaram o ensino médio e 1 não o concluiu, ademais, 17 possuíam ensino superior completo, 7 não haviam o completado, 4 já eram pós-graduadas e 30 não responderam A média do IMC foi de 26,8 (com o cálculo sendo realizado em 83 participantes). No tocante ao tabagismo 13 das entrevistadas eram tabagistas 36 eram etilistas e 2 não responderam essas questões. Em relação aos exames preventivos para o câncer de mama 42 mulheres haviam realizado o exame clínico das mamas em menos de 1 ano; 22 realizaram entre 1 e 2 anos; 7 realizaram entre 2 e 3 anos, 11 realizaram há mais de 3 anos e 30 nunca realizaram. Já a mamografia, 27 haviam realizado há menos de 1 ano, 16 entre 1 e 2 anos, 11 entre 2 e 3 anos, 10 há mais de 3 anos e 51 nunca realizaram. Para o rastreio de CA de colo uterino, foi questionado às participantes sobre o exame colpocitopatológico e obtivemos resultados de que 16 delas nunca realizaram o exame, 48 realizaram há menos de 1 ano, 31 realizaram entre 1 e 2 anos e 20 realizaram entre 2 e 3 anos.

Conclusão: já é consenso sobre a importância da prevenção e promoção da saúde da mulher e diante deste trabalho verificou-se que ainda é necessária uma maior adesão por parte das mulheres com os cuidados de saúde. Além disso deve-se haver um maior empenho por parte dos profissionais de saúde para que se construa uma melhor relação com essa população para que haja uma maior captação e adesão as campanhas de cuidado em relação a saúde.

PALAVRAS-CHAVE: OUTUBRO ROSA, CÂNCER DE MAMA, CÂNCER DE COLO DE ÚTERO, PREVENÇÃO PRIMÁRIA. 


\title{
SAÚDE DO HOMEM: AVALIAÇÃO DO PERFIL DOS TRABALHADORES EM UMA EMPRESA NA CIDADE DE ARAGUARI - MG.
}

\author{
LINCOLN RODRIGUES FERNANDES JUNIOR, CICERA SAIANE AMARAL SOUZA , JHONATAN PEREIRA \\ CASTRO, LEILIANE APARECIDA VIEIRA DELFINO, KARLA CRISTINA WALTER / DANIELLE FERNANDES \\ ALVES
}

INSTITUTO MASTER DE ENSINO PRESIDENTE ANTÔNIO CARLOS - IMEPAC

lincoln_fernandesjr@yahoo.com.br

Comunicação Oral

Resumo

Área do Conhecimento: Saúde coletiva e bem-estar

Introdução: Os estudos sobre a saúde do homem surgiram no final dos anos 1970, nos Estados Unidos. Em 2009, foi lançada a Política Nacional de Atenção Integral à Saúde do Homem pelo Ministério da Saúde, que tem por objetivo destacar a singularidade masculina nos seus diversos contextos socioculturais e políticoeconômicos, bem como apontar princípios para o aumento da expectativa de vida e a redução dos índices de morbimortalidade por causas preveníveis na população de 20 a 59 anos.

Objetivo: avaliar o perfil da saúde dos homens de uma empresa da cidade de Araguari - MG

Metodologia: trata-se de um estudo transversal descritivo, realizado com trabalhadores do sexo masculino de uma empresa da cidade de Araguari - MG. Tivemos o intuito de avaliar o perfil de saúde dos trabalhadores, sendo aplicado um questionário semiestruturado vislumbrando os seguintes dados: Idade, escolaridade, IMC, se é tabagista e/ou etilista, quantos cigarros fuma por dia, com que frequência consome bebida alcoólica, se algum médico já indicou o exame de próstata, se já realizou o exame de toque retal e se já realizou o PSA.

Resultado: Foram avaliados 27 trabalhadores, sendo que 21 são menores de 45 anos, 3 são maiores de 45 anos e 3 não responderam; 3 não concluíram o ensino fundamental, 2 haviam concluído, 2 não concluíram o ensino médio e 3 haviam concluído, ademais, 6 possuíam ensino superior incompleto e 6 possuem a conclusão. A média do IMC foi de 27, 98 (com o cálculo sendo realizado com 25 pessoas), 5 dos 27 participantes eram tabagistas, sendo que 4 já fumavam por um período entre 10 e 15 anos e 1 fumava por um período entre 15 e 20 anos. Em relação a quantidade de cigarros fumados por dia, 1 deles fumava 5 cigarros/dia , um fumava de 10 a 15 cigarros/dia, dois fumavam de 10 a 15 cigarros/dia e um fumava mais de 20 cigarros/ dia. No que tange o consumo de álcool, 12 possuíam esse hábito, sendo que 10 faziam uso entre 1 e 2 vezes por semana, 1 entre 5 a 5 vezes por semana e 1 todos os dias da semana. Quanto aos cuidados em relação ao câncer de próstata: 4 já haviam sido orientados sobre a realização do PSA, 2 não responderam e os demais não haviam recebido nenhum tipo de orientação, no entanto, apenas 3 realizaram o exame. Dos que realizaram o PAS 1 realizou há menos de um mês e 2 realizaram entre 6 meses e 1 ano. Conclusão: já é consenso sobre a importância da prevenção da saúde do homem e diante deste trabalho verificou-se que ainda é necessária uma maior adesão por parte dos homens com os cuidados de saúde. Além disso deve-se haver um maior empenho por parte dos profissionais de saúde para que se construa uma melhor relação com essa população para que haja uma maior captação e adesão as campanhas de cuidado em relação a saúde.

PALAVRAS-CHAVE: NOVEMBRO AZUL, PREVENÇÃO PRIMÁRIA, CÂNCER DE PRÓSTATA. 


\title{
SEMELHANÇA ENTRE URSACOL E ÁCIDOS BILIARES DE AVES PARA POSSÍVEL TRATAMENTO DE ASCITE E COLESTASE EM CÃES
}

\author{
ROSANA APARECIDA MARTINS DOS SANTOS., EDUARDA APARECIDA DE MELO, RAFAEL QUIRINO \\ MOREIRA
}

INSTITUTO MASTER DE ENSINO PRESIDENTE ANTÔNIO CARLOS - IMEPAC

rosanateck@gmail.com

Apresentação de Pôster

Resumo

Área do Conhecimento: Responsabilidade, Tecnologia e Ciência

Introdução: A insuficiência hepática é a perda na capacidade do fígado de realizar suas funções biológicas. A doença hepática é muito variada, mas normalmente está associada a causas endócrinas, tóxicas, infecciosas, autoimunes e nutricionais. Em cães, uma das indicações para o tratamento de colestase é o medicamento Ursacol®, composto pelo ácido biliar ursodesoxicólico, de baixo peso molecular. Práticas da medicina popular-tradicional implicam no uso de bile de aves no tratamento de ascite e colestase em cães. Objetivo: Identificar a composição da bile de aves, por meio de levantamento bibliográfico, para verificar a semelhança dos sais biliares com o ácido ursodesoxicólico, aventando uma ação análoga da bile de aves no tratamento tradicional de hepatopatias e colangites em cães.

Metodologia: Fez-se um levantamento de artigos científicos publicados nos últimos 10 anos, a partir das bases de dados Google acadêmico, Elsevier e Scielo, sobre a composição da bile de pato (Cairina moschata momelanotus) e frango (Gallus gallus domesticus). Comparou-se a composição dos sais destas secreções com a molécula do ácido ursodesoxicólico.

Resultados: A bile de frango é composta por: $9,6(+-0,5) \mathrm{mg} / \mathrm{g}$ de ácido cólico, com peso molecular 408; 25,2 (+-2,2) mg/g de ácido quenodesoxicólico, com peso molecular 392,57;68,7 (+-2,1) mg/g de ácido litocólico, com peso molecular 376,57; 152,3 (+-2,1) mg/g de ácido taurocólico, com peso molecular 515; 35,9 (+-0,6) $\mathrm{mg} / \mathrm{g}$ de ácido taurolitocólico, com peso molecular 483; 228,4 (+-1,6) mg/g de ácido glicolitocólico, com peso molecular 433. Já a bile de pato é composta por: 45,2 (+-2,3) mg/g de ácido cólico, com peso molecular 408; 28,2 (+-1,6) mg/g de ácido quenodesoxicólico, com peso molecular 392,57; 37,5 (+-2,1) mg/g de ácido litocólico, com peso molecular 376,57; $16,8(+-1,5) \mathrm{mg} / \mathrm{g}$ de ácido taurocólico, com peso molecular 515; $97,5(+-3,4) \mathrm{mg} / \mathrm{g}$ de ácido tauroquenodesoxicólico, com peso molecular 499; 43,5 (+-2,1) mg/g de ácido ursodesoxicólico, com peso molecular 392,6; $31,6(+-1,9) \mathrm{mg} / \mathrm{g}$ de ácido desoxicólico, com peso molecular 392,58. Os ácidos biliares quenodesoxicólico e litocólico presentes na bile do frango, assim como os ácidos quenodesoxicólico, litocólico e desoxicólico presentes na bile de pato, foram os de maior semelhança ao princípio ativo do Ursacol®. A bile de pato apresenta o ácido ursodesoxicólico, presente no Ursacolß.

Conclusão - Encontraram-se sais na bile de pato e frango com composição e peso moleculares semelhantes ou idênticos ao ácido ursodesoxicólico. Aventa-se a possibilidade de ação análoga ao Ursacol@, destes sais biliares, no tratamento tradicional de hepatopatias em cães. 


\title{
SERVIÇO DE LIMPEZA URBANA, A SOCIEDADE, E UM AMBIENTE ECOLOGICAMENTE EQUILIBRADO
}

\author{
ADRIANA RODRIGUES BARBOSA, GABRIEL SILVA SOUZA, GEILSON NUNES
}

INSTITUTO MASTER DE ENSINO PRESIDENTE ANTÔNIO CARLOS - IMEPAC

arbrestauradora@hotmail.com

Apresentação de Pôster

Resumo

Área do Conhecimento: Sustentabilidade e Direitos

Introdução: A Constituição Federal garante a proteção ao meio ambiente, a limpeza se encontra diretamente ligada ao meio ambiente. Para garantir que os direitos fundamentais sejam protegidos, e não serem mais do que meras palavras do ordenamento jurídico, são necessárias políticas públicas, quem contenha, programas de ação e diretrizes para que a sociedade tenha melhores condições de vida.

Objetivo: Analisar a eficiência do serviço público na demanda de limpeza urbana, para que tal ato venha a atender e conscientizar a população a respeito dos malefícios do descarte do lixo em locais inadequado.

Metodologia: Trata-se de caráter exploratório em âmbito municipal, utilizando de técnicas da pesquisa bibliográfico, em doutrinas, artigos científicos e demais documentos pertinentes ao tema, e utilização do método sistêmico de abordagem.

Resultado: Dentro do contexto urbano, são necessárias políticas ambientais, estas vinculadas a limpeza urbana. Em maior discernimento do assunto tratado, o poder público tem o dever de manter as vias públicas limpas, coletar os resíduos sólidos gerados pela população. Visando maior ênfase a questão ambiental, pois estes resíduos deixados no meio ambiente estariam prejudicando a sociedade e seu futuro. A limpeza urbana, em particular, por vezes é vista predominantemente como fator de embelezamento das vias públicas. Em verdade, o tratamento de resíduos e dejetos e sua destinação final apropriada são essenciais à eliminação de focos transmissores de doenças e à preservação do meio ambiente. Ao que se diz respeito ao conceito do agente poluidor, onde todas as pessoas possam usar e gozar do meio ambiente ecologicamente equilibrado, e assim essas mesmas pessoas são responsáveis pela sua guarda e proteção. 0 tratamento e destinação final do lixo têm relação direta com as condições de higidez do meio ambiente e os indicadores de saúde. 0 que diz o meio ambiente até então equilibrado foi afetado pelo povo em uso comum, não havendo como ser desfeito tal ato aonde se foi afetado, cabe a pena de violação constitucional.

Conclusão: notavelmente se observou que apenas o serviço prestado através da administração pública não é suficiente, pois mesmo a população sendo a maior interessada em seu bem-estar, é necessário a sensibilização para o devido descarte do lixo. Além de expor conceitos e sugerir modos de estruturação das tarefas, a publicação apresenta critérios orientadores. Redigido em linguagem simples e direta, aclarada com farta ilustração, o trabalho é acessível a autoridades, administradores, a todos quantos se interessem pela questão da limpeza urbana. Parte do pressuposto que o conhecimento é ingrediente essencial à solução do problema, menos lixo em vias públicas em locais indevidos, mais saúde e um ambiente ecologicamente equilibrado.

PALAVRAS-CHAVE: LIMPEZA URBANA, AGENTE POLUIDOR, AMBIENTE ECOLOGICAMENTE EQUILIBRADO. 


\title{
SÍNDROME DE CHURG-STRAUSS: UMA SÍNDROME RARA DISFARÇADA DE DOENÇAS COMUNS
}

\author{
ALFREDO OLIVEIRA SARUBBY DO NASCIMENTO, ANANGÉLICA SILVA GUIMARÃES, HENRIQUE \\ MOREIRA DE OLIVEIRA, ISADORA LUIZA GOMES PAGÔTTO, MYKAELA LEADYLA FERREIRA LOPES, \\ FERNANDA SANTOS DE OLIVEIRA, ROSANA DE CÁSSIA OLIVEIRA
}

INSTITUTO MASTER DE ENSINO PRESIDENTE ANTÔNIO CARLOS - IMEPAC

alfredosarubby@gmail.com

Apresentação de Pôster

Resumo

Área do Conhecimento: Saúde coletiva e bem-estar

Introdução: Em 1951, Churg e Strauss, após necropsia de 13 pacientes observaram seis sintomas característicos: asma de moderada a grave, eosinofilia periférica, mono ou polineuropatia, infiltrados pulmonares transitórios, comprometimento dos seios paranasais e eosinófilos extravasculares. Esse quadro passou a caracterizar a síndrome de Churg-Strauss - SCS. Por ser uma doença rara, esse relato de caso foi proposto com o intuito de compartilhar as características dessa Síndrome com toda a comunidade acadêmica.

Objetivo: Avaliar o curso do diagnóstico nas complicações respiratórias apresentadas por paciente com síndrome de Churg-Strauss.

Metodologia: 0 relato foi desenvolvido a partir do depoimento do paciente, dos exames complementares do tratamento e artigos científicos presentes em plataformas digitais (Scielo e Pubmed).

Relato de Experiência: Paciente G.K.F.D., sexo feminino, parda, 24 anos, natural de Anápolis-GO. Exames pré-cirúrgicos para procedimento no menisco em janeiro de 2018 mostraram elevada taxa de eosinófilos livres no sangue, parâmetro considerado irrelevante à época. Em março de 2018 procurou atendimento médico por causa de crise de tosse e grave quadro de sinusite. Novamente a taxa de eosinófilos estava elevada, sendo atribuindo-lhe diagnóstico de asma. Iniciou terapêutica com corticoide (Predsim $60 \mathrm{mg}$, uma vez ao dia, por 4 dias e $40 \mathrm{mg}$ no último dia) e Alenia (Fumarato de formoterol $12 \mathrm{mcg}$ e Budesonida 400mcg, duas vezes ao dia e uso continuo). 0 índice de eosinófilos diminuiu durante o tratamento, mas voltou a subir em seguida. Concomitante, o volume de secreções nos pulmões aumentou gerando desconforto respiratório. Recebeu então diagnóstico de pneumonia aspirativa. 0 tratamento com corticoides, antibióticos e analgésicos ocorreu até novembro de 2018, sem sucesso. Realizou novos exames de sangue, tomografia computadorizada do tórax e biópsia pulmonar e em dezembro de 2018 foi diagnosticada com a síndrome de Churg-Strauss, por pneumologista.

Considerações finais: Por se tratar de síndrome rara, dificilmente se observa um quadro semelhante na prática clínica cotidiana e no ensino médico. Nesse sentido, a demora no diagnóstico, que resultou em perda da qualidade de vida da paciente pode ser atribuída à própria raridade e ao curso da doença que mimetiza outras patologias comuns, como a asma e a pneumonia aspirativa. A história natural da síndrome SCS divide-se em três fases: a primeira e mais longa que cursa com asma e sintomas de rinite e sinusite; a fase eosinofílica, que se pode manifestar em anos; e a fase vasculítica, que pode ser grave e aumentar a morbimortalidade dos pacientes. Nesse sentido, é fundamental o olhar atento dos profissionais de saúde aos diagnósticos diferenciais, de forma a maximizar o tratamento com vistas ao bem estar do paciente.

PALAVRAS-CHAVE: SÍNDROME DE CHURG-STRAUSS; EOSINOFILIA ELEVADA; DEMORA NO DIAGNÓSTICO; QUALIDADE DE VIDA. 


\title{
SÍNDROME DE FOURNIER: A IMPORTÂNCIA DA ATENÇÃO BÁSICA NOS CUIDADOS PÓS-OPERATÓRIOS
}

\author{
MARCOS HENRIQUE PEREIRA MARCOS PEREIRA, ADILSON BRÁS PESSIM BORGES FILHO, ALFREDO \\ OLIVEIRA SARUBBY DO NASCIMENTO, FERNANDA SANTOS DE OLIVEIRA, RAFAELA MIRANDA \\ PROTO PEREIRA, RAPHAELA ALVES VILELA GARCIA, ROSANA DE CÁSSIA OLIVEIRA, FERNANDA \\ SANTOS DE OLIVEIRA
}

INSTITUTO MASTER DE ENSINO PRESIDENTE ANTÔNIO CARLOS - IMEPAC

marcoshpharma@hotmail.com

Apresentação de Pôster

Resumo

Área do Conhecimento: Saúde coletiva e bem-estar

\begin{abstract}
Introdução: A síndrome de Fournier é uma fasceíte necrotizante que acomete região perianal e genital. 0 tratamento baseia-se no manejo cirúrgico, variando desde a simples drenagem até o desbridamento radical, uso de antibióticos e medidas de suporte. Os pacientes pós-cirúrgicos com alta hospitalar são referenciados para a atenção primária, sendo esta a responsável pela continuidade da assistência.

Objetivo: Conhecer os desafios pós-cirúrgicos e complicações psicossociais enfrentadas por paciente com histórico de Síndrome de Fournier, na atenção primária no município de Itumbiara-GO.

Metodologia: Relato de caso obtido por meio do acompanhamento de paciente pelos alunos do $2^{\mathrm{o}}$ período do curso de Medicina do IMEPAC Itumbiara em visita domiciliar dos profissionais de saúde da Unidade Básica de Saúde da Família “Dr. Mário Guedes”, no município, de abril e maio de 2019. Foi realizada a análise de variáveis de complicação do paciente por meio de determinantes sociais (modelo Dahlgren e Whitehead). Paciente e familiares receberam orientações quanto ao uso de antibióticos, a troca de curativos, doenças associadas e o prognóstico esperado.

Relato de Experiência:

V.L.S.F., masculino, 41 anos, com quadro de Síndrome de Fournier, em antibioticoterapia após cirurgia de drenagem e retirada de tecido necrótico, apresentou queixas de dificuldades no cuidado da lesão e em interações sociais, até mesmo com familiares. 0 tratamento de escolha foi o alternativo Ciprofloxacino $500 \mathrm{mg}$ de 12 em 12 horas e Clindamicina 600mg de 8 em 8 horas por 7 dias, devido a não disponibilidade da Gentamicina na rede pública. Foi orientado a troca de curativos duas vezes ao dia.

Observou-se o desconforto do paciente no momento dos cuidados que estão sendo realizados por uma enteada devido a lesão ser encontrar na região perianal, acometendo o órgão genital.

Outro fator de complicações psicossociais do paciente foi a recusa de sua cônjuge em se deitar na mesma cama com o marido devido ao receio de transmissão por contato, perspectiva essa que foi alterada após ser informada sobre as causas da doença pelos profissionais de saúde.

Também foi percebida a presença de fatores de risco para o desenvolvimento da doença; a presença de diabetes mellitus, a hipertensão arterial e condições de moradia (higiene precária, desorganização e lixo próximo à casa), além de um serviço público de coleta de lixo ineficiente.

Considerações finais: A síndrome de Fournier é uma doença rara e deve ser tratada com urgência por ter rápida evolução e causar mutilação de tecidos saudáveis. Nesse sentido, observou-se que o apoio constante da equipe multiprofissional da Unidade Básica de Saúde da Família “Dr. Mário Guedes” ao paciente e família, no que tange aos cuidados pós-operatórios e orientações bio-psico-sociais resultaram na evolução satisfatória do quadro.
\end{abstract}

PALAVRAS-CHAVE: SÍNDROME DE FOURNIER; ATENÇÃO BÁSICA; EQUIPE MULTIPROFISSIONAL. 


\title{
SISTEMA DE INTEGRAÇÃO LAVOURA - PECUÁRIA NO AUMENTO DA PRODUÇÃO ANIMAL INTERLIGADO AO DESENVOLVIMENTO SOCIOAMBIENTAL.
}

\author{
MATHEUS BATISTA PEREIRA, FERNANDO FERREIRA TEIXEIRA E BASTOS, HÉLIDA FERNANDES LEÃO, \\ RAFAEL QUIRINO MOREIRA
}

INSTITUTO MASTER DE ENSINO PRESIDENTE ANTÔNIO CARLOS - IMEPAC

matheusbatistapereira@hotmail.com

Comunicação Oral

Resumo

Área do Conhecimento: Responsabilidade, Tecnologia e Ciência

Resumo

A iLP (Integração Lavoura-Pecuária) consiste na implantação de diferentes sistemas produtivos de grãos, fibras, carne, leite, agroenergia e outros, na mesma área, em plantio consorciado, sequencial ou rotacionado. Dentro da fazenda, o uso da terra é alternado, no tempo e no espaço, entre lavoura e pecuária. E é no potencial sinergismo entre os componentes pastagem e lavoura que reside grande parte dos benefícios da iLP (Vilela).

A utilização deste método tem sido utilizada, não apenas visando a produtividade, mas também, em relação a proteção do meio ambiente, correção de solo, entre outros aspectos.

Objetivo

Estudar técnicas e analisar os novos rumos para o aumento da produção em conjunto ao desenvolvimento socioambiental, dentro da integração lavoura - pecuária.

Metodologia

Trata-se de uma revisão de artigos, relacionado ao tema Integração Lavoura - Pecuária. Foram realizadas buscas no portal Google Acadêmico, Embrapa Pastagens, Embrapa Gado de Corte, utilizando os seguintes descritores: Pastagens, Produtividade, Desenvolvimento Socioambiental Pecuário, sendo incluídos artigos que relatam a Integração Lavoura - Pecuária, como instrumento de aumento de produtividade e sua importância para a proteção ambiental, publicados na língua portuguesa.

Resultados

A partir da leitura na íntegra, verificou-se que foram desenvolvidas associações, como a criação da: Unipasto que, atua em prol da pesquisa cientifica para o lançamento de novos cultivares forregeiras e tecnologias pra diversificar e fortalecer o desenvolvimento agropecuário, como também uma ferramenta web que permite que produtores e técnicos façam simulações futuras do cultivo de pastagens.

Identifica-se que a otimização do uso da terra, eleva os patamares de produtividade, diversificando a produção e gerando produtos de qualidade. Com isso reduz a pressão sobre a abertura de novas áreas. Verifica - se entre os principais benefícios da ILPF.

melhoria do bem-estar animal em decorrência do conforto térmico e melhor ambiência;

otimização e intensificação da ciclagem de nutrientes no solo;

melhoramento da qualidade e conservação das características produtivas do solo;

manutenção da biodiversidade e sustentabilidade da agropecuária;

melhoria do bem-estar animal em decorrência do conforto térmico e melhor ambiência;

Conclusão

As demandas por produtos agrícolas, pecuários e florestais são crescentes, assim como a necessidade de preservação da vegetação natural, aumentando as exigências sobre sistemas de produção pecuários, para minimizar impactos ambientais. Sistemas de integração lavoura-pecuária-floresta (iLPF), para recuperação e intensificação do uso de pastagens, são alternativas viáveis do ponto de vista técnico, ambiental e sócio econômico, entretanto, são mais complexos, exigem conhecimentos de outras áreas e maiores investimentos iniciais. (VILLA ALVES)

PALAVRAS-CHAVE: PECUÁRIA, AGRICULTURA, PRODUÇ̃̃O, BENEFÍCIOS, DESENVOLVIMENTO SOCIOAMBIENTAL. 


\title{
SISTEMA GERENCIAL E SEUS IMPACTOS NO PLANEJAMENTO TRIBUTÁRIO
}

\author{
MARCIO HENRIQUE RODRIGUES SÃO JOSÉ, GABRIEL BATISTA LOURENÇO PEIXOTO, JÉSSICA \\ APARECIDA DE OLIVEIRA SILVA, MIRIAN FERREIRA DE ALMEIDA, PAOLA CARDOSO DA SILVA, \\ FABIANO JOSE LUCAS
}

INSTITUTO MASTER DE ENSINO PRESIDENTE ANTÔNIO CARLOS - IMEPAC

marciosaojose18@gmail.com

Apresentação de Pôster

Resumo

Área do Conhecimento: Responsabilidade e Negócios

Introdução: No campo investigado, notamos que é necessário adotar um sistema de gestão e automatizar as atividades da empresa e proporcionar maior confiabilidade às informações geradas possibilitando a tomada de decisões na base em dados concretos e otimizando o tempo dos gestores. Por meio do sistema é possível identificar falhas, desperdícios, gargalos, automatizar atividades rotineiras e melhorar a comunicação com clientes e fornecedores, outra possibilidade de impor um sistema de gestão é gerar relatórios com muitas facilidades comparando os indicadores de desempenho de cada uma das áreas da empresa.

Objetivo: Relatar a experiência sobre os determinados fatores apresentados, que nos apresenta a importância de um planejamento tributário para melhor funcionamento da empresa.

Metodologia: Tendo em vista o desenvolvimento de um trabalho de pesquisa utilizando a Metodologia da Problematização com o Arco de Maguerez, escolhemos como campo de observação da realidade uma empresa do ramo alimentício. Tal escolha se deve pela disponibilidade de oferecer informações de grande importância, por parte dos administradores.

Resultados: No campo investigado, notamos que é necessário adotar um sistema de gestão e automatizar as atividades da empresa e proporcionar maior confiabilidade às informações geradas possibilitando a tomada de decisões na base em dados concretos e otimizando o tempo dos gestores. Por meio do sistema é possível identificar falhas, desperdícios, gargalos, automatizar atividades rotineiras e melhorar a comunicação com clientes e fornecedores, outra possibilidade de impor um sistema de gestão é gerar relatórios com muitas facilidades comparando os indicadores de desempenho de cada uma das áreas da empresa. Ao procurar fatores imediatos relacionados a falta de um sistema gerencial encontramos principalmente a identificação incorreta dos campos da nota fiscal, a ineficiência do controle de estoque, manuseio indevidos de livros contábeis, a falta de um planejamento tributário e o desconhecimento de custo da empresa. A principal função é reunir todas as informações em um único lugar e possibilitar sua comparação de maneira simples e efetiva, sendo possível gerenciar as contas a receber, a pagar, o fluxo de caixa, a disponibilidade de capital de giro e acompanhar o pagamento de juros e créditos realizando o controle financeiro em sua totalidade.

Conclusão: Compreendemos que estudar mais profundamente sobre este tema buscando possíveis soluções para esse problema, contribuirá para redução de gastos na área de produção, maior ganho na revenda, maximização do lucro, além da otimização da eficiência dos serviços prestados. E finalmente para nossa formação e experiencia, foi apresentado a importância de um planejamento tributário para o melhor funcionamento da empresa.

PALAVRAS-CHAVE: SISTEMA; PLANEJAMENTO, ESTOQUE, CUSTOS, NOTA FISCAL, LIVROS CONTÁBEIS. 


\title{
TECNIFICAÇÃO DA PROPRIEDADE, VISANDO A PRODUTIVIDADE LEITEIRA.
}

\author{
MATHEUS BATISTA PEREIRA, FERNANDO FERREIRA TEIXEIRA E BASTOS, HÉLIDA FERNANDES LEÃO, \\ RAFAEL QUIRINO MOREIRA
}

INSTITUTO MASTER DE ENSINO PRESIDENTE ANTÔNIO CARLOS - IMEPAC

matheusbatistapereira@hotmail.com

Apresentação de Pôster

Resumo

Área do Conhecimento: Responsabilidade, Tecnologia e Ciência

Atualmente existem diversas técnicas que visam o aumento da produtividade no campo, porém com o tempo se tornam obsoletas, sendo necessário implantar novas tecnologias, treinamento de mão de obra, melhoramento genético, nutrição animal e sanidade, são pontos que em conjunto contribuem e resultam no aumento da produção. Diante da importância da atividade leiteira, a não tecnificação da propriedade se torna um problema que deve ser solucionado para que não se prejudique a cadeia produtiva.

Objetivo

0 presente trabalho tem como objetivo determinar, conhecer e aplicar técnicas, que beneficiem a propriedade, tendo como principal propósito o aumento da produção leiteira, no mesmo sentindo reduzindo custos e preservando o meio ambiente.

Metodologia

Trata-se de uma revisão de artigos científicos, relacionado ao tema tecnificação da propriedade, visando o aumento da produtividade leiteira. Foram realizadas buscas em portais de artigos científicos, utilizando os seguintes descritores: Técnicas Pecuária, Produção, Custos, Meio Ambiente, Produtividade Leiteira, sendo incluídos artigos que relatam a Tecnificação da Propriedade Rural, como instrumento de aumento de produtividade e sua importância para a proteção ambiental, publicados na língua portuguesa.

Resultados

Para a implantação de novas tecnologias devemos observar alguns aspectos de suma importância para a propriedade, tais como: A tecnologia a ser implantada irá caminhar com o termo de sustentabilidade? Qual benefício além da produtividade leiteira está tecnologia ira trazer ao produtor e a propriedade? Se a maximização da tecnologia e trabalho rural, irá trazer vantagens congruentes para a propriedade.Para que o produtor saiba como aumentar as tecnologias já existentes ou implantar novas, faz se necessário que ele conheça qual o sistema de escrituração zootécnica usado em sua propriedade, analise e avalie por exemplo a inseminação artificial como método de aumento de animais e consequentemente produção, levando em conta que, esta tecnologia tem sido responsável pelo aumento de produção em diversas fazendas e é considerado um método bastante seguro, desde que tenha profissionais habilitados e responsáveis pelo mesmo. Outro fator observado e de grande relevância é a parte da nutrição animal, como o rebanho se alimenta, pode resultar no aumento ou queda da produção, para cada período de desenvolvimento temos alimentações especificas.

Considerações Finais

Em suma por todos os fatores apresentados e expostos, sabemos da importância da tecnologia e acreditamos no aumento da produção interligado ao desenvolvimento pecuário socioambiental, e que se o produtor rural, trabalhador rural e médico veterinário trabalharem em conjunto para o aumento não só da produção em determinada propriedade, mas também para o aumento da pecuária leiteira brasileira, podemos ter grandes conquistas para o nosso rebanho como um todo.

PALAVRAS-CHAVE: TÉCNICAS, PRODUÇÃO, CUSTOS, MEIO AMBIENTE. 


\title{
TERRORISMO E O DIREITO PENAL DO INIMIGO- A ANÁLISE DA INFLUENCIA DO DIREITO PENAL DO INIMIGO SOBRE O TERRORISMO
}

\author{
JANAÍNA CARDOSO AMORIM, DAIANE VIEIRA PINTO DA SILVA,
}

INSTITUTO MASTER DE ENSINO PRESIDENTE ANTÔNIO CARLOS - IMEPAC

janaina.ca@hotmail.com

Apresentação de Pôster

Resumo

Área do Conhecimento: Sustentabilidade e Direitos

0 assunto abordado nesta pesquisa faz menção à influência do Direito Penal do Inimigo na prevenção ao Terrorismo que retratado de forma corriqueira no cenário mundial tem sido tema cada vez mais discutido e aprofundado. Desde o grande atentado terrorista de 11 de setembro de 2001, diversas medidas radicais foram adotadas em vários países com o objetivo de evitar ataques terroristas. Porém com a adoção dessas medidas muitas pessoas foram presas e torturadas até que se chegasse a se ter realmente um crime, é aí que entra em cena o Direito Penal do Inimigo. PROBLEMA DE PESQUISA Considerando o aumento significativo no número de atentados terroristas ao longo dos anos e a enorme necessidade de se buscar um meio de prevenção do mesmo, a problemática desta pesquisar é indagar: qual a relação que se estabelece quando se aborda a temática da prevenção do Terrorismo e o Direito Penal do Inimigo? OBJETIVO Quanto ao objetivo a ser alcançado, refere-se à tentativa de compreender a necessidade da prevenção ao terrorismo e porque ela tem sido analisada correlata com o direito penal do inimigo, demonstrando o caminho que foi percorrido para que se chegasse a essa conclusão. MÉTODO A presente pesquisa adotará o método dedutivo, partindo de alegações gerais para alegações particulares, de forma a alcançar os resultados propostos na problemática em questão. RESULTADOS ALCANÇADOS Após explanar o que seria o terrorismo e indicar ações que o configuram, a Lei criminalizou a fase de preparação delituosa tendente a consumar tal delito. Ao analisarmos verificamos que o legislador aparentemente esqueceu de elaborar um tipo remetido e uma norma explicativa para "terror social" e para "organização terrorista", o que vai de encontro a ideologia do direito penal do inimigo reproduzido em medidas penais. A Lei 13.260/16 declara o sujeito ativo dos crimes previstos nela como uma pessoa perigosa, razão pela qual, a sua condição pessoal já revela a necessidade da intervenção penal. A reprovação social, nestes casos, concentra-se no desvalor da ação. A simples possibilidade de causa de um resultado ilícito justifica a antecipação da tutela ao bem jurídico. 0 perigo é mediato, mas a intervenção estatal deve ser imediata. Concluindo, estamos diante de um elemento subjetivo vago uma vez que é impossível de se determinar este alcance em razão da indeterminação do bem jurídico tutelado. Esta mitigação do princípio da estrita legalidade é imperiosa porquanto não ser possível prever a conduta do inimigo, que deve ser combatido antes mesmo de iniciar suas condutas. Os tipos penais que punem atos preparatórios refletem crimes de perigo. Para o terrorismo, de forma vigorosa, o legislador criminalizou a preparação nos limites até mesmo da ideação. Tem-se aqui o chamado "delito obstáculo", em que a incriminação reclama a intervenção estatal a momento anterior à situação de perigo imediato PALAVRAS-CHAVE: DIREITO PENAL , DIREITO PENAL DO INIMIGO, TERRORISMO. 


\title{
TESTE DE HIPÓTESE
}

\author{
OTONIEL GONÇALVES DE ALMEIDA, DANIELA CAETANO DA SILVA COSTA, MÁRCIO ALBERTO DE \\ MELO, RAPHAELA DA SILVA OLIVEIRA, RAYRA RANYE DA SILVA RAMOS, FREDERICO CELESTINO \\ BARBOSA
}

INSTITUTO MASTER DE ENSINO PRESIDENTE ANTÔNIO CARLOS - IMEPAC

otonielestrela@yahoo.com.br

Apresentação de Pôster

Resumo

Área do Conhecimento: Responsabilidade e Negócios

Introdução: Teste de hipóteses, teste estatístico ou teste de significância é um procedimento estatístico que permite tomar uma decisão entre duas ou mais hipóteses ou hipótese alternativa utilizando os dados observados de um determinado experimento. Por meio da teoria da probabilidade, é possível inferir sobre quantidades de interesse de uma população a partir de uma amostra observada de um experimento científico. Por exemplo, estimar pontualmente e de forma intervalar um parâmetro de interesse, testar se uma determinada teoria científica deve ser descartada, verificar se um lote de remédios deve ser devolvido por falta de qualidade, entre outros. Por meio do rigor matemático, a inferência estatística pode ser utilizada para auxiliar a tomada de decisões nas mais variadas áreas.

Objetivo: Este trabalho tem como objetivo estudar e entender a função do teste de hipóteses.

Metodologia: Os testes de hipóteses são utilizados para determinar quais resultados de um estudo científico podem levar à rejeição da hipótese nula a um nível de significância pré-estabelecido. 0 estudo da teoria das probabilidades e a determinação da estatística de teste correta são fundamentais para a coerência de um teste de hipótese. Se as hipóteses do teste de hipóteses não forem assumidas de maneira correta, o resultado será incorreto e a informação será incoerente com a questão do estudo científico. Os tipos conceituais de erro (erro do tipo I e erro do tipo II) e os limites paramétricos ajudam a distinguir entre a hipótese nula e a hipótese alternativa. A hipótese nula é a hipótese assumida como verdadeira para a construção do teste. É a teoria, o efeito ou a alternativa que se está interessado em testar, já a hipótese alternativa é considerada quando a hipótese nula não tem evidência estatística.

Resultados: Com a aplicação do teste de hipóteses foi possível identificar várias analises populacionais, podendo comprovar ou negar uma declaração, porém podemos corrigir o nível de significância para ser pequeno antes da análise, trabalhando com uma variação de 5\%, sempre gerando um resultado com 95\% de confiabilidade.

Conclusão: Através das análises aplicadas podemos concluir que o teste de hipótese é uma importante ferramenta para testar uma afirmação sobre uma propriedade da população, sendo uma afirmação ou uma asserção. 0 que permite o auxílio na tomada de decisões.

PALAVRAS-CHAVE: TESTE DE HIPÓTESES; AMOSTRA; POPULAÇÃO. 


\title{
TOJOTA: TORNEIO DE JOGOS DE TABULEIRO COMO ESTRATÉGIA DE APRENDIZAGEM
}

\author{
LEONARDO DE SOUZA E SILVA, MARIA TERESA DE BEAUMONT
}

CENTRO UNIVERSITÁRIO CLARETIANO

leonardosouza.silva23@outlook.com

Apresentação de Pôster

Resumo

Área do Conhecimento: Agenda 2030 e os Objetivos de Desenvolvimento Sustentável

Introdução: Trata-se de um jogo promovido pelo curso de Pedagogia do IMEPAC em parceria com a Instituição Cristã de Assistência social de Uberlândia (ICASU).

Objetivo: Realizar uma competição de um jogo de tabuleiro como atividade educativa lúdica, visando, ainda, a interação social entre os participantes.

Metodologia: Foram construídas cinco réplicas do jogo Ricochet Robots, de Alex Randolph, utilizando-se: tabuleiro em MDF, marcadores de papel, robôs impressos na impressora 3D da IES, ampulhetas e tintas para tecido. 0 contexto do jogo se passa em uma fábrica onde trabalham robôs que, por uma pane, ficaram desgovernados. Isso lhes causa um movimento contínuo, parando de "andar" quando encontra um obstáculo: bordas externas do tabuleiro, "paredes" e outros robôs. Há os objetivos que são quatro formas geométricas: quadrado, triângulo, círculo e hexágono de quatro cores diferentes: azul, amarelo, verde e vermelho, espalhadas em quatro quadrantes do tabuleiro. Há as fichas de objetivo: uma forma geométrica de cada cor. Há quatro robôs, um de cada cor, colocados pelos jogadores em posições aleatórias. É um jogo de raciocínio rápido que consiste em levar o robô com a cor corresponde à da ficha de objetivo até o seu objetivo. Inicialmente, é sorteada uma ficha de objetivo, por exemplo, círculo azul que vai para o centro do tabuleiro. A seguir os jogadores definem, mentalmente, o trajeto que o robô (azul) fará até chegar ao objetivo (círculo azul), respeitando os obstáculos. Quando encontra um obstáculo, o robô muda de direção. Cada vez que o robô se desloca de um ponto até um obstáculo, é considerado um movimento. Assim, mentalmente, ao definir o trajeto, o jogador conta quantos movimentos serão necessários. Quando tiver certeza da quantidade de movimentos que o robô fará, o jogador anuncia e gira a ampulheta. Durante 1 minuto, ele mesmo e os demais jogadores continuam planejando e anunciando, tentando uma quantidade menor de movimentos. Transcorrido o tempo, aquele que tiver anunciado a menor quantidade de movimentos deve reproduzir o trajeto, no tabuleiro, movendo o robô até o objetivo. Esse jogador fica com a ficha. Vence aquele que obtiver mais fichas.

Relato da experiência: Os 30 participantes foram selecionados entre os alunos do curso de Formação da ICASU, solicitados a responder cinco desafios de lógica, dentre aqueles que obtiveram melhor desempenho, quatorze com $100 \%$ de acertos e dezesseis com $80 \%$, divididos em quatro equipes. 0 torneio foi realizado na Brinquedoteca da IES, onde os participantes obtiveram instruções sobre o jogo. Cada equipe jogou uma partida e os vencedores disputaram a final. 0 vencedor ganhou como prêmio um cartão fidelidade da empresa Table Games.

Considerações finais: Consideramos produtivo o uso de jogos analógicos para o desenvolvimento do raciocínio lógico, bem como a interação promovida nessa circunstância. Esperamos realizar outras edições deste torneio.

PALAVRAS-CHAVE: JOGO; RACIOCÍNIO; INTERAÇÃO; APRENDIZAGEM. 


\title{
TRABALHO VOLUNTÁRIO: A VIVÊNCIA DE ACADÊMICOS DE MEDICINA EM VIAGEM MISSIONÁRIA AO CONTINENTE AFRICANO.
}

\author{
EMANNUEL NOVAES DE CARVALHO, NATHÁLIA NUNES BESSA SOUSA, THAIS RIBEIRO OLIVEIRA \\ SANTOS DE MARCELLO, JULIANA PONTES PINTO FREITAS
}

INSTITUTO MASTER DE ENSINO PRESIDENTE ANTÔNIO CARLOS - IMEPAC

emannuelnovaes@hotmail.com

Apresentação de Pôster

Resumo

Área do Conhecimento: Saúde coletiva e bem-estar

Introdução: A Organização Não Governamental (ONG) Missão África foi fundada em 2012 com o intuito de atuar na transformação da realidade de pessoas que vivem em situação de miséria e vulnerabilidade em Moçambique. 0 objetivo da ONG é contribuir de forma diferenciada para o desenvolvimento do ser humano em sua totalidade, estabelecendo assim maior justiça social por meio da promoção de saúde e da educação de crianças e adultos, que vivem em regiões de extrema pobreza. Ambiciona-se que por meio da mudança da realidade individual essas pessoas sejam agentes transformadores da comunidade que estão inseridas. Para dar continuidade a esse trabalho, a ONG organizou sua $18^{a}$ viagem missionária com o objetivo de levar atendimento digno, amplo e cuidadoso para o maior número de pessoas possível, com base no amor, respeito, fé e cooperativismo.

Metodologia: Este projeto foi desenvolvido a partir dos relatos de experiência de três estudantes de medicina em Novembro de 2018, durante à 18ª Missão África em Moçambique, com uma equipe composta por 25 voluntários de diversas áreas do conhecimento.

Relato da experiência: Foram 10 dias de atendimento em várias comunidades onde mais de mil pessoas receberam atendimento médico e nutricional adequado, além de doações de brinquedos, roupas, chinelos e leite em pó. Em todos os atendimentos, os pacientes passaram por uma avaliação clínica detalhada e, foram feitos registros dos dados antropométricos e socioeconômicos de todas as crianças assistidas pela ONG. Analisou-se as circunferências torácica, abdominal e braquial, peso, altura e IMC. Os dados obtidos eram prontamente avaliados por um nutricionista que realizava a imediata intervenção nutricional à partir das necessidades de cada criança. Posteriormente, acontecia a avaliação clínica por parte das médicas da equipe, as medicações prescritas e os testes rápidos de malária eram realizados pela equipe de enfermagem. Além dos atendimentos, houve dias de palestras e capacitações para estudantes e profissionais da saúde no Instituto Superior de Ciência e Tecnologia Alberto Chipande, no Hospital do Dondo e no Hospital da Beira. Por fim, em um projeto de educação profissionalizante chamado Yang África, realizou-se um bate papo com os jovens ali inseridos, sobre Infecções Sexualmente Transmissíveis, uso de preservativos e a importância do planejamento familiar.

Considerações finais: É valido enaltecer a aprendizagem desenvolvida durante este projeto, no qual foi possível conceber a Medicina como uma verdadeira missão. 0 crescimento alcançado durante essa experiência transcende o acadêmico e atinge a vida pessoal, espiritual e emocional. Diante da sublimidade e da magnificência da experiência do voluntariado, muito do que antes era importante, desapareceu e entendeu-se que o voluntário é quem ao doar, recebe o que mais importa, em uma dimensão que vai além da compreensão que pode ser proposta em um texto escrito.

PALAVRAS-CHAVE: VOLUNTÁRIO; HUMANIZAÇÃO; SERVIÇO SOCIAL. 


\title{
TREINAMENTO E DESENVOLVIMENTO
}

\author{
JAÍNE SOUZA DOS SANTOS, ANNA GABRIELLY CASTRO RIBEIRO, GABRIEL SEVERINO DA SILVA \\ FILHO , IZABELLA DE OLIVEIRA COSTA, WAGNERSON BATISTA NEVES, ROSANIA EMILIA
}

INSTITUTO MASTER DE ENSINO PRESIDENTE ANTÔNIO CARLOS - IMEPAC

jaynne19souza@gmail.com

Apresentação de Pôster

Resumo

Área do Conhecimento: Educação e Inclusão

Introdução: A área de Gestão de Pessoas desempenha uma função estratégica nas organizações, garantindo a qualidade do trabalho e a satisfação dos clientes. Treinamento é a educação profissional que adapta a pessoa para um cargo ou função e está dentro da Gestão de Pessoas. Seus objetivos situados no curto prazo são restritos e imediatos, visando dar ao homem elementos essenciais para o exercício de um cargo, preparando-o adequadamente para ele. 0 treinamento é aplicado de maneira sistemática, através dele, as pessoas aprendem conhecimentos, habilidades e competências em função de objetivos definidos. A ação de treinamento está presente no dia a dia da empresa e dos colaboradores de modo geral, e em particular daqueles voltados para o aumento e aprimoramento de suas habilidades. A partir da observação da realidade vivenciada em uma indústria produtora e exportadora de bens localizada na cidade de Araguari (MG), foi constatada a ausência de controle de treinamento dos funcionários. 0 objetivo do presente trabalho é tentar solucionar o problema de falta de controle. Metodologia: Trata-se de um estudo transversal, descritivo, de caráter quantitativo, realizado através de pesquisa com questionário objetivo, composto por três questões relativas ao treinamento oferecido pela empresa. Relato da experiência: A pesquisa foi realizada com funcionários de indústria produtora e exportadora de bens, existente na cidade de Araguari (MG). 0 tamanho amostral foi definido em 3 (três) funcionários, para que o "n" possua uma margem de erro mínimo. A amostra foi proporcional por setores, sendo os trabalhadores selecionados aleatoriamente. A pesquisa foi conduzida no dia 15 de outubro de 2018, com a aplicação dos questionários aos funcionários selecionados, com foco principal na investigação do problema encontrado: a ausência do controle de treinamento dos funcionários. Considerações finais: Ao final, concluímos que para resolver o problema do controle dos funcionários em relação aos treinamentos que a empresa proporciona, foi elaborada uma planilha, que se utilizada, poderá resolver a falta de controle existente na empresa em questão.

PALAVRAS-CHAVE: GESTÃO DE PESSOAS; TREINAMENTO; CONTROLE DE TREINAMENTO. 


\title{
UM ESTUDO DE CASO: GESTÃO HOSPITALAR EM UMA UNIDADE MISTA DE SAÚDE DE ARAGUARI - MG
}

\author{
TALITTA FIGUEIREDO MATOS, ANA CAROLINA LEITE HANNA, ANNA LAURA SAVINI BERNARDES \\ DE ALMEIDA RESENDE, BRUNA MONIQUE CAMPOS RODRIGUES, FERNANDA FABRÍCIA RESENDE \\ BELO, HERBERT CRISTIAN DE SOUZA
}

INSTITUTO MASTER DE ENSINO PRESIDENTE ANTÔNIO CARLOS - IMEPAC

talittafmatos@hotmail.com

Comunicação Oral

Resumo

Área do Conhecimento: Gestão de recursos econômicos (naturais)

Introdução: Gestão hospitalar é a área responsável pela organização e administração de hospitais, clínicas de saúde, laboratórios médicos entre outros. Nesta área os gestores hospitalares desempenham papeis de planejamento, organização e gerenciamento de processos, envolvendo gestão de pessoas, insumos, equipamentos, logística, recursos financeiros e serviços. A complexidade da estrutura hospitalar está relacionada às características peculiares das atividades desenvolvidas e aos serviços prestados. Diante da evolução da mesma, percebe-se a necessidade da gestão dos hospitais por profissionais capazes de compreender e administrar sua estrutura complexa, prezando pela participação da equipe de saúde multiprofissional.

Objetivo: Analisar a gestão hospitalar de uma unidade mista de saúde de Araguari (MG).

Metodologia: Trata-se de uma pesquisa descritiva, qualitativa, realizada no Hospital Santa Casa de Misericórdia de Araguari, entre o período de março a abril de 2018. 0 local foi escolhido por ser um cenário de saúde que abarca níveis de complexidade crescentes e complexos, com uma gestão organizada e direcionada. Foi elaborado um roteiro semiestruturado com questões que versavam sobre o tema objeto da pesquisa, aplicado diretamente aos gestores do hospital, considerando o controle da gestão, sistemas de informação, divisão/composição dos setores, fluxos de serviços, financiamentos e especialidades oferecidas.

Resultados: A Santa Casa de Araguari é um hospital misto, filantrópico, sem fins lucrativos, cuja gerên cia é estratificada em financeira e administrativa, que se intercomunicam. A administração financeira é responsável pelo setor financeiro propriamente dito,

responsável por pagamento de contas; tesouraria; compras; tecnologia da informação;

farmácia; serviço de nutrição e dietética; faturamento e almoxarifado. Já no

administrativo são inclusos o setor de manutenção, recursos humanos, entre outros. A gestão conta com um sistema informatizado usado nos setores de recepção, financeiro, recursos humanos e tesouraria. Embora a Instituição conte com o apoio dessa tecnologia, os

prontuários são, ainda, manuscritos e únicos. A origem dos recursos financeiros da Instituição é proveniente de $60 \%$ SUS, e $40 \%$ de atendimentos particulares e de aditivos oriundos da Prefeitura e de uma Instituição de Ensino Superior da cidade. Ademais, anualmente o Estado envia o PRO HOSP, um incentivo baseado no número de leitos e de internações anuais.

Conclusão: A gestão hospitalar eficiente é imprescindível para otimizar o funcionamento da Santa Casa, os gestores exercem papéis baseados no entendimento da organização por meio da utilização de práticas específicas, visando fornecer melhor nível de qualidade e profissionalismo.

PALAVRAS-CHAVE: GESTÃO EM SAÚDE; ADMINISTRAÇÃO HOSPITALAR; SISTEMA ÚNICO DE SAÚDE. 


\title{
UMA EXPERIÊNCIA DE APRENDIZAGEM COM CRIANÇAS INSTITUCIONALIZADAS: ATIVIDADE EDUCATIVA E DINÂMICA
}

\author{
GRAZIELLA CRISTINA DUTRA FERREIRA, AMANDA CECÍLIA VIEIRA CHAGAS, GIOVANNA LYSSA DE \\ CASTRO ANDRADE, CLÁUDIA DUTRA CONSTANTIN FARIA
}

INSTITUTO MASTER DE ENSINO PRESIDENTE ANTÔNIO CARLOS - IMEPAC

grazielladutraferreira@gmail.com

Apresentação de Pôster

Resumo

Área do Conhecimento: Educação e Inclusão

\begin{abstract}
Introdução: A família tem papel fundamental no potencial de crescimento e desenvolvimento de uma criança, presumindo-se ser complicado viver e conviver em casas de apoio. A longa permanência de crianças em instituições, a exemplo dos abrigos e orfanatos, é frequente, sendo essencial designar estratégias e intervenções que propiciem subsídios para amparar o viver saudável. Sabe-se que as brincadeiras e ensinamentos dinâmicos são recursos que proporcionam investigação e construção de conhecimento, sendo facilitadores do desenvolvimento pessoal, social e cultural, bem como contribuintes de uma boa saúde mental e simplificadores dos processos de expressão, comunicação, socialização e inclusão, sendo o objetivo da atividade levar às crianças residentes em um abrigo da cidade de Araguari, conhecimento dinâmico e didático acerca de um pouco do que se estuda na Semiologia Médica a fim de proporcionar aprendizagem e distração das rotinas.

Metodologia: A atividade foi desenvolvida por três acadêmicas do curso de Medicina do Projeto de Extensão Hospital dos Ursinhos da cidade de Araguari, com duração de 2 horas e participação de oito crianças de faixas etárias diversas residentes na Casa Lar. Constou de uma dinâmica explicativa e participativa, de abordagem teórico-prática, realizada em 14 de novembro de 2018, a partir de seis peças sintéticas do laboratório de anatomia do Instituto Master de Ensino Presidente Antônio Carlos- IMEPAC para desenvolver a temática órgãos do corpo humano. Como não houve rastreio prévio, as crianças que participaram da atividade foram aquelas que estavam presentes na instituição no momento da dinâmica. Relato da experiência: Houve uma busca pelas acadêmicas de assuntos que pudessem despertar maior interesse nas crianças dentro da Semiologia Médica, sendo escolhido o trabalho com peças sintéticas para representação de órgãos do corpo humano: pulmão, coração, estômago, intestino, fígado e rim, atividade realizada com cada órgão separadamente. Em um primeiro momento foi ministrada uma palestra mostrando cada órgão, sua função e localização no corpo humano. Durante a explicação da temática houve a participação das crianças a partir de respostas frente às perguntas que eram feitas, e a partir de questionamentos que as mesmas apresentavam. Para finalizar, foi entregue para cada criança uma cruzadinha com desenhos sobre o que havia sido explicado. As crianças realizaram a atividade demonstrando conhecimento, curiosidade, vontade de aprender e participar do que era proposto.

Considerações finais: A atividade foi importante para a formação acadêmica das alunas organizadoras, visto que retratou uma experiência única tanto para ensinamento quanto para formação pessoal. As crianças se interessam pelo diferente, se sentem incluídas ao participar e aprendem ao vivenciar ensinamentos que instigam sua capacidade como criança e como adulto em formação.
\end{abstract}

PALAVRAS-CHAVE: CRIANÇAS, ORFANATO, EDUCAÇÃO, INCLUSÃO. 


\title{
USO DA MEDITAÇÃO COMO FERRAMENTA AUXILIAR NO TRABALHO DE PSICÓLOGOS: UM ESTUDO TEÓRICO E REFLEXIVO SOBRE O TEMA
}

\author{
SAMIRA BADARÓ RODRIGUES DE CARVALHO, ANA LÚCIA COSTA E SILVA
}

INSTITUTO MASTER DE ENSINO PRESIDENTE ANTÔNIO CARLOS - IMEPAC

carvalhosamira0@gmail.com

Apresentação de Pôster

Resumo

Área do Conhecimento: Saúde coletiva e bem-estar

Introdução: Gazzaniga, Heatheerton \& Halpern (2018) apresentam a meditação como método mental que foca a atenção em um objeto ou num sentido de consciência, pois o praticante consegue desenvolver, por meio da contemplação, um profundo estado de paz. Estudiosos da área investigaram e descobriram que a técnica possui especificidade na ação do desenvolvimento cognitivo e afetivo relacionado às atividades mentais e físicas. Com isso, a relação do psicólogo com a técnica contribui para o autoconhecimento individual, gerando bem estar e crescimento pessoal. É preciso mencionar que existem duas formas gerais de meditação: a concentrativa, que ajuda no foco e atenção em algo (respiração, visualização de olhos fechados, ou até uma frase) e. a mindfulness, técnica oposta a anterior, trabalhando o relaxamento, pensamento e atenção livre, não reagir sobre a eles, mas deixar fluir. Objetivo: Apresentar, a partir da literatura, como a técnica da meditação pode ser eficaz para auxiliar psicólogos junto aos seus pacientes, em tratamentos terapêuticos. Metodologia: Utilizamos a pesquisa bibliográfica, a partir dos descritores meditação e psicologia, em indexadores brasileiros, como Scielo, Bireme. Buscou-se, na literatura, referenciais que faziam menção quanto ao uso da meditação como ferramenta terapêutica, ligada ao trabalho do psicólogo discutido por alguns profissionais. Resultados: Menezes \& Dell'Aglio (2009) afirmam que a meditação pode ser caracterizada prática nos objetivos semelhantes a algumas técnicas da psicoterapia cognitiva, embora por meios distintos. Gazzaniga, Heatheerton \& Halpern (2018) relatam que além das especificidades técnicas; predisposições genéticas, traços de personalidade, vivências particulares, expectativas, motivações e valores também podem mediar o tipo e a qualidade da resposta que a prática produzirá. Os autores apresentaram que praticantes experientes se expressam melhor, tornam-se mais adaptados, alegres, maduros e autoconfiantes. Considerações Finais: A pesquisa e estudo realizado apresentaram informações relevantes através dos autores à proposta de utilizar esta prática em benefício do indivíduo. Mesmo sob investigação, compreendemos que a utilização da meditação como ferramenta pode auxiliar através atendimentos terapêuticos mudanças comportamentais advindos em relação à personalidade, conduta, pensamento e interação social do paciente.

Palavras-chave: Meditação, Psicologia, Ferramenta.

PALAVRAS-CHAVE: MEDITAÇÃO, PSICOLOGIA, FERRAMENTA. 


\title{
USO DO INFOGRÁFICO COMO INSTRUMENTO FORMATIVO DO PROFISSIONAL CRÍTICO-REFLEXIVO NO CURSO DE MEDICINA
}

\author{
ANA LUCIA COSTA E SILVA, ANNA LUIZA FERREIRA LEMOS, THIAGO ARTUR DE MORAIS,
}

INSTITUTO MASTER DE ENSINO PRESIDENTE ANTÔNIO CARLOS - IMEPAC

anaciacosta332@gmail.com

Comunicação Oral

Resumo

Área do Conhecimento: Saúde coletiva e bem-estar

Introdução: O infográfico, no contexto da educação médica, pode ser compreendido como instrumento coletivo de ensino-aprendizagem, de avaliação formativa e, ainda, somativa. Trata-se de um recurso estético, com vistas à educação em saúde, estruturado a partir da relação conjunta de informações verbais e não verbais, ou seja, são representações visuais que apresentam informações complexas de forma clara e rápida aos olhos do usuário, atraindo e informando grandes audiências. Assim, considerando o eixo formativo do curso de Medicina "Comunicação, Profissionalismo e Humanização", decidiu-se fazer o uso do infográfico como produto de oficinas crítico-reflexivas sobre ética médica e bioética na área da saúde. Objetivo: Utilizar o infográfico como instrumento formativo e somativo sobre ética médica e bioética na área da saúde. Metodologia: 0 projeto foi desenvolvido em sete turmas de acadêmicos do segundo período do curso de Medicina de uma instituição de ensino superior privada do município de Araguari - MG. Inicialmente foi realizada uma exposição dialogada sobre ética médica e bioética na área da saúde para cada uma das turmas, utilizando o Código de Ética Médica e o Código de Ética do Estudante de Medicina. Em seguida, cada turma foi dividida em dois subgrupos e cada subgrupo recebeu uma consigna com a explicação acerca do processo de construção de infográficos na área da saúde. Posteriormente, os subgrupos foram convidados a iniciarem a construção de um infográfico sobre a temática abordada. Após período de elaboração, os subgrupos compartilharam suas produções iniciais e, após socialização, os subgrupos receberam um Termo de Referência para orientação do processo de conclusão e apresentação avaliativa dos infográficos. Relato da experiência: Concluído o processo de construção do infográfico, cada subgrupo o imprimiu em uma folha A3, deixando-o exposto na sala de aprendizagem ativa, em data e horários pré-estabelecidos e elegendo um representante para a apresentação de seu infográfico diante da banca avaliadora. Foram elencados os seguintes critérios avaliativos: relevância e originalidade do tema, postura e comportamento durante a apresentação, objetividade e domínio do assunto, capacidade de expressão oral do grupo e criatividade na forma como abordou a informação, uso correto da referência ao final do trabalho, dificuldades e facilidades na construção do infográfico, o que poderia ter sido melhorado em seu trabalho e se o grupo demonstrou a pesquisa feita durante a apresentação.Considerações finais: A realização do projeto foi de grande valor para a formação acadêmica dos alunos, visto que proporcionou experiências favoráveis ao crescimento profissional no âmbito de sua formação e permitiu a troca de experiências quanto às informações que foram compartilhadas no dia da apresentação do infográfico para avaliação.

PALAVRAS-CHAVE: INFOGRÁFICO, METODOLOGIA ATIVA, MEDICINA, COMUNICAÇÃO, ÉTICA, PROFISSIONALISMO. 


\title{
VALORAÇÃO DO DANO EXTRAPATRIMONIAL
}

\author{
MARIANA REGINA LIOTTI, LUCAS FLÁVIO DE LIMA NETO, RODRIGO GUILHERME TOMAZ
}

INSTITUTO MASTER DE ENSINO PRESIDENTE ANTÔNIO CARLOS - IMEPAC

marianaliotti1@hotmail.com

Apresentação de Pôster

Resumo

Área do Conhecimento: Responsabilidade e Negócios

0 presente artigo busca relatar as modificações inseridas; aprofundando-se no denominado Dano Extrapatrimonial, discorrendo sobre a valoração do mesmo, dentro das relações de trabalho. OBJETIVO: Objetiva-se com o presente trabalho, conhecer os principais pontos e falhas que verifica-se na Reforma Trabalhista, em especial no âmbito do dano extrapatrimonial sofrido em relações empregatícias, discorrendo sobre a valoração do referido dano, tendo a indenização do mesmo, por base de cálculo o salário vigente do empregado. MÉTODO: 0 método utilizado foi o dedutivo, através de pesquisas documentais, com base em materiais jurídicos como livros, jurisprudências e principalmente a Lei $n^{\circ}$ 13.467/2017. RESULTADOS ALCANÇADOS: A responsabilidade civil no Brasil tem como pilar principal o direito civil, entretanto, com o avanço da sociedade a responsabilidade civil, agora, também baseia-se em outros ramos do direito, principalmente o trabalhista. A reforma trabalhista foi aprovada com apenas quatro meses de tramitação e sancionada em 13 de julho de 2017, resultando na lei que já sofreu substancialmente alteração pela medida provisória $n^{\circ} 808 / 2017$, logo no início de sua vigência, demonstrando a falta de preparo do legislador reformista. A reforma trabalhista alterou a CLT e resultante as atualizações da redação da Lei $n^{\circ} 13.467 / 2017$, vem relatando vários temas polêmicos. Um desses temas é a redação do art. 223-G prevendo regras para que a justiça aplique e valorize a indenização sobre o dano extrapatrimonial. Tal discussão pode ser comprovada através da alteração da referida lei pela medida provisória citada neste artigo. 0 artigo versa que as indenizações por dano moral devem ter como base de cálculo o salário do empregado, pontuando que, o profissional que receber mais no trabalho ganhará maior indenização. Exemplo: um diretor assedia sexualmente a secretária que recebe a remuneração de $R \$ 1.500$ e assedia também da mesma forma uma gerente que recebe $\mathrm{R} \$ 6.000$. De acordo com o referido dispositivo a gerente ganharia uma indenização bem maior do que o valor recebido pela secretária. Percebe-se aqui que há uma injusta diferenciação de sentença já que as duas foram abusadas da mesma maneira. Essa situação é incabível, visto que, a dignidade humana é imensurável, possui valor inestimável. Se a ba se de cálculo for o salário dos trabalhadores estão calculando o quanto vale a dignidade humana. Fica a indagação: o quanto vale a dignidade humana? 0 valor recebido de acordo com o salário, foi suficiente para atenuar o sofrimento pelo abuso cometido? CONCLUSÃO: Conclui-se que a reforma trabalhista foi precocemente elaborada e aprovada, demostrando a falta de preparo do legislador. Vemos uma afronta a dignidade humana, quando é valorizado tendo em vista o salário do trabalhador.

PALAVRAS-CHAVE: DIREITO; REFORMA TRABALHISTA; CONSTITUIÇÃO; DANO EXTRAPATRIMONIAL; 


\title{
VIOLAÇAO DOS DIREITOS FUNDAMENTAIS DOS ENCARREGADOS DA APLICAÇÃO DA LEI
}

\author{
MARCIONE LUIZ DE ALMEIDA, KELLYMAN CARDOSO DA SILVA, WOILLE AGUIAR BARBOSA
}

INSTITUTO MASTER DE ENSINO PRESIDENTE ANTÔNIO CARLOS - IMEPAC

marcyonealmeida@yahoo.com.br

Apresentação de Pôster

Resumo

Área do Conhecimento: Sustentabilidade e Direitos

Introdução: O presente estudo colocará em fomento as maneiras que o Estado democrático de Direito trata juridicamente todos os encarregados de aplicação da lei, no tocante a violação de seus direitos e garantias fundamentais. Assim, demonstrara uma nova visão e quais são os seus efeitos.

Objetivo: demonstrar que os sistemas e as leis estão sempre em evolução, e dentro desta evolução fomentar a extensão desta proteção a aqueles que são encarregados de aplicação e preservação dos direitos humanos. Metodologia: Será adotado o método dedutivo, a partir de argumentos gerais para argumentos particulares, fomentando a discussão de forma inversa aos propostos pela sociedade atual e forma se obter uma nova visão de proteção dos direitos e garantias.

Resultados: a proteção aos Direitos fundamentais, ganha força nos séculos XIX e XX com a grande evolução da sociedade, os quais também geram contornos importantes para a construção e manutenção do Estado, diante da necessidade de se penalizar aqueles que desobedecem às leis. Porem mesmo diante da figura forte do Estado, com passar dos anos se mostra ineficiente em proteger aqueles que são encarregados de aplicar a lei, fazendo surgir assim um Estado paralelo que cria as suas regras e regulamentos passando a punir aqueles que não obedecem. Estas punições chegam até a ceifar vidas inocentes com requintes de crueldades. A Constituição da República Federativa do Brasil de 1988 inicia, proclamando em seu art. 1ํㅡ, inciso III, ser a dignidade da pessoa humana o principal fundamento da República. Nas palavras de Ingo Wolfgang Scarlet (2008, p. 63), se o Estado que se diz democrático, não assumir sua função e dar a devida proteção a seus atores estatais protegendo a individualidade e autonomia de todas as pessoas, inclusive dos seus agentes, de tal modo a assegurar o papel do ser humano como sujeito de direitos, o Estado perderá a sua função. A qualidade intrínseca do ser humano se faz necessário para proteger todos os seres humanos inclusive os agentes encarregados para a aplicação da lei.

Conclusão: trata-se de uma reflexão a vulnerabilidade dos agentes do Estado. Em um mundo com tamanha diversidade cultural e social, é difícil imaginar um sistema universal que proteja todos os seres humano e dentre estes destacamos aqui a necessidade de se proteger os agentes encarregados de aplicação da lei. Com base no exposto acima, salta aos olhos que estamos correndo um grande risco, se não começarmos a pensar em uma maneira de proteger esses grupos em especial. Esse tema deve ser de especial reflexão de todo aquele que compõe o arcabouço jurídico brasileiro, para que todos recebam igual consideração e respeito por parte da comunidade e principalmente do Estado.

PALAVRAS-CHAVE: DIREITOS HUMANOS; AGENTES; ENCARREGADOS DE APLICAÇÃO DA LEI; VULNERABILIDADE. 


\title{
VIVÊNCIA DE UMA CUIDADORA DE PACIENTE COM A DOENÇA DE ALZHEIMER: UM RELATO DE CASO
}

\author{
DANIELA MARIN MACHADO SILVEIRA, LANNA SILVA AMORIM , NATHÁLIA NUNES BESSA SOUSA, \\ THASSIA SOARES DE MENDONÇA, LÍBERA HELENA RIBEIRO FAGUNDES DE SOUZA
}

INSTITUTO MASTER DE ENSINO PRESIDENTE ANTÔNIO CARLOS - IMEPAC

danielammsilveira@gmail.com

Apresentação de Pôster

\section{Resumo}

Área do Conhecimento: Saúde coletiva e bem-estar

Introdução: Doença de Alzheimer (DA) representa 60\% dos processos demenciais. Apresenta lento e longo processo de degeneração e início insidioso, ocorrendo por volta dos 65 anos. É de ocorrência esporádica, mas $10 \%$ dos casos são familiares. 0 sintoma inicial é a perda de memória (amnésia anterógrada). Com o decorrer do tempo, o paciente começa a apresentar comprometimentos significativos, tornando-se dependente de terceiros. Assim, o trabalho da equipe multidisciplinar, do cuidador e o apoio familiar são fundamentais para proporcionar ao paciente uma maximização de suas habilidades funcionais remanescentes, proporcionando maior autonomia, dignidade e qualidade de vida, que são obtidos através de cuidados paliativos. 0 objetivo é relatar vivência de uma cuidadora que presta cuidado domiciliar a um paciente com DA, de uma microárea de uma Unidade Básica de Saúde da Família (UBSF) de Araguari-MG. Metodologia: Trata-se de uma pesquisa qualitativa descritiva exploratória, modalidade de relato de caso. A coleta de dados foi realizada por acadêmicos de medicina, em visitas domiciliares realizadas em outubro de 2017. A cuidadora respondeu a uma série de perguntas: histórico profissional, conhecimento dos cuidados destinados a portadores de doenças degenerativas, principais dificuldades enfrentadas cotidianamente, sua relação com familiares do paciente, cuidados paliativos destinados ao paciente e sua importância no quadro clínico geral e na obtenção de qualidade de vida. Relato de experiência: Estudo foi realizado com L.J.S., 48 anos, casada, aposentada, $1^{\text {o }}$ grau incompleto, que presta cuidados ao vizinho, 0.M., 84 anos, aposentado, acamado e reside sozinho. Ela relata que se aproximou do paciente há um ano, passando a ajuda-lo quando este começou a ter quedas, devido alterações de marcha. Há três meses passou a cuidar formalmente do idoso, sendo essa sua primeira experiência com cuidados paliativos. L.J.S. recebeu orientações da UBSF do bairro: realização de curativos nas escaras, higiene pessoal, troca de fraldas e técnica de uso de sonda nasogástrica. Considerações finais: Ainda que os cuidados paliativos sejam essenciais para a qualidade de vida de inúmeros pacientes, o conhecimento a cerca de procedimentos em casos específicos ainda é insuficiente para suprir a demanda, cabendo ao profissional de saúde orientar familiares e cuidadores de acordo com o que é preconizado a cada paciente.

PALAVRAS-CHAVE: ALZHEIMER; CUIDADOS PALIATIVOS; IDOSOS. 


\title{
VIVÊNCIAS DOS ACADÊMICOS DE FARMÁCIA EM GRUPOS DO PROGRAMA HIPERDIA
}

\author{
JOÃO PAULO ASSUNÇÃO BORGES, ALEXSANDRA GABRIELA GUERRA, LAUANE RAMOS DE MATOS, \\ RITA ALESSANDRA CARDOSO, SARAH EDUARDA LIRA MARQUES, JOÃO PAULO ASSUNÇÃO \\ BORGES, RITA ALESSANDRA CARDOSO
}

INSTITUTO MASTER DE ENSINO PRESIDENTE ANTÔNIO CARLOS - IMEPAC

enf_joaopaulo@yahoo.com.br

Apresentação de Pôster

Resumo

Área do Conhecimento: Saúde coletiva e bem-estar

Introdução: A Hipertensão Arterial Sistêmica (HAS) e o Diabetes Mellitus (DM) são doenças crônicas relevantes no contexto da Atenção Primária à Saúde (APS), sobretudo na Estratégia Saúde da Família (ESF). Ações de promoção da saúde e prevenção de doenças por meio da Educação em Saúde são fundamentais para otimizar o cuidado aos usuários dos serviços de saúde. Neste contexto, o Programa Hiperdia representa um eixo de atuação das equipes multiprofissionais que atuam na ESF, com ênfase na captação, cadastramento, acompanhamento e controle dos indivíduos com HAS e/ou DM. Objetivos: relatar a experiência dos acadêmicos do Curso de Farmácia no Estágio Supervisionado em Saúde Pública, realizado na Unidade Básica de Saúde da Família (UBSF), com ênfase na descrição e reflexão da vivência nos grupos Hiperdia. Métodos: Trata-se de um Relato de Experiência, de caráter descritivo e reflexivo, baseado na observação participativa do desenvolvimento de duas reuniões do Grupo Hiperdia, realizadas no mês de abril de 2019 pela equipe da ESF em parceria com profissionais do Núcleo Ampliado de Saúde da Família (NASF). Relato da experiência: As reuniões dos Grupos Hiperdia desta UBSF acontecem periodicamente com intervalo de dois meses, são planejadas pelos agentes comunitários, sob supervisão do enfermeiro coordenador da equipe. 0 público-alvo são usuários cadastrados com HAS e/ou DM e comunidade em geral. As reuniões realizadas contaram com palestras com temas diversificados: "Autocuidado em Doenças Crônicas", "Prevenção e Manejo de Dengue e Influenza", "Alimentação Saudável”, "Sedentarismo e Importância da atividade física" e "O papel do Serviço Social e Psicologia na Atenção Básica". Os profissionais convidados para ministrar as palestras foram: o enfermeiro da UBSF, assistente social, educador físico, nutricionista e psicóloga do NASF. Os acadêmicos puderam observar a dinâmica de desenvolvimento do Grupo Hiperdia, assim como realizar a aferição de pressão arterial e verificação da glicemia capilar dos usuários, sob a supervisão do enfermeiro coordenador. Ao todo, 116 usuários e profissionais da UBSF foram atendidos com a realização das reuniões neste período. Considerações finais: A realização do Grupo Hiperdia representou uma oportunidade de grande valor para a formação acadêmica, visto que proporcionou experiências favoráveis ao crescimento profissional quanto ao conhecimento teórico-prático, proporcionando avanço no entendimento de conceitos e desenvolvimento de habilidades sobre o trabalho e as ações desenvolvidas pelos profissionais no âmbito da APS e ESF. A participação ativa dos acadêmicos nas atividades do Grupo Hiperdia foi fundamental para consolidar a compreensão da importância da promoção da saúde e da prevenção de doenças como pilares da APS e focos da ESF.

PALAVRAS-CHAVE: SAÚDE PÚBLICA; EDUCAÇÃO EM SAÚDE; ATENÇÃO PRIMÁRIA À SAÚDE; DOENÇA CRÔNICA. 


\title{
VOCÊ SOBREVIVERIA NO TITANIC? UM EXEMPLO DE REGRESSÃO LOGÍSTICA
}

\author{
FREDERICO VASCONCELOS DE PAIVA NEVES, ALEXANDRE DE OLIVEIRA, CHRYSLAINE LOURDES \\ CORREIA DE OLIVEIRA, JOÃO GUSTAVO DUARTE SOARES DA SILVA, MATHEUS LUIS DE OLIVEIRA, \\ FREDERICO CELESTINO BARBOSA
}

INSTITUTO MASTER DE ENSINO PRESIDENTE ANTÔNIO CARLOS - IMEPAC

frederico_neves@uol.com.br

Apresentação de Pôster

Resumo

Área do Conhecimento: Responsabilidade, Tecnologia e Ciência

Introdução: A regressão logística é uma técnica recomendada para situações em que a variável dependente é de natureza dicotômica ou binária. Quanto às independentes, tanto podem ser categóricas ou não. A regressão logística é um recurso que nos permite estimar a probabilidade associada à ocorrência de determinado evento em face de um conjunto de variáveis explanatórias.

Objetivo: Frente ao exposto, o objetivo deste trabalho foi estudar sobre a Regressão Logística e suas aplicações no caso da tragédia do Titanic, em 1912.

Metodologia: Trata - se de um estudo estatístico que tem como objetivo produzir, a partir de um conjunto de observações, um modelo chamado Modelos Lineares Generalizados (GLM) e é adequada quando a variável de interesse (resposta) é binária, isto é, "sim" ou "não". Através da Regressão Logística é possível avaliar os fatores de influenciam a ocorrência de determinado evento.

Resultados: Foi possível observar que as características da tripulação na amostra, foram: 424 indivíduos $(59,38 \%)$ não sobreviveram e $290(40,62 \%)$ sobreviveram. Cerca de $68 \%$ dos sobreviventes eram do sexo feminino e $85 \%$ dos não sobreviventes eram do sexo masculino. Em relação a classe, $42 \%$ dos sobreviventes

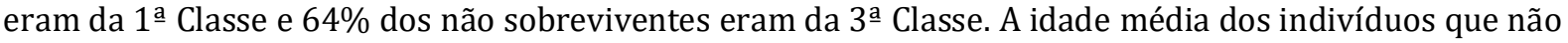
sobreviveram foi de 30,62 anos, sendo a idade mínima de 1 ano e a máxima de 74 anos. A Idade média dos indivíduos que sobreviveram foi de 28,24 anos, sendo a idade mínima menor que 1 ano e a máxima de 80 anos.

Conclusão: Sendo $\mathrm{g}(\mathrm{X})$ a função de ligação, a equação do modelo é dada por:

Fórmula 01

"IFeminino" recebe 1 se o indivíduo é do sexo feminino e 0 se é do sexo masculino, "I2a Classe" recebe 1 se o indivíduo navegava na $2^{\underline{a}}$ Classe e 0 caso contrário e "I $1 \underline{a}$ Classe" recebe 1 se o indivíduo navegava na $1^{\underline{a}}$ Classe e 0 caso contrário. Para calcular a probabilidade de sobrevivência de um indivíduo, E(Y), é necessário aplicar uma função inversa a função de ligação, sendo representada por:

Fórmula 02

Dessa forma, uma Mulher de 42 anos que estava na 1 a Classe tem probabilidade de sobrevivência de 0,90, enquanto que uma mulher de mesma idade na $3^{\text {a }}$ Classe tem probabilidade de sobrevivência de 0,41 . Um homem de 30 anos de idade da $1^{\underline{a}}$ Classe tem probabilidade de sobrevivência de 0,42 , enquanto que um homem de mesma idade na $2^{\text {a }}$ Classe tem probabilidade de sobrevivência de 0,16.

PALAVRAS-CHAVE: REGRESSÃO LOGÍSTICA; PROBABILIDADE; VARIÁVEL. 


\title{
VOLUNTÁRIOS: BUSCANDO AJUDAR O PRÓXIMO DOANDO CUIDADO E CARINHO
}

\author{
GABRIELA PEIXOTO CARVALHO, ELISANGELA DE CÁSSIA RODRIGUES, GEOVANNA INGRID \\ RODRIGUES, JANAÍNA MARIA DA SILVA, KARLA CRISTINA WALTER
}

INSTITUTO MASTER DE ENSINO PRESIDENTE ANTÔNIO CARLOS - IMEPAC

gabicarvalho401@gmail.com

Apresentação de Pôster

Resumo

Área do Conhecimento: Saúde coletiva e bem-estar

Introdução e Objetivo: Casa Lar é uma instituição de acolhimento provisório para crianças e adolescentes afastados do âmbito familiar devido o abandono ou quando os responsáveis estejam provisoriamente incapazes de cumprir a função de cuidado até que seja possibilitado o retorno à família de origem ou encaminhamento para outra família. A instituição deve proporcionar que as crianças e adolescentes se sintam protegidos e criem vínculos de confiança que aprimorem o seu desenvolvimento integral e a construção de autonomia. De forma a proporcionar o crescimento pessoal e o fortalecimento da identidade das crianças e adolescentes acolhidos no local, os voluntários precisam se envolver nos cuidados destes a partir da parceria com a equipe do serviço de acolhimento.

Contribuir para a melhoria da qualidade de vida dos residentes da Casa Lar. Promover saúde e prevenir doenças dos que ali vivem.

Metodologia: O projeto foi desenvolvido com 21 residentes de uma Casa Lar do município de Araguari (MG), e contou com ministração de palestras, atividades educativas, anamnese e exame físico, brincadeiras, dia da beleza, educação ambiental, avaliação nutricional, atividades artesanais, aulas de reforço e atividades físicas. Realizado de Outubro a Dezembro de 2018, totalizando 14 visitas mais uma ação social para encerramento das atividades.

Relato da experiência: Foram ministradas palestras referentes à higiene pessoal, ensinamento prático sobre lavagem das mãos, alimentação saudável e infecções sexualmente transmissíveis (IST's) utilizando slides de forma dinâmica e interativa. Realizado atividades educativas sendo caça palavras, dama, dominó, cruzadinha e desenhos para colorir. Efetuado anamnese e exame físico, diversas brincadeiras e também dia da beleza com arrumação do cabelo, unhas e maquiagem. Na educação ambiental, plantio de verduras e conscientização do uso racional da água. Executado avaliação nutricional, índice de massa corporal (IMC), circunferência do quadril e cintura. Efetuado atividades artesanais com a confecção de papai noel, árvore de natal e emojis. Reforço escolar de português e matemática e atividades físicas de menor complexibilidade.

Considerações finais: A realização deste projeto foi de suma importância para a formação acadêmica dos discentes, proporcionou experiências únicas a cada um envolvido. 0 voluntariado é um trabalho não remunerado, mas é recompensado através do engrandecimento de tod os. E para a comunidade em questão, não temos dúvida da transformação vivida nesses dias, não só para a entidade como um todo, mas para um aprendizado deixado a cada um, que ali vive.

PALAVRAS-CHAVE: VOLUNTARIADO; CRIANÇAS; ADOLESCENTES. 